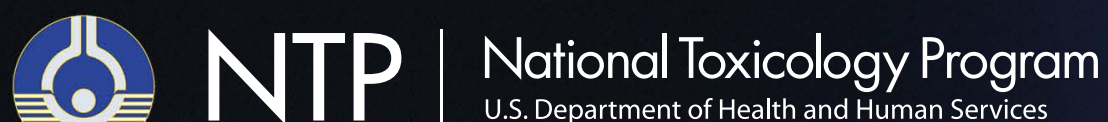

NTP Monograph on the Systematic Review of Traffic-related Air Pollution and Hypertensive Disorders of Pregnancy

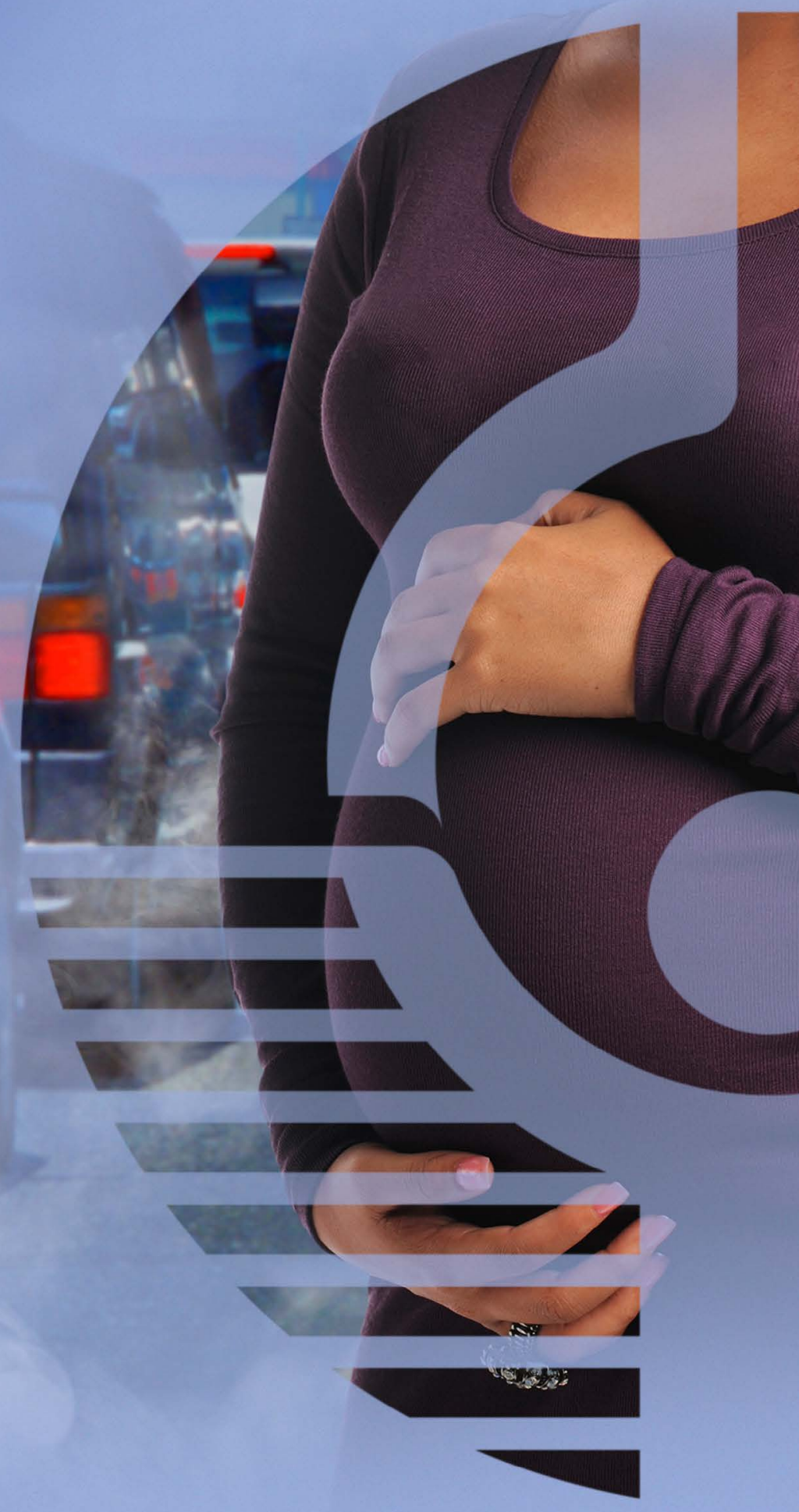




\title{
NTP Monograph on the Systematic Review of Traffic-related Air Pollution and Hypertensive Disorders of Pregnancy
}

\author{
NTP Monograph 07
}

December 2019

National Toxicology Program

Public Health Service

U.S. Department of Health and Human Services

ISSN: 2378-5144

Research Triangle Park, North Carolina, USA 


\section{Foreword}

The National Toxicology Program (NTP), established in 1978, is an interagency program within the Public Health Service of the U.S. Department of Health and Human Services. Its activities are executed through a partnership of the National Institute for Occupational Safety and Health (part of the Centers for Disease Control and Prevention), the Food and Drug Administration (primarily at the National Center for Toxicological Research), and the National Institute of Environmental Health Sciences (part of the National Institutes of Health), where the program is administratively located. NTP offers a unique venue for the testing, research, and analysis of agents of concern to identify toxic and biological effects, provide information that strengthens the science base, and inform decisions by health regulatory and research agencies to safeguard public health. NTP also works to develop and apply new and improved methods and approaches that advance toxicology and better assess health effects from environmental exposures.

NTP conducts literature-based evaluations to determine whether exposure to environmental substances (e.g., chemicals, physical agents, and mixtures) may be associated with adverse health effects. These evaluations result in hazard conclusions or characterize the extent of the evidence and are published in the NTP Monograph series, which began in 2011. NTP Monographs serve as an environmental health resource to provide information that can be used to make informed decisions about whether exposure to a substance may be of concern for human health.

NTP conducts these health effects evaluations following pre-specified protocols that apply the general methods outlined in the "Handbook for Conducting a Literature-Based Health Assessment Using the OHAT Approach for Systematic Review and Evidence Integration." $"$ The protocol describes project-specific procedures tailored to each systematic review in a process that facilitates evaluation and integration of scientific evidence from published human, experimental animal, and mechanistic studies.

The key feature of the systematic review approach is the application of a transparent framework to document the evaluation methods and the basis for scientific judgements. This process includes steps to comprehensively search for studies, select relevant evidence, assess individual study quality, rate confidence in bodies of evidence across studies, and then integrate evidence to develop conclusions for the specific research question. Draft monographs undergo external peer review prior to being finalized and published.

NTP Monographs are available free of charge on the NTP website and cataloged in PubMed, a free resource developed and maintained by the National Library of Medicine (part of the National Institutes of Health). Data for these evaluations are included in the Health Assessment and Workspace Collaborative.

For questions about the monographs, please email NTP or call 984-287-3211.

OHAT is the abbreviation for Office of Health Assessment and Translation, which is within the Division of the National Toxicology Program at the National Institute of Environmental Health Sciences. 


\section{Table of Contents}

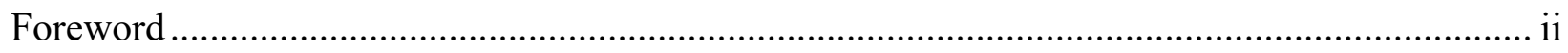

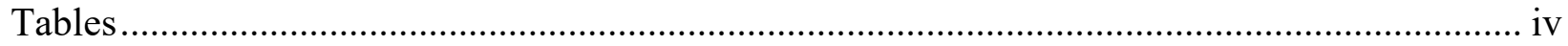

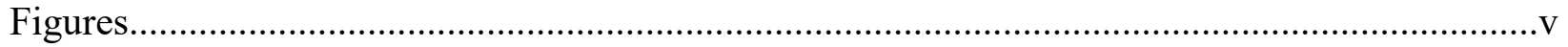

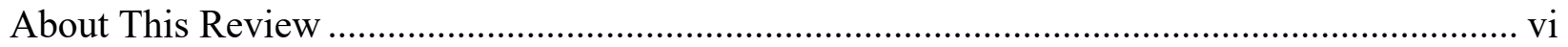

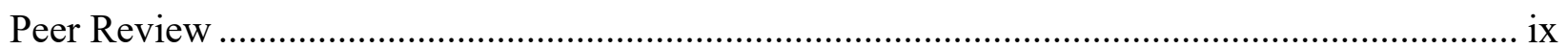

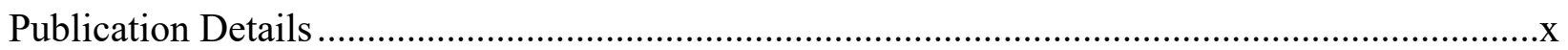

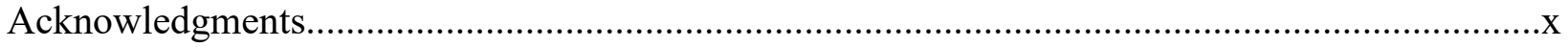

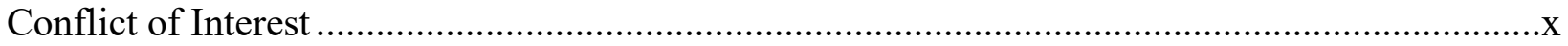

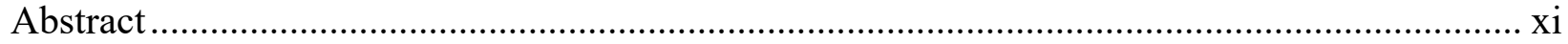

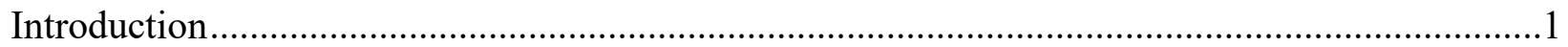

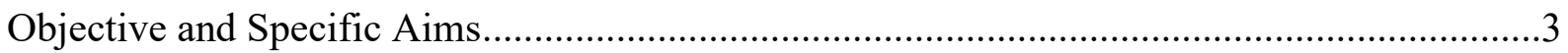

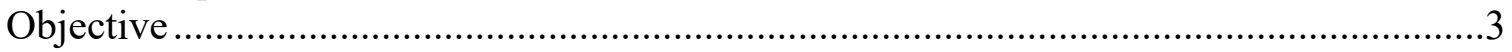

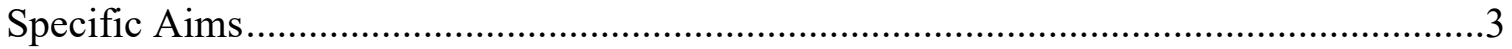

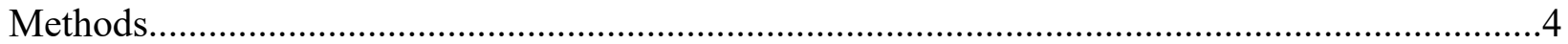

Problem Formulation and Protocol Development …….........................................................

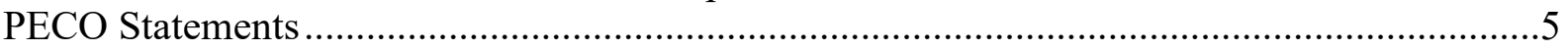

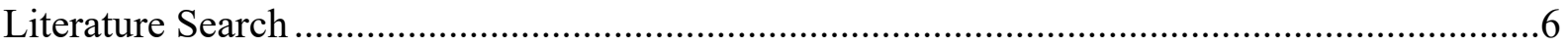

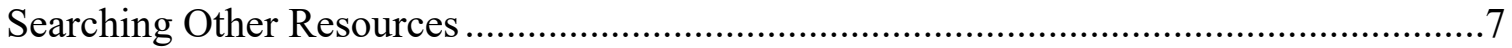

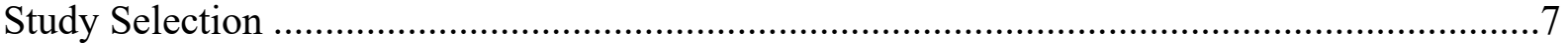

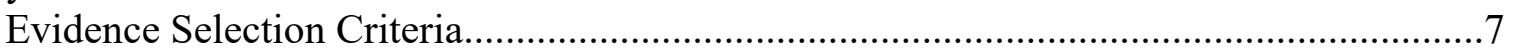

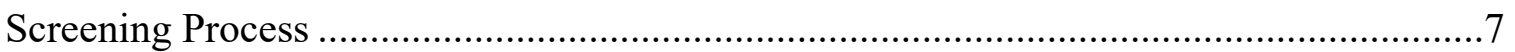

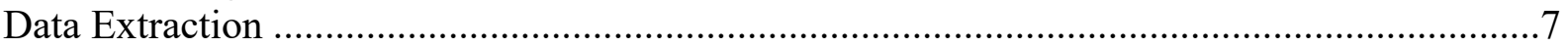

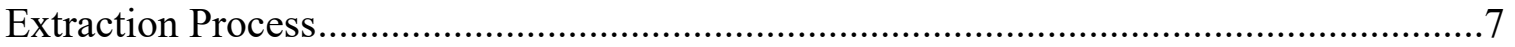

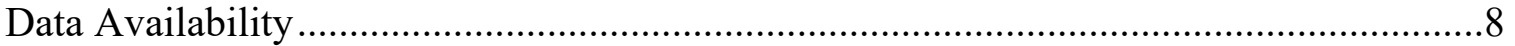

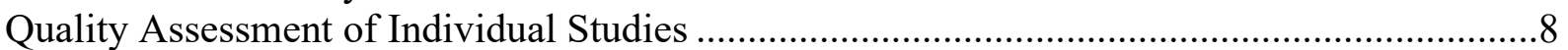

Organizing and Rating Confidence in Bodies of Evidence .....................................................10

Health Outcome and Endpoint Grouping by Categories of Health Effects and

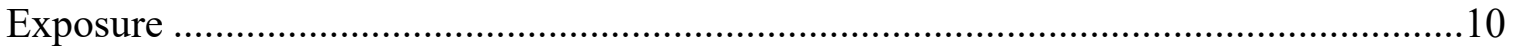

Considerations for Pursuing a Narrative or Quantitative Evidence Synthesis...........................11

Confidence Rating: Assessment of Body of Evidence ......................................................11

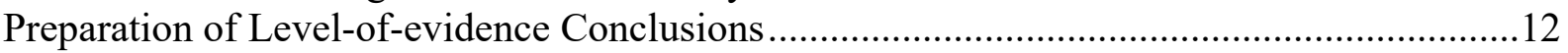

Integration of Evidence to Develop Hazard Identification Conclusions ...................................13

Considerations for Human and Animal Data.................................................................13

Considerations for Evaluating Combined Traffic-related Air Pollution Exposure ............14

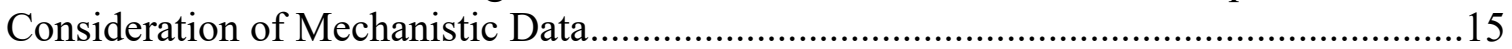

Considerations for Meta-analyses and Meta-analyses Methods..........................................16

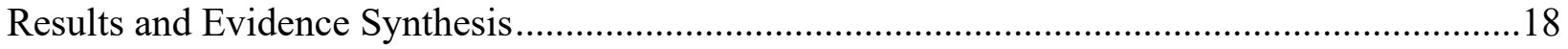

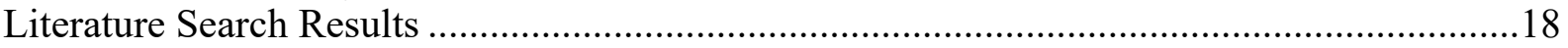

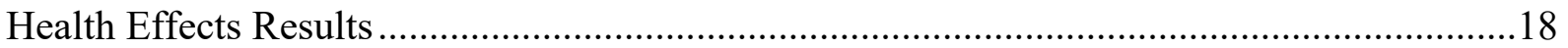


Main Findings for Associations between Exposures to Traffic-related Air

Pollution and Hypertensive Disorders of Pregnancy ...................................................19

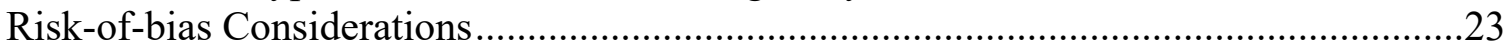

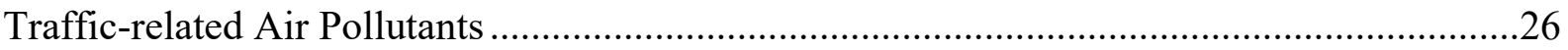

Particulate Matter and Hypertensive Disorders of Pregnancy .......................................26

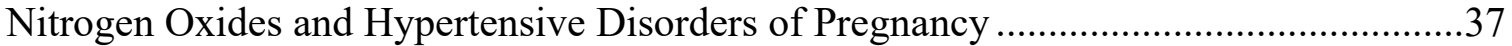

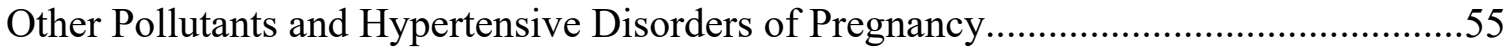

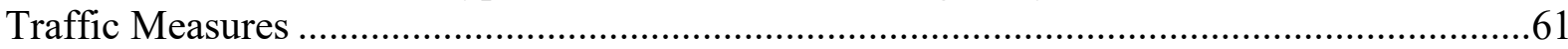

Traffic Measures and Hypertensive Disorders of Pregnancy .....................................61

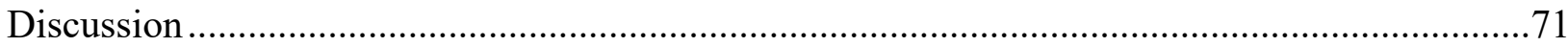

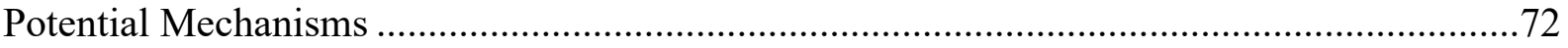

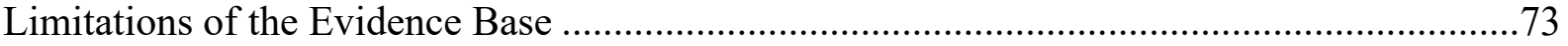

Limitations of the Systematic Review ...................................................................... 74

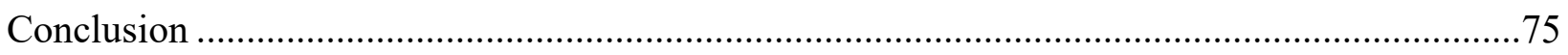

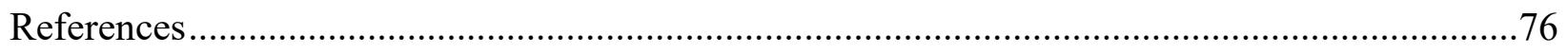

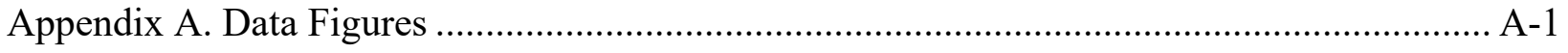

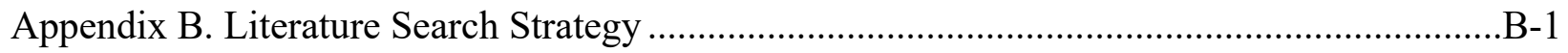

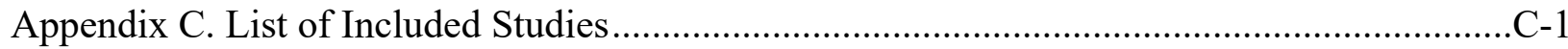

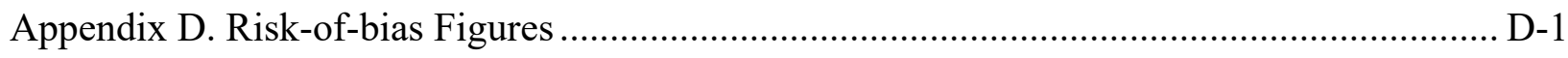

Appendix E. Meta-analysis Sub-analyses Results .........................................................

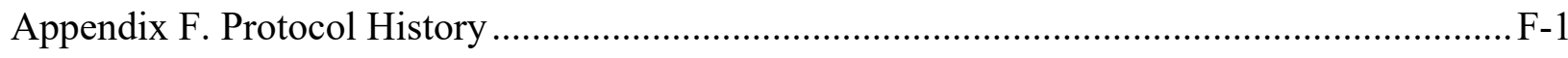

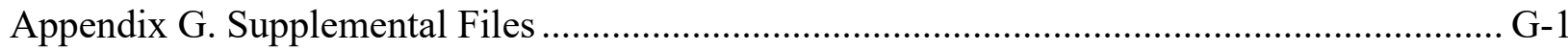

\section{Tables}

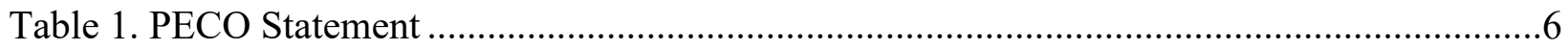

Table 2. Traffic Exposure Metrics .......................................................................................6

Table 3. Hypertensive Disorders of Pregnancy: Endpoint Categories for Human and

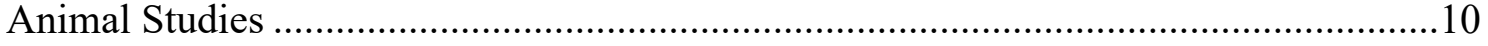

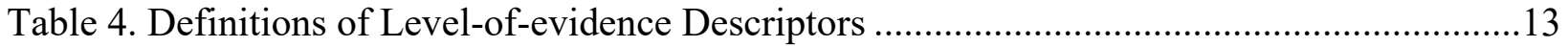

Table 5. Traffic-related Air Pollution Summary Table ............................................................22

Table 6. Studies on Hypertensive Disorders of Pregnancy with TRAP-related PM2.5

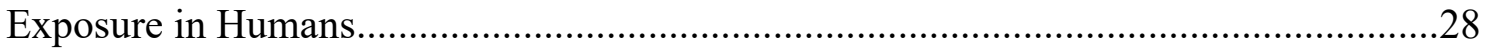

Table 7. References Included in Meta-analysis: Studies on Hypertensive Disorders of Pregnancy with TRAP-related PM2.5 Exposure in Humans ............................................32

Table 8. Pooled ORs and 95\% CIs for TRAP-related $\mathrm{PM}_{2.5}$ and Preeclampsia ...........................33

Table 9. Studies on Hypertensive Disorders of Pregnancy with TRAP-related $\mathrm{NO}_{2}$ or

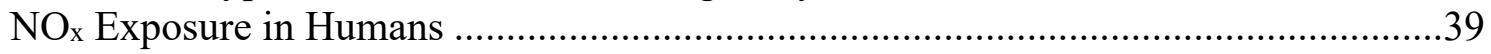

Table 10. References Included in Meta-analysis: Studies on Hypertensive Disorders of Pregnancy with TRAP-related $\mathrm{NO}_{2}$ Exposure in Humans ........................................46

Table 11. Pooled ORs and 95\% CIs for Full Gestational Period TRAP-related $\mathrm{NO}_{2}$ Exposures and Hypertensive Disorders of Pregnancy. 
Table 12. Studies on Hypertensive Disorders of Pregnancy with TRAP-related CO, ECAT, and BC Exposure in Humans ......................................................................57

Table 13. Studies on Hypertensive Disorders of Pregnancy with TRAP-related CO, ECAT, and BC Exposure in Animals

Table 14. Studies on Hypertensive Disorders of Pregnancy and Traffic Measures in Humans

\section{Figures}

Figure 1. OHAT Risk-of-bias Questions and Applicability by Study Design.................................9

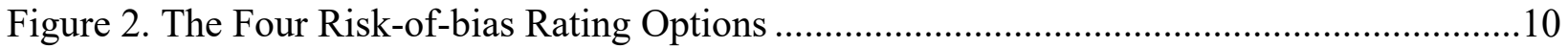

Figure 3. Assessing Confidence in the Body of Evidence............................................................12

Figure 4. Translation of Confidence Ratings into Evidence of Health Effect Conclusions ...........12

Figure 5. Hazard Identification Scheme for Hypertensive Disorders of Pregnancy........................14

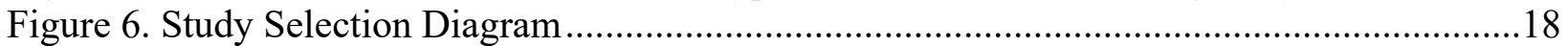

Figure 7. Evidence Profile of the Main Findings for Traffic-related Air Pollution.........................23

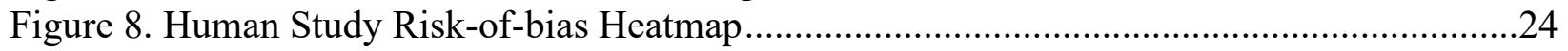

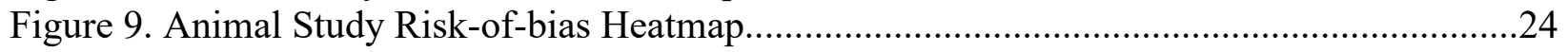

Figure 10. Full Gestation Exposure to $\mathrm{PM}_{2.5}$ and Preeclampsia..................................................... 34

Figure 11. Risk-of-bias Heatmap: $\mathrm{PM}_{2.5}$ and Hypertensive Disorders of Pregnancy.......................35

Figure 12. Risk-of-bias Bar Chart: $\mathrm{PM}_{2.5}$ and Hypertensive Disorders of Pregnancy......................35

Figure 13. Full Gestation Exposure to $\mathrm{NO}_{2}$ and Hypertensive Disorders of Pregnancy ................50

Figure 14. Full Gestation Exposure to $\mathrm{NO}_{2}$ and Preeclampsia................................................51

Figure 15. Full Gestation Exposure to $\mathrm{NO}_{\mathrm{x}}$ and Preeclampsia ...................................................52

Figure 16. Risk-of-bias Heatmap: $\mathrm{NO}_{\mathrm{x}}$ and Hypertensive Disorders of Pregnancy .......................53

Figure 17. Risk-of-bias Bar Chart: $\mathrm{NO}_{\mathrm{x}}$ and Hypertensive Disorders of Pregnancy......................53

Figure 18. Traffic Density and Hypertensive Disorders of Pregnancy..........................................66

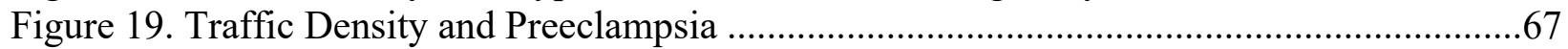

Figure 20. Proximity to Traffic and Combined Hypertensive Disorders during Pregnancy .........68

Figure 21. Risk-of-bias Heatmap: Traffic and Hypertensive Disorders of Pregnancy..................69

Figure 22. Risk-of-bias Bar Chart: Traffic and Hypertensive Disorders of Pregnancy...................70

This report has been reformatted to meet new NTP publishing requirements; its content has not changed. 


\section{About This Review}

National Toxicology Program ${ }^{1}$

${ }^{1}$ Division of the National Toxicology Program, National Institute of Environmental Health

Sciences, Research Triangle Park, North Carolina, USA

\section{Collaborators}

Brandiese E.J. Beverly, Kembra L. Howdeshell, Kyla W. Taylor, Alexandra E. Goldstone, Robyn B. Blain, Sorina E. Eftim, Andrew A. Rooney

Division of the National Toxicology Program, National Institute of Environmental Health Sciences, Research Triangle Park, North Carolina, USA

Contributed to conception or design and drafting of report

Brandiese E.J. Beverly, Ph.D., Project Lead

Andrew A. Rooney, Ph.D.

Assessed risk of bias, contributed to meta-analysis, and critically reviewed draft report

Kyla W. Taylor, Ph.D.

Screened studies, extracted data, and contributed to conception, design, and drafting of protocol Kembra L. Howdeshell, Ph.D.

ICF, Fairfax, Virginia, USA

Assessed risk of bias, screened studies, and extracted data

Robyn B. Blain, Ph.D.

Alexandra E. Goldstone, M.P.H., Lead Work Assignment Manager

Conducted meta-analysis

Sorina E. Eftim, Ph.D.

Alexandra E. Goldstone, M.P.H., Lead Work Assignment Manager

\section{Contributors}

Division of the National Toxicology Program, National Institute of Environmental Health Sciences, Research Triangle Park, North Carolina, USA

Provided oversight of peer review

Elizabeth A. Maull, Ph.D.

Mary S. Wolfe, Ph.D.

Critically reviewed draft report and figures

Windy A. Boyd, Ph.D.

John R. Bucher, Ph.D.

Ruth M. Lunn, Dr.P.H.

Cynthia V. Rider, Ph.D.

Matthew D. Stout, Ph.D. 
Vicki L. Sutherland, Ph.D.

Vickie R. Walker, B.S.

Division of Intramural Research, National Institute of Environmental Health Sciences, Research Triangle Park, North Carolina, USA

Critically reviewed draft report and figures

Quaker E. Harmon, M.D., Ph.D.

Office of Data Science, Division of the National Toxicology Program, National Institute of Environmental Health Sciences, Research Triangle Park, North Carolina, USA

Designed and executed literature searches

Stephanie D. Holmgren, M.S.L.S., MBA

Office of Transportation and Air Quality, Office of Air and Radiation, U.S. Environmental Protection Agency, Ann Arbor, Michigan, USA

Critically reviewed protocol, draft report, and figures

Chad R. Bailey, M.P.H.

Office of Research and Development, Center for Public Health and Environmental Assessment, U.S. Environmental Protection Agency, Research Triangle Park, North Carolina, USA

Critically reviewed protocol, draft report, and figures

Erin P. Hines, Ph.D.

Thomas J. Luben, Ph.D.

Contributed to conception or design and drafting of protocol

Kristina Thayer, Ph.D. (formally with NIEHS/DNTP)

Centers for Disease Control and Prevention, Atlanta, Georgia, USA

Critically reviewed protocol, draft report, and figures

Tegan K. Boehmer, Ph.D.

ICF, Durham, North Carolina, USA

Provided contract oversight

David F. Burch, M.E.M.

Contributed to data extraction support

Katherine S. Duke, Ph.D.

Alexander Lindahl, M.P.H.

Maureen Malloy, B.S.

Devon A. Morgan, B.A.

Raquel A. Silva, Ph.D.

Contributed to meta-analysis support

Jennifer M. Yourkavitch, Ph.D. 
Coordinated peer review

Canden N. Byrd, B.S.

Designed and executed literature searches

Jeremy S. Frye, M.S.L.S.

Nicole L. Vetter, M.L.I.S.

Edited and formatted report

Kathleen A. Clark, B.A.

Tyler W. Cromer, M.P.S.

Tara Hamilton, M.S.

Pamela A. Hartman, M.E.M.

Camryn Lieb, B.S.

Christopher A. Sibrizzi, M.P.H.

Heath Effects Institute, Boston, Massachusetts, USA

Critically reviewed protocol and assisted with risk-of-bias assessment

Hanna Boogaard, Ph.D.

New York Medical College, Valhalla, New York, USA

Critically reviewed protocol

Heather L. Brumberg, M.D., FAAP

University of Washington, Seattle, Washington, USA

Critically reviewed protocol

Catherine J. Karr, M.D., Ph.D.

Office of Environmental Health Hazard Assessment, State of California, Sacramento, California, USA

Critically reviewed protocol

Melanie A. Marty, Ph.D. 


\section{Peer Review}

The National Toxicology Program (NTP) conducted a peer review of the draft NTP Monograph on the Systematic Review of Traffic-related Air Pollution and Hypertensive Disorders of Pregnancy by letter in August 2019 by the experts listed below. NTP announced the availability of the draft document in the Federal Register (84 FR 29529, June 24, 2019), and opportunities were provided for submission of written public comments. Reviewer selection and document review followed established NTP practices. The reviewers were charged to:

(1) Comment on whether the draft NTP Monograph on Traffic-Related Air Pollution and Hypertensive Disorders of Pregnancy is technically correct, clearly stated, and objectively presented.

(2) Determine whether the scientific evidence from human and animal studies supports the NTP's confidence ratings in the bodies of evidence regarding hypertensive disorders of pregnancy following exposure to individual TRAP components.

(3) Determine whether the scientific evidence from human and animal studies supports the NTP's level of evidence conclusions regarding hypertensive disorders of pregnancy following TRAP exposure in the combined body of evidence.

(4) Determine whether the scientific evidence supports NTP's policy decisions for hazard categorization on hypertensive disorders of pregnancy following TRAP exposure.

NTP carefully considered reviewer comments in finalizing this monograph.

\section{Peer Reviewers}

\section{Rebecca Schmidt, Ph.D.}

Assistant Professor, Department of Public Health Sciences

University of California, Davis, School of Medicine

Davis, California, USA

\section{Karen Racicot, Ph.D.}

Assistant Professor, Department of Obstetrics, Gynecology, and Reproductive Biology Michigan State University, College of Human Medicine

East Lansing, Michigan, USA

\section{Amy Padula, Ph.D.}

Assistant Professor, Department of Obstetrics, Gynecology, and Reproductive Sciences University of California, San Francisco

San Francisco, California, USA

\section{Matthew Campen, Ph.D.}

Regents' Professor, Department of Pharmaceutical Sciences

University of New Mexico, College of Pharmacy

Albuquerque, New Mexico, USA

\section{Alex Carll, Ph.D.}

Assistant Professor, Department of Physiology

University of Louisville, School of Medicine

Louisville, Kentucky, USA 


\section{Publication Details}

Publisher: National Toxicology Program

Publishing Location: Research Triangle Park, NC

ISSN: $2378-5144$

DOI: https://doi.org/10.22427/NTP-MGRAPH-7

Report Series: NTP Monograph Series

Report Series Number: 07

Official citation: National Toxicology Program (NTP). 2019. NTP monograph on the systematic review of traffic-related air pollution and hypertensive disorders of pregnancy. Research Triangle Park, NC: National Toxicology Program. NTP Monograph 07.

\section{Acknowledgments}

This work was supported by the Intramural Research Program (ES103316, ES103317) at the National Institute of Environmental Health Sciences, National Institutes of Health and performed for the National Toxicology Program, Public Health Service, U.S. Department of Health and Human Services under contracts HHSN316201200028W (Order No. HHSN27300006) and GS00Q14OADU417 (Order No. HHSN273201600015U).

\section{Conflict of Interest}

Individuals identified as collaborators in the About This Review section have certified that they have no known real or apparent conflict of interest related to traffic-related air pollution or hypertensive disorders of pregnancy. 


\section{Abstract}

Introduction: Traffic-related air pollution (TRAP) contributes significantly to ambient air pollution, especially in urban settings. Air pollution has been established as a risk factor for hypertension and cardiovascular disease in adults, but this effect is less studied in other susceptible populations. There is increasing evidence that air pollution may adversely affect hypertensive disorders of pregnancy (e.g., gestational hypertension, preeclampsia, eclampsia).

Objective: Because reports indicate that air pollution may be linked to hypertensive disorders, the National Toxicology Program (NTP) conducted a systematic review to evaluate whether exposure to TRAP during pregnancy is associated with hypertensive disorders of pregnancy.

Methods: A systematic review protocol was developed and utilized for this evaluation that followed the Office of Health Assessment and Translation approach for conducting literaturebased health assessments. This evaluation considered a range of traffic-related air pollutant measurements (e.g., fine particulate matter [ $\left.\mathrm{PM}_{2.5}\right]$ ) and traffic measures (e.g., proximity to major roads) in the literature search. Confidence ratings and level-of-evidence conclusions were developed for bodies of evidence for a given exposure measure when there was sufficient evidence (i.e., more than three studies). Changes in blood pressure during pregnancy, gestational hypertension, preeclampsia, eclampsia, or hemolysis, elevated liver enzyme levels, and low platelet count (HELLP) syndrome were considered as measures of hypertension. Hazard conclusions were developed using a two-step process. First, confidence ratings were developed for individual air pollutants (e.g., $\mathrm{PM}_{2.5}$, nitrogen oxides $\left[\mathrm{NO}_{\mathrm{x}}\right]$ ) and traffic measures (traffic density and proximity to major roads). Overall hazard conclusions were then developed for TRAP, considering the combined bodies of evidence across different individual measures of traffic-related pollutants.

Results and Evidence Synthesis: The literature search and screening process identified 18 relevant epidemiological studies and one relevant animal study (from 344 potentially relevant references) that met the objective and the inclusion criteria. The human bodies of evidence for traffic-related $\mathrm{PM}_{2.5}$ and $\mathrm{NO}_{2}$ present a consistent pattern of findings that exposure to these pollutants is associated with the development of hypertensive disorders of pregnancy. There is a similar pattern of findings, but a smaller effect size, for bodies of evidence that residing in hightraffic density regions or in close proximity to major roads are associated with developing hypertensive disorders during pregnancy. There is a moderate level of evidence in the combined human body of evidence based primarily on the TRAP air pollutant studies with support from the traffic measures studies. There is an inadequate level of evidence in the animal body of evidence due to the lack of experimental animal studies identified for these measures. Evidence for other traffic-related pollutants that were identified (i.e., carbon monoxide [CO], black carbon [BC], and elemental carbon $[\mathrm{EC}]$ ), including one animal study for $\mathrm{CO}$, were few in number or provided inconsistent results across studies, and level-of-evidence conclusions were not reached.

Discussion and Conclusion: NTP concludes that exposure to TRAP is presumed to be a hazard to pregnant women for developing hypertensive disorders of pregnancy. This conclusion was based on moderate confidence and moderate level of evidence in the combined body of evidence from human studies reporting on multiple measures of TRAP exposure (traffic-related $\mathrm{PM}_{2.5}$ and $\mathrm{NO}_{2}$ ) with support from studies on traffic measures (residing in high-traffic density regions or in close proximity to major roads during pregnancy). 
The effect of TRAP was consistent across bodies of evidence for individual TRAP components and was supported by meta-analyses for individual traffic-related metrics (i.e., $\mathrm{PM}_{2.5}$ and $\mathrm{NO}_{2}$ ) and supported by studies that evaluated traffic measures. The collective evidence across the air pollutant measurements and traffic measurements shows consistency in the direction of effect across multiple populations and geographic locations, strengthening the confidence in the association between combined TRAP exposure (versus exposure to the individual TRAP components) and hypertensive disorders of pregnancy. Many of the studies evaluated only one TRAP component, and those that evaluated more than one component still found significant associations between the individual components and hypertensive disorders of pregnancy after statistically accounting for other exposures, although the effect size may have been reduced by controlling for other TRAP measures.

In addition to consistency across bodies of evidence, mechanistic data evaluating single pollutants indicate that the individual $\mathrm{PM}_{2.5}$ and $\mathrm{NO}_{2}$ exposures can act independently to affect different pathways (e.g., vascular inflammation and oxidative stress) that lead to increased blood pressure. Because TRAP comprises multiple pollutants, the likelihood of being exposed simultaneously to multiple TRAP components is high. The independent mechanisms by which these TRAP exposures can elevate blood pressure - combined with evidence of an association between increased TRAP exposure and development of hypertensive disorders of pregnancy (supported by meta-analyses) - increase support for the moderate level of evidence that multiple TRAP components can act on blood pressure parameters during pregnancy to lead to hypertension. Therefore, the combined body of evidence is considered robust due to the greater number of studies, the multiple mechanisms by which the individual components can affect blood pressure, and the greater likelihood of exposure to multiple components of TRAP. Taken together, these factors demonstrate a moderate level of evidence that exposure to TRAP is associated with the development of hypertensive disorders of pregnancy and support a conclusion of presumed to be a hazard to pregnant women.

Overall, based on the body of evidence for the combined TRAP exposure, the available evidence supports that exposure to TRAP during pregnancy increases the likelihood of developing hypertensive disorders of pregnancy. Because of the recognized relationship between maternal blood pressure status and the effect of hypertension during pregnancy on fetal and infant health outcomes, hypertensive disorders of pregnancy associated with TRAP exposure may have significant adverse health effects in the developing offspring. 


\section{Introduction}

The National Toxicology Program (NTP) Office of Health Assessment and Translation (OHAT) conducted a systematic review to evaluate the evidence that exposure to traffic-related air pollution (TRAP) is associated with hypertensive disorders of pregnancy.

TRAP refers to air pollution exposures derived from primary emissions from motor vehicles due to fossil fuel combustion. Sources of TRAP include passenger cars, diesel trucks and buses, and nonroad equipment (e.g., recreational vehicles, lawn and garden equipment). Motor vehicles emit large amounts of carbon dioxide $\left(\mathrm{CO}_{2}\right)$, carbon monoxide $(\mathrm{CO})$, nitrogen and sulfur oxides $\left(\mathrm{NO}_{\mathrm{x}}\right.$ and $\mathrm{SO}_{\mathrm{x}}$, respectively), volatile organic compounds (VOCs), and particulate matter (PM). Many of these pollutants are regulated by the U.S. Environmental Protection Agency (EPA) and are used as pollutant surrogates for TRAP (https://www.epa.gov/criteria-air-pollutants ${ }^{1}$ ).

Pollution-control regulations, along with innovative technologies and approaches developed to improve air quality domestically and abroad, reflect the increased concern over potential health effects associated with exposure to TRAP. Currently, 39\% of the U.S. population lives in areas with populations greater than 2.5 million people (USEPA 2016). Rapid population growth, expansion of metropolitan areas, and increased dependence on motor vehicles contribute to TRAP exposure (HEI 2010). In addition, the fraction of the population living and working near busy roads and highways continues to increase. As a result, TRAP may contribute significantly to ambient air pollution, especially in urban settings where high-density traffic patterns and domiciles in close proximity to high-traffic roadways are common (Krzyzanowski et al. 2005).

Across the United States, TRAP emissions have declined since the 1990s, but the urban setting continues to be an area of higher exposures to traffic-related emissions. There is considerable variability in fine particulate matter ( $\left.\mathrm{PM}_{2.5}\right)$ and other TRAP component concentrations across the United States, with the highest concentrations of PM2.5 $\left(>18 \mu \mathrm{g} / \mathrm{m}^{3}\right)$ reported in areas of southern California, Alabama, and Pennsylvania. Overall PM2.5 concentrations have decreased since 1999 (the beginning of nationwide monitoring for $\mathrm{PM}_{2.5}$ ) and remained nearly constant from 2002 to 2007 (USEPA 2009). The most recent analysis from EPA's Air Quality System network data indicate that $\mathrm{PM}_{2.5}$ concentrations continue to decline. Similarly, total $\mathrm{NO}_{\mathrm{x}}$ emissions have declined from 1990 to 2013, but highway vehicles and off-highway vehicles and engines continue to contribute substantially (with more than three-quarters of total emissions) in urban areas (USEPA 2016). With the recognized role of motor vehicles in air pollutionparticularly in urban environments - identifying and further characterizing health effects associated with TRAP exposure is needed, especially for susceptible populations (HEI 2010).

The components of TRAP are recognized risk factors for cardiovascular disease in the general population in the United States and abroad (Coogan et al. 2012; Guo et al. 2010; Sorensen et al. 2012; USEPA 2009; WHO 2016). Although the mechanisms by which air pollution affects cardiovascular disease, particularly hypertension, are not completely understood, some of the likely and overlapping pathways that may be involved include effects on oxidative stress, the autonomic nervous system, and vascular function (Brook and Rajagopalan 2009).

\footnotetext{
${ }^{1}$ The broken link http://www.epa.gov/oms/toxics.htm was changed to https://www.epa.gov/criteria-air-pollutants on February 16, 2021.
} 
Epidemiological and toxicological studies suggest a causal relationship between acute and long-term exposures to components of PM and cardiovascular effects in the general population (USEPA Abraham et al. 2018; 2009). Hypertension, which is an important risk factor for developing cardiovascular disease, poses a greater burden in women than in men (Mozaffarian et al. 2016). Although hypertension affects women in all phases of life, hypertension in pregnancy presents unique challenges. Hypertensive disorders of pregnancy pose risks to the mother and child, increasing the risk for developing cardiovascular disease later in life for the mother and increasing the risk of preterm birth, prematurity-related diseases, and other adverse effects for the child. Air pollution-related research on children's health have focused mainly on the development and exacerbation of asthma or other respiratory problems (HEI 2010). Fewer studies have evaluated other aspects of children's health, although there is growing evidence that TRAP increases the likelihood of developing hypertensive disorders of pregnancy, which increases the risk for adverse health outcomes in children.

The American College of Obstetricians and Gynecologists classifies hypertensive disorders of pregnancy into four categories: (1) gestational hypertension, (2) preeclampsia/eclampsia, (3) chronic hypertension, and (4) chronic hypertension with superimposed preeclampsia. These disorders complicate approximately $10 \%$ of pregnancies and are one of the leading causes of maternal and fetal morbidity and mortality worldwide (ACOG 2013). Hypertensive disorders of pregnancy are characterized typically by differences in the timing of onset of symptoms (Duley 2009). Chronic hypertension with or without superimposed preeclampsia is defined by elevated blood pressure that predates conception or is detected during the first half of gestation, whereas gestational hypertension and preeclampsia/eclampsia typically occur during the second half of gestation. These disorders range in severity from hypertension alone to multiorgan dysfunction and seizures. Preeclampsia, for example, is responsible for 50,000-60,000 maternal deaths each year and is associated with multiple maternal complications, including edema, intravascular coagulation, renal and liver dysfunction, stroke, and placental abruption (separation) or infarction (blockage of blood supply) (Duley 2009). Although viewed as a condition specific to the pregnancy and (in some cases) postpartum periods, hypertensive disorders of pregnancy can have long-term effects on the mother's health and the health of her offspring. Women who experience hypertension in pregnancy are at an increased risk for developing cardiovascular disease, stroke, and type 2 diabetes later in life (Bauer and Cleary 2009; Bellamy et al. 2007; Duley 2009). Of relevance to children's health, infants born to mothers with hypertension during pregnancy are at higher risk for preterm delivery, low birth weight, being small for gestational age, and a range of prematurity-related neonatal diseases with long-term effects that can persist into adulthood (Doyle 2008). As such, this assessment will extend the literature synthesis efforts of the Health Effects Institute (HEI), EPA, Centers for Disease Control and Prevention (CDC), and other researchers to understand the effects of TRAP that are relevant to maternal and children's health.

Given the relationship between maternal blood pressure status and adverse maternal and early childhood health outcomes and the increasing evidence suggesting that TRAP is significantly associated with hypertension during pregnancy, this systematic review was developed to evaluate the human, animal, and mechanistic evidence for an association between TRAP and hypertensive disorders of pregnancy. 


\section{Objective and Specific Aims}

\section{Objective}

The overall objective of this evaluation was to develop hazard identification conclusions about whether traffic-related air pollution is associated with hypertensive disorders of pregnancy by integrating levels of evidence from human and experimental animal studies.

\section{Specific Aims}

- Identify literature reporting the effects of TRAP exposure characterized by traffic measures (e.g., distance to main road, length of main streets with a buffer zone around homes or schools, traffic volume) and air pollutants associated with traffic emissions (e.g., carbon monoxide, nitrogen oxides, black carbon, coarse particulate matter $[2.5-10 \mu \mathrm{m}]$, fine particulate matter [0.1-2.5 $\mu \mathrm{m}]$, and ultrafine particulate matter $[<0.1 \mu \mathrm{m}]$ as well as benzene, diesel exhaust, and polycyclic aromatic hydrocarbons) on hypertensive disorders of pregnancy in humans and animals (experimental and wildlife).

- Extract data on potential health effects from relevant studies (data extraction files of the included studies will be shared upon release of final report).

- Assess the internal validity (risk of bias) of individual human and animal studies using predefined criteria.

Dependent on the extent and nature of the available evidence:

- Synthesize the evidence using a narrative approach or meta-analysis (if appropriate) considering the limitations on data integration such as study design heterogeneity.

- Rate the confidence in the body of evidence for human and animal studies separately according to one of four statements: (1) High, (2) Moderate, (3) Low, or (4) Very Low or No Evidence Available.

- Translate confidence ratings into level of evidence of health effects for human and animal studies separately according to one of four statements: (1) High, (2) Moderate, (3) Low, or (4) Inadequate.

- Use the level-of-evidence ratings for human and animal data to reach one of five possible hazard identification conclusions: (1) Known, (2) Presumed, (3) Suspected, (4) Not Classifiable, or (5) Not Identified to Be a Hazard to Pregnant Women. 


\section{Methods}

\section{Problem Formulation and Protocol Development}

The National Toxicology Program (NTP) Office of Health Assessment and Translation (OHAT) received a nomination to evaluate emerging children's health issues associated with ambient air pollution (Federal Register 77 FR 41406, 13 July 2012; https://ntp.niehs.nih.gov/go/trap). The nomination suggested that OHAT focus on traffic-derived air pollutants and avoid reviewing the effects of well-characterized exposures (e.g., tobacco smoke, mercury, lead, arsenic).

The health effects nominated for evaluation focused on emerging children's health outcomes. To help refine the focus, OHAT conducted a preliminary inventory of the literature using a search strategy designed to capture the types of pollutants outlined in the original nomination and a variety of health outcomes relevant to children's health. The preliminary search results were used to identify emerging health areas of concern in addition to types of air pollution that could be considered together in a systematic review (e.g., traffic-related sources). OHAT prioritized the list of emerging health outcomes to review based on the extent of the available literature and evaluations of health effects conducted by other federal agencies. Outcomes related to respiratory health were not considered for evaluation as these outcomes are studied and reviewed more commonly.

Based on the results of this effort, OHAT determined that hypertensive disorders of pregnancy were among the best health outcomes to evaluate due to their effect on children's health. In addition, the majority of literature on these health outcomes had been published recently (since 2009) and would not have been included in the 2010 Health Effects Institute (HEI) Special Report 17 on health effects of traffic-related air pollution (TRAP) (HEI 2010) or the U.S. Environmental Protection Agency (EPA) Integrated Science Assessments for carbon monoxide (CO) (USEPA 2010), nitrogen oxides ( $\mathrm{NO}_{\mathbf{x}}$ ) (USEPA 2008), or particulate matter (PM) (USEPA 2009). The only recent review by a federal agency evaluating health effects in children following TRAP exposure was published by the Centers for Disease Control and Prevention (CDC) and focused on pediatric cancer (Boothe et al. 2014). Two additional groups evaluated the association between ambient air pollution and hypertensive disorders of pregnancy, but these studies did not specifically focus on traffic-derived air pollution nor did they assess internal validity (risk of bias) for the individual studies (Hu et al. 2014; Pedersen et al. 2014).

The overall objective and specific aims stated above were developed and refined through a series of problem formulation steps including: (1) review of the topic by the evaluation design team and other technical experts with backgrounds in air pollution, toxicology, epidemiology, reproductive physiology, information science, and systematic review; (2) deliberation with NTP staff and consultation with scientists at other federal agencies represented on the NTP Executive Committee; ${ }^{2}$ (3) public review of the concept for Evaluation of Traffic-Related Air Pollution and

\footnotetext{
${ }^{2}$ The NTP Executive Committee provides programmatic and policy oversight to the NTP Director and meets once or twice a year in closed forum. Members of this committee include the heads (or their designees) from the following federal agencies: Consumer Product Safety Commission (CPSC), Department of Defense (DoD), Environmental Protection Agency (EPA), Food and Drug Administration (FDA), National Cancer Institute (NCI), National Center for Environmental Health/Agency for Toxic Substances and Disease Registry (NCEH/ATSDR), National Institute of
} 
Children's Health at the April 16-18, 2014 meeting of the NTP Board of Scientific Counselors (http://ntp.niehs.nih.gov/go/9741); (4) guidance outlined in the OHAT Handbook for Conducting a Literature-Based Health Assessment (NTP 2015); and (5) external peer review of the draft protocol. The protocol was posted in June 2016 (Appendix G) and was used to conduct this review. Updates and clarifications to the OHAT Handbook were posted in March 2019 (https://ntp.niehs.nih.gov/go/systematic review) and included clarifications to the OHAT approach for reaching conclusions across multiple related exposures. A brief summary of the methods is presented below.

\section{PECO Statements}

To address NTP's overall objective and specific aims, a PECO (Population, Exposure,

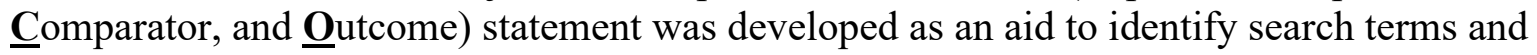
inclusion/exclusion criteria as appropriate for addressing the overall research question for the systematic review (AHRQ 2014; Higgins and Green 2011). The PECO statement is provided below for human and animal studies (Table 1). For the evaluation of hypertensive disorders of pregnancy associated with TRAP, the outcomes of interest were gestational hypertension; preeclampsia; eclampsia; hemolysis, elevated liver enzyme levels, and low platelet count (HELLP) syndrome; and changes in blood pressure.

The exposure characterization was an important consideration for this assessment because it focuses on air pollution derived specifically from traffic rather than more general ambient air pollution. Exposures were characterized by direct measures of traffic or measured or modeled concentrations of traffic-related air pollutant surrogates. Direct measures of traffic included distance to the nearest road or highway, distance to street canyons (i.e., streets lined with tall buildings on either side), and length of main streets within a buffer zone around homes or schools. Concentrations of traffic-related air pollutants included those obtained from monitors or other sources of measurement for pollutant-exposure surrogates that could be reasonably attributed to traffic (e.g., roadway-specific monitoring or subjects who lived within short distances of fixed monitors) or those estimated from dispersion models of traffic-related air pollutants or other models used to estimate traffic-related air pollutants (e.g., land use regression model) (Table 2). Many of the air pollutants regulated by EPA are established pollutant surrogates for TRAP (e.g., $\mathrm{CO}, \mathrm{NO}_{\mathrm{x}}, \mathrm{PM}$ ), and the criteria used in this assessment were peer reviewed and accepted by epidemiologists with expertise in exposure characterization. Although it is acknowledged that many exposure surrogates used to identify TRAP are also generated by other sources, these exposure characterization criteria substantially increase the confidence in reaching hazard conclusions about associations between exposure to air pollution derived from traffic and hypertensive disorders of pregnancy.

Environmental Health Sciences (NIEHS), National Institute for Occupational Safety and Health (NIOSH), and Occupational Safety and Health Administration (OSHA). 
Table 1. PECO Statement

\begin{tabular}{|c|c|}
\hline PECO Element & Evidence \\
\hline Population & $\begin{array}{l}\text { Female humans or mammalian animals who were pregnant at exposure and outcome } \\
\text { assessment }\end{array}$ \\
\hline Exposure & $\begin{array}{l}\text { Exposure to traffic-related air pollution, including traffic measures (e.g., distance to main } \\
\text { road, length of main streets with a buffer zone around homes or schools, traffic volume) and } \\
\text { air pollutants associated with traffic emissions (e.g., } \mathrm{CO}, \mathrm{NO}_{\mathrm{x}}, \mathrm{BC}, \mathrm{EC} \text {, coarse } \mathrm{PM}, \mathrm{PM}_{2.5} \text {, and } \\
\text { ultrafine } \mathrm{PM} \text { ) as well as mobile source toxics (e.g., benzene, diesel exhaust, PAHs); air } \\
\text { pollutants measured or modeled that estimate the pollutant-exposure surrogate and could } \\
\text { reasonably be traffic-related (e.g., near-road monitors); inhalation route of exposure (human, } \\
\text { animal), including nasal installation (animal) }\end{array}$ \\
\hline
\end{tabular}

Comparator A comparison population exposed to lower levels (or no exposure/exposure below detection levels) of traffic-related air pollution

Outcome Gestational hypertension, preeclampsia, eclampsia, HELLP syndrome, blood pressure measurements

$\mathrm{BC}=$ black carbon; $\mathrm{CO}=$ carbon monoxide; $\mathrm{EC}=$ elemental carbon; HELLP $=$ hemolysis, elevated liver enzymes, low platelet count; $\mathrm{NO}_{\mathrm{x}}=$ nitrogen oxides; $\mathrm{PAHs}=$ polycyclic aromatic hydrocarbons; $\mathrm{PM}=$ particulate matter.

Table 2. Traffic Exposure Metrics

\begin{tabular}{|c|c|}
\hline Metric & Examples \\
\hline \multicolumn{2}{|r|}{ Direct Measurements of Traffic ${ }^{a}$} \\
\hline Distance or Length & $\begin{array}{l}\text { Distance to nearest main road of highway; distance to street canyons (i.e., streets lined with } \\
\text { tall buildings on either side); length of main streets within buffer zone around homes or } \\
\text { schools }\end{array}$ \\
\hline Traffic Density & $\begin{array}{l}\text { Density on nearest road; average density estimated from road networks with buffer zones } \\
\text { around homes or schools; street canyons with buffers }\end{array}$ \\
\hline \multicolumn{2}{|r|}{ Traffic-related Air Pollutants ${ }^{b}$} \\
\hline Measurements ${ }^{\mathrm{c}}$ & $\begin{array}{l}\text { Measurements of traffic-related air pollutants from monitors or other sources of } \\
\text { measurements that could reasonably be attributed to traffic (e.g., near-road monitors) }\end{array}$ \\
\hline Modeling & $\begin{array}{l}\text { Dispersion of traffic-related air pollutants; other models used to estimate traffic-related air } \\
\text { pollution (e.g., land use regression model) }\end{array}$ \\
\hline \multicolumn{2}{|c|}{$\begin{array}{l}\text { a Studies with self-reporting of direct measures of traffic will be included; however, they will be identified as definitely high risk } \\
\text { of bias. } \\
\text { bIncludes carbon monoxide; black carbon; elemental carbon; nitrogen oxides; particulate matter (specifically PM }{ }_{2.5}[\text { fine PM], } \\
\text { ultrafine PM, and coarse PM); and mobile source toxics such as benzene, diesel exhaust, and polycyclic aromatic hydrocarbons. } \\
\text { cStudies utilizing personal air monitoring and/or urine biomarkers will be used as long as some description of traffic is included } \\
\text { in the methods. }\end{array}$} \\
\hline
\end{tabular}

\section{Literature Search}

Literature search strategies were developed to identify all relevant published evidence on hypertensive disorders of pregnancy potentially associated with TRAP through (1) review of PubMed's Medical Subject Headings for relevant and appropriate terms, (2) data extraction of a test set of relevant studies, and (3) evaluation of search strategies presented in other reviews. The search strategy was performed, and the results were assessed to ensure that $100 \%$ of the previously identified relevant primary studies were retrieved. Three databases (PubMed, Scopus, and Web of Science) were searched through January 28, 2019, using a strategy customized for 
each database (Appendix B). No publication year limits or language restrictions were imposed. The literature search was developed in collaboration with a librarian trained in systematic review methodology. Although unpublished studies were eligible (see protocol for more details; Appendix G), there were no unpublished data that met the PECO criteria for inclusion for this assessment.

\section{Searching Other Resources}

The reference lists of all included studies, relevant reviews, commentaries, and other nonresearch articles identified during the initial literature search were manually searched for additional relevant publications. Studies were evaluated using the same inclusion and exclusion criteria that were used for screening records retrieved from the electronic search.

\section{Study Selection}

\section{Evidence Selection Criteria}

To be eligible for inclusion, studies had to satisfy eligibility criteria specified by the PECO statement in Table 1. Reviews and other papers that did not provide original data on potential health effects were excluded but were considered for context if the information they provided (e.g., exposure, metabolism data) was useful for evaluating confidence in bodies of evidence or integrating evidence across human and animal data from the included studies. The following additional exclusion criteria were applied: (1) studies using nonpregnant subjects or animals other than nonhuman mammals; (2) studies that evaluated $\mathrm{CO}$ poisoning, noninhalation routes of exposure to relevant pollutants, heavy or transitional metals, formaldehyde or other volatile organic compounds relevant to vehicle exhaust; (3) articles with no original data, conference abstracts or other studies published in abstract form only, and retracted articles.

\section{Screening Process}

References retrieved from the literature search were screened for relevance and eligibility against the evidence selection criteria using DistillerSR ${ }^{\circledR}$ by Evidence Partners, a web-based, systematic review software program with structured forms and procedures to ensure standardization of the process. Screeners from the evidence evaluation team were trained with an initial pilot phase to improve clarity of the inclusion and exclusion instructions and to improve accuracy and consistency among screeners. All references were independently screened by two trained screeners (one of which was the project lead) at the title and abstract level to determine whether a reference met the evidence selection criteria. Studies that were not excluded during the title and abstract review were screened with a full-text review. Screening conflicts were resolved through discussion. Following full-text review, the remaining studies were "included" and used for the evaluation.

\section{Data Extraction}

\section{Extraction Process}

Data were collected (i.e., extracted) from included studies by one member of the evaluation team and checked by a second member for completeness and accuracy. Any discrepancies in data extraction were resolved by discussion. Information that was inferred, converted, or estimated 
during data extraction is annotated (e.g., using brackets $[n=10])$. Study extraction files noted when an attempt was made to contact study authors by email (and whether a response was received) for missing data considered important for evaluating key study findings.

\section{Data Availability}

Data extraction was completed using the Health Assessment Workspace Collaborative (HAWC), an open-source and freely available web-based interface application, for visualization and warehousing. ${ }^{3}$ The data extraction results for included studies are publicly available (https://hawcproject.org/assessment/60/) and can be downloaded in Excel format through HAWC (NTP 2019a). Data extraction elements are listed separately for human, animal, and in vitro studies in the protocol (Appendix G) (NTP 2019b).

\section{Quality Assessment of Individual Studies}

Risk of bias was assessed for individual studies using a tool developed by OHAT that outlines a parallel approach to evaluating risk of bias in human and animal studies to facilitate consideration of risk of bias across evidence streams with common terms and categories (NTP 2015). The risk-of-bias tool comprises a common set of 11 questions that are answered based on the specific details of individual studies to develop risk-of-bias ratings for each question. Study design determines the subset of questions used to assess risk of bias for an individual study (Figure 1).

Assessors were trained with an initial pilot phase undertaken to improve clarity of rating criteria and to improve consistency among assessors. Studies were independently evaluated by two trained assessors who answered all applicable risk-of-bias questions with one of four options shown in Figure 2 following pre-specified criteria detailed in the protocol (Appendix G). The criteria describe aspects of study design, conduct, and reporting required to reach risk-of-bias ratings for each question and specify factors that can distinguish among ratings (e.g., what separates "definitely low" from "probably low" risk of bias).

In the OHAT approach, some risk-of-bias questions or elements are considered potentially more important when assessing studies because there is more empirical evidence that these areas of bias have a greater effect on estimates of the effect size or because these issues are generally considered to have a greater effect on the credibility of study results in environmental health studies (Rooney et al. 2016). There were three key questions for observational human studies: confounding, exposure characterization, and outcome assessment. There were also three key questions for the experimental animal study: randomization, exposure characterization, and outcome assessment.

${ }^{3} \mathrm{HAWC}$ (Health Assessment Workspace Collaborative): A Modular Web-based Interface to Facilitate Development of Human Health Assessments of Chemicals (https://hawcproject.org/portal/). 


\begin{tabular}{|c|c|c|c|c|c|c|}
\hline Risk-of-bias Questions & 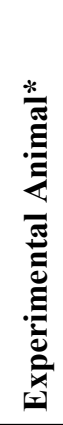 & 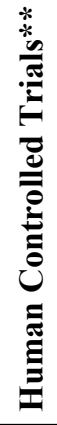 & 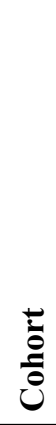 & 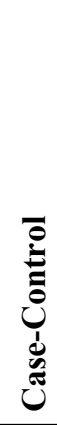 & 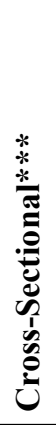 & 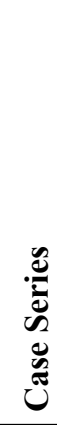 \\
\hline 1. Was administered dose or exposure level adequately randomized? & $\mathrm{X}$ & $\mathrm{X}$ & & & & \\
\hline 2. Was allocation to study groups adequately concealed? & $\mathrm{X}$ & $\mathrm{X}$ & & & & \\
\hline $\begin{array}{l}\text { 3. Did selection of study participants result in the appropriate comparison } \\
\text { groups? }\end{array}$ & & & $\mathrm{X}$ & $\mathrm{X}$ & $\mathrm{X}$ & \\
\hline $\begin{array}{l}\text { 4. Did study design or analysis account for important confounding and } \\
\text { modifying variables? }\end{array}$ & & & $\mathrm{X}$ & $\mathrm{X}$ & $\mathrm{X}$ & $\mathrm{X}$ \\
\hline 5. Were experimental conditions identical across study groups? & $\mathrm{X}$ & & & & & \\
\hline 6. Were research personnel blinded to the study group during the study? & $\mathrm{X}$ & $\mathrm{X}$ & & & & \\
\hline 7. Were outcome data complete without attrition or exclusion from analysis? & $\mathrm{X}$ & $\mathrm{X}$ & $\mathrm{X}$ & $\mathrm{X}$ & $\mathrm{X}$ & \\
\hline 8. Can we be confident in the exposure characterization? & $\mathrm{X}$ & $\mathrm{X}$ & $\mathrm{X}$ & $\mathrm{X}$ & $\mathrm{X}$ & $\mathrm{X}$ \\
\hline $\begin{array}{l}\text { 9. Can we be confident in the outcome assessment (including blinding of } \\
\text { outcome assessors)? }\end{array}$ & $\mathrm{X}$ & $\mathrm{X}$ & $\mathrm{X}$ & $\mathrm{X}$ & $\mathrm{X}$ & $\mathrm{X}$ \\
\hline 10. Were all measured outcomes reported? & $\mathrm{X}$ & $\mathrm{X}$ & $\mathrm{X}$ & $\mathrm{X}$ & $\mathrm{X}$ & $\mathrm{X}$ \\
\hline 11. Were there no other potential threats to internal validity? & $\mathrm{X}$ & $\mathrm{X}$ & $\mathrm{X}$ & $\mathrm{X}$ & $\mathrm{X}$ & $\mathrm{X}$ \\
\hline
\end{tabular}

Figure 1. OHAT Risk-of-bias Questions and Applicability by Study Design

\footnotetext{
*Experimental animal studies are controlled exposure studies. Nonhuman animal observational studies can be evaluated using the design features of observational human studies such as cross-sectional study design.

**Human controlled trials are studies in humans with controlled exposure (e.g., randomized controlled trials).

$* * *$ Cross-sectional studies include population surveys with individual data (e.g., NHANES) and surveys with aggregate data (i.e., ecological studies).
}

Any discrepancies in ratings between assessors were resolved through discussion to reach the final recorded risk-of-bias rating for each question along with a statement of the basis for that rating. Members of the evaluation team were consulted for assistance if additional expertise was necessary to reach final risk-of-bias ratings based on specific aspects of study design or performance reported for individual studies. Information or study procedures that were not reported is assumed not to have been conducted, resulting in an assessment of probably high risk of bias. Authors were queried by email to obtain missing information, and responses received were used to update risk-of-bias ratings. 


\begin{tabular}{ll}
\hline Symbol & \multicolumn{1}{c}{ Description } \\
\hline++ & $\begin{array}{l}\text { Definitely Low risk of bias: } \\
\text { There is direct evidence of low risk of bias practices. }\end{array}$ \\
\hline$+\quad \begin{array}{l}\text { Probably Low risk of bias: } \\
\text { There is indirect evidence of low risk of bias practices OR it is deemed that deviations from low risk of } \\
\text { bias practices for these criteria during the study would not appreciably bias results, including } \\
\text { consideration of direction and magnitude of bias. }\end{array}$ \\
\hline $\begin{array}{l}\text { Probably High risk of bias: } \\
\text { There is indirect evidence of high risk of bias practices (indicated with “-") }\end{array}$ \\
$\begin{array}{l}\text { OR there is insufficient information provided about relevant risk of bias practices (indicated as not } \\
\text { reported (NR)). Both symbols indicate probably high risk of bias. }\end{array}$ \\
\hline$-\quad \begin{array}{l}\text { Definitely High risk of bias: } \\
\text { There is direct evidence of high risk of bias practices. }\end{array}$ \\
\hline
\end{tabular}

Figure 2. The Four Risk-of-bias Rating Options

Answers to the risk-of-bias (study quality) questions result in one of the four risk-of-bias ratings.

\section{Organizing and Rating Confidence in Bodies of Evidence}

\section{Health Outcome and Endpoint Grouping by Categories of Health Effects and Exposure}

After data were extracted from all studies, the health effects results were grouped across studies to develop bodies of evidence or collections of studies with data on the same or related outcomes for the four main categories of interest: (1) blood pressure change during pregnancy, (2) gestational hypertension, (3) preeclampsia, and (4) eclampsia and HELLP syndrome (Table 3). Within these main endpoint categories, studies were grouped by exposure (e.g., traffic measures, $\mathrm{PM}, \mathrm{NO}_{\mathrm{x}}$ ) and evaluated individually and together as combined hypertensive disorders of pregnancy for each exposure.

Table 3. Hypertensive Disorders of Pregnancy: Endpoint Categories for Human and Animal Studies

\begin{tabular}{ll}
\hline \multicolumn{1}{c}{ Endpoint Category } & \multicolumn{1}{c}{ Description } \\
\hline Blood Pressure Change & $\begin{array}{l}\text { An increase or decrease related to the reference pregnant population (human or } \\
\text { animal) }\end{array}$ \\
Gestational Hypertension & $\begin{array}{l}\text { Isolated systolic blood pressure (SBP) } \geq 140 \mathrm{mmHg} \text { or diastolic blood pressure } \\
(\mathrm{DBP}) \geq 90 \mathrm{mmHg} \text { during the second half of pregnancy }\end{array}$ \\
Preeclampsia & $\begin{array}{l}\text { Gestational hypertension accompanied by proteinuria after } 20 \text { weeks of gestation } \\
\text { Eclampsia and HELLP }\end{array}$ \\
& $\begin{array}{l}\text { Eclampsia: Gestational hypertension, with or without proteinuria, plus at least } \\
\text { one observed seizure in a woman with no prior history of a seizure disorder }\end{array}$ \\
& $\begin{array}{l}\text { Hemolysis elevated liver enzyme low platelet count (HELLP) syndrome: } \\
\text { Hemolysis (abnormal peripheral smear, bilirubin }>1.2 \mathrm{mg} / \mathrm{dl}, \text { or lactose } \\
\text { dehydrogenase }>600 \text { IU/L), elevated liver enzymes (aspartate amino transferase } \\
\text { or alanine aminotransferase }>70 \text { IU/L), and low platelet count }\left(<100,000 \text { mm }{ }^{3}\right)\end{array}$ \\
\hline
\end{tabular}




\section{Considerations for Pursuing a Narrative or Quantitative Evidence Synthesis}

Heterogeneity within the available evidence was used to determine whether a narrative approach with or without a quantitative synthesis (meta-analysis) was most appropriate for evidence integration. Meta-analysis approaches are considered most suitable if there are at least 6-10 results for a continuous variable and at least 4 results for a categorical variable (Rudra et al. 2011). Groups of studies for two pollutants displayed enough similarity across exposures to deem them appropriate for meta-analyses: $\mathrm{PM}_{2.5}$ and $\mathrm{NO}_{2}$. Due to heterogeneity of the evidence or small bodies of evidence across other TRAP measures, only a narrative approach (and not a meta-analysis) was appropriate for evidence synthesis of these measures.

\section{Confidence Rating: Assessment of Body of Evidence}

The quality of evidence for hypertensive disorders of pregnancy was evaluated using the GRADE system for rating the confidence in the body of evidence (AHRQ 2014; Guyatt et al. 2011). More detailed guidance on reaching confidence ratings in the body of evidence as "high," "moderate," "low," or "very low" is provided in the OHAT Handbook for Conducting a Literature-Based Health Assessment (http://ntp.niehs.nih.gov/go/38673, see STEP 5). In brief, available human and animal studies on a particular health outcome in Table 3 were initially grouped by key study design features, and each grouping of studies was given an initial confidence rating by those features. Starting at this initial rating (column 1 of Figure 3), potential downgrading of the confidence rating was considered for factors that decrease confidence in the results (column 2 of Figure 3 [risk of bias, unexplained inconsistency, indirectness or lack of applicability, imprecision, and publication bias]); and potential upgrading of the confidence rating was considered for factors that increase confidence in the results (column 3 of Figure 3 [large magnitude of effect, dose response, consistency across study designs/populations/animal models or species, consideration of residual confounding, and other factors that increase confidence in the association or effect]). Consideration of consistency across study designs, human populations, or animal species is not included in the GRADE guidance (Guyatt et al. 2011); however, it is considered in the modified version of GRADE used by OHAT (Rooney et al. 2014).

Confidence ratings were assessed by federal staff and reviewed by members of the evaluation review team for accuracy and consistency, and discrepancies were resolved by consensus and consultation with technical advisors as needed. Confidence ratings for the outcomes are summarized in evidence profile tables for each outcome. 


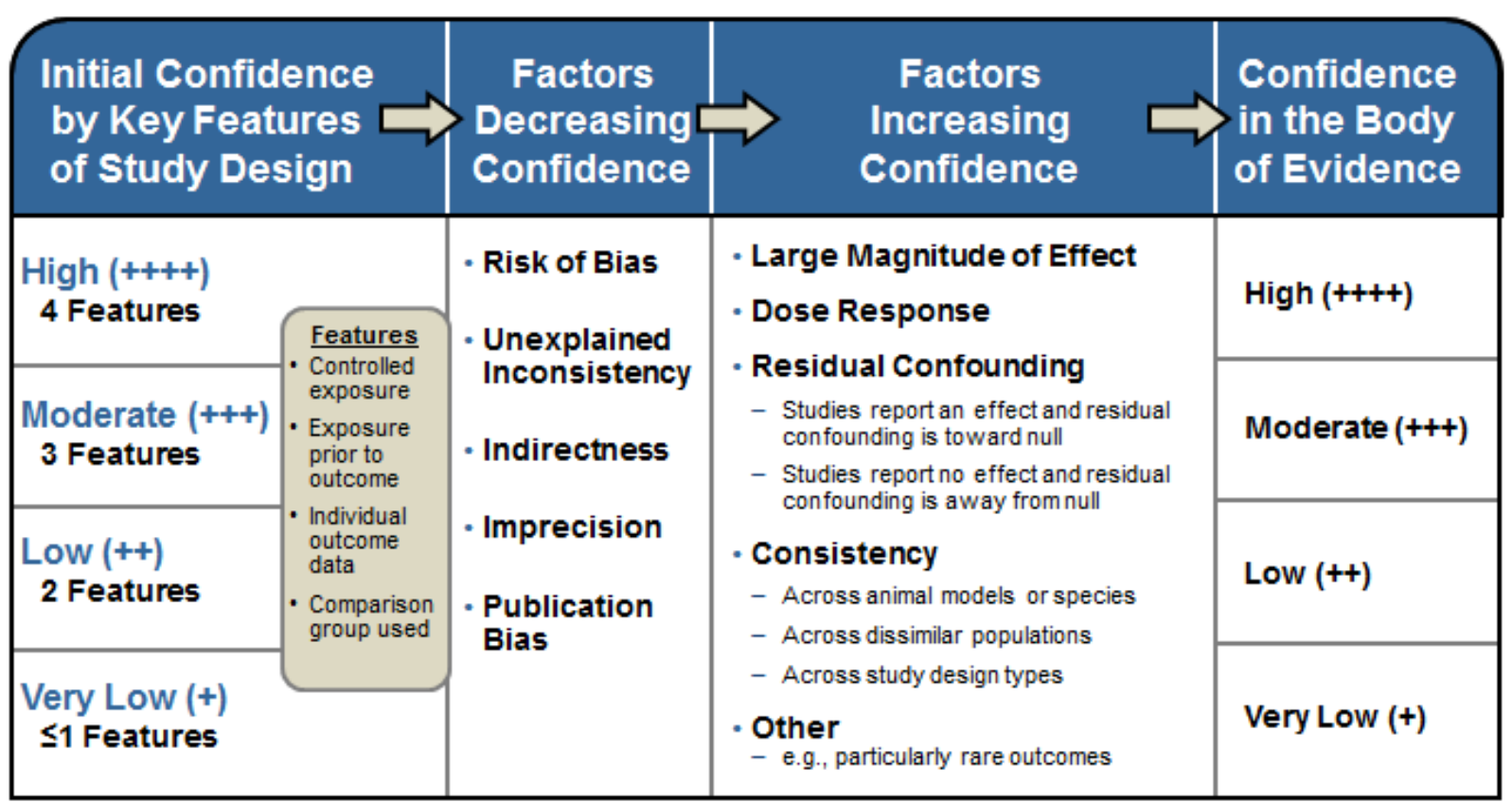

Figure 3. Assessing Confidence in the Body of Evidence

\section{Preparation of Level-of-evidence Conclusions}

The confidence ratings were translated into level of evidence of health effects for each type of health outcome (if applicable) and hypertensive disorders of pregnancy as a whole for each traffic-related pollutant, each traffic measure, and traffic-related air pollution as a whole according to one of four statements: (1) High, (2) Moderate, (3) Low, or (4) Inadequate (Figure 4 and Table 4). The descriptor "evidence of no health effect" is used to indicate confidence that the substance is not associated with a health effect. Because of the inherent difficulty in proving a negative, the conclusion "evidence of no health effect" is only reached when there is high confidence in the body of evidence.

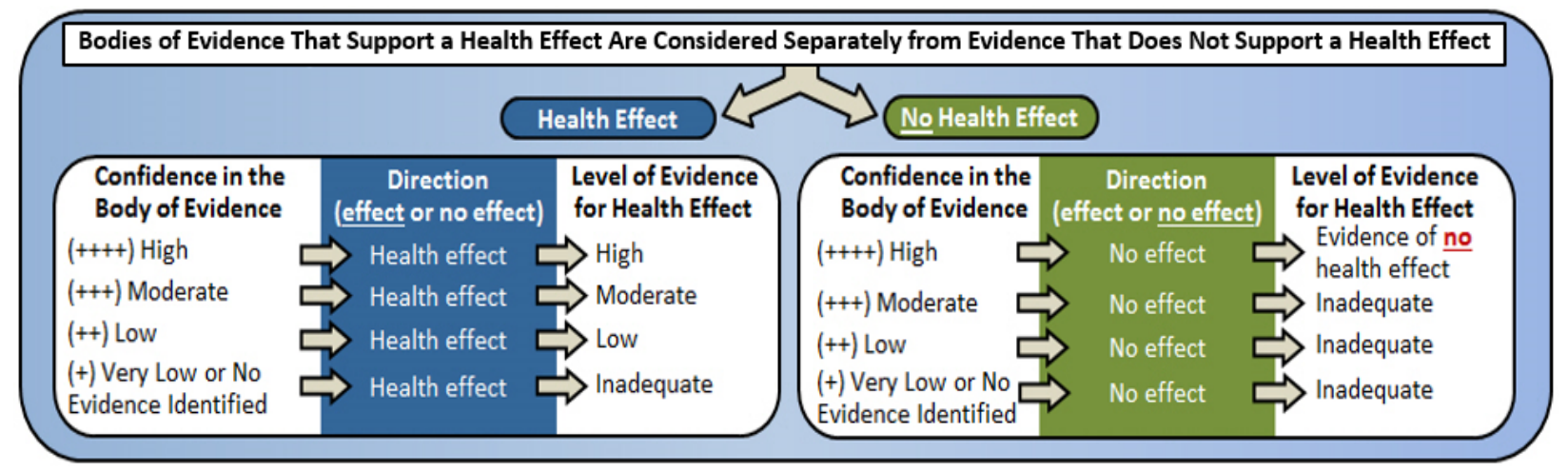

Figure 4. Translation of Confidence Ratings into Evidence of Health Effect Conclusions 
Table 4. Definitions of Level-of-evidence Descriptors

\begin{tabular}{ll}
\hline \multicolumn{1}{c}{ Evidence Descriptors } & \multicolumn{1}{c}{ Definition } \\
\hline High Level of Evidence & $\begin{array}{l}\text { There is high confidence in the body of evidence for an } \\
\text { association between exposure to TRAP and the health outcome(s). } \\
\text { Moderate Level of Evidence }\end{array}$ \\
$\begin{array}{l}\text { There is moderate confidence in the body of evidence for an } \\
\text { association between exposure to TRAP and the health outcome(s). } \\
\text { Low Level of Evidence }\end{array}$ & $\begin{array}{l}\text { There is low confidence in the body of evidence for an association } \\
\text { between exposure to TRAP and the health outcome(s), or no data } \\
\text { are available. } \\
\text { Thadequate Evidence }\end{array}$ \\
There is insufficient evidence available to assess if exposure to \\
TRAP is associated with the health outcome(s). \\
There is high confidence in the body of evidence that exposure to \\
TRAP is not associated with the health outcome(s).
\end{tabular}

\section{Integration of Evidence to Develop Hazard Identification Conclusions}

Finally, the level-of-evidence ratings for human and animal data were integrated with consideration of in vitro/mechanistic data to reach one of five possible hazard identification categories: Known, Presumed, Suspected, Not classifiable, or Not Identified to Be a Hazard to Pregnant Women (Figure 5).

\section{Considerations for Human and Animal Data}

Initial hazard identification conclusions were reached by integrating the highest level-ofevidence conclusions for TRAP-related hypertensive disorders of pregnancy for human and animal evidence streams. Hazard identification conclusions were reached on the effects of individual exposures to induce or exacerbate each health outcome (Figure 2) or the combined hypertensive disorders of pregnancy. The level-of-evidence conclusion for human data for the health outcome was considered together with the level of evidence for nonhuman animal data on the health outcome to reach one of four initial hazard identification conclusions: Known, Presumed, Suspected, or Not classifiable. When either the human or animal evidence stream was characterized as inadequate evidence for a particular outcome, conclusions were based on the remaining evidence stream alone (which is equivalent to treating the missing evidence as "Low" in Figure 5). 


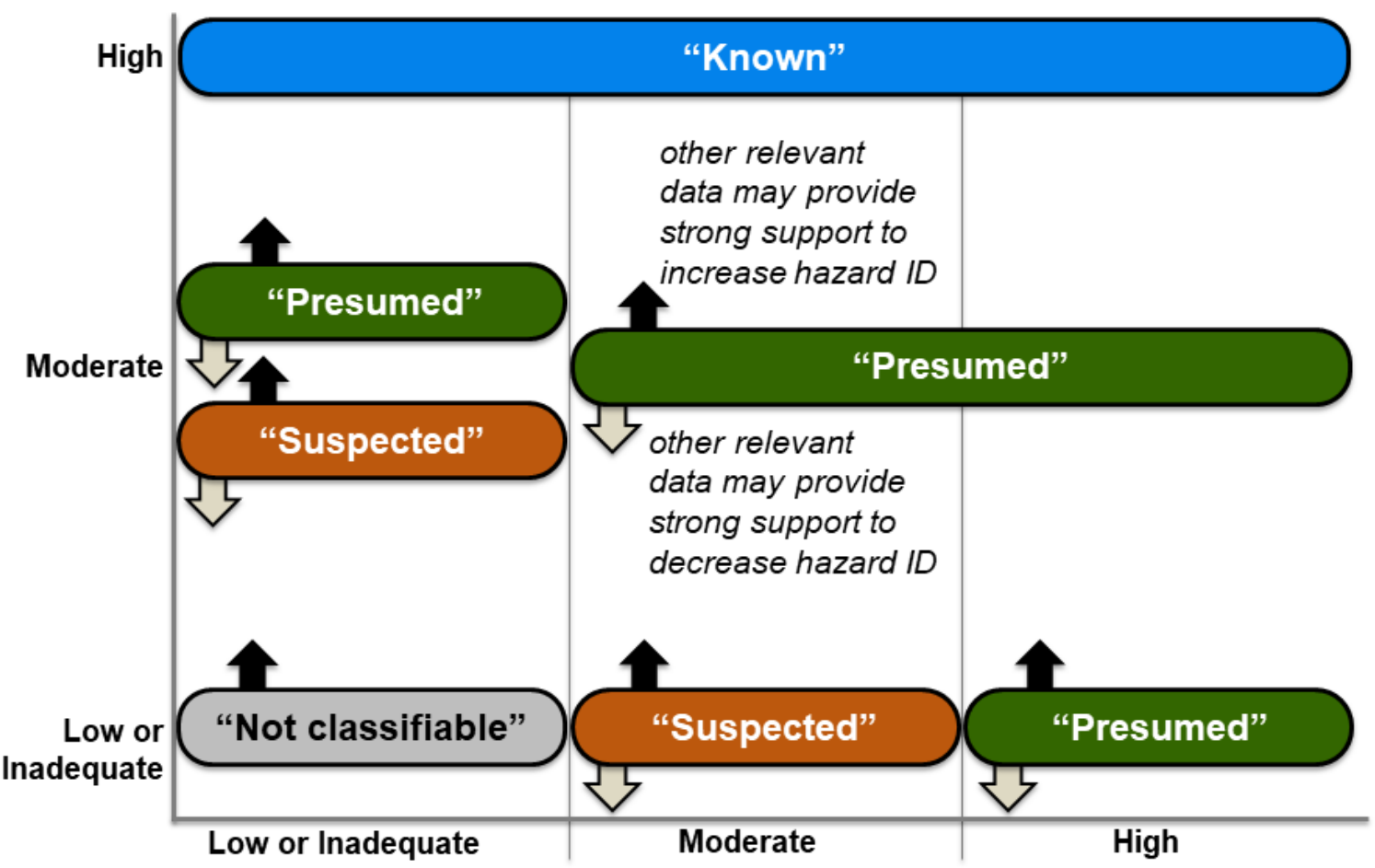

Level of Evidence for Health Effects in Nonhuman Animal Studies

Figure 5. Hazard Identification Scheme for Hypertensive Disorders of Pregnancy

\section{Considerations for Evaluating Combined Traffic-related Air Pollution Exposure}

Evidence for an association between TRAP and hypertensive disorders of pregnancy was evaluated in a stepwise manner. This stepwise approach for considering the combined evidence across multiple exposures or the individual pollutants that make up TRAP is analogous to the method for evaluating multiple biologically related outcomes to inform confidence on the overall health outcome. In each case, the evidence is evaluated for individual exposures or outcomes and then the combined evidence is considered collectively. First, the bodies of evidence for individual TRAP components (e.g., $\mathrm{PM}_{2.5}, \mathrm{NO}_{\mathrm{x}}$ ) were evaluated. A confidence rating for each TRAP component was then developed.

Because TRAP comprises multiple pollutants, NTP considered the appropriateness of evaluating the evidence across all TRAP measures included in the evaluation as a single combined TRAP exposure. Two key points were weighed in making this determination: (1) whether individual TRAP components could act independently to elevate blood pressure and (2) if exposure to multiple TRAP components is likely during pregnancy. Most studies in the human evidence evaluated single TRAP components, and studies were generally consistent in finding an association (with the same direction of effect) between the individual TRAP components and elevated blood pressure during pregnancy. Studies that evaluated multiple TRAP components 
still found significant associations between the individual components and hypertensive disorders of pregnancy after statistically accounting for other exposures. Further, mechanistic studies demonstrated that multiple TRAP components could act independently on pathways that lead to elevated blood pressure (e.g., through vascular inflammation and oxidative stress). Therefore, consistency in the evidence for an association between the individual TRAP components and hypertensive disorders of pregnancy and mechanistic data supporting independent mechanisms by which TRAP can elevate blood pressure enabled NTP to support the development of a hazard conclusion for the combined TRAP exposure. Thus, the evidence in the body of literature was considered together and then reevaluated for properties related to downgrading or upgrading confidence in the body of evidence.

\section{Consideration of Mechanistic Data}

There is no requirement to consider mechanistic or mode-of-action data to reach hazard identification conclusions; however, when available, this and other relevant supporting types of evidence may be used to raise (or lower) the category of the hazard identification conclusion. Mechanistic data can come from a wide variety of studies that are not intended to identify a disease phenotype. This source of experimental data includes in vitro and in vivo laboratory studies directed at cellular, biochemical, and molecular mechanisms that explain how a chemical produces particular adverse effects.

The factors outlined for increasing or decreasing confidence that the mechanistic data support biological plausibility are conceptually similar to those used to rate confidence in bodies of evidence for human or animal in vivo studies and are listed below and described in depth in the protocol (Appendix G). Four factors were considered that contribute to increased confidence: potency, dose response, consistency in terms of cellular events observed at the same or lower doses than in vivo health effects, and consistency across cellular targets on the same pathway. Four factors were considered that contribute to decreased confidence: unexplained inconsistency across studies of the same endpoint, risk of bias, indirectness/applicability of the pathway for human health or concentrations for human exposure, and publication bias. Evaluations of the strength of evidence provided by mechanistic data were made on an outcome-specific basis following a discussion by the evaluation team and consultation with technical advisors as needed.

- If mechanistic data provided strong support for biological plausibility of the relationship between exposure and the health effect, the hazard identification conclusion may be upgraded (indicated by black "up" arrows in Figure 5) from that initially derived by considering the human and nonhuman animal evidence together.

- If mechanistic data provided strong opposition for biological plausibility of the relationship between exposure and the health effect, the hazard identification conclusion may be downgraded (indicated by gray "down" arrows in Figure 5) from that initially derived by considering the human and nonhuman animal evidence together.

To date, the mechanism(s) underlying the effects of air pollution on blood pressure during pregnancy have not been investigated. A significant challenge to this area of research lies in the fact that the mechanisms underlying the etiology of hypertensive disorders of pregnancy themselves are not clearly understood, although improper remodeling of the uterine arteries 
resulting in reduced blood flow to the placenta appears to play a role. Although studies investigating the physiology of vascular remodeling events and endocrine adaptations during pregnancy were considered to provide context for the available data, none of those studies investigated the effect of air pollution on those mechanisms. Thus, mechanistic data relevant to the hemodynamic, endocrine, and cardiovascular adaptations during normal pregnancy were not used to assess biological plausibility for consideration of upgrading or downgrading confidence.

Although it is envisioned that strong evidence for a relevant process from mechanistic data alone could indicate a greater potential for the substance to induce or exacerbate hypertensive disorders of pregnancy, for this evaluation, the mechanistic data on individual TRAP components on blood pressure parameters in the nonpregnant state were considered only to inform the appropriateness of developing a hazard conclusion for the combined TRAP exposure. The mechanistic studies considered for this assessment evaluated several features associated with hypertensive disorders of pregnancy, although none of the studies specifically evaluated the effects of air pollutants on mechanisms affecting blood pressure during pregnancy. Studies that were considered included those that evaluated effects of air pollutants on placental vascularization in early pregnancy or effects of air pollutants on mechanisms related to blood pressure changes in the nonpregnant state.

\section{Considerations for Meta-analyses and Meta-analyses Methods}

Meta-analyses were conducted to explore the associations between exposures to $\mathrm{PM}_{2.5}, \mathrm{NO}_{2}$, or $\mathrm{NO}_{\mathrm{x}}$ and hypertensive disorders of pregnancy. The available evidence was evaluated with respect to several criteria to ensure results included in the meta-analyses would be sufficiently similar. The following criteria were considered:

- Outcome: The outcome of interest was hypertensive disorders of pregnancy, including gestational hypertension, preeclampsia, and eclampsia.

- Exposure unit: The study outcomes were evaluated with respect to a $10 \mu \mathrm{g} / \mathrm{m}^{3}$ increase in exposure.

- Effect estimate: The study reported effects as odds ratios (ORs) and included $95 \%$ confidence intervals (CIs) or standard errors (SES).

When necessary, to ensure consistent units across studies and to allow comparisons of effect estimates between studies, the reported effect estimates were converted to common exposure increments. For example, in this assessment, most of the studies that evaluated associations between $\mathrm{PM}_{2.5}$ exposure and preeclampsia reported effects for every $10 \mu \mathrm{g} / \mathrm{m}^{3}$ increase in $\mathrm{PM}_{2.5}$. Therefore, for $\mathrm{PM}_{2.5}$ studies that reported effects associated with a $5 \mu \mathrm{g} / \mathrm{m}^{3}$ increase in $\mathrm{PM}_{2.5}$, effect estimates were transformed to represent effects at a $10 \mu \mathrm{g} / \mathrm{m}^{3}$ increase. Several studies reported exposures in parts per billion ( $\mathrm{ppb}$ ), and these exposures were converted as described in the Pedersen et al. (2014) meta-analysis supplement. Exposure estimations for $\mathrm{NO}_{2}$ that were expressed in ppb instead of mass per volume of air were converted to $\mu \mathrm{g} / \mathrm{m}^{3}$ using a general conversion factor of 1.88 (assuming that $1 \mathrm{ppb}$ equals $1.88 \mu \mathrm{g} / \mathrm{m}^{3}$ at 1 atmosphere for both pollutants). Thus, for each study, an OR and 95\% CI were obtained for the association between the outcome of interest and a $10 \mu \mathrm{g} / \mathrm{m}^{3}$ increase in $\mathrm{PM}_{2.5}, \mathrm{NO}_{2}$, or $\mathrm{NO}_{\mathrm{x}}$.

Adjusted ORs were used in the meta-analyses, and if results from multiple models were reported within a single study, the fully adjusted, single-pollutant models were selected. 
Wu et al. (2011) reports results associated with $\mathrm{PM}_{2.5}, \mathrm{NO}_{2}, \mathrm{NO}_{\mathrm{x}}$, and traffic measures from two separate study locations (Los Angeles County and Orange County, California). Because the land use regression (LUR) models were originally developed based on measurements taken only in Los Angeles County and the difference in socioeconomic status between the two counties is remarkable, the two county results were treated as independent effects and both were included in the analyses. Furthermore, given that the focus of the assessment was on TRAP, the CALINE4 line-source dispersion modeling estimates for $\mathrm{PM}_{2.5}$ and $\mathrm{NO}_{\mathrm{x}}$ were used (rather than the estimates based on ambient monitoring data) because these estimates are more precise than other exposure measurements and can capture the local traffic emissions within $3 \mathrm{~km}$ of each residence for five traffic-related pollutants. The adjusted LUR model results were used for the $\mathrm{NO}_{2}$ analyses.

In general, if a study reported multiple hypertension-related results (e.g., gestational hypertension and preeclampsia, mild and severe preeclampsia), the effect estimates were pooled, and one effect estimate was included in the exposure-specific combined hypertensive disorders of pregnancy meta-analysis.

The combined risk estimates for studies with categorical effect estimates were estimated using the highest versus the lowest exposure category. When effect estimates of two different categorical analyses of proximity to major roads were reported (Miranda et al. 2013), the one with the greatest exposure contrast was selected.

If possible, estimates for multiple exposure periods (e.g., full gestational period, trimester 1, trimester 2) were reported. Meta-analyses were not performed if fewer than four results were available for a specific exposure-outcome combination.

Fixed- and random-effects models were used to obtain the summary risk estimates. Heterogeneity of the included studies was assessed using the Q-test (Cochran 1954). The random-effects model results are presented when the Q-test showed evidence of heterogeneity $(\mathrm{p}<0.05)$ (DerSimonian and Laird 1986). When the $\mathrm{p}$ value for heterogeneity was greater than 0.05, the random-effects model results are identical to the fixed-effects model results (Mantel and Haenszel 1959). Forest plots were used to display the individual study-specific results and summary risk estimates. Publication bias was examined using the Egger's test and funnel plots (Egger et al. 1997).

Data management was performed with Excel. Statistical analyses were performed using STATA version 15 (StataCorp 2017) using the metan, metareg, metainf, metafunnel, metabias, and metatrim packages. 


\section{Results and Evidence Synthesis}

\section{Literature Search Results}

The electronic database searches retrieved 344 individual references. From the total references retrieved, 246 were excluded during the title and abstract screening, and 79 studies were excluded during the full-text review. The screening results are outlined in a study selection diagram with reasons for exclusion documented at the full-text review level (Figure 6). The 19 included studies (18 human studies and 1 animal study) are listed in Appendix C.

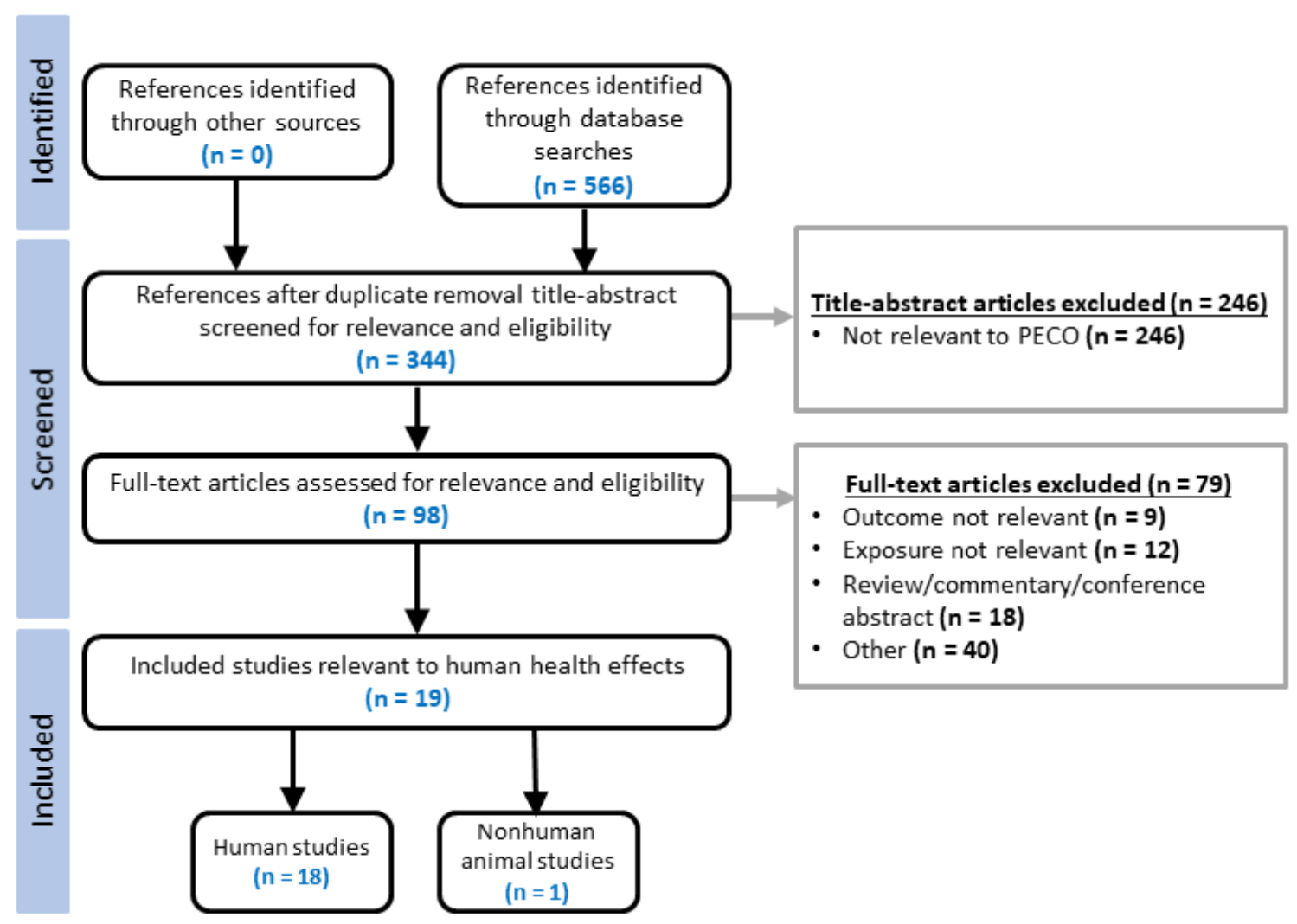

Figure 6. Study Selection Diagram

\section{Health Effects Results}

The human and animal data across all studies were sorted by exposure and then, if applicable, by individual health outcomes: changes in blood pressure; gestational hypertension; preeclampsia; or eclampsia/hemolysis, elevated liver enzyme levels, and low platelet count (HELLP) syndrome. The associations between TRAP components or traffic measures and health outcomes were evaluated individually and in totality (i.e., hypertensive disorders of pregnancy). The majority of the available evidence for this evaluation comes from epidemiological studies; however, experimental animal studies are presented where applicable. Individual TRAP components that were evaluated within the body of evidence were fine particulate matter $\left(\mathrm{PM}_{2.5}\right)$, nitrogen oxides $\left(\mathrm{NO}_{\mathrm{x}}\right)$, carbon monoxide $(\mathrm{CO})$, black carbon $(\mathrm{BC})$, and elemental carbon (EC); direct exposure measurements of traffic density and proximity to major roads were also 
evaluated. When there was a sufficient number of results and similarity across studies, metaanalyses were conducted to synthesize the findings.

The main findings for associations between exposures to TRAP and hypertensive disorders of pregnancy are summarized below. Sections for Traffic-related Air Pollutants and Traffic Measures present the results and evidence synthesis in detail for each exposure and health outcome evaluated.

\section{Main Findings for Associations between Exposures to Traffic-related Air Pollution and Hypertensive Disorders of Pregnancy}

The principal findings are outlined below including a brief description for the confidence ratings and level-of-evidence conclusions for the data that support the hazard identification conclusion for associations between exposures to TRAP and hypertensive disorders of pregnancy (Figure 7). The overall conclusion for this assessment was developed using a stepwise process. First, confidence ratings were developed for the individual TRAP components. Relevant data, including mechanistic studies, were then used to determine the appropriateness of developing a hazard conclusion for the combined TRAP exposure. The bodies of evidence for each TRAP component were combined and considered as a single TRAP exposure measure and reevaluated for factors that would increase or decrease confidence. Finally, a hazard identification conclusion for the combined TRAP exposure was developed.

\section{Summary}

There is moderate confidence in the combined body of evidence from human studies reporting that exposures to TRAP during the entire gestation period is associated with the development of hypertensive disorders of pregnancy. The moderate confidence in the body of evidence across multiple measures of TRAP exposure translates to a moderate level of evidence. No experimental animal studies were identified for these measures, resulting in an inadequate level of evidence for the animal data. The moderate level of evidence from the human studies alone supports a hazard conclusion of presumed on the basis of a combined body of evidence that supports a consistent effect of TRAP on hypertensive disorders of pregnancy across a larger number of studies. This conclusion indicates multiple mechanisms by which the individual components can affect blood pressure and suggests a greater likelihood that individuals may be exposed to more than one component of TRAP. Therefore, the integration of the body of evidence supports a final hazard conclusion of TRAP exposure of presumed to be a hazard to pregnant women.

\section{Individual Traffic-related Air Pollution Components}

The effect of TRAP for individual traffic-related components- $\mathrm{PM}_{2.5}, \mathrm{NO}_{2}$, and traffic measures - was supported by meta-analyses. The strongest evidence from the individual TRAP components came from the $\mathrm{PM}_{2.5}$ data, which showed an association for preeclampsia per 10 $\mu \mathrm{g} / \mathrm{m}^{3}$ increase in $\mathrm{PM}_{2.5}$ during the full pregnancy period (meta-OR: $1.51,95 \% \mathrm{CI}: 1.04,2.20$ ). Small but positive associations were also demonstrated for $\mathrm{NO}_{2}$ exposure and preeclampsia (meta-OR: 1.04, 95\% CI: 0.97, 1.10). Consideration of these TRAP components, along with traffic measures, supports moderate initial confidence for the individual components, and there were no factors that would increase or decrease the confidence resulting in a final confidence rating of moderate. 


\section{Combined Body of Evidence for Traffic-related Air Pollution Exposure}

Following the evaluation of individual TRAP components, other relevant factors, including mechanistic data, were considered to determine the appropriateness of developing a hazard conclusion for the combined TRAP exposure. Additional data (not evaluating blood pressure regulation during pregnancy) evaluating single pollutants support that individual $\mathrm{PM}_{2.5}$ and $\mathrm{NO}_{2}$ exposures can act independently to affect vascular inflammation and oxidative stress pathways that lead to increased blood pressure. Indeed, there was consistency in the direction of effect for studies in the human evidence that evaluated single TRAP components. Studies that evaluated more than one TRAP component also found significant associations between individual components and hypertensive disorders of pregnancy after statistically accounting for other exposures. However, TRAP includes multiple pollutants, and the likelihood of being exposed simultaneously to multiple TRAP components is high. The independent mechanisms by which these pollutants can elevate blood pressure along with evidence of an association between increased TRAP exposure and development of hypertensive disorders of pregnancy (supported by meta-analyses) demonstrate that multiple TRAP components can act on blood pressure parameters during pregnancy to lead to hypertension. Therefore, it was appropriate to develop a hazard conclusion for combined TRAP exposure to more accurately reflect the true exposure to pregnant women.

Conclusions for combined TRAP exposure were based on 18 epidemiological studies from 15 cohort studies, ${ }^{4} 1$ cross-sectional study, and 2 case-control studies. Similar to the ratings developed for the individual components of TRAP, the initial confidence rating for the combined TRAP exposure was moderate. Factors that could increase or decrease confidence were then considered for the combined body of evidence. Upgrading for consistency was considered for the combined TRAP exposure because of the consistency in the directions of effect across multiple populations and geographic locations from separate lines of evidence for air pollution measures and traffic measures. In several cases, study authors evaluated associations between hypertensive disorders of pregnancy and exposure to a single air pollutant that served as a proxy for TRAP, whereas others evaluated associations between hypertensive disorders of pregnancy and multiple measures of TRAP (e.g., $\mathrm{PM}_{2.5}$ and $\mathrm{NO}_{\mathrm{x}}$ ). While studies that evaluated multiple measures of TRAP accounted for co-exposures statistically, the body of literature does not represent completely independent lines of evidence, which would have strengthened the overall confidence in the associations. Thus, although consistency was considered as a factor for upgrading confidence, no changes were applied to the initial confidence, resulting in a final confidence rating of moderate for the combined TRAP exposure.

The moderate confidence in the combined body of literature translates to a moderate level of evidence for the human data. There were no experimental animal studies in the body of evidence that were included in the assessment for the combined TRAP exposure, which translates to an inadequate level of evidence for the animal data. Integration of these level-of-evidence conclusions supports an initial hazard conclusion of presumed to be a hazard to pregnant women because of the extent and consistency of the available data. The body of evidence for combined TRAP exposure was determined to be presumed on the basis of a combined body of evidence that supports a consistent effect of TRAP on hypertensive disorders of pregnancy across a large number of studies. This determination indicates multiple mechanisms by which the individual

\footnotetext{
${ }^{4} \mathrm{Wu}$ et al. (2011) evaluated two independent cohorts.
} 
components can affect blood pressure and suggests a greater likelihood that individuals may be exposed to more than one component of TRAP.

Mechanistic data were not considered to upgrade the final hazard conclusion because, to date, there are no mechanistic studies that investigate the effects of combined TRAP exposure on blood pressure during pregnancy. Mechanistic data that were reviewed were deemed not directly relevant and, therefore, were not considered for potentially upgrading the initial hazard conclusion based on biological plausibility. Taken together, the available evidence for combined TRAP exposure and hypertensive disorders of pregnancy supports a final hazard conclusion of presumed to be a hazard to pregnant women.

\section{Integration of Evidence for Hypertensive Disorders of Pregnancy}

The final conclusion for the combined TRAP body of evidence was developed after considering the individual TRAP components separately. The effect of TRAP was consistent across bodies of evidence for the individual components and was supported by meta-analyses for individual traffic-related $\mathrm{PM}_{2.5}$, and $\mathrm{NO}_{2}$.

\section{Individual Traffic-related Air Pollution Components $\left(\mathrm{PM}_{2.5}, \mathrm{NO}_{2}\right)$ and Traffic Measures}

- Human body of evidence: Moderate confidence

○ $\quad \mathbf{P M}_{2.5}$ : Moderate confidence

○ $\mathbf{N O}_{2}$ : Moderate confidence

○ Traffic Measures: Low confidence

- Animal body of evidence ${ }^{5}$ : No evidence identified

○ PM2.5: No studies

○ $\mathbf{N O}_{2}$ : No studies

○ Traffic Measures: No studies

\section{Combined Traffic-related Air Pollution Measures}

- Initial hazard conclusion (Moderate human $\times$ Inadequate animal) $=$ Presumed to be a hazard to pregnant women

- Final hazard conclusion: No change (after considering biological plausibility) $=$ Presumed to be a hazard to pregnant women

Taken together, the data support a final hazard conclusion that exposure to TRAP is presumed to be a hazard to pregnant women (see Table 5).

\footnotetext{
${ }^{5}$ Erratum: The confidence rating for the animal body of evidence was changed from "Low (inadequate) confidence"
} to "No evidence identified" on July 25, 2019. 
Systematic Review of TRAP and Hypertensive Disorders of Pregnancy

Table 5. Traffic-related Air Pollution Summary Table

\begin{tabular}{|c|c|c|c|c|c|c|}
\hline \multirow{2}{*}{ Exposure } & \multirow{2}{*}{$\begin{array}{l}\text { Health } \\
\text { Outcome }\end{array}$} & \multicolumn{2}{|c|}{$\begin{array}{l}\text { Confidence Rating in the } \\
\text { Body of Evidence }\end{array}$} & \multicolumn{2}{|c|}{$\begin{array}{l}\text { Level of Evidence in the Body } \\
\text { of Evidence }\end{array}$} & \multirow{2}{*}{$\begin{array}{l}\text { Hazard } \\
\text { Conclusion }\end{array}$} \\
\hline & & Human & Animal & Human & Animal & \\
\hline $\mathrm{PM}_{2.5}$ & Preeclampsia & Moderate & $\begin{array}{l}\text { No Evidence } \\
\text { Identified }\end{array}$ & - & - & - \\
\hline $\mathrm{NO}_{2}$ & Preeclampsia & Moderate & $\begin{array}{l}\text { No Evidence } \\
\text { Identified }\end{array}$ & - & - & - \\
\hline $\begin{array}{l}\text { Traffic } \\
\text { Density }\end{array}$ & Preeclampsia & Low & $\begin{array}{l}\text { No Evidence } \\
\text { Identified }\end{array}$ & - & - & - \\
\hline $\begin{array}{l}\text { Distance to } \\
\text { Road Traffic }\end{array}$ & Preeclampsia & Low & $\begin{array}{l}\text { No Evidence } \\
\text { Identified }\end{array}$ & - & - & - \\
\hline $\begin{array}{l}\text { Combined } \\
\text { TRAP }\end{array}$ & $\begin{array}{l}\text { Hypertensive } \\
\text { Disorders of } \\
\text { Pregnancy }\end{array}$ & Moderate & $\begin{array}{l}\text { No Evidence } \\
\text { Identified }\end{array}$ & Moderate & Inadequate & $\begin{array}{l}\text { Presumed to } \\
\text { be a hazard to } \\
\text { pregnant } \\
\text { women }\end{array}$ \\
\hline
\end{tabular}




\begin{tabular}{|c|c|c|c|c|c|c|c|c|c|c|}
\hline \multirow[b]{2}{*}{$\begin{array}{l}\text { Initial Confidence for } \\
\text { Each Body of Evidence } \\
\text { (\# of Studies) }\end{array}$} & \multicolumn{5}{|c|}{$\begin{array}{l}\text { Factors Decreasing Confidence } \\
\text { “---”If No Concern; “ } \downarrow ” \text { If Serious } \\
\text { Concern to Downgrade Confidence }\end{array}$} & \multicolumn{4}{|c|}{$\begin{array}{l}\text { Factors Increasing Confidence } \\
\text { “_-_-” If Not Present; “ } \downarrow ” \text { If } \\
\text { Sufficient to Upgrade } \\
\text { Confidence } \\
\end{array}$} & \multirow[b]{2}{*}{$\begin{array}{l}\text { Final } \\
\text { Confidence } \\
\text { Rating }\end{array}$} \\
\hline & 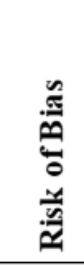 & 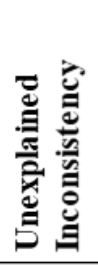 & 毵 & 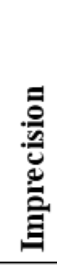 & 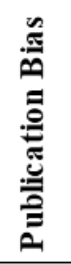 & 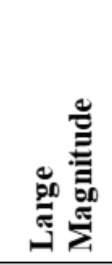 & 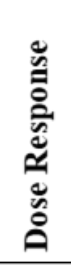 & 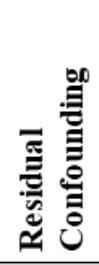 & 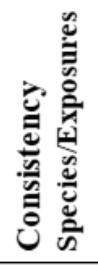 & \\
\hline \multicolumn{11}{|c|}{ Individu al Traffic-related Air Pollutants } \\
\hline 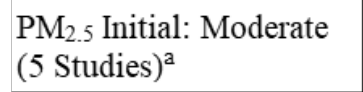 & --- & --- & --- & --- & --- & --- & --- & --- & --- & Moderate \\
\hline $\begin{array}{l}\text { NOx Initial: Moderate } \\
\text { (9 Studies) })^{\mathrm{b}}\end{array}$ & --- & --- & --- & --- & --- & --- & --- & --- & --- & Moderate \\
\hline \multicolumn{11}{|l|}{ Traffic Measures } \\
\hline $\begin{array}{l}\text { Traffic Density Initial: } \\
\text { Moderate }(5 \text { Studies })^{c}\end{array}$ & --- & --- & --- & $\downarrow$ & --- & --- & --- & --- & --- & Low \\
\hline $\begin{array}{l}\text { Proximity to Road } \\
\text { Initial: Moderate } \\
\text { (5 Studies) }^{\text {d }}\end{array}$ & --- & --- & --- & $\downarrow$ & --- & --- & --- & --- & --- & Low \\
\hline \multicolumn{11}{|c|}{ Combined Measures of TRAP } \\
\hline $\begin{array}{l}\text { Combined TRAP } \\
\text { Initial: Moderate } \\
\text { (18 Studies) }\end{array}$ & --- & --- & --- & --- & --- & --- & --- & --- & --- & Moderate \\
\hline
\end{tabular}

Figure 7. Evidence Profile of the Main Findings for Traffic-related Air Pollution

aDadvand et al. (2013), Rudra et al. (2011), Wu et al. (2011), Savitz et al. (2015), Choe et al. (2018).

bMalmqvist et al. (2013), Olsson et al. (2015), Dadvand et al. (2013), Wu et al. (2011); Pereira et al. (2013), van den Hooven et al. (2011), Pedersen et al. (2017), Savitz et al. (2015), Madsen et al. (2018).

'Olsson et al. (2015), Wu et al. (2011), Wu et al. (2016), van den Hooven et al. (2009), Malmqvist et al. (2013).

${ }^{d}$ Yorifuji et al. (2015), Miranda et al. (2013), van den Hooven et al. (2009), Madsen et al. (2018), Choe et al. (2018).

\section{Risk-of-bias Considerations}

Risk-of-bias ratings for each study for all questions are presented in Figure 8 (human studies) and Figure 9 (animal studies). The risk of bias for individual studies in the body of evidence and for the body of evidence as a whole was considered in developing the confidence ratings for each health effect. The key risk-of-bias questions for human studies (e.g., exposure characterization, confounding/modifying variables, and outcome assessment) are discussed in the consideration of the body of evidence for each TRAP metric. Although no study was excluded based on concerns for risk of bias, confidence conclusions were considered with and without higher risk-of-bias studies (e.g., studies rating probably high or definitively high risk of bias for at least two key risk-of-bias questions) to assess the influence of these higher risk-of-bias studies. 


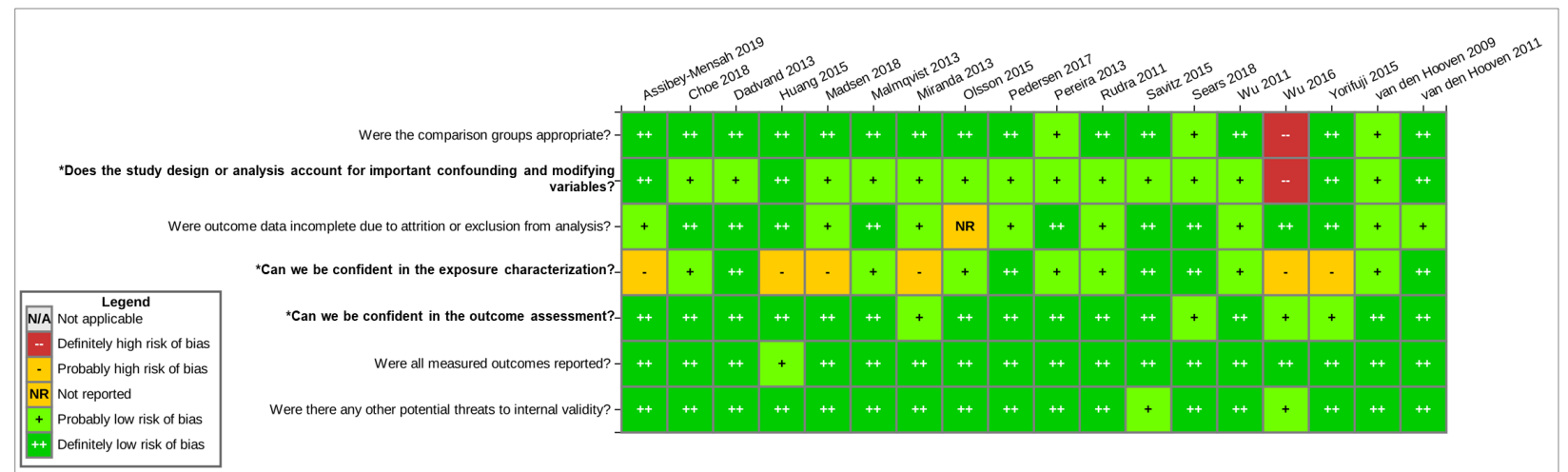

Figure 8. Human Study Risk-of-bias Heatmap

Interactive figure and additional study details in Health Assessment Workspace Collaborative (HAWC) (NTP, 2019a). *Questions in bold are the key risk-of-bias questions for human epidemiological studies. These key questions relate to areas of bias that may have a greater impact on estimates of the overall effect size and are generally considered to have a greater effect on the credibility of study results in environmental health studies.

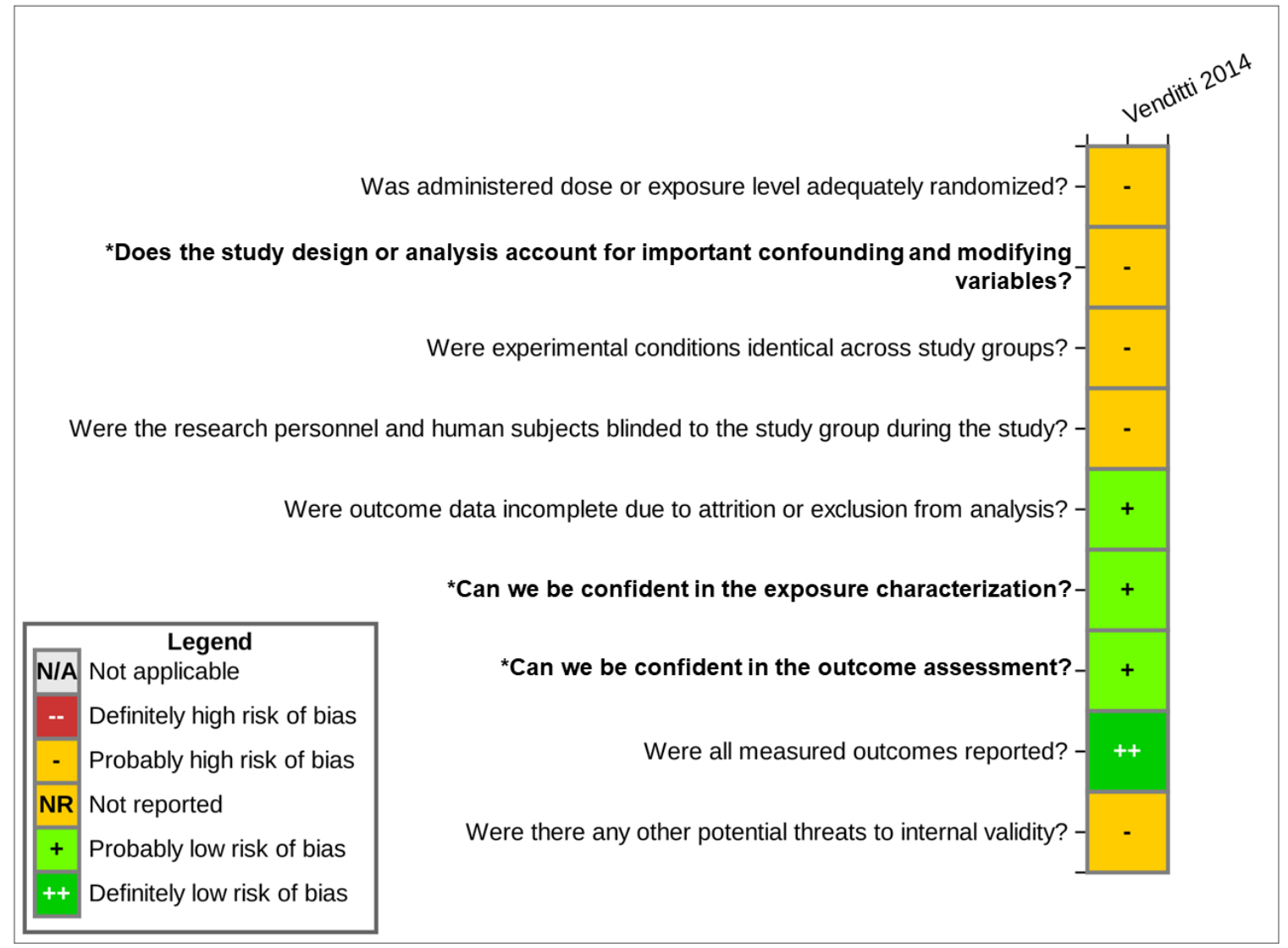

Figure 9. Animal Study Risk-of-bias Heatmap

Interactive figure and additional study details in $\mathrm{HAWC}$ (NTP, 2019a).

*Questions in bold are the key risk-of-bias questions for experimental animal studies. These key questions relate to areas of bias that may have a greater impact on estimates of the overall effect size and are generally considered to have a greater effect on the credibility of study results in environmental health studies. 
For this assessment, one of the key risk-of-bias questions addresses the exposure characterization. To draw conclusions about the associations between air pollution specifically derived from traffic and hypertensive disorders of pregnancy, individual studies are required to use valid, reliable, and sensitive methods to measure the exposure and these methods must be applied consistently across groups. Key considerations include reasonable alignment of the timing of exposure and the development of the outcome, the density of the monitoring network, and the use of appropriate models that account for spatial and temporal variability. Multiple approaches can be used to measure exposures of TRAP components in pregnant women. In general, ambient pollutant monitoring-based measurements, although widely used as a method for measuring air pollution, are generally poor in spatial coverage and are unlikely to capture the high spatial heterogeneity of air pollutants directly emitted from traffic. Geographical information systems (GIS)-based methods, such as land use regression (LUR) models, can provide better estimates of exposure to traffic-specific pollutants compared with monitoringbased measurements. GIS can account for the high spatial heterogeneity of local traffic emissions because they consider traffic surrogate parameters (e.g., distance-weighted traffic density) in the models. Thus, there is higher confidence that exposures can be attributed to traffic when using GIS-based methods to estimate exposures, and only studies in which the exposures could be reasonably attributed to traffic were included in the assessment. Other considerations for exposure include use of models based on individual residential addresses versus aggregated levels and residential mobility of the women during pregnancy. Risk-of-bias responses about the exposure characterization were reviewed and accepted by an external technical expert on exposures.

Another key risk-of-bias question for this assessment was confounding. Potential confounders for the individual pollutant evaluations included co-exposure to other traffic pollutants and traffic-related noise. When reported, correlations were discussed, however, the majority of the studies in the body of literature evaluated single pollutants and/or used single-pollutant models. Because many studies evaluated one pollutant that served as a surrogate for a combined TRAP exposure, the ability to reach hazard conclusions on individual exposures and hypertensive disorders of pregnancy was a limitation of the body of evidence. In addition, most study designs did not distinguish the contribution of traffic-related noise on the outcome of interest, and disentangling and evaluating the overall (and independent) effects of traffic noise on these outcomes is another limitation of this body of evidence (discussed further in Limitations of the Evidence Base). Other potential confounders were body mass index (BMI) and socioeconomic status (SES) - which are known risk factors for hypertensive disorders of pregnancy — and smoking, which, despite being a risk factor for hypertension in the general population, reduces the risk of hypertensive disorders during pregnancy. Race and ethnicity were not considered major confounders if the study evaluated a relatively homogeneous population, such as those studies observing populations in certain regions in Europe.

The third key risk-of-bias question addresses outcome assessment. Chronic or preexisting hypertension refers to elevated blood pressure that occurs before 20 weeks gestation and often predates pregnancy. Many studies in the available body of evidence excluded pregnant women with chronic hypertension or adjusted for this group in the analyses; however, depending on the source of the outcome data (e.g., birth certificate, hospital), this is generally difficult to do with certainty. Consequently, outcome misclassification may be a factor in some analyses. 
The following sections include detailed discussions of the available evidence for effects of TRAP on hypertensive disorders of pregnancy (individual and combined outcomes).

\section{Traffic-related Air Pollutants}

Traffic-related air pollutants are one of the main exposures used to characterize TRAP (the other exposure type, traffic measures, is discussed in the Traffic Measures section) and are defined by those primarily emitted by mobile sources due to fossil fuel combustion. Several major air pollutants regulated by the U.S. Environmental Protection Agency (EPA) are used as pollution surrogates for TRAP. Because many exposure surrogates used to identify TRAP are also generated by other sources, many studies utilized multiple exposure metrics to increase the confidence in the exposure characterization. The sections below begin with a brief summary of the bodies of evidence, followed by a narrative summary or meta-analysis of the human and (when applicable) animal evidence and confidence rating for the body of evidence. Some studies evaluated multiple traffic-related measures so there are instances of overlap across some studies.

\section{Particulate Matter and Hypertensive Disorders of Pregnancy}

Particulate matter (PM) is a complex mixture whose major components include solid and liquid organic and inorganic substances (e.g., sulfate, nitrites, ammonia, sodium chloride, black carbon, mineral dust, water) suspended in the air. PM is typically categorized by the aerodynamic diameter of the particles: $\mathrm{PM}_{10}$ (coarse particles 2.5-10 $\mu \mathrm{m}$ ); $\mathrm{PM}_{2.5}$ (fine particles $0.1-2.5 \mu \mathrm{m}$ ); and $\mathrm{PM}_{0.1}$ (ultrafine particles $\leq 0.1 \mu \mathrm{m}$ ). Coarse particle measurements, measured by monitoring stations alone, tend to be more uniform across large areas than the finer particles and therefore are not the best indicator for TRAP. PM2.5 or smaller exhibits higher spatial variation and, with the appropriate study design, there is higher confidence that the exposure can be attributed to traffic. There were no studies that evaluated ultrafine PM and met the PECO criteria. Therefore, although coarse, fine, and ultrafine PM are present in vehicle exhaust, this assessment will focus on $\mathrm{PM}_{2.5}$.

\section{Human Health Studies for $\mathrm{PM}_{2.5}$}

\section{Summary}

There is moderate confidence in the body of evidence that exposure to traffic-related $\mathrm{PM}_{2.5}$ during the entire gestation period is associated with an increased risk for preeclampsia. The five studies identified reported consistent evidence of an association between $\mathrm{PM}_{2.5}$ and preeclampsia in six cohorts of pregnant women in the United States and Spain (Dadvand et al. 2013; Rudra et al. 2011; Savitz et al. 2015; Wu et al. 2011). The studies and data provided were sufficiently similar to support meta-analyses with the summary effect estimate for the main analysis of 1.51 (95\% CI: 1.04, 2.20) for risk of preeclampsia after full gestation $\mathrm{PM}_{2.5}$ exposure (Table 8; Figure 10). The initial confidence rating was moderate because all the studies included in the body of evidence were cohort studies that contained three out of four study design features (exposure prior to outcome, individual outcome data, and comparison group used). There was no change in the initial moderate confidence rating in the body of evidence after considering factors that may increase or decrease confidence. 


\section{Overview of Available Human Data for PM 2.5}

Table 6 summarizes the available data in the human body of evidence that evaluated the association between exposure to traffic-related $\mathrm{PM}_{2.5}$ and hypertensive disorders of pregnancy. Five studies were identified that reported traffic-related $\mathrm{PM}_{2.5}$ exposures (Choe et al. 2018; Dadvand et al. 2013; Rudra et al. 2011; Savitz et al. 2015; Wu et al. 2011). These five studies comprised six independent cohorts from the United States or Spain. The body of evidence from the United States included one prospective cohort study conducted in western Washington (Rudra et al. 2011) and four retrospective cohort studies conducted in New York City (New York) (Savitz et al. 2015), Los Angeles and Orange Counties (California) (Wu et al. 2011), and Providence (Rhode Island) (Choe et al. 2018). In addition, there was one European study that was conducted in a cohort in Barcelona, Spain (Dadvand et al. 2013). The cohorts in Los Angeles and Orange Counties that were evaluated by Wu et al. (2011) were treated as two distinct populations based on the study locations and sociodemographic status of the cohorts and independent exposure assessments.

Each study evaluated associations between $\mathrm{PM}_{2.5}$ exposure and the risk for developing preeclampsia. Additional outcomes evaluated include early- and late-onset preeclampsia (Dadvand et al. 2013), gestational hypertension (Choe et al. 2018; Savitz et al. 2015), severe and mild preeclampsia/eclampsia, and combined hypertensive pregnancy disorders (Savitz et al. 2015).

Most studies evaluated exposure over the entire gestational period, although two studies considered only trimester-specific exposures (Choe et al. 2018; Savitz et al. 2015). Dadvand et al. (2013) assessed the full gestational period in addition to trimester-specific exposures. Investigators reported the odds of developing hypertensive disorders of pregnancy associated with $\mathrm{PM}_{2.5}$ using various units of exposure. Most studies reported effect estimates based on interquartile range (IQR) increases in $\mathrm{PM}_{2.5}$, whereas others, including Rudra et al. (2011) and Savitz et al. (2015), reported effect estimates associated with $10 \mu \mathrm{g} / \mathrm{m}^{3}$ or $0.5 \mu \mathrm{g} / \mathrm{m}^{3}$ increases in $\mathrm{PM}_{2.5 .}$

The range in the number of participants varied by study from approximately 3,100 to over 280,000 , with the number of cases ranging between 47 and 3,928. Overall, the exposures were well characterized, and the timings of exposure were reasonably well aligned with the outcome assessments for the body of evidence. All studies assessed traffic-related PM2.5 exposures using LUR models with the exception of the Wu et al. (2011) study, which used an air dispersion model. The CALINE4 air dispersion model measurement reported in this study was a more sensitive measure of traffic-related $\mathrm{PM}_{2.5}$ because it could capture local traffic emissions within $3 \mathrm{~km}$ of each residence. This study examined multiple exposure measurements and also included ambient monitoring data for $\mathrm{PM}_{2.5}$. 
Table 6. Studies on Hypertensive Disorders of Pregnancy with TRAP-related PM $\mathbf{M}_{2.5}$ Exposure in Humans

\begin{tabular}{|c|c|c|c|c|c|c|c|c|c|}
\hline Study & $\begin{array}{c}\text { Study Design } \\
\text { (Location) } \\
\text { Exposure } \\
\text { Measure }\end{array}$ & $\begin{array}{c}\text { Sample } \\
\text { Size }\end{array}$ & Cases & Outcome & Exposure Period & OR $(95 \%$ CI $)$ & Unit Increase & $\begin{array}{c}\text { Mean }(\mathrm{SD})^{\mathrm{a}} \\
\text { Exposure Level }\end{array}$ & $\begin{array}{l}\text { Covariates } \\
\text { Considered for } \\
\text { Inclusion }\end{array}$ \\
\hline \multirow[t]{5}{*}{$\begin{array}{l}\text { Choe et al. } \\
(2018)\end{array}$} & \multirow[t]{5}{*}{$\begin{array}{l}\text { Retrospective } \\
\text { cohort (Rhode } \\
\text { Island, USA) } \\
\text { Land use } \\
\text { regression } \\
\text { models }\end{array}$} & \multirow[t]{5}{*}{61,640} & 2,211 & Preeclampsia & Trimester 1 & $0.96(0.86,1.06)$ & Undefined IQR increase & $9.6(1.9) \mu \mathrm{g} / \mathrm{m}^{3}$ & \multirow{5}{*}{$\begin{array}{l}\text { Maternal age, parity, } \\
\text { race, education, } \\
\text { marital status, health } \\
\text { insurance status, } \\
\text { tobacco use, } \\
\text { neighborhood } \\
\text { socioeconomic status, } \\
\text { year of last menstrual } \\
\text { period }\end{array}$} \\
\hline & & & & & Trimester 3 & $0.97(0.89,1.05)$ & Undefined IQR increase & $9.5(2.1) \mu \mathrm{g} / \mathrm{m}^{3}$ & \\
\hline & & & 2,877 & $\begin{array}{l}\text { Gestational } \\
\text { hypertension }\end{array}$ & Trimester 1 & $1.00(0.91,1.09)$ & Per $3.1 \mu \mathrm{g} / \mathrm{m}^{3 *}$ & $9.7(1.9) \mu \mathrm{g} / \mathrm{m}^{3}$ & \\
\hline & & & & & Trimester 2 & $1.04(0.96,1.14)$ & Undefined IQR increase & $9.6(1.9) \mu \mathrm{g} / \mathrm{m}^{3}$ & \\
\hline & & & & & Trimester 3 & $0.94(0.87,1.01)$ & Undefined IQR increase & $9.5(2.1) \mu \mathrm{g} / \mathrm{m}^{3}$ & \\
\hline \multirow[t]{12}{*}{$\begin{array}{l}\text { Dadvand et } \\
\text { al. (2013) }\end{array}$} & \multirow{12}{*}{$\begin{array}{l}\text { Retrospective } \\
\text { cohort } \\
\text { (Barcelona, } \\
\text { Spain) } \\
\text { Land use } \\
\text { regression } \\
\text { models }\end{array}$} & \multirow[t]{12}{*}{8,398} & 103 & $\begin{array}{l}\text { Preeclampsia } \\
\text { (all cases) }\end{array}$ & $\begin{array}{l}\text { Full gestational } \\
\text { period }\end{array}$ & $1.32(1.02,1.71)$ & Per $5.1 \mu \mathrm{g} / \mathrm{m}^{3 *}$ & $16.5(5.1) \mu \mathrm{g} / \mathrm{m}^{3}$ & \multirow{12}{*}{$\begin{array}{l}\text { Maternal age, } \\
\text { ethnicity, education, } \\
\text { smoking, alcohol use, } \\
\text { BMI, marital status, } \\
\text { pre-gestational/ } \\
\text { gestational diabetes, } \\
\text { parity, multiple } \\
\text { pregnancy, } \\
\text { neighborhood } \\
\text { socioeconomic status, } \\
\text { season of conception, } \\
\text { year of conception }\end{array}$} \\
\hline & & & & & Trimester 1 & $1.29(0.94,1.76)$ & Per $7.6 \mu \mathrm{g} / \mathrm{m}^{3}$ & $17.0(7.6) \mu \mathrm{g} / \mathrm{m}^{3}$ & \\
\hline & & & & & Trimester 2 & $1.12(0.85,1.48)$ & Per $7.4 \mu \mathrm{g} / \mathrm{m}^{3 *}$ & $17.3(7.4) \mu \mathrm{g} / \mathrm{m}^{3}$ & \\
\hline & & & & & Trimester 3 & $1.51(1.13,2.01)$ & Per $7.3 \mu \mathrm{g} / \mathrm{m}^{3 *}$ & $17.3(7.3) \mu \mathrm{g} / \mathrm{m}^{3}$ & \\
\hline & & & \multirow[t]{4}{*}{26} & \multirow[t]{4}{*}{$\begin{array}{l}\text { Early-onset } \\
\text { preeclampsia }\end{array}$} & $\begin{array}{l}\text { Full gestational } \\
\text { period }\end{array}$ & $1.53(0.94,2.49)$ & Per $5.1 \mu \mathrm{g} / \mathrm{m}^{3 *}$ & $16.5(5.1) \mu \mathrm{g} / \mathrm{m}^{3}$ & \\
\hline & & & & & Trimester 1 & $1.69(0.93,3.05)$ & Per $7.6 \mu \mathrm{g} / \mathrm{m}^{3 *}$ & $17.0(7.6) \mu \mathrm{g} / \mathrm{m}^{3}$ & \\
\hline & & & & & Trimester 2 & $1.41(0.83,2.40)$ & Per $7.4 \mu \mathrm{g} / \mathrm{m}^{3 *}$ & $17.3(7.4) \mu \mathrm{g} / \mathrm{m}^{3}$ & \\
\hline & & & & & Trimester 3 & $1.29(0.72,2.32)$ & Per $7.3 \mu \mathrm{g} / \mathrm{m}^{3 *}$ & $17.3(7.3) \mu \mathrm{g} / \mathrm{m}^{3}$ & \\
\hline & & & \multirow[t]{4}{*}{75} & \multirow[t]{4}{*}{$\begin{array}{l}\text { Late-onset } \\
\text { preeclampsia }\end{array}$} & $\begin{array}{l}\text { Full gestational } \\
\text { period }\end{array}$ & $1.18(0.87,1.60)$ & Per $5.1 \mu \mathrm{g} / \mathrm{m}^{3 *}$ & $16.5(5.1) \mu \mathrm{g} / \mathrm{m}^{3}$ & \\
\hline & & & & & Trimester 1 & $1.04(0.75,1.44)$ & Per $7.6 \mu \mathrm{g} / \mathrm{m}^{3 *}$ & $17.0(7.6) \mu \mathrm{g} / \mathrm{m}^{3}$ & \\
\hline & & & & & Trimester 2 & $1.14(0.79,1.66)$ & Per $7.4 \mu \mathrm{g} / \mathrm{m}^{3 *}$ & $17.3(7.4) \mu \mathrm{g} / \mathrm{m}^{3}$ & \\
\hline & & & & & Trimester 3 & $1.42(1.01,2.00)$ & Per $7.3 \mu \mathrm{g} / \mathrm{m}^{3 *}$ & $17.3(7.3) \mu \mathrm{g} / \mathrm{m}^{3}$ & \\
\hline
\end{tabular}


Systematic Review of TRAP and Hypertensive Disorders of Pregnancy

\begin{tabular}{|c|c|c|c|c|c|c|c|c|c|}
\hline Study & $\begin{array}{c}\text { Study Design } \\
\text { (Location) } \\
\text { Exposure } \\
\text { Measure }\end{array}$ & $\begin{array}{l}\text { Sample } \\
\text { Size }\end{array}$ & Cases & Outcome & Exposure Period & OR $(95 \%$ CI $)$ & Unit Increase & $\begin{array}{c}\text { Mean (SD) } \\
\text { Exposure Level }\end{array}$ & $\begin{array}{l}\text { Covariates } \\
\text { Considered for } \\
\text { Inclusion }\end{array}$ \\
\hline $\begin{array}{l}\text { Rudra et al. } \\
\text { (2011) }\end{array}$ & $\begin{array}{l}\text { Prospective } \\
\text { cohort } \\
\text { (Western } \\
\text { Washington, } \\
\text { USA) } \\
\text { Land use } \\
\text { regression } \\
\text { models }\end{array}$ & 3,675 & 117 & Preeclampsia & Periconceptional $^{\mathrm{b}}$ & $1.02(0.93,1.12)$ & Per $0.5 \mu \mathrm{g} / \mathrm{m}^{3}$ & $\begin{array}{l}10.1 \\
(8.7-11.4) \mu \mathrm{g} / \mathrm{m}^{3}\end{array}$ & $\begin{array}{l}\text { Maternal age, } \\
\text { nulliparity, BMI, } \\
\text { race/ethnicity, } \\
\text { education, marital } \\
\text { status, smoking, } \\
\text { household income, } \\
\text { employment in early } \\
\text { pregnancy, pre- } \\
\text { pregnancy secondhand } \\
\text { smoke, physical } \\
\text { activity, history of } \\
\text { asthma, diabetes, } \\
\text { chronic hypertension, } \\
\text { year and month of } \\
\text { conception }\end{array}$ \\
\hline \multirow[t]{8}{*}{$\begin{array}{l}\text { Savitz et al. } \\
(2015)\end{array}$} & \multirow{8}{*}{$\begin{array}{l}\text { Retrospective } \\
\text { cohort (New } \\
\text { York City, } \\
\text { USA) } \\
\text { Land use } \\
\text { regression } \\
\text { models }\end{array}$} & \multirow[t]{8}{*}{268,601} & \multirow[t]{8}{*}{$\mathrm{NR}^{\mathrm{c}}$} & \multirow{2}{*}{$\begin{array}{l}\text { Total } \\
\text { hypertensive } \\
\text { disorders }\end{array}$} & Trimester 1 & $0.93(0.86,1.0)$ & Per $10 \mu \mathrm{g} / \mathrm{m}^{3}$ & $11.9(2.5) \mu \mathrm{g} / \mathrm{m}^{3}$ & \multirow{8}{*}{$\begin{array}{l}\text { Maternal age, parity, } \\
\text { race/ethnicity, } \\
\text { conception year, } \\
\text { - education, BMI, } \mathrm{BMI}^{2} \text {, } \\
\text { Medicaid status, social } \\
\text { deprivation index, } \\
\text { hospital of delivery }\end{array}$} \\
\hline & & & & & Trimester 2 & $0.91(0.84,0.99)$ & Per $10 \mu \mathrm{g} / \mathrm{m}^{3}$ & $11.9(2.4) \mu \mathrm{g} / \mathrm{m}^{3}$ & \\
\hline & & & & \multirow{2}{*}{$\begin{array}{l}\text { Gestational } \\
\text { hypertension }\end{array}$} & Trimester 1 & $0.97(0.86,1.1)$ & Per $10 \mu \mathrm{g} / \mathrm{m}^{3}$ & $11.9(2.5) \mu \mathrm{g} / \mathrm{m}^{3}$ & \\
\hline & & & & & Trimester 2 & $0.88(0.77,1.0)$ & Per $10 \mu \mathrm{g} / \mathrm{m}^{3}$ & $11.9(2.4) \mu \mathrm{g} / \mathrm{m}^{3}$ & \\
\hline & & & & \multirow{2}{*}{$\begin{array}{l}\text { Severe } \\
\text { preeclampsia/ } \\
\text { eclampsia }\end{array}$} & Trimester 1 & $0.95(0.82,1.1)$ & Per $10 \mu \mathrm{g} / \mathrm{m}^{3}$ & $11.9(2.5) \mu \mathrm{g} / \mathrm{m}^{3}$ & \\
\hline & & & & & Trimester 2 & $0.96(0.81,1.1)$ & Per $10 \mu \mathrm{g} / \mathrm{m}^{3}$ & $11.9(2.4) \mu \mathrm{g} / \mathrm{m}^{3}$ & \\
\hline & & & & \multirow{2}{*}{$\begin{array}{l}\text { Mild } \\
\text { preeclampsia }\end{array}$} & Trimester 1 & $0.88(0.78,1.0)$ & Per $10 \mu \mathrm{g} / \mathrm{m}^{3}$ & $11.9(2.5) \mu \mathrm{g} / \mathrm{m}^{3}$ & \\
\hline & & & & & Trimester 2 & $0.91(0.80,1.0)$ & Per $10 \mu \mathrm{g} / \mathrm{m}^{3}$ & $11.9(2.4) \mu \mathrm{g} / \mathrm{m}^{3}$ & \\
\hline $\begin{array}{l}\text { Wu et al. } \\
(2011)\end{array}$ & $\begin{array}{l}\text { Retrospective } \\
\text { cohort (Los } \\
\text { Angeles } \\
\text { County, USA) } \\
\text { CALINE } 4 \text { air } \\
\text { dispersion } \\
\text { models }\end{array}$ & 38,709 & 1,303 & Preeclampsia & $\begin{array}{l}\text { Full gestational } \\
\text { period }\end{array}$ & $1.08(1.02,1.15)$ & Per $1.4 \mu \mathrm{g} / \mathrm{m}^{3 *}$ & $2.1(1.2) \mu \mathrm{g} / \mathrm{m}^{3}$ & $\begin{array}{l}\text { Maternal age, } \\
\text { race/ethnicity, parity, } \\
\text { prenatal care insurance } \\
\text { type, season of } \\
\text { conception, diabetes, } \\
\text { poverty }\end{array}$ \\
\hline
\end{tabular}


Systematic Review of TRAP and Hypertensive Disorders of Pregnancy

\begin{tabular}{|c|c|c|c|c|c|c|c|c|c|}
\hline Study & $\begin{array}{c}\text { Study Design } \\
\text { (Location) } \\
\text { Exposure } \\
\text { Measure }\end{array}$ & $\begin{array}{l}\text { Sample } \\
\text { Size }\end{array}$ & Cases & Outcome & Exposure Period & OR (95\% CI) & Unit Increase & $\begin{array}{c}\text { Mean (SD) }{ }^{\mathrm{a}} \\
\text { Exposure Level }\end{array}$ & $\begin{array}{l}\text { Covariates } \\
\text { Considered for } \\
\text { Inclusion }\end{array}$ \\
\hline $\begin{array}{l}\text { Wu et al. } \\
(2011)\end{array}$ & $\begin{array}{l}\text { Retrospective } \\
\text { cohort (Orange } \\
\text { County, USA) } \\
\text { CALINE } 4 \text { air } \\
\text { dispersion } \\
\text { models }^{\mathrm{d}}\end{array}$ & 42,477 & 1,139 & Preeclampsia & $\begin{array}{l}\text { Full gestational } \\
\text { period }\end{array}$ & $1.10(1.04,1.17)$ & Per $1.4 \mu \mathrm{g} / \mathrm{m}^{3 *}$ & $1.6(1.4) \mu \mathrm{g} / \mathrm{m}^{3}$ & $\begin{array}{l}\text { Maternal age, } \\
\text { race/ethnicity, parity, } \\
\text { prenatal care insurance } \\
\text { type, season of } \\
\text { conception, diabetes, } \\
\text { poverty }\end{array}$ \\
\hline
\end{tabular}

Effect estimates marked with an asterisk were reported per interquartile range increase in $\mathrm{PM}_{2.5}$.

${ }^{a}$ Dadvand et al. (2013) and Rudra et al. (2011), reported median (IQR) levels of PM2.5.

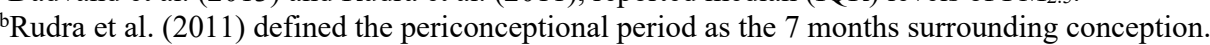

${ }^{\mathrm{c}} \mathrm{NR}=$ Not reported: The overall number of cases for this study was not reported. The number of cases used in the statistical analyses are presented below in Table 7 .

${ }^{\mathrm{d}} \mathrm{Wu}$ et al. (2011) also reported land use regression model estimates that are based on ambient air pollution data. The CALINE4 dispersion modeling estimates for PM 2.5 and $\mathrm{NO}_{x}$

were selected as these estimates capture local traffic emissions at a finer resolution (within $3 \mathrm{~km}$ of each residence) for five traffic-related pollutants. 


\section{Synthesis of Human Evidence and Meta-analysis}

The studies that evaluated associations between exposure to $\mathrm{PM}_{2.5}$ and hypertensive disorders of pregnancy generally reported an increased risk for developing hypertensive disorders of pregnancy (particularly preeclampsia) with increasing exposures to $\mathrm{PM}_{2.5}$. The mean exposures reported by the study authors ranged from $9.3-17.3 \mu \mathrm{g} / \mathrm{m}^{3}$ in studies that modeled exposures using LUR methods. The Wu et al. (2011) study modeled $\mathrm{PM}_{2.5}$ exposures using the CALINE4 air dispersion model (but also measured $\mathrm{PM}_{2.5}$ using ambient monitoring stations; data not included in the assessment), and mean exposure levels were lower due to the finer resolution by which the model estimate could capture $\mathrm{PM}_{2.5}$ concentrations from a single emission source (i.e., local traffic within $3 \mathrm{~km}$ of a residence). Associations were evaluated for $\mathrm{PM}_{2.5}$ exposures during the entire pregnancy period and/or during each trimester. Studies that estimated exposure to traffic-related $\mathrm{PM}_{2.5}$ during the entire pregnancy period reported consistent associations between this TRAP component and hypertensive disorders of pregnancy. Results for trimester-specific exposures were less consistent. Many of the trimester-specific evaluations showed positive associations that did not reach statistical significance, except for Choe et al. (2018) who reported slightly negative (not statistically significant) associations. First trimester associations were generally weakly correlated with hypertensive disorders of pregnancy. In the Savitz et al. (2015) study, trimester-specific odds ratios (ORs) from the standard adjusted model showed significant associations between first and second trimester exposures to $\mathrm{PM}_{2.5}$ and total hypertensive disorders, gestational hypertension, and severe preeclampsia, but those associations were eliminated when the models were further adjusted for delivery hospital. Although the pathogenesis of hypertensive disorders of pregnancy (discussed in more detail in the Discussion) is thought to originate in the first trimester, there is inadequate evidence from these studies to determine if specific trimesters are more strongly correlated with hypertensive disorders of pregnancy. The lack of consistent associations during these windows is more likely due to the small number of studies that evaluated trimester-specific exposures and might not reflect the true relationship between these exposure windows and hypertensive disorders of pregnancy.

Correlations across multiple pollutants were not consistently reported across the body of evidence. Some studies evaluated correlations between exposures (e.g., Rudra et al. (2011), Wu et al. (2011)); others used single-pollutant models (Dadvand et al. 2013) and/or adjusted for the other exposures evaluated (Choe et al. 2018; Savitz et al. 2015). For those studies that did evaluate correlations between exposures, authors generally reported moderate correlations between LUR-modeled PM2.5 and other pollutants; the CALINE4 model showed high correlation among pollutants (Wu et al. 2011).

The available data for the full pregnancy exposure period were sufficient to perform a meta-analysis to evaluate the effects of $\mathrm{PM}_{2.5}$ exposure on the risk of preeclampsia as three or more individual study results were available (Table 7). Choe et al. (2018) did not report an association between $\mathrm{PM}_{2.5}$ exposure and preeclampsia. This study was not included in the meta-analysis because this study included ORs for all three trimesters but did not include trimester-specific interquartile range increases. Savitz et al. (2015) reported risk estimates for trimesters 1 and 2, and these results were pooled into one risk estimate for trimesters 1 and 2 combined. Rudra et al. (2011) reported an exposure window around the conception period (i.e., a 7-month period). Because Savitz et al. (2015) and Rudra et al. (2011) reported exposure windows other than the entire pregnancy period, sensitivity analyses were performed with and without these two studies. 


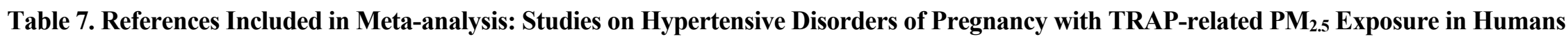

\begin{tabular}{|c|c|c|c|c|c|c|c|c|}
\hline Study & $\begin{array}{l}\text { Study Design } \\
\text { (Location) }\end{array}$ & $\begin{array}{l}\text { Analysis } \\
\text { Sample } \\
\text { Size }\end{array}$ & $\begin{array}{c}\text { Cases } \\
\text { Included in } \\
\text { Analysis }\end{array}$ & Outcome & Exposure Period & $\begin{array}{c}\text { OR }(95 \% \mathrm{CI}) \\
\text { per } 10 \mu \mathrm{g} / \mathrm{m}^{3} \\
\text { Increase* }\end{array}$ & $\begin{array}{c}\text { Mean (SD) } \\
\text { Exposure Level }\end{array}$ & $\begin{array}{c}\text { Covariates Included in } \\
\text { Final Model }\end{array}$ \\
\hline $\begin{array}{l}\text { Dadvand } \\
\text { et al. } \\
(2013)\end{array}$ & $\begin{array}{l}\text { Retrospective } \\
\text { cohort (Barcelona, } \\
\text { Spain) }\end{array}$ & 8,398 & 103 & Preeclampsia & $\begin{array}{l}\text { Full gestational } \\
\text { period }\end{array}$ & $1.72(1.22,2.43)$ & $16.5(5.1) \mu \mathrm{g} / \mathrm{m}^{3}$ & $\begin{array}{l}\text { Maternal age, ethnicity, } \\
\text { education, smoking, alcohol } \\
\text { use, BMI, marital status, pre- } \\
\text { gestational/ gestational } \\
\text { diabetes, parity, multiple } \\
\text { pregnancy, neighborhood } \\
\text { socioeconomic status, season } \\
\text { of conception, year of } \\
\text { conception }\end{array}$ \\
\hline $\begin{array}{l}\text { Rudra et } \\
\text { al. }(2011)\end{array}$ & $\begin{array}{l}\text { Prospective cohort } \\
\text { (Western } \\
\text { Washington, USA) }\end{array}$ & 3,509 & 117 & Preeclampsia & Periconceptional $^{\mathrm{b}}$ & $1.49(1.35,1.63)$ & $\begin{array}{l}10.1 \\
(8.7-11.4) \mu \mathrm{g} / \mathrm{m}^{3}\end{array}$ & $\begin{array}{l}\text { Maternal age, nulliparity, } \\
\text { BMI, race/ethnicity, } \\
\text { smoking, season, and year of } \\
\text { conception }\end{array}$ \\
\hline \multirow[t]{3}{*}{$\begin{array}{l}\text { Savitz et } \\
\text { al. }(2015)\end{array}$} & \multirow{3}{*}{$\begin{array}{l}\text { Retrospective } \\
\text { cohort (New York } \\
\text { City, USA) }\end{array}$} & \multirow[t]{3}{*}{268,601} & 4,226 & Severe preeclampsia & Trimesters 1,2 & $0.96(0.89,1.03)$ & $\begin{array}{l}\text { Pooled mean not } \\
\text { reported }^{\text {c }}\end{array}$ & \multirow{3}{*}{$\begin{array}{l}\text { Maternal age, ethnicity, } \\
\text { education, Medicaid status, } \\
\text { parity, conception year, } \\
\text { social deprivation index, } \\
\text { - BMI, BMI }{ }^{2} \text {, hospital of } \\
\text { delivery }\end{array}$} \\
\hline & & & 6,940 & Mild preeclampsia & Trimesters 1,2 & $0.90(0.86,0.94)$ & $\begin{array}{l}\text { Pooled mean not } \\
\text { reported }^{\mathrm{c}}\end{array}$ & \\
\hline & & & 11,166 & $\begin{array}{l}\text { Combined mild and } \\
\text { severe preeclampsia }\end{array}$ & Trimesters 1,2 & $0.92(0.88,0.95)^{\mathrm{d}}$ & $\begin{array}{l}\text { Pooled mean not } \\
\text { reported }^{c}\end{array}$ & \\
\hline \multirow[t]{2}{*}{$\begin{array}{l}\text { Wu et al. } \\
(2011)\end{array}$} & $\begin{array}{l}\text { Retrospective } \\
\text { cohort (Los Angeles } \\
\text { County, USA) }\end{array}$ & $\begin{array}{l}\text { Not } \\
\text { reported }^{\mathrm{e}}\end{array}$ & 1,303 & Preeclampsia & $\begin{array}{l}\text { Full gestational } \\
\text { period }\end{array}$ & $1.73(1.62,1.85)$ & $2.1(1.2) \mu \mathrm{g} / \mathrm{m}^{3}$ & \multirow{2}{*}{$\begin{array}{l}\text { Maternal age, race/ethnicity, } \\
\text { parity, diabetes, prenatal care } \\
\text { insurance type, poverty, } \\
\text { season of conception }\end{array}$} \\
\hline & $\begin{array}{l}\text { Retrospective } \\
\text { cohort (Orange } \\
\text { County, USA) }\end{array}$ & $\begin{array}{l}\text { Not } \\
\text { reported }^{\mathrm{e}}\end{array}$ & 1,103 & Preeclampsia & $\begin{array}{l}\text { Full gestational } \\
\text { period }\end{array}$ & $1.98(1.85,2.11)$ & $1.6(1.4) \mu \mathrm{g} / \mathrm{m}^{3}$ & \\
\hline
\end{tabular}

*All ORs were converted to a $10 \mu \mathrm{g} / \mathrm{m}^{3}$ increase before analysis.

aDadvand et al. (2013) and Rudra et al. (2011) reported median (IQR) levels of $\mathrm{PM}_{2.5}$.

${ }^{b}$ Rudra et al. (2011) defined the periconceptional period as the 7 months surrounding conception.

cSavitz et al. (2015) reported mean $\mathrm{PM}_{2.5}$ exposures for trimester 1 and trimester 2 separately.

${ }^{\mathrm{d}}$ This effect estimate was calculated by combining the severe and mild preeclampsia values that were reported by Savitz et al. (2015).

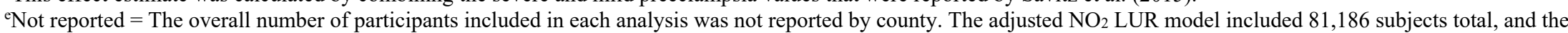

$\mathrm{NO}_{\mathrm{x}}$ CALINE4 model included 79,629 individuals total. 
The available evidence indicate that the meta-OR for preeclampsia was 1.51 (95\% CI: 1.04 , 2.20) per $10 \mu \mathrm{g} / \mathrm{m}^{3}$ increase in $\mathrm{PM}_{2.5}$ concentration (Table 8; Figure 10). Sensitivity analyses with and without Rudra et al. (2011) and Savitz et al. (2015) were performed and showed a larger effect estimate when the analysis only included studies that evaluated the full gestational period (Table 8).

There was evidence of heterogeneity among studies that reported $\mathrm{PM}_{2.5}$ exposure during the full gestational period $(\mathrm{p}<0.001$ [Table 8]). Separate sensitivity analyses that excluded each study one at a time and reevaluated the model revealed that no single study influenced the meta-analysis to a large degree (Table E-1; Figure E-1). In addition, a formal test of publication bias (Egger's test and funnel plots) revealed no evidence of publication bias $(p=0.318)$

(Figure E-2; Table E-2); thus, a trim and fill analysis was not necessary.

Table 8. Pooled ORs and 95\% CIs for TRAP-related $\mathrm{PM}_{2.5}$ and Preeclampsia

\begin{tabular}{|c|c|c|c|c|}
\hline \multirow{2}{*}{ Exposure Window } & \multirow{2}{*}{$\begin{array}{l}\text { Number of } \\
\text { Results }\end{array}$} & \multirow{2}{*}{$\begin{array}{c}\text { OR }(95 \% \mathrm{CI}) \\
\text { per } 10 \mu \mathrm{g} / \mathrm{m}^{3} \text { Increase }\end{array}$} & \multicolumn{2}{|c|}{ Heterogeneity } \\
\hline & & & P Value* & $\mathbf{I}^{2}$ \\
\hline Full Gestational Period ${ }^{\mathrm{a}}$ & 5 & $1.51(1.04,2.20)$ & $<0.001$ & $99 \%$ \\
\hline $\begin{array}{l}\text { Full Gestational Period [Excluding Savitz et al. } \\
(2015)]\end{array}$ & 4 & $1.73(1.51,1.98)$ & $<0.001$ & $88 \%$ \\
\hline $\begin{array}{l}\text { Full Gestational Period [Excluding Rudra et al. } \\
\text { (2011)] }\end{array}$ & 4 & $1.52(0.96,2.40)$ & $<0.001$ & $99 \%$ \\
\hline $\begin{array}{l}\text { Full Gestational Period }^{\mathrm{a}} \\
\text { [Excluding Rudra et al. (2011) and Savitz et al. } \\
(2015) \text { ] }\end{array}$ & 3 & $1.84(1.64,2.07)$ & 0.017 & $76 \%$ \\
\hline
\end{tabular}

*P value for test for heterogeneity. Significant values $(\mathrm{p}<0.05)$ reflect results of the random-effects model.

${ }^{a}$ One study (Wu et al. 2011) contributed two effect estimates to the analysis. 


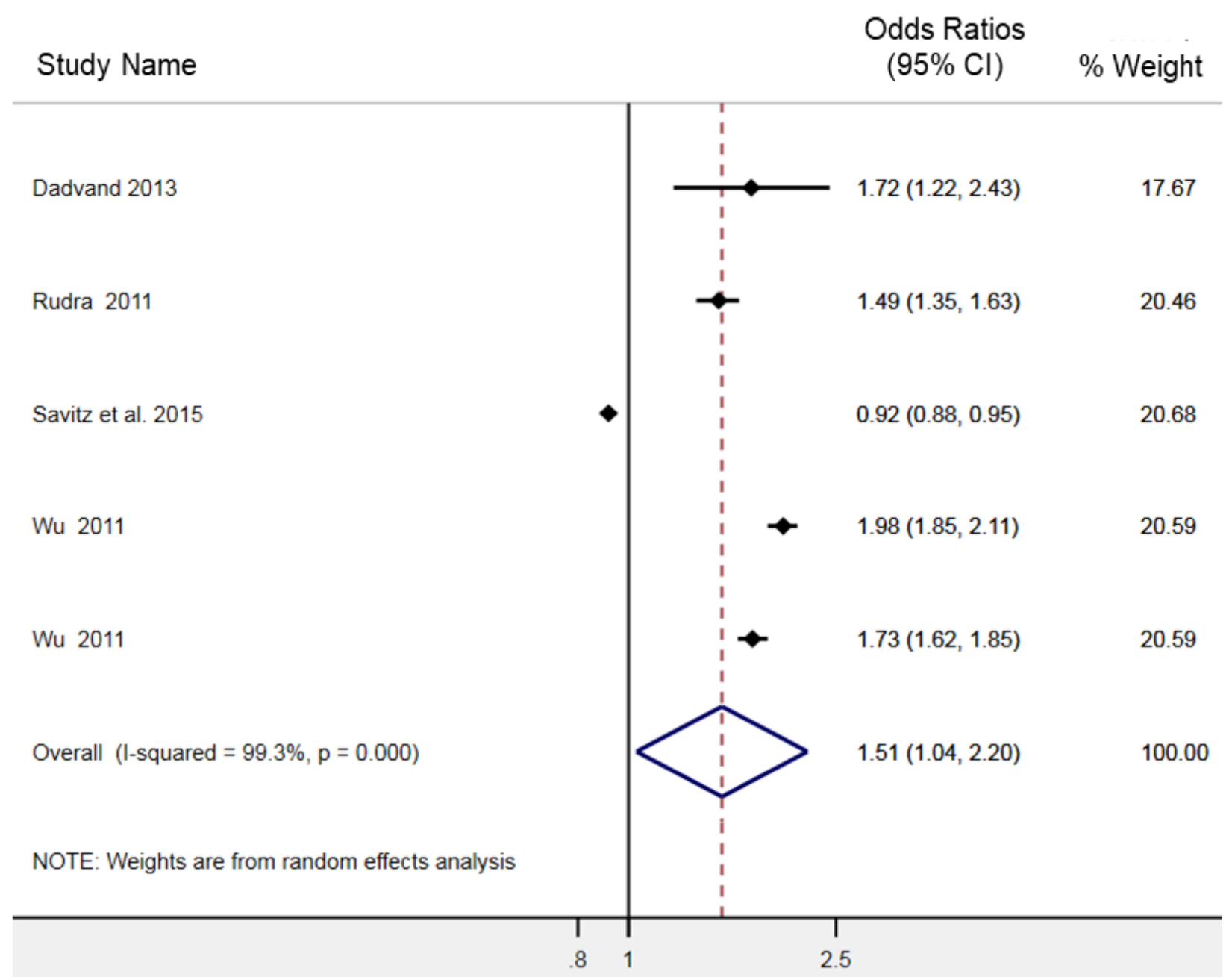

Figure 10. Full Gestation Exposure to $\mathbf{P M}_{2.5}$ and Preeclampsia ${ }^{a}$

When $\mathrm{I}^{2} \mathrm{p}$ value is significant $(\mathrm{p}<0.05)$, the random-effects model results are presented. When nonsignificant, the random-effects model results are identical to the fixed-effects model results.

${ }^{\mathrm{a} A l l}$ ORs were converted to a $10 \mu \mathrm{g} / \mathrm{m}^{3}$ increase before analysis.

\section{Risk-of-bias Considerations}

The PM2.5 studies were generally rated probably low or definitely low across all risk-of-bias domains, including the key risk-of-bias questions, as shown in the risk-of-bias heatmap (Figure 11) and bar chart (Figure 12). Therefore, confidence in the body of evidence for $\mathrm{PM}_{2.5}$ was not changed for risk of bias. The key risk-of-bias considerations are detailed below, and the study-specific rating details can be found in HAWC (https://hawcproject.org/assessment/60/) (NTP 2019a). 


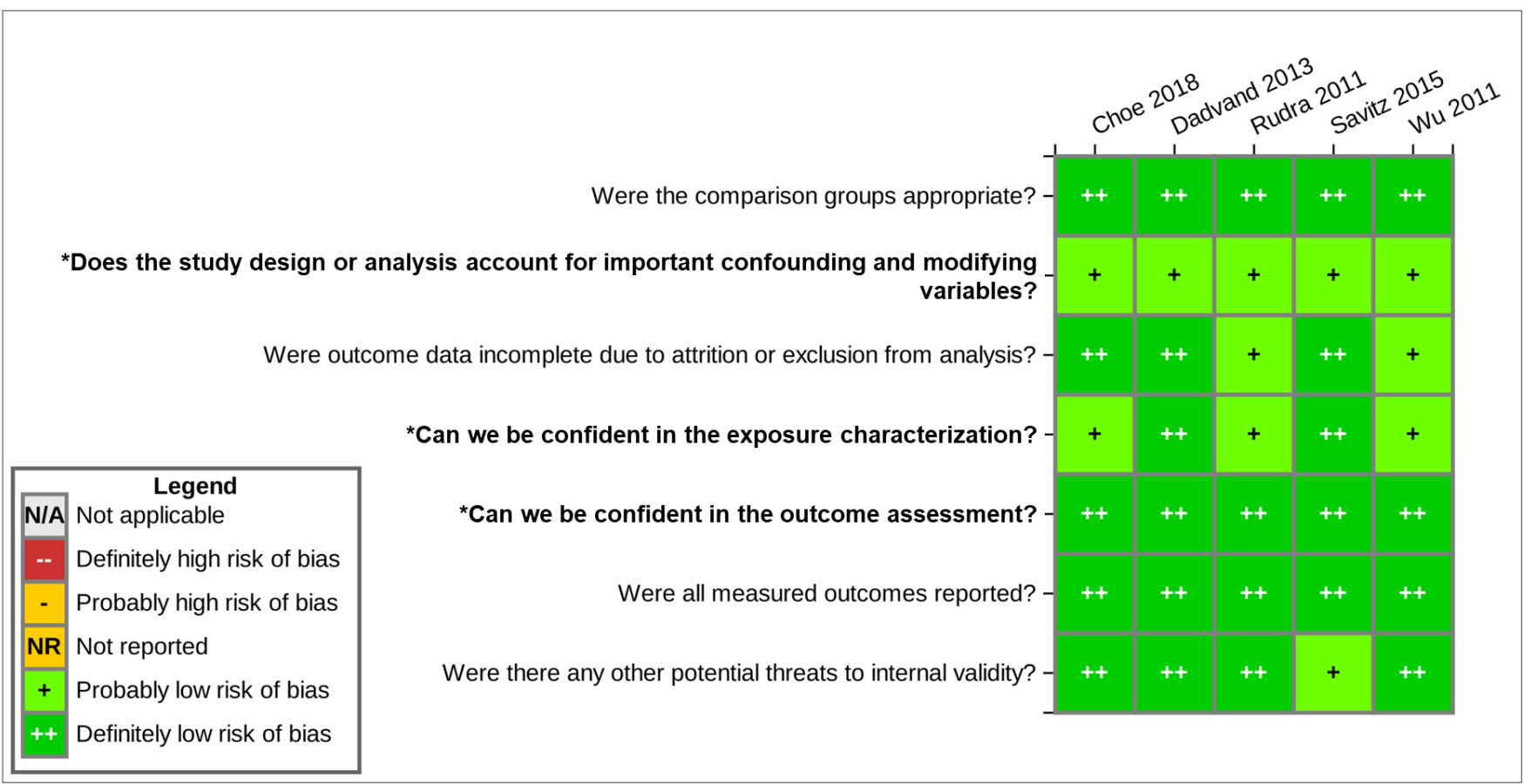

Figure 11. Risk-of-bias Heatmap: $\mathbf{P M}_{2.5}$ and Hypertensive Disorders of Pregnancy

Interactive figure and additional study details in HAWC (NTP, 2019a).

*Questions in bold are the key risk-of-bias questions for human epidemiological studies. These key questions relate to areas of bias that may have a greater impact on estimates of the overall effect size and are generally considered to have a greater effect on the credibility of study results in environmental health studies.

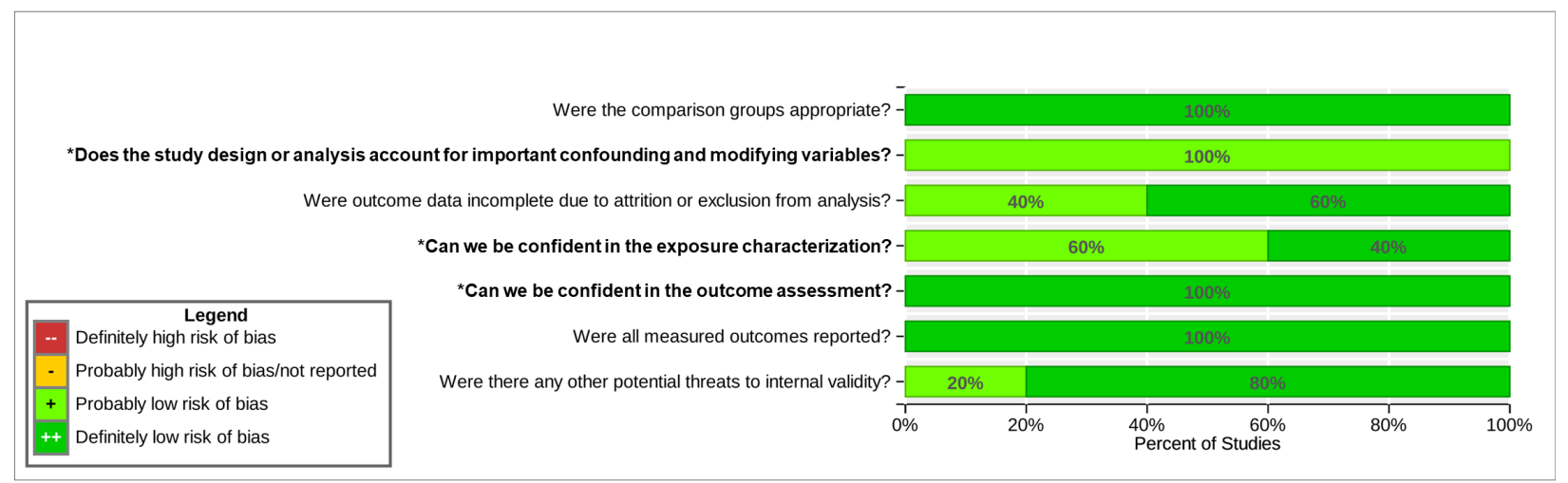

Figure 12. Risk-of-bias Bar Chart: $\mathbf{P M}_{2.5}$ and Hypertensive Disorders of Pregnancy

Interactive figure and additional study details in HAWC (NTP, 2019a).

*Questions in bold are the key risk-of-bias questions for human epidemiological studies. These key questions relate to areas of bias that may have a greater impact on estimates of the overall effect size and are generally considered to have a greater effect on the credibility of study results in environmental health studies.

\section{Exposure Characterization}

Overall, the exposure and outcome data were reasonably well aligned, although the exposures were not truncated at the time of diagnosis in three studies (Choe et al. 2018; Savitz et al. 2015; Wu et al. 2011). The monitoring networks were sufficiently dense. The LUR exposure models used in all but one study have high resolution to capture the spatial heterogeneity of air pollutants 
directly emitted from traffic and can characterize temporal variability using temporal trends derived from ambient monitoring stations to reasonably attribute the $\mathrm{PM}_{2.5}$ exposures to traffic. The CALINE4 air dispersion model has high spatial and moderate temporal variability and has the resolution to estimate concentrations of $\mathrm{PM}_{2.5}$ from local traffic within $3 \mathrm{~km}$ of a residence (Wu et al. 2011), thus making it a more sensitive model to estimate traffic-related contributions. Exposures were assessed at the residential address level at the time of delivery, however, there is a potential exposure misclassification due to the lack of residential mobility information (e.g., moving or working in a different location) from any of the studies for this exposure. This might represent a nondifferential exposure misclassification, which would likely bias the results toward the null because exposures may vary at a different location.

\section{Outcome Assessment}

Chronic hypertension was usually excluded from analyses, and study authors explicitly stated this exclusion or it was inferred from the definition of the outcome evaluated (e.g., preeclampsia was defined as elevated blood pressure and proteinuria after 20 weeks gestation in previously normotensive women). In some cases, the availability of this information depends on the source of outcome data. In general, birth certificate data poorly report information surrounding preexisting hypertension because they are more often dependent on the timing of the first prenatal visit in clinical records for first pregnancies. However, documentation for both hospital and birth certificate data of preexisting (chronic) hypertension is typically more complete in women who have pregnancy complications. Thus, there is likely some outcome misclassification in the "noncases" for these studies that would bias the effect estimates toward the null. There were no other risk-of-bias concerns about outcome classification in the other studies evaluating associations between $\mathrm{PM}_{2.5}$ and hypertensive disorders of pregnancy.

\section{Confounding and Modifying Variables}

Covariates used in the models are provided in tables for this report. All of the studies considered the standard covariates that are thought to be associated with hypertensive disorders of pregnancy (e.g., maternal age, race/ethnicity, socioeconomic status [SES]). Smoking was not addressed consistently across the body of evidence. Statistical adjustments were made for smokers in half of the studies examined; in other studies, smokers were excluded. Because of the established, although paradoxical, negative association (Conde-Agudelo et al. 1999; Engel et al. 2013; England and Zhang 2007; Jeyabalan et al. 2008; Karumanchi and Levine 2010; Wei et al. 2015; Wikstrom et al. 2010) between smoking and hypertensive disorders of pregnancy, the lack of adjustment in some studies could bias the effect sizes toward the null, and the true relationship between the $\mathrm{PM}_{2.5}$ exposure and preeclampsia may be greater than what is reported in the analyses. Considerations of BMI were more consistent, with most studies adjusting for BMI. In general, the same studies that included smokers in the analysis also did not adjust for BMI (Wu et al. 2011). The lack of adjustments for BMI in some cohorts complicates the interpretation of results because obesity is also a risk factor for hypertensive disorders of pregnancy. Savitz et al. (2015) reported positive associations between exposure to $\mathrm{PM}_{2.5}$ during the first and second trimesters and total hypertensive disorders, gestational hypertension, and severe preeclampsia using standard adjustments (e.g., maternal age, race/ethnicity, education, parity, conception year, BMI); however, when data were adjusted for the delivery hospital, those positive associations were eliminated. This potential source of confounding was not considered in other studies, and the interpretation of those findings is unclear. The outcome data were obtained primarily from hospital discharge data (some data were obtained from linked birth certificate files if they were 
available), and the impact of the delivery hospital more likely reflects differences in disease coding for degrees of hypertensive disorders of pregnancy across the different hospitals. While this adjustment may be warranted for gestational hypertension and mild preeclampsia, as disorders with milder effects are more likely to be misclassified, this is less of a concern when evaluating total hypertensive disorders of pregnancy and severe preeclampsia/eclampsia. Thus, adjusting for hospital would likely be an over adjustment; however, for consistency, only the fully adjusted models (including hospital delivery) were included in the analysis. Because the standard adjusted model showed positive associations for several outcomes, the overall effect size would be slightly larger (meta-OR: 1.58 (95\% CI: 1.35, 1.86)) if those estimates were included in the analysis. Other potential or known confounders and variables were appropriately adjusted in the analyses.

\section{Summary}

While there were some risk-of-bias concerns, those concerns would potentially bias the results toward and away from the null. Given the general consistency of effects across studies despite the different directions of potential bias, the results support the likelihood of a true association between exposure to PM2.5 during pregnancy and hypertensive disorders of pregnancy. For all remaining risk-of-bias questions in all other individual studies that evaluated $\mathrm{PM}_{2.5}$, there was low risk of bias and, thus, no major concerns over the internal validity of the reported results that would decrease the overall confidence in the body of evidence.

\section{Experimental Animal Studies for $\mathbf{P M}_{2.5}$}

There were no animal data evaluating associations between $\mathrm{PM}_{2.5}$ exposure and hypertensive disorders of pregnancy that met the PECO criteria for this assessment.

\section{Evidence Synthesis for Studies of $P M_{2.5}$}

Traffic-related $\mathrm{PM}_{2.5}$ exposure is consistently associated with the development of preeclampsia in humans based on the available evidence. There is moderate confidence in the body of evidence that exposure to traffic-related $\mathrm{PM}_{2.5}$ during the entire gestation period is associated with an increased risk for preeclampsia. The summary effect estimate for the meta-analysis is $1.51(95 \%$ CI: $1.04,2.20$ ) for developing preeclampsia with increasing (per $10 \mu \mathrm{g} / \mathrm{m}^{3}$ increase) trafficrelated $\mathrm{PM}_{2.5}$ exposure. No animal studies were identified. The confidence ratings are summarized below.

- Human body of evidence: Moderate confidence

- Animal body of evidence: No studies

\section{Nitrogen Oxides and Hypertensive Disorders of Pregnancy}

Nitrogen oxides $\left(\mathrm{NO}_{\mathrm{x}}\right)$ is a generic term that refers to the sum of seven nitrogen oxide compounds, including nitric oxide (NO) and nitrogen dioxide $\left(\mathrm{NO}_{2}\right)$. These compounds are derived primarily from combustion-related emissions sources, such as motor vehicles, although $\mathrm{NO}_{\mathrm{x}}$ are also produced naturally by lightning and (minimally) by microbial processes in soils. $\mathrm{NO}_{\mathrm{x}}$ can react with other chemicals in the air to form $\mathrm{PM}$ and ozone. Of the seven $\mathrm{NO}_{\mathrm{x}}$ compounds, $\mathrm{NO}_{2}$ is used as the indicator for the larger group of $\mathrm{NO}_{\mathrm{x}}$ because it is the most prevalent form in the atmosphere generated by human activities. Thus, although the available evidence for this assessment evaluated associations between $\mathrm{NO}_{2}$ or combined $\mathrm{NO}_{x}$ exposures 
and hypertensive disorders of pregnancy, the main conclusions are based primarily on $\mathrm{NO}_{2}$ evidence.

\section{Human Health Studies for $\mathrm{NO}_{2}$ or $\mathrm{NO}_{\mathrm{x}}$}

\section{Summary}

There is moderate confidence in the body of evidence that exposure to traffic-related $\mathrm{NO}_{2}$ or $\mathrm{NO}_{\mathrm{x}}$ during the entire gestation period is associated with an increased risk for preeclampsia or hypertensive disorders of pregnancy. The nine studies identified (eight cohort studies and one case-control study in the United States, Spain, Sweden, Australia, Denmark, Norway, and The Netherlands) reported consistent evidence of an association between $\mathrm{NO}_{2}$ or $\mathrm{NO}_{\mathrm{x}}$ and preeclampsia or combined hypertensive disorders of pregnancy. The studies and data for $\mathrm{NO}_{2}$ were sufficiently similar to perform meta-analyses with a summary effect estimate for the main analysis of 1.04 (95\% CI: $0.97,1.10)$ for risk of preeclampsia after full gestation exposure to $\mathrm{NO}_{2}$ (Figure 14). The initial confidence rating was moderate because all of the studies included in the body of evidence were cohort studies that contained three out of four study design features (exposure prior to outcome, individual outcome data, comparison group used). There was no change in the initial moderate confidence rating in the body of evidence after considering factors that may increase or decrease confidence.

\section{Overview of Available Human Data for $\mathrm{NO}_{2}$ or $\mathrm{NO}_{x}$}

Table 9 summarizes the available data in the human body of evidence that evaluated the associations between exposure to traffic-related $\mathrm{NO}_{2}$ or combined $\mathrm{NO}_{\mathrm{x}}$ and the health outcomes of interest. Nine studies were identified that evaluated associations between traffic-related $\mathrm{NO}_{2}$ or $\mathrm{NO}_{\mathrm{x}}$ exposures and preeclampsia or combined hypertensive disorders of pregnancy. The available evidence included five retrospective cohort studies from Spain (Dadvand et al. 2013), Sweden (Olsson et al. 2015), the United States (Savitz et al. 2015; Wu et al. 2011) and Australia (Pereira et al. 2013); three prospective cohort studies from Denmark (Pedersen et al. 2017), Norway (Madsen et al. 2018), and The Netherlands (van den Hooven et al. 2011); and one casecontrol study from Sweden (Malmqvist et al. 2013). The number of participants in these studies ranged from 7,000 to more than 260,000 pregnant women and included between 100 and 17,000 cases. All studies assessed traffic-related $\mathrm{NO}_{2}$ or $\mathrm{NO}_{x}$ exposures using LUR models (Dadvand et al. 2013; Madsen et al. 2018; Pereira et al. 2013; Savitz et al. 2015) or air dispersion models (Malmqvist et al. 2013; Olsson et al. 2015; Pedersen et al. 2017; van den Hooven et al. 2011). Wu et al. (2011) compared multiple exposure measures and estimated $\mathrm{NO}_{2}$ exposures using LUR models and $\mathrm{NO}_{\mathrm{x}}$ exposures using air dispersion models for each cohort in Los Angeles and Orange Counties.

With the exception of the Olsson et al. (2015) study, which evaluated only combined hypertensive disorders of pregnancy, preeclampsia was the primary outcome in every study. In addition to preeclampsia, four studies assessed gestational hypertension (Madsen et al. 2018; Pedersen et al. 2017; Savitz et al. 2015; van den Hooven et al. 2011) and one study evaluated changes in blood pressure (van den Hooven et al. 2011). 
Table 9. Studies on Hypertensive Disorders of Pregnancy with TRAP-related $\mathrm{NO}_{2}$ or $\mathrm{NO}_{x}$ Exposure in Humans

\begin{tabular}{|c|c|c|c|c|c|c|c|c|c|c|}
\hline Study & $\begin{array}{c}\text { Study Design } \\
\text { (Location) } \\
\text { Exposure } \\
\text { Measure }\end{array}$ & $\begin{array}{l}\text { Sample } \\
\text { Size }\end{array}$ & Cases & Outcome & Exposure & Exposure Period & $\begin{array}{c}\text { OR } \\
(95 \% \mathrm{CI})\end{array}$ & Unit Increase & $\begin{array}{c}\text { Mean (SD) } \\
\text { Exposure Level }\end{array}$ & $\begin{array}{c}\text { Covariates } \\
\text { Considered for } \\
\text { Inclusion }\end{array}$ \\
\hline \multirow{24}{*}{$\begin{array}{l}\text { Dadvand } \\
\text { et al. } \\
(2013)\end{array}$} & \multirow{24}{*}{$\begin{array}{l}\text { Retrospective } \\
\text { cohort } \\
\text { (Barcelona, } \\
\text { Spain) } \\
\text { Land use } \\
\text { regression } \\
\text { models }\end{array}$} & \multirow[t]{24}{*}{8,398} & \multirow[t]{8}{*}{103} & \multirow{8}{*}{$\begin{array}{l}\text { Preeclampsia } \\
\text { (all cases) }\end{array}$} & \multirow[t]{4}{*}{$\mathrm{NO}_{2}$} & Full gestational period & $1.09(0.94,1.27)$ & Per $19.7 \mu \mathrm{g} / \mathrm{m}^{3 *}$ & $55.7(19.7) \mu \mathrm{g} / \mathrm{m}^{3}$ & \multirow{24}{*}{$\begin{array}{l}\text { Maternal age, } \\
\text { ethnicity, } \\
\text { education, } \\
\text { smoking, alcohol } \\
\text { use, BMI, } \\
\text { marital status, } \\
\text { pre-gestational/ } \\
\text { gestational } \\
\text { diabetes, parity, } \\
\text { multiple } \\
\text {-pregnancy, } \\
\text { neighborhood } \\
\text { socioeconomic } \\
\text { status, season of } \\
\text { conception, year } \\
\text { of conception }\end{array}$} \\
\hline & & & & & & Trimester 1 & $1.11(0.91,1.35)$ & Per $28.1 \mu \mathrm{g} / \mathrm{m}^{3 *}$ & $56.8(28.1) \mu \mathrm{g} / \mathrm{m}^{3}$ & \\
\hline & & & & & & Trimester 2 & $1.05(0.85,1.30)$ & Per $27.8 \mu \mathrm{g} / \mathrm{m}^{3 *}$ & $58.0(27.8) \mu \mathrm{g} / \mathrm{m}^{3}$ & \\
\hline & & & & & & Trimester 3 & $1.17(0.99,1.37)$ & Per $27.7 \mu \mathrm{g} / \mathrm{m}^{3 *}$ & $57.7(27.7) \mu \mathrm{g} / \mathrm{m}^{3}$ & \\
\hline & & & & & $\mathrm{NO}_{\mathrm{x}}$ & Full gestational period & $1.07(0.97,1.18)$ & Per $43.7 \mu \mathrm{g} / \mathrm{m}^{3 *}$ & $107.5(43.7) \mu \mathrm{g} / \mathrm{m}^{3}$ & \\
\hline & & & & & & Trimester 1 & $1.09(0.94,1.26)$ & Per $73.4 \mu \mathrm{g} / \mathrm{m}^{3 *}$ & $105.3(73.4) \mu \mathrm{g} / \mathrm{m}^{3}$ & \\
\hline & & & & & & Trimester 2 & $1.06(0.90,1.26)$ & Per $73.6 \mu \mathrm{g} / \mathrm{m}^{3 *}$ & $107.8(73.6) \mu \mathrm{g} / \mathrm{m}^{3}$ & \\
\hline & & & & & & Trimester 3 & $1.14(0.99,1.29)$ & Per $73.8 \mu \mathrm{g} / \mathrm{m}^{3 *}$ & $106.5(73.8) \mu \mathrm{g} / \mathrm{m}^{3}$ & \\
\hline & & & \multirow[t]{8}{*}{26} & \multirow{8}{*}{$\begin{array}{l}\text { Early-onset } \\
\text { preeclampsia }\end{array}$} & $\mathrm{NO}_{2}$ & Full gestational period & $1.11(0.86,1.44)$ & Per $19.7 \mu \mathrm{g} / \mathrm{m}^{3 *}$ & $55.7(19.7) \mu \mathrm{g} / \mathrm{m}^{3}$ & \\
\hline & & & & & & Trimester 1 & $1.17(0.85,1.59)$ & Per $28.1 \mu \mathrm{g} / \mathrm{m}^{3 *}$ & $56.8(28.1) \mu \mathrm{g} / \mathrm{m}^{3}$ & \\
\hline & & & & & & Trimester 2 & $1.13(0.82,1.55)$ & Per $27.8 \mu \mathrm{g} / \mathrm{m}^{3 *}$ & $58.0(27.8) \mu \mathrm{g} / \mathrm{m}^{3}$ & \\
\hline & & & & & & Trimester 3 & $1.08(0.73,1.60)$ & Per $27.7 \mu \mathrm{g} / \mathrm{m}^{3 *}$ & $57.7(27.7) \mu \mathrm{g} / \mathrm{m}^{3}$ & \\
\hline & & & & & $\overline{\mathrm{NO}_{\mathrm{x}}}$ & Full gestational period & $1.10(0.95,1.27)$ & Per $43.7 \mu \mathrm{g} / \mathrm{m}^{3 *}$ & $107.5(43.7) \mu \mathrm{g} / \mathrm{m}^{3}$ & \\
\hline & & & & & & Trimester 1 & $1.14(0.94,1.38)$ & Per $73.4 \mu \mathrm{g} / \mathrm{m}^{3 *}$ & $105.3(73.4) \mu \mathrm{g} / \mathrm{m}^{3}$ & \\
\hline & & & & & & Trimester 2 & $1.13(0.90,1.42)$ & Per $73.6 \mu \mathrm{g} / \mathrm{m}^{3 *}$ & $107.8(73.6) \mu \mathrm{g} / \mathrm{m}^{3}$ & \\
\hline & & & & & & Trimester 3 & $1.12(0.85,1.46)$ & Per $73.8 \mu \mathrm{g} / \mathrm{m}^{3 *}$ & $106.5(73.8) \mu \mathrm{g} / \mathrm{m}^{3}$ & \\
\hline & & & \multirow[t]{8}{*}{75} & \multirow{8}{*}{$\begin{array}{l}\text { Late-onset } \\
\text { preeclampsia }\end{array}$} & \multirow[t]{4}{*}{$\mathrm{NO}_{2}$} & Full gestational period & $1.06(0.86,1.29)$ & Per $19.7 \mu \mathrm{g} / \mathrm{m}^{3 *}$ & $55.7(19.7) \mu \mathrm{g} / \mathrm{m}^{3}$ & \\
\hline & & & & & & Trimester 1 & $1.06(0.82,1.37)$ & Per $28.1 \mu \mathrm{g} / \mathrm{m}^{3 *}$ & $56.8(28.1) \mu \mathrm{g} / \mathrm{m}^{3}$ & \\
\hline & & & & & & Trimester 2 & $1.01(0.77,1.33)$ & Per $27.8 \mu \mathrm{g} / \mathrm{m}^{3 *}$ & $58.0(27.8) \mu \mathrm{g} / \mathrm{m}^{3}$ & \\
\hline & & & & & & Trimester 3 & $1.14(0.93,1.40)$ & Per $27.7 \mu \mathrm{g} / \mathrm{m}^{3 *}$ & $57.7(27.7) \mu \mathrm{g} / \mathrm{m}^{3}$ & \\
\hline & & & & & \multirow[t]{4}{*}{$\overline{\mathrm{NO}_{\mathrm{x}}}$} & Full gestational period & $1.04(0.98,1.21)$ & Per $43.7 \mu \mathrm{g} / \mathrm{m}^{3 *}$ & $107.5(43.7) \mu \mathrm{g} / \mathrm{m}^{3}$ & \\
\hline & & & & & & Trimester 1 & $1.04(0.84,1.22)$ & Per $73.4 \mu \mathrm{g} / \mathrm{m}^{3 *}$ & $105.3(73.4) \mu \mathrm{g} / \mathrm{m}^{3}$ & \\
\hline & & & & & & Trimester 2 & $0.94(0.72,1.22)$ & Per $73.6 \mu \mathrm{g} / \mathrm{m}^{3 *}$ & $107.8(73.6) \mu \mathrm{g} / \mathrm{m}^{3}$ & \\
\hline & & & & & & Trimester 3 & $1.10(0.92,1.32)$ & Per $73.8 \mu \mathrm{g} / \mathrm{m}^{3 *}$ & $106.5(73.8) \mu \mathrm{g} / \mathrm{m}^{3}$ & \\
\hline
\end{tabular}


Systematic Review of TRAP and Hypertensive Disorders of Pregnancy

\begin{tabular}{|c|c|c|c|c|c|c|c|c|c|c|}
\hline Study & $\begin{array}{c}\text { Study Design } \\
\text { (Location) } \\
\text { Exposure } \\
\text { Measure }\end{array}$ & $\begin{array}{l}\text { Sample } \\
\text { Size }\end{array}$ & Cases & Outcome & Exposure & Exposure Period & $\begin{array}{c}\text { OR } \\
(95 \% \mathrm{CI})\end{array}$ & Unit Increase & $\begin{array}{c}\text { Mean (SD) } \\
\text { Exposure Level }\end{array}$ & $\begin{array}{c}\text { Covariates } \\
\text { Considered for } \\
\text { Inclusion }\end{array}$ \\
\hline \multirow[t]{2}{*}{$\begin{array}{l}\text { Madsen et } \\
\text { al. (2018) }\end{array}$} & \multirow{2}{*}{$\begin{array}{l}\text { Prospective } \\
\text { cohort } \\
\text { (Norway) } \\
\text { Land use } \\
\text { regression } \\
\text { models }\end{array}$} & \multirow[t]{2}{*}{17,533} & 590 & Preeclampsia & $\mathrm{NO}_{2}$ & Full gestational period & $0.89(0.74,1.08)$ & \multirow[t]{2}{*}{ Per $10 \mu \mathrm{g} / \mathrm{m}^{3}$} & \multirow[t]{2}{*}{$13.6(6.9) \mu \mathrm{g} / \mathrm{m}^{3}$} & \multirow{2}{*}{$\begin{array}{l}\text { Maternal age, } \\
\text { marital status, } \\
\text { education, BMI, } \\
\text { parity, smoking, } \\
\text { diabetes, chronic } \\
\text { hypertension, } \\
\text { child sex, area, } \\
\text { year of birth }\end{array}$} \\
\hline & & & 941 & $\begin{array}{l}\text { Hypertension } \\
\text { during } \\
\text { pregnancy }\end{array}$ & $\mathrm{NO}_{2}$ & Full gestational period & $0.91(0.78,1.06)$ & & & \\
\hline \multirow{9}{*}{$\begin{array}{l}\text { Malmqvist } \\
\text { et al. } \\
(2013)\end{array}$} & \multirow{9}{*}{$\begin{array}{l}\text { Case-control } \\
\text { (Sweden) } \\
\text { Dispersion } \\
\text { models }\end{array}$} & \multirow[t]{9}{*}{81,110} & \multirow[t]{3}{*}{2,323} & \multirow{3}{*}{$\begin{array}{l}\text { Preeclampsia } \\
\text { (all cases) }\end{array}$} & \multirow[t]{3}{*}{$\mathrm{NO}_{\mathrm{x}}$} & Trimester 1 & $1.43(1.25,1.63)$ & \multirow{9}{*}{$\begin{array}{l}\text { For }>22.7 \mu \mathrm{g} / \mathrm{m}^{3} \\
\text { compared with } \\
2.5-8.9 \mu \mathrm{g} / \mathrm{m}^{3} \\
\text { (reference) }\end{array}$} & \multirow{9}{*}{$14.2 \mu \mathrm{g} / \mathrm{m}^{3}$} & \multirow{9}{*}{$\begin{array}{l}\text { Maternal age, } \\
\text { BMI, smoking, } \\
\text { parity, ethnicity, } \\
\text { type } 1 \text { diabetes, } \\
\text { gestational } \\
\text { diabetes, year of } \\
\text { delivery }\end{array}$} \\
\hline & & & & & & Trimester 2 & $1.50(1.31,1.71)$ & & & \\
\hline & & & & & & Trimester 3 & $1.51(1.32,1.73)$ & & & \\
\hline & & & \multirow[t]{3}{*}{1,799} & \multirow{3}{*}{$\begin{array}{l}\text { Mild } \\
\text { preeclampsia }\end{array}$} & \multirow[t]{3}{*}{$\mathrm{NO}_{\mathrm{x}}$} & Trimester 1 & $1.47(1.26,1.71)$ & & & \\
\hline & & & & & & Trimester 2 & $1.59(1.36,1.86)$ & & & \\
\hline & & & & & & Trimester 3 & $1.51(1.29,1.77)$ & & & \\
\hline & & & \multirow[t]{3}{*}{571} & \multirow{3}{*}{$\begin{array}{l}\text { Severe } \\
\text { preeclampsia }\end{array}$} & \multirow[t]{3}{*}{$\mathrm{NO}_{\mathrm{x}}$} & Trimester 1 & $1.30(1.00,1.69)$ & & & \\
\hline & & & & & & Trimester 2 & $1.24(0.95,1.62)$ & & & \\
\hline & & & & & & Trimester 3 & $1.48(1.12,1.95)$ & & & \\
\hline $\begin{array}{l}\text { Olsson et } \\
\text { al. }(2015)\end{array}$ & $\begin{array}{l}\text { Retrospective } \\
\text { cohort } \\
\text { (Sweden) } \\
\text { Dispersion } \\
\text { models }\end{array}$ & 102,768 & 2,762 & $\begin{array}{l}\text { Pregnancy- } \\
\text { induced } \\
\text { hypertensive } \\
\text { disorders }\end{array}$ & $\mathrm{NO}_{\mathrm{x}}$ & Trimester 1 & $1.17(1.10,1.26)$ & Per $10 \mu \mathrm{g} / \mathrm{m}^{3}$ & $15.1(7.4) \mu \mathrm{g} / \mathrm{m}^{3}$ & $\begin{array}{l}\text { Maternal age, } \\
\text { asthma, region } \\
\text { of origin, } \\
\text { education, } \\
\text { parity, date of } \\
\text { conception, first } \\
\text { trimester ozone, } \\
\text { first trimester } \\
\text { temperature, } \\
\text { smoking, BMI, } \\
\text { family situation }\end{array}$ \\
\hline
\end{tabular}


Systematic Review of TRAP and Hypertensive Disorders of Pregnancy

\begin{tabular}{|c|c|c|c|c|c|c|c|c|c|c|}
\hline Study & $\begin{array}{c}\text { Study Design } \\
\text { (Location) } \\
\text { Exposure } \\
\text { Measure } \\
\end{array}$ & $\begin{array}{l}\text { Sample } \\
\text { Size }\end{array}$ & Cases & Outcome & Exposure & Exposure Period & $\begin{array}{c}\text { OR } \\
(95 \% \mathrm{CI})\end{array}$ & Unit Increase & $\begin{array}{c}\text { Mean (SD) } \\
\text { Exposure Level }\end{array}$ & $\begin{array}{l}\text { Covariates } \\
\text { Considered for } \\
\text { Inclusion }\end{array}$ \\
\hline \multirow{7}{*}{$\begin{array}{l}\text { Pedersen } \\
\text { et al. } \\
(2017)\end{array}$} & \multirow{7}{*}{$\begin{array}{l}\text { Prospective } \\
\text { cohort } \\
\text { (Denmark) } \\
\text { Dispersion } \\
\text { models }\end{array}$} & \multirow[t]{7}{*}{72,745} & 1,880 & $\begin{array}{l}\text { Preeclampsia } \\
\text { (all cases) }\end{array}$ & $\mathrm{NO}_{2}$ & Full gestational period & $1.08(1.01,1.15)$ & \multirow[t]{7}{*}{ Per $10 \mu \mathrm{g} / \mathrm{m}^{3}$} & \multirow[t]{7}{*}{$11.5(6.7) \mu \mathrm{g} / \mathrm{m}^{3}$} & \multirow{7}{*}{$\begin{array}{l}\text { Maternal age, } \\
\text { BMI, height, } \\
\text { parity, season of } \\
\text { conception, } \\
\text { education, } \\
\text { household } \\
\text { income, } \\
\text { smoking, } \\
\text { physical activity, } \\
\text { railway or } \\
\text { airport noise, } \\
\text { year of last } \\
\text { menstrual period }\end{array}$} \\
\hline & & & 487 & $\begin{array}{l}\text { Severe } \\
\text { preeclampsia }\end{array}$ & $\mathrm{NO}_{2}$ & Full gestational period & $0.90(0.78,1.04)$ & & & \\
\hline & & & 1,393 & $\begin{array}{l}\text { Mild } \\
\text { preeclampsia }\end{array}$ & $\mathrm{NO}_{2}$ & Full gestational period & $1.14(1.06,1.23)$ & & & \\
\hline & & & 671 & $\begin{array}{l}\text { Early-onset } \\
\text { preeclampsia }\end{array}$ & $\mathrm{NO}_{2}$ & Full gestational period & $1.19(1.07,1.32)$ & & & \\
\hline & & & 1,209 & $\begin{array}{l}\text { Late-onset } \\
\text { preeclampsia }\end{array}$ & $\mathrm{NO}_{2}$ & Full gestational period & $1.01(0.93,1.10)$ & & & \\
\hline & & & 765 & $\begin{array}{l}\text { Gestational } \\
\text { hypertension }\end{array}$ & $\mathrm{NO}_{2}$ & Full gestational period & $1.01(0.91,1.13)$ & & & \\
\hline & & & 2,430 & $\begin{array}{l}\text { Hypertensive } \\
\text { disorders in } \\
\text { pregnancy }\end{array}$ & $\mathrm{NO}_{2}$ & Full gestational period & $1.07(1.01,1.14)$ & & & \\
\hline \multirow[t]{4}{*}{$\begin{array}{l}\text { Pereira et } \\
\text { al. }(2013)\end{array}$} & \multirow{4}{*}{$\begin{array}{l}\text { Retrospective } \\
\text { cohort } \\
\text { (Perth, } \\
\text { Australia) } \\
\text { Land use } \\
\text { regression } \\
\text { models }\end{array}$} & \multirow[t]{4}{*}{23,425} & \multirow[t]{4}{*}{943} & \multirow[t]{4}{*}{ Preeclampsia } & $\mathrm{NO}_{2}$ & Full gestational period & $1.12(1.01,1.25)$ & $\begin{array}{l}\text { Per } 5.63 \mathrm{ppb}^{*} \\
\left(10.58 \mu \mathrm{g} / \mathrm{m}^{3}\right)\end{array}$ & $\begin{array}{l}23.04(4.14) \mathrm{ppb} \\
{[43.32} \\
\left.(7.8) \mu \mathrm{g} / \mathrm{m}^{3}\right]\end{array}$ & \multirow{4}{*}{$\begin{array}{l}\text { Maternal age, } \\
\text { pre-gestational } \\
\text { and gestational } \\
\text { diabetes, } \\
\text { aboriginal status, } \\
\text { parity, season of } \\
\text { conception, } \\
\text { smoking, area } \\
\text { socioeconomic } \\
\text { status }\end{array}$} \\
\hline & & & & & & Trimester 1 & $1.07(0.91,1.27)$ & $\begin{array}{l}\text { Per } 15.99 \mathrm{ppb} \\
\left(30.06 \mathrm{ug} / \mathrm{m}^{3}\right)\end{array}$ & $\begin{array}{l}23.29(10.19) \mathrm{ppb} \\
{[43.79} \\
\left.(19.2) \mu \mathrm{g} / \mathrm{m}^{3}\right]\end{array}$ & \\
\hline & & & & & & Trimester 2 & $1.04(0.86,1.26)$ & $\begin{array}{l}\text { Per } 16.97 \mathrm{ppb}^{*} \\
\left(31.90 \mu \mathrm{g} / \mathrm{m}^{3}\right)\end{array}$ & $\begin{array}{l}23.27(10.29) \mathrm{ppb} \\
{[43.75} \\
\left.(19.3) \mu \mathrm{g} / \mathrm{m}^{3}\right]\end{array}$ & \\
\hline & & & & & & Trimester 3 & $1.30(1.07,1.58)$ & $\begin{array}{l}\text { Per } 16.64 \mathrm{ppb}^{*} \\
\left(31.28 \mu \mathrm{g} / \mathrm{m}^{3}\right)\end{array}$ & $\begin{array}{l}22.54(9.87) \mathrm{ppb} \\
{[42.38} \\
\left.(18.6) \mu \mathrm{g} / \mathrm{m}^{3}\right]\end{array}$ & \\
\hline
\end{tabular}


Systematic Review of TRAP and Hypertensive Disorders of Pregnancy

\begin{tabular}{|c|c|c|c|c|c|c|c|c|c|c|}
\hline Study & $\begin{array}{c}\text { Study Design } \\
\text { (Location) } \\
\text { Exposure } \\
\text { Measure } \\
\end{array}$ & $\begin{array}{c}\text { Sample } \\
\text { Size }\end{array}$ & Cases & Outcome & Exposure & Exposure Period & $\begin{array}{c}\text { OR } \\
(95 \% \mathrm{CI})\end{array}$ & Unit Increase & $\begin{array}{c}\text { Mean (SD) } \\
\text { Exposure Level }\end{array}$ & $\begin{array}{l}\text { Covariates } \\
\text { Considered for } \\
\text { Inclusion }\end{array}$ \\
\hline \multirow[t]{8}{*}{$\begin{array}{l}\text { Savitz et } \\
\text { al. }(2015)\end{array}$} & \multirow{8}{*}{$\begin{array}{l}\text { Retrospective } \\
\text { cohort } \\
\text { (New York } \\
\text { City, USA) } \\
\text { Land use } \\
\text { regression } \\
\text { models }\end{array}$} & \multirow[t]{8}{*}{268,601} & \multirow[t]{2}{*}{4,226} & \multirow[t]{2}{*}{$\begin{array}{l}\text { Severe } \\
\text { preeclampsia }\end{array}$} & \multirow[t]{2}{*}{$\mathrm{NO}_{2}$} & Trimester 1 & $0.96(0.90,1.0)$ & $\begin{array}{l}\text { Per } 10 \mathrm{ppb} \\
\left(18.8 \mu \mathrm{g} / \mathrm{m}^{3}\right)\end{array}$ & $\begin{array}{l}27.8(6.2) \mathrm{ppb} \\
{[52.26} \\
\left.(11.7) \mu \mathrm{g} / \mathrm{m}^{3}\right]\end{array}$ & \multirow{8}{*}{$\begin{array}{l}\text { Maternal age, } \\
\text { parity, } \\
\text { race/ethnicity, } \\
\text { conception year, } \\
\text { education, BMI, } \\
\text { BMI }^{2} \text {, Medicaid } \\
\text { - status, social } \\
\text { deprivation } \\
\text { index, hospital } \\
\text { of delivery }\end{array}$} \\
\hline & & & & & & Trimester 2 & $0.93(0.87,0.99)$ & $\begin{array}{l}\text { Per } 10 \mathrm{ppb} \\
\left(18.8 \mu \mathrm{g} / \mathrm{m}^{3}\right)\end{array}$ & $\begin{array}{l}27.0(6.2) \mathrm{ppb} \\
{[50.76} \\
\left.(11.7) \mu \mathrm{g} / \mathrm{m}^{3}\right]\end{array}$ & \\
\hline & & & \multirow[t]{2}{*}{6,940} & \multirow[t]{2}{*}{$\begin{array}{l}\text { Mild } \\
\text { preeclampsia }\end{array}$} & \multirow[t]{2}{*}{$\mathrm{NO}_{2}$} & Trimester 1 & $0.89(0.84,0.93)$ & $\begin{array}{l}\text { Per } 10 \mathrm{ppb} \\
\left(18.8 \mu \mathrm{g} / \mathrm{m}^{3}\right)\end{array}$ & $\begin{array}{l}27.8(6.2) \mathrm{ppb} \\
{[52.26} \\
\left.(11.7) \mu \mathrm{g} / \mathrm{m}^{3}\right]\end{array}$ & \\
\hline & & & & & & Trimester 2 & $0.94(0.89,0.99)$ & $\begin{array}{l}\text { Per } 10 \mathrm{ppb} \\
\left(18.8 \mu \mathrm{g} / \mathrm{m}^{3}\right)\end{array}$ & $\begin{array}{l}27.0(6.2) \mathrm{ppb} \\
{[50.76} \\
\left.(11.7) \mu \mathrm{g} / \mathrm{m}^{3}\right] \\
\end{array}$ & \\
\hline & & & \multirow[t]{2}{*}{5,834} & \multirow[t]{2}{*}{$\begin{array}{l}\text { Gestational } \\
\text { hypertension }\end{array}$} & \multirow[t]{2}{*}{$\mathrm{NO}_{2}$} & Trimester 1 & $0.95(0.90,1.0)$ & $\begin{array}{l}\text { Per } 10 \mathrm{ppb} \\
\left(18.8 \mu \mathrm{g} / \mathrm{m}^{3}\right)\end{array}$ & $\begin{array}{l}27.8(6.2) \mathrm{ppb} \\
{[52.26} \\
\left.(11.7) \mu \mathrm{g} / \mathrm{m}^{3}\right]\end{array}$ & \\
\hline & & & & & & Trimester 2 & $1.0(0.95,1.1)$ & $\begin{array}{l}\text { Per } 10 \mathrm{ppb} \\
\left(18.8 \mu \mathrm{g} / \mathrm{m}^{3}\right)\end{array}$ & $\begin{array}{l}27.0(6.2) \mathrm{ppb} \\
{[50.76} \\
\left.(11.7) \mu \mathrm{g} / \mathrm{m}^{3}\right]\end{array}$ & \\
\hline & & & \multirow[t]{2}{*}{17,000} & \multirow[t]{2}{*}{$\begin{array}{l}\text { Total } \\
\text { Hypertensive } \\
\text { Disorders }\end{array}$} & \multirow[t]{2}{*}{$\mathrm{NO}_{2}$} & Trimester 1 & $0.93(0.90,0.96)$ & $\begin{array}{l}\text { Per } 10 \mathrm{ppb} \\
\left(18.8 \mu \mathrm{g} / \mathrm{m}^{3}\right)\end{array}$ & $\begin{array}{l}27.8(6.2) \mathrm{ppb} \\
{[52.26} \\
\left.(11.7) \mu \mathrm{g} / \mathrm{m}^{3}\right]\end{array}$ & \\
\hline & & & & & & Trimester 2 & $0.96(0.93,0.99)$ & $\begin{array}{l}\text { Per } 10 \mathrm{ppb} \\
\left(18.8 \mu \mathrm{g} / \mathrm{m}^{3}\right)\end{array}$ & $\begin{array}{l}27.0(6.2) \mathrm{ppb} \\
{[50.76} \\
\left.(11.7) \mu \mathrm{g} / \mathrm{m}^{3}\right] \\
\end{array}$ & \\
\hline \multirow{6}{*}{$\begin{array}{l}\text { van den } \\
\text { Hooven et } \\
\text { al. (2011) }\end{array}$} & \multirow{6}{*}{$\begin{array}{l}\text { Prospective } \\
\text { cohort } \\
\text { (Rotterdam, } \\
\text { Netherlands) } \\
\text { Dispersion } \\
\text { Models }\end{array}$} & \multirow[t]{6}{*}{7,006} & 250 & Preeclampsia & $\mathrm{NO}_{2}$ & Full gestational period & $1.23(0.75,2.02)$ & Per $10 \mu \mathrm{g} / \mathrm{m}^{3}$ & $39.9(4.2) \mu \mathrm{g} / \mathrm{m}^{3}$ & \multirow{6}{*}{$\begin{array}{l}\text { Maternal age, } \\
\text { height, weight, } \\
\text { ethnicity, } \\
\text { education, } \\
\text { - parity, } \\
\text { gestational age, } \\
\text { folic acid } \\
\text { supplementation, } \\
\text { - smoking, alcohol }\end{array}$} \\
\hline & & & 141 & $\begin{array}{l}\text { Pregnancy- } \\
\text { induced } \\
\text { hypertension }\end{array}$ & $\mathrm{NO}_{2}$ & Full gestational period & $1.21(0.83,1.77)$ & Per $10 \mu \mathrm{g} / \mathrm{m}^{3}$ & $39.9(4.2) \mu \mathrm{g} / \mathrm{m}^{3}$ & \\
\hline & & & $4,853^{\mathrm{b}}$ & Diastolic blood & $\mathrm{NO}_{2}$ & Trimester 1 & $0.35(-0.15,0.86)^{\mathrm{c}}$ & Per $10 \mu \mathrm{g} / \mathrm{m}^{3}$ & $40.5(5.4) \mu \mathrm{g} / \mathrm{m}^{3}$ & \\
\hline & & & $6,361^{\mathrm{b}}$ & pressure & & Trimester 2 & $0.37(-0.11,0.85)^{\mathrm{c}}$ & Per $10 \mu \mathrm{g} / \mathrm{m}^{3}$ & $40.3(5.0) \mu \mathrm{g} / \mathrm{m}^{3}$ & \\
\hline & & & $6,488^{\mathrm{b}}$ & & & Trimester 3 & $-0.05(-0.59,0.50)^{\mathrm{c}}$ & Per $10 \mu \mathrm{g} / \mathrm{m}^{3}$ & $40.0(4.5) \mu \mathrm{g} / \mathrm{m}^{3}$ & \\
\hline & & & $4,853^{\mathrm{b}}$ & & $\mathrm{NO}_{2}$ & Trimester 1 & $1.19(0.54,1.83)^{\mathrm{c}}$ & Per $10 \mu \mathrm{g} / \mathrm{m}^{3}$ & $40.5(5.4) \mu \mathrm{g} / \mathrm{m}^{3}$ & \\
\hline
\end{tabular}


Systematic Review of TRAP and Hypertensive Disorders of Pregnancy

\begin{tabular}{|c|c|c|c|c|c|c|c|c|c|c|}
\hline Study & $\begin{array}{c}\text { Study Design } \\
\text { (Location) } \\
\text { Exposure } \\
\text { Measure }\end{array}$ & $\begin{array}{l}\text { Sample } \\
\text { Size }\end{array}$ & Cases & Outcome & Exposure & Exposure Period & $\begin{array}{c}\text { OR } \\
(95 \% \mathrm{CI})\end{array}$ & Unit Increase & $\begin{array}{c}\text { Mean (SD) } \\
\text { Exposure Level }\end{array}$ & $\begin{array}{c}\text { Covariates } \\
\text { Considered for } \\
\text { Inclusion }\end{array}$ \\
\hline & & & $6,361^{\mathrm{b}}$ & Systolic blood & & Trimester 2 & $1.35(0.76,1.95)^{\mathrm{c}}$ & Per $10 \mu \mathrm{g} / \mathrm{m}^{3}$ & $40.3(5.0) \mu \mathrm{g} / \mathrm{m}^{3}$ & use, road traffic \\
\hline & & & $6,488^{\mathrm{b}}$ & pressure & & Trimester 3 & $0.73(0.04,1.41)^{\mathrm{c}}$ & Per $10 \mu \mathrm{g} / \mathrm{m}^{3}$ & $40.0(4.5) \mu \mathrm{g} / \mathrm{m}^{3}$ & noise exposure \\
\hline \multirow[t]{2}{*}{$\begin{array}{l}\text { Wu et al. } \\
(2011)\end{array}$} & \multirow{2}{*}{$\begin{array}{l}\text { Retrospective } \\
\text { cohort (Los } \\
\text { Angeles } \\
\text { County, } \\
\text { USA) } \\
\text { Land use } \\
\text { regression } \\
\left(\mathrm{NO}_{2}\right) \text {; } \\
\text { CALINE } 4 \\
\text { dispersion } \\
\text { models (NOx) }\end{array}$} & \multirow[t]{2}{*}{38,709} & \multirow[t]{2}{*}{1,303} & \multirow[t]{2}{*}{ Preeclampsia } & $\mathrm{NO}_{2}$ & Full gestational period & $1.12(1.02,1.23)$ & $\begin{array}{l}\text { Per } 5.1 \mathrm{ppb} \\
\left(9.59 \mu \mathrm{g} / \mathrm{m}^{3}\right)\end{array}$ & $\begin{array}{l}28.6(6.0) \mathrm{ppb} \\
{[53.77} \\
\left.(11.3) \mu \mathrm{g} / \mathrm{m}^{3}\right]\end{array}$ & \multirow{2}{*}{$\begin{array}{l}\text { Maternal age, } \\
\text { race/ethnicity, } \\
\text { parity, diabetes, } \\
\text { prenatal care } \\
\text { insurance type, } \\
\text { poverty, season } \\
\text { of conception }\end{array}$} \\
\hline & & & & & $\mathrm{NO}_{\mathrm{x}}$ & Full gestational period & $1.08(1.02,1.15)$ & $\begin{array}{l}\text { Per } 5.6 \mathrm{ppb}^{*} \\
\left(10.53 \mu \mathrm{g} / \mathrm{m}^{3}\right)\end{array}$ & $\begin{array}{l}8.9(4.9) \mathrm{ppb} \\
{[16.73} \\
\left.(9.2) \mu \mathrm{g} / \mathrm{m}^{3}\right]\end{array}$ & \\
\hline \multirow[t]{2}{*}{$\begin{array}{l}\text { Wu et al. } \\
(2011)\end{array}$} & \multirow{2}{*}{$\begin{array}{l}\text { Retrospective } \\
\text { cohort } \\
\text { (Orange } \\
\text { County, } \\
\text { USA) } \\
\text { Land use } \\
\text { regression } \\
\left(\mathrm{NO}_{2}\right) \text {; } \\
\text { CALINE } 4 \\
\text { dispersion } \\
\text { models }\left(\mathrm{NO}_{\mathrm{x}}\right)\end{array}$} & \multirow[t]{2}{*}{42,277} & \multirow[t]{2}{*}{1,139} & \multirow[t]{2}{*}{ Preeclampsia } & $\mathrm{NO}_{2}$ & Full gestational period & $1.01(0.93,1.10)$ & $\begin{array}{l}\text { Per } 5.1 \mathrm{ppb}^{*} \\
\left(9.59 \mu \mathrm{g} / \mathrm{m}^{3}\right)\end{array}$ & $\begin{array}{l}27.5(7.7) \mathrm{ppb} \\
{[51.70} \\
\left.(14.8) \mu \mathrm{g} / \mathrm{m}^{3}\right]\end{array}$ & \multirow{2}{*}{$\begin{array}{l}\text { Maternal age, } \\
\text { race/ethnicity, } \\
\text { parity, diabetes, } \\
\text { prenatal care } \\
\text {-insurance type, } \\
\text { poverty, season } \\
\text { of conception }\end{array}$} \\
\hline & & & & & $\mathrm{NO}_{\mathrm{x}}$ & Full gestational period & $1.08(1.01,1.16)$ & $\begin{array}{l}\text { Per } 5.6 \mathrm{ppb} * \\
\left(10.53 \mu \mathrm{g} / \mathrm{m}^{3}\right)\end{array}$ & $\begin{array}{l}5.7(5.0) \mathrm{ppb} \\
{[10.72} \\
\left.(9.4) \mu \mathrm{g} / \mathrm{m}^{3}\right]\end{array}$ & \\
\hline
\end{tabular}




\section{Summary of the Human Evidence and Meta-analyses}

The human evidence evaluating the associations between hypertensive disorders of pregnancy and $\mathrm{NO}_{2}$ or $\mathrm{NO}_{x}$ generally reported slight but significant increased risk for developing preeclampsia or hypertensive disorders of pregnancy with increasing concentrations of $\mathrm{NO}_{2}$ or combined $\mathrm{NO}_{\mathrm{x}}$ exposures. Slight negative associations were reported between exposure to relatively low levels of $\mathrm{NO}_{2}$ during the full gestational period and preeclampsia and gestational hypertension (Madsen et al. 2018) and between first and second trimester $\mathrm{NO}_{2}$ exposures and hypertensive disorders of pregnancy (after adjusting for the delivery hospital [Savitz et al. (2015)]). $\mathrm{NO}_{2}$ or $\mathrm{NO}_{x}$ exposures that were estimated using air dispersion models were between 10.7 and $16.7 \mu \mathrm{g} / \mathrm{m}^{3}$ for most studies (Malmqvist et al. 2013; Olsson et al. 2015; Pedersen et al. 2017; Wu et al. 2011), but the highest concentration $\left(40 \mu \mathrm{g} / \mathrm{m}^{3}\right)$ was reported by van den Hooven et al. (2011). Estimates of $\mathrm{NO}_{2}$ concentrations using LUR models ranged from $43.3-55.7 \mu \mathrm{g} / \mathrm{m}^{3}$ (Dadvand et al. 2013; Pereira et al. 2013; Savitz et al. 2015; Wu et al. 2011). Lower concentrations $\left(13.6 \mu \mathrm{g} / \mathrm{m}^{3}\right)$ were reported by Madsen et al. (2018), which may have contributed to the lack of an association observed between $\mathrm{NO}_{2}$ exposure and hypertensive disorders of pregnancy. Only one study estimated $\mathrm{NO}_{x}$ concentrations using LUR (2013), and those concentrations $\left(105.3-107.8 \mu \mathrm{g} / \mathrm{m}^{3}\right)$ were higher than those estimated using air dispersion models. Multiple studies evaluated trimester-specific exposures in addition to the entire pregnancy period (Dadvand et al. 2013; Malmqvist et al. 2013; Olsson et al. 2015; Pereira et al. 2013; Savitz et al. 2015; van den Hooven et al. 2011), and positive associations were reported for most trimester exposure windows and hypertensive disorders of pregnancy, although some did not reach statistical significance for some outcomes. Third trimester exposures were also positively associated with hypertensive disorders of pregnancy and, in some cases (e.g., for preeclampsia or severe preeclampsia), were more strongly correlated than first trimester exposures (Malmqvist et al. 2013; Pereira et al. 2013). These correlations may reflect different mechanisms of action for $\mathrm{NO}_{\mathrm{x}}$ exposure on the pathogenesis of hypertension during pregnancy, but additional studies would be needed to support this assertion. Most studies evaluated preeclampsia (and various subcategories of preeclampsia) or combined hypertensive disorders of pregnancy, but one study found a statistically significant positive association between $\mathrm{NO}_{\mathrm{x}}$ exposures and systolic blood pressure, particularly in the first trimester. However, the evidence from a single study is inadequate to draw conclusions on associations between systolic and/or diastolic blood pressures and hypertensive disorders of pregnancy following $\mathrm{NO}_{\mathrm{x}}$ exposure. There were also limited data to determine if associations between $\mathrm{NO}_{2}$ or $\mathrm{NO}_{x}$ concentrations were more strongly correlated with subcategories of preeclampsia (e.g., mild versus severe, early onset versus late onset).

Correlations across exposures were the highest between $\mathrm{NO}_{\mathrm{x}}$ and $\mathrm{NO}_{2}$ and were generally low to moderate for other pollutants when reported (although the majority of studies used singlepollutant models). The data were sufficient to evaluate the effects of $\mathrm{NO}_{2}$ exposure on hypertensive disorders of pregnancy using meta-analyses (Table 10). The analyses evaluated associations between traffic-related $\mathrm{NO}_{2}$ exposures during the full gestational period and (1) preeclampsia and (2) combined hypertensive disorders of pregnancy.

Four studies (Madsen et al. 2018; Pedersen et al. 2017; Savitz et al. 2015; van den Hooven et al. 2011) reported both gestational hypertension and preeclampsia as separate effect estimates; those risk estimates were first combined for each study, and the pooled estimates from each study were included in the combined hypertensive disorders of pregnancy meta-analysis. As discussed for 
the PM analysis, Wu et al. (2011) evaluated two cohorts, and risk estimates from each these groups were treated as independent effects. Savitz et al. (2015) reported risk estimates for trimesters 1 and 2 for mild and severe preeclampsia. These were pooled into one risk for trimesters 1 and 2 for preeclampsia combined. Because Savitz et al. (2015) reported exposure windows other than the entire pregnancy period, sensitivity analyses were performed with and without this study.

Six studies reported effects following exposure to $\mathrm{NO}_{2}$ over the full gestational period, and all of those studies reported preeclampsia as the outcome. In addition to preeclampsia, three studies (Pedersen et al. 2017; Savitz et al. 2015; van den Hooven et al. 2011) reported gestational hypertension. Together with the two separate risk estimates reported by Wu et al. (2011), a total of eight results were included in the combined hypertensive disorders of pregnancy metaanalysis (Table 11; Figure 13). Eight results were included in the preeclampsia-only metaanalysis (Table 11; Figure 14).

The available evidence indicates that the summary risk estimates from this meta-analysis were 1.03 (95\% CI: 0.97, 1.09) and 1.04 (95\% CI: 0.97, 1.10) for the associations between exposure to traffic-related $\mathrm{NO}_{2}$ and combined hypertensive disorders of pregnancy (Table 11; Figure 13) and preeclampsia only (Table 11; Figure 14), respectively. The summary risk estimate was 1.06 $(95 \%$ CI: $0.98,1.14)$ for the association between traffic-related $\mathrm{NO}_{\mathrm{x}}$ and preeclampsia only (Figure 15). For both combined hypertensive disorders of pregnancy and preeclampsia-only analyses, there was moderate heterogeneity among the studies, and an influence analysis revealed that no single study influenced either meta-analysis to a large degree (Table E-3; Table E-4; Figure E-3; Figure E-4). A formal test for publication bias revealed no evidence of publication bias ( $p$-values $=0.068$, and 0.089 , respectively) in the meta-analyses (Table E-5; Table E-6; Figure E-5; Figure E-6). 
Table 10. References Included in Meta-analysis: Studies on Hypertensive Disorders of Pregnancy with $\mathrm{TRAP}^{-r e l a t e d} \mathrm{NO}_{2}$ Exposure in Humans

\begin{tabular}{|c|c|c|c|c|c|c|c|c|c|}
\hline Study & $\begin{array}{l}\text { Study Design } \\
\text { (Location) }\end{array}$ & $\begin{array}{l}\text { Sample } \\
\text { Size }\end{array}$ & $\begin{array}{c}\text { Cases } \\
\text { Included in } \\
\text { Analysis }\end{array}$ & Outcome & Exposure & $\begin{array}{l}\text { Exposure } \\
\text { Period }\end{array}$ & $\begin{array}{c}\text { OR } \\
(95 \% \mathrm{CI})^{*}\end{array}$ & $\begin{array}{c}\text { Mean (SD) } \\
\text { Exposure Levels }\end{array}$ & $\begin{array}{l}\text { Covariates Included } \\
\text { in Final Model }\end{array}$ \\
\hline $\begin{array}{l}\text { Dadvand et al. } \\
\text { (2013) }\end{array}$ & $\begin{array}{l}\text { Retrospective } \\
\text { cohort (Barcelona, } \\
\text { Spain) }\end{array}$ & 8,398 & 103 & Preeclampsia & $\mathrm{NO}_{2}$ & $\begin{array}{l}\text { Full gestational } \\
\text { period }\end{array}$ & $1.04(0.89,1.23)$ & $55.7(19.7) \mu \mathrm{g} / \mathrm{m}^{3}$ & $\begin{array}{l}\text { Maternal age, } \\
\text { ethnicity, education, } \\
\text { smoking, alcohol use, } \\
\text { BMI, marital status, } \\
\text { pre-gestational/ } \\
\text { gestational diabetes, } \\
\text { parity, multiple } \\
\text { pregnancy, } \\
\text { neighborhood } \\
\text { socioeconomic status, } \\
\text { season of conception, } \\
\text { year of conception }\end{array}$ \\
\hline \multirow[t]{3}{*}{$\begin{array}{l}\text { Madsen et al. } \\
(2018)\end{array}$} & \multirow[t]{3}{*}{$\begin{array}{l}\text { Prospective cohort } \\
\text { (Norway) }\end{array}$} & \multirow[t]{3}{*}{17,533} & 526 & Preeclampsia & $\mathrm{NO}_{2}$ & $\begin{array}{l}\text { Full gestational } \\
\text { period }\end{array}$ & $0.89(0.74,1.08)$ & \multirow[t]{3}{*}{$13.6(6.9) \mu \mathrm{g} / \mathrm{m}^{3}$} & \multirow{3}{*}{$\begin{array}{l}\text { Maternal age, BMI, } \\
\text { diabetes, chronic } \\
\text { hypertension, } \\
\text { education, marital } \\
\text { status, parity, smoking, } \\
\text { area, season, and year } \\
\text { of birth }\end{array}$} \\
\hline & & & 841 & $\begin{array}{l}\text { Hypertension } \\
\text { during } \\
\text { pregnancy }\end{array}$ & $\mathrm{NO}_{2}$ & $\begin{array}{l}\text { Full gestational } \\
\text { period }\end{array}$ & $0.91(0.78,1.06)$ & & \\
\hline & & & 1,367 & $\begin{array}{l}\text { Combined } \\
\text { hypertensive } \\
\text { disorders of } \\
\text { pregnancy }\end{array}$ & $\mathrm{NO}_{2}$ & $\begin{array}{l}\text { Full gestational } \\
\text { period }\end{array}$ & $0.90(0.80,1.02)^{\mathrm{b}}$ & & \\
\hline \multirow[t]{3}{*}{$\begin{array}{l}\text { Pedersen et al. } \\
(2017)\end{array}$} & \multirow[t]{3}{*}{$\begin{array}{l}\text { Prospective cohort } \\
\text { (Denmark) }\end{array}$} & \multirow[t]{3}{*}{72,745} & 1,880 & $\begin{array}{l}\text { Preeclampsia } \\
\text { (all cases) }\end{array}$ & $\mathrm{NO}_{2}$ & $\begin{array}{l}\text { Full gestational } \\
\text { period }\end{array}$ & $1.08(1.01,1.15)$ & \multirow[t]{3}{*}{$11.5(6.7) \mu \mathrm{g} / \mathrm{m}^{3}$} & \multirow{3}{*}{$\begin{array}{l}\text { Maternal age, parity, } \\
\text { BMI, height, } \\
\text { household income, } \\
\text { education, season of } \\
\text { conception, traffic } \\
\text { noise }\end{array}$} \\
\hline & & & 765 & $\begin{array}{l}\text { Gestational } \\
\text { hypertension }\end{array}$ & $\mathrm{NO}_{2}$ & $\begin{array}{l}\text { Full gestational } \\
\text { period }\end{array}$ & $1.01(0.91,1.13)$ & & \\
\hline & & & 2,430 & $\begin{array}{l}\text { Combined } \\
\text { hypertensive } \\
\text { disorders of } \\
\text { pregnancy }\end{array}$ & $\mathrm{NO}_{2}$ & $\begin{array}{l}\text { Full gestational } \\
\text { period }\end{array}$ & $1.07(1.01,1.14)^{\mathrm{c}}$ & & \\
\hline
\end{tabular}


Systematic Review of TRAP and Hypertensive Disorders of Pregnancy

\begin{tabular}{|c|c|c|c|c|c|c|c|c|c|}
\hline Study & $\begin{array}{l}\text { Study Design } \\
\text { (Location) }\end{array}$ & $\begin{array}{l}\text { Sample } \\
\text { Size }\end{array}$ & $\begin{array}{c}\text { Cases } \\
\text { Included in } \\
\text { Analysis }\end{array}$ & Outcome & Exposure & $\begin{array}{l}\text { Exposure } \\
\text { Period }\end{array}$ & $\begin{array}{c}\text { OR } \\
(95 \% \mathrm{CI})^{*}\end{array}$ & $\begin{array}{c}\text { Mean (SD) } \\
\text { Exposure Levels }\end{array}$ & $\begin{array}{l}\text { Covariates Included } \\
\text { in Final Model }\end{array}$ \\
\hline $\begin{array}{l}\text { Pereira et al. } \\
(2013)\end{array}$ & $\begin{array}{l}\text { Retrospective } \\
\text { cohort (Perth, } \\
\text { Australia) }\end{array}$ & 23,452 & 943 & Preeclampsia & $\mathrm{NO}_{2}$ & $\begin{array}{l}\text { Full gestational } \\
\text { period }\end{array}$ & $1.11(0.99,1.25)$ & $\begin{array}{l}23.04(4.14) \mathrm{ppb} \\
{[43.32} \\
\left.(7.8) \mu \mathrm{g} / \mathrm{m}^{3}\right]\end{array}$ & $\begin{array}{l}\text { Maternal age, diabetes, } \\
\text { aboriginal status, } \\
\text { parity, season of } \\
\text { conception, smoking, } \\
\text { area socioeconomic } \\
\text { status }\end{array}$ \\
\hline \multirow[t]{5}{*}{$\begin{array}{l}\text { Savitz et al. } \\
(2015)\end{array}$} & \multirow{5}{*}{$\begin{array}{l}\text { Retrospective } \\
\text { cohort (New York } \\
\text { City, USA) }\end{array}$} & \multirow[t]{5}{*}{268,601} & 4,226 & $\begin{array}{l}\text { Severe } \\
\text { preeclampsia }\end{array}$ & $\mathrm{NO}_{2}$ & Trimesters 1,2 & $0.97(0.94,1.01)$ & \multirow[t]{5}{*}{$\begin{array}{l}\text { Pooled mean not } \\
\text { reported }^{c}\end{array}$} & \multirow{5}{*}{$\begin{array}{l}\text { Maternal age, } \\
\text { ethnicity, education, } \\
\text { Medicaid status, parity, } \\
\text { conception year, social } \\
\text { deprivation index, } \\
\text { BMI, BMI }{ }^{2} \text {, and } \\
\text { hospital of delivery }\end{array}$} \\
\hline & & & 6,940 & $\begin{array}{l}\text { Mild } \\
\text { preeclampsia }\end{array}$ & $\mathrm{NO}_{2}$ & Trimesters 1,2 & $0.95(0.92,0.98)$ & & \\
\hline & & & 11,166 & $\begin{array}{l}\text { Combined mild } \\
\text { and severe } \\
\text { preeclampsia }\end{array}$ & $\mathrm{NO}_{2}$ & Trimesters 1,2 & $0.96(0.94,0.98)^{\mathrm{d}}$ & & \\
\hline & & & 5,834 & $\begin{array}{l}\text { Gestational } \\
\text { hypertension }\end{array}$ & $\mathrm{NO}_{2}$ & Trimesters 1,2 & $0.98(0.94,1.02)$ & & \\
\hline & & & 17,000 & $\begin{array}{l}\text { Combined } \\
\text { hypertensive } \\
\text { disorders of } \\
\text { pregnancy }\end{array}$ & $\mathrm{NO}_{2}$ & Trimesters 1,2 & $0.96(0.95,0.98)^{\mathrm{f}}$ & & \\
\hline \multirow{3}{*}{$\begin{array}{l}\text { van den } \\
\text { Hooven et al. } \\
(2011)\end{array}$} & \multirow{3}{*}{$\begin{array}{l}\text { Prospective cohort } \\
\text { (Rotterdam, } \\
\text { Netherlands) }\end{array}$} & 6,518 & 250 & Preeclampsia & $\mathrm{NO}_{2}$ & $\begin{array}{l}\text { Full gestational } \\
\text { period }\end{array}$ & $1.23(0.75,2.02)$ & \multirow[t]{3}{*}{$39.9(4.2) \mu \mathrm{g} / \mathrm{m}^{3}$} & \multirow{3}{*}{$\begin{array}{l}\text { Maternal age, height, } \\
\text { weight, parity, } \\
\text { ethnicity, education, } \\
\text { folic acid } \\
\text { supplementation, } \\
\text { smoking, alcohol use, } \\
\text { gestational age, road } \\
\text { traffic noise exposure }\end{array}$} \\
\hline & & 6,626 & 141 & $\begin{array}{l}\text { Pregnancy- } \\
\text { induced } \\
\text { hypertension }\end{array}$ & $\mathrm{NO}_{2}$ & $\begin{array}{l}\text { Full gestational } \\
\text { period }\end{array}$ & $1.21(0.83,1.77)$ & & \\
\hline & & 6,626 & 391 & $\begin{array}{l}\text { Combined } \\
\text { hypertensive } \\
\text { disorders of } \\
\text { pregnancy }\end{array}$ & $\mathrm{NO}_{2}$ & $\begin{array}{l}\text { Full gestational } \\
\text { period }\end{array}$ & $1.22(0.90,1.65)^{\mathrm{g}}$ & & \\
\hline
\end{tabular}




\begin{tabular}{|c|c|c|c|c|c|c|c|c|c|}
\hline Study & $\begin{array}{l}\text { Study Design } \\
\text { (Location) }\end{array}$ & $\begin{array}{l}\text { Sample } \\
\text { Size }\end{array}$ & $\begin{array}{c}\text { Cases } \\
\text { Included in } \\
\text { Analysis }\end{array}$ & Outcome & Exposure & $\begin{array}{l}\text { Exposure } \\
\text { Period }\end{array}$ & $\begin{array}{c}\text { OR } \\
(95 \% \mathrm{CI})^{*}\end{array}$ & $\begin{array}{c}\text { Mean (SD) } \\
\text { Exposure Levels }\end{array}$ & $\begin{array}{c}\text { Covariates Included } \\
\text { in Final Model }\end{array}$ \\
\hline \multirow[t]{2}{*}{$\begin{array}{l}\text { Wu et al. } \\
(2011)^{\mathrm{i}}\end{array}$} & $\begin{array}{l}\text { Retrospective } \\
\text { cohort } \\
\text { (Los Angeles } \\
\text { County, USA) }\end{array}$ & $\begin{array}{l}\text { Not } \\
\text { reported }^{\text {h }}\end{array}$ & 1,303 & Preeclampsia & $\mathrm{NO}_{2}$ & $\begin{array}{l}\text { Full gestational } \\
\text { period }\end{array}$ & $1.13(1.01,1.25)$ & $\begin{array}{l}28.6(6.0) \mathrm{ppb} \\
{[53.77} \\
\left.(11.3) \mu \mathrm{g} / \mathrm{m}^{3}\right]\end{array}$ & \multirow{2}{*}{$\begin{array}{l}\text { Maternal age, } \\
\text { race/ethnicity, parity, } \\
\text { diabetes, prenatal care } \\
\text { insurance type, } \\
\text { poverty, season of } \\
\text { conception }\end{array}$} \\
\hline & $\begin{array}{l}\text { Retrospective } \\
\text { cohort (Orange } \\
\text { County, USA) }\end{array}$ & $\begin{array}{c}\text { Not } \\
\text { reported }^{\text {h }}\end{array}$ & 1,139 & Preeclampsia & $\mathrm{NO}_{2}$ & $\begin{array}{l}\text { Full gestational } \\
\text { period }\end{array}$ & $1.01(0.93,1.10)$ & $\begin{array}{l}27.5(7.7) \mathrm{ppb} \\
{[51.7} \\
\left.(14.5) \mu \mathrm{g} / \mathrm{m}^{3}\right]\end{array}$ & \\
\hline
\end{tabular}

*All ORs were converted to a $10 \mu \mathrm{g} / \mathrm{m}^{3}$ increase before analysis. The numbers in parentheses were calculated by the authors of monograph.

${ }^{a}$ Dadvand et al. (2013) and Pedersen et al. (2017) reported median (IQR) levels of $\mathrm{NO}_{2}$ and $\mathrm{NO}_{x}$.

${ }^{b}$ This effect estimate was calculated by combining the preeclampsia and hypertensive during pregnancy values that were reported by Madsen et al. (2018).

${ }^{c}$ This effect estimate was calculated by combining the preeclampsia (all cases) and gestational hypertension values that were reported by Pedersen et al. (2017).

dThis effect estimate was calculated by combining the severe and mild preeclampsia values that were reported by Savitz et al. (2015).

eSavitz et al. (2015) reported mean $\mathrm{NO}_{2}$ exposures for trimester 1 and trimester 2 separately.

${ }^{\mathrm{f}}$ This effect estimate was calculated by combining the severe preeclampsia, mild preeclampsia, and gestational hypertension values that were reported by Savitz et al. (2015).

gThis effect estimate was calculated by combining the preeclampsia and pregnancy-induced hypertension values that were reported by van den Hooven et al. (2011).

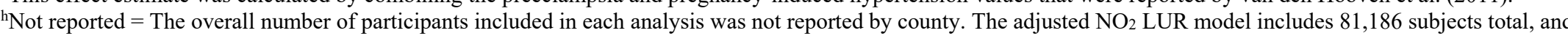
the $\mathrm{NO}_{\mathrm{x}}$.

${ }^{i}$ CALINE4 model included 79,629 individuals total. 
Systematic Review of TRAP and Hypertensive Disorders of Pregnancy

Table 11. Pooled ORs and 95\% CIs for Full Gestational Period TRAP-related $\mathrm{NO}_{2}$ Exposures and Hypertensive Disorders of Pregnancy

\begin{tabular}{|c|c|c|c|c|}
\hline \multirow[b]{2}{*}{ Outcome } & \multirow[b]{2}{*}{$\begin{array}{c}\text { Number of } \\
\text { Results }\end{array}$} & \multirow{2}{*}{$\begin{array}{c}\text { OR }(95 \% \mathrm{CI}) \\
\text { per } 10 \mu \mathrm{g} / \mathrm{m}^{3} \text { increase }\end{array}$} & \multicolumn{2}{|c|}{ Heterogeneity } \\
\hline & & & P Value* & $\mathbf{I}^{2}$ \\
\hline $\begin{array}{l}\text { Hypertensive Disorders of } \\
\text { Pregnancy }\end{array}$ & 8 & $1.03(0.97,1.09)$ & $<0.001$ & $74 \%$ \\
\hline Preeclampsia ${ }^{\mathrm{c}}$ & 8 & $1.04(0.97,1.10)$ & 0.001 & $73 \%$ \\
\hline $\begin{array}{l}\text { Hypertensive Disorders of } \\
\text { Pregnancy } \\
\text { [excluding Savitz et al. } \\
(2015) \text { ] }\end{array}$ & 7 & $1.05(1.01,1.09)$ & 0.085 & $46 \%$ \\
\hline $\begin{array}{l}\text { Preeclampsia }^{\mathrm{d}} \\
\text { [excluding Savitz et al. } \\
\text { (2015)] }\end{array}$ & 7 & $1.06(1.02,1.11)$ & 0.299 & $17 \%$ \\
\hline
\end{tabular}

*P value for test for heterogeneity. When significant $(\mathrm{p}<0.05)$, the random-effects model results are presented. When nonsignificant, the random-effects model results are identical to the fixed-effects model results.

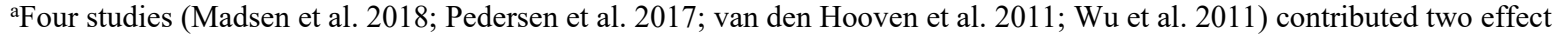
estimates each to the analysis.

${ }^{\mathrm{b}}$ One study (Savitz et al. 2015) contributed three effect estimates to the analysis.

${ }^{\mathrm{c}}$ Two studies (Savitz et al. 2015; Wu et al. 2011) contributed two effect estimates each to the analysis.

${ }^{\mathrm{d}}$ One study (Wu et al. 2011) contributed two effect estimates to the analysis. 


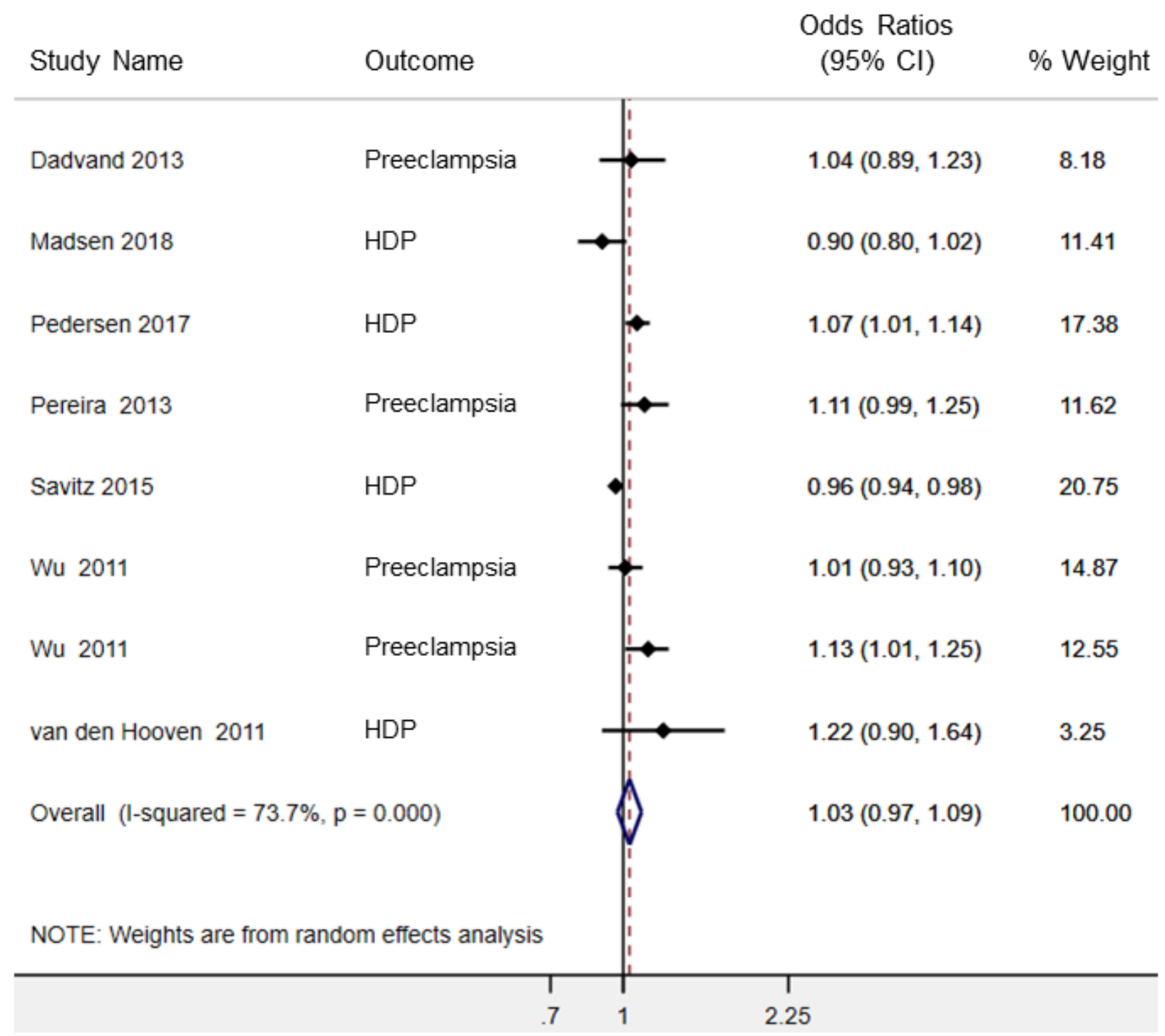

Figure 13. Full Gestation Exposure to $\mathrm{NO}_{2}$ and Hypertensive Disorders of Pregnancy ${ }^{\mathrm{a}}$

When $\mathrm{I}^{2} \mathrm{p}$ value is significant $(\mathrm{p}<0.05)$, the random-effects model results are presented. When nonsignificant, the random-effects model results are identical to the fixed-effects model results.

HDP $=$ hypertensive disorders of pregnancy.

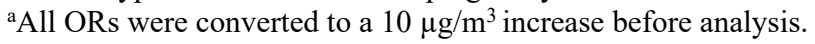




Study Name
Dadvand 2013
Madsen 2018
Pedersen 2017
Pereira 2013
Savitz 2015
Wu 2011
Wu 2011

Figure 14. Full Gestation Exposure to $\mathrm{NO}_{2}$ and Preeclampsia ${ }^{a}$

When $\mathrm{I}^{2} \mathrm{p}$ value is significant $(\mathrm{p}<0.05)$, the random-effects model results are presented. When nonsignificant, the random-effects model results are identical to the fixed-effects model results.

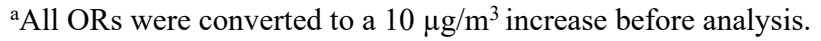




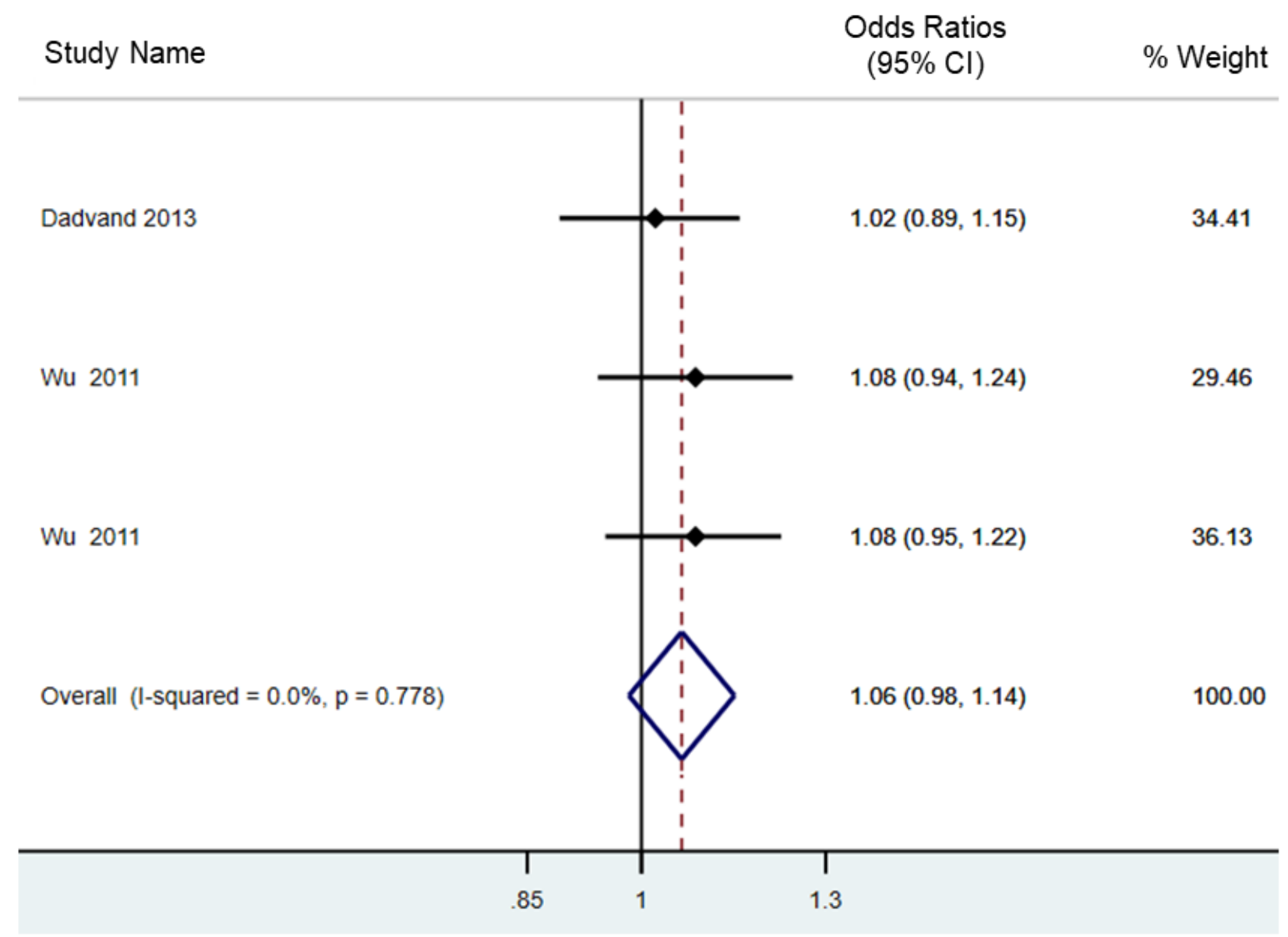

Figure 15. Full Gestation Exposure to $\mathrm{NO}_{\mathrm{x}}$ and Preeclampsia ${ }^{\mathrm{a}}$

When $\mathrm{I}^{2} \mathrm{p}$ value is significant $(\mathrm{p}<0.05)$, the random-effects model results are presented. When nonsignificant, the random-effects model results are identical to the fixed-effects model results.

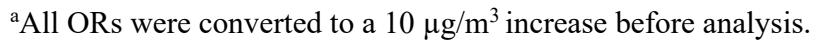

\section{Risk-of-bias Considerations}

The $\mathrm{NO}_{2}$ and $\mathrm{NO}_{x}$ studies were generally rated probably low or definitely low across all risk-ofbias domains, including the key risk-of-bias questions, as shown in the risk-of-bias heatmap (Figure 16) and bar chart (Figure 17). Therefore, confidence in the body of evidence for $\mathrm{NO}_{2}$ and $\mathrm{NO}_{\mathrm{x}}$ was not changed for risk of bias. The key risk-of-bias considerations are discussed below, and the study-specific rating details can be found in HAWC (https://hawcproject.org/assessment/60/) (NTP 2019a). 


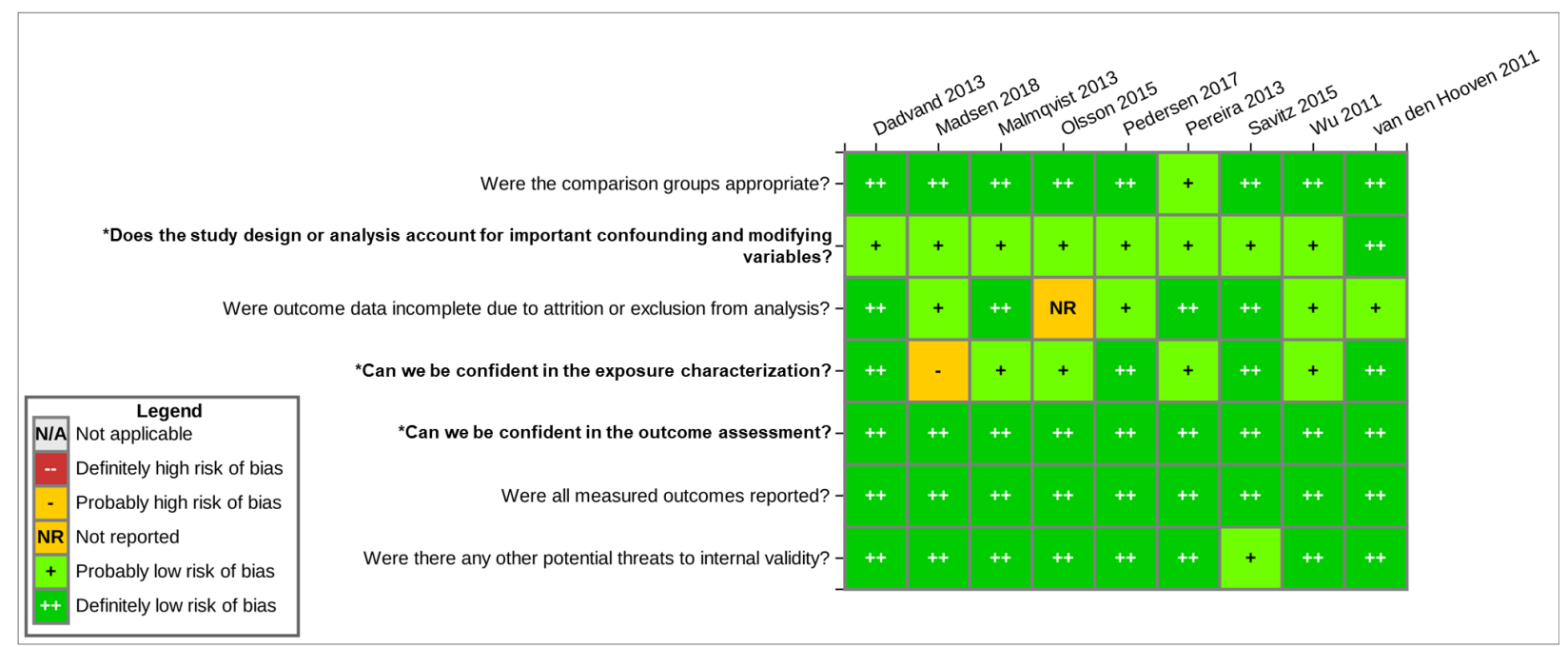

Figure 16. Risk-of-bias Heatmap: $\mathrm{NO}_{\mathrm{x}}$ and Hypertensive Disorders of Pregnancy

Interactive figure and additional study details in HAWC (NTP, 2019a).

*Questions in bold are the key risk-of-bias questions for human epidemiological studies. These key questions relate to areas of bias that may have a greater impact on estimates of the overall effect size and are generally considered to have a greater effect on the credibility of study results in environmental health studies.

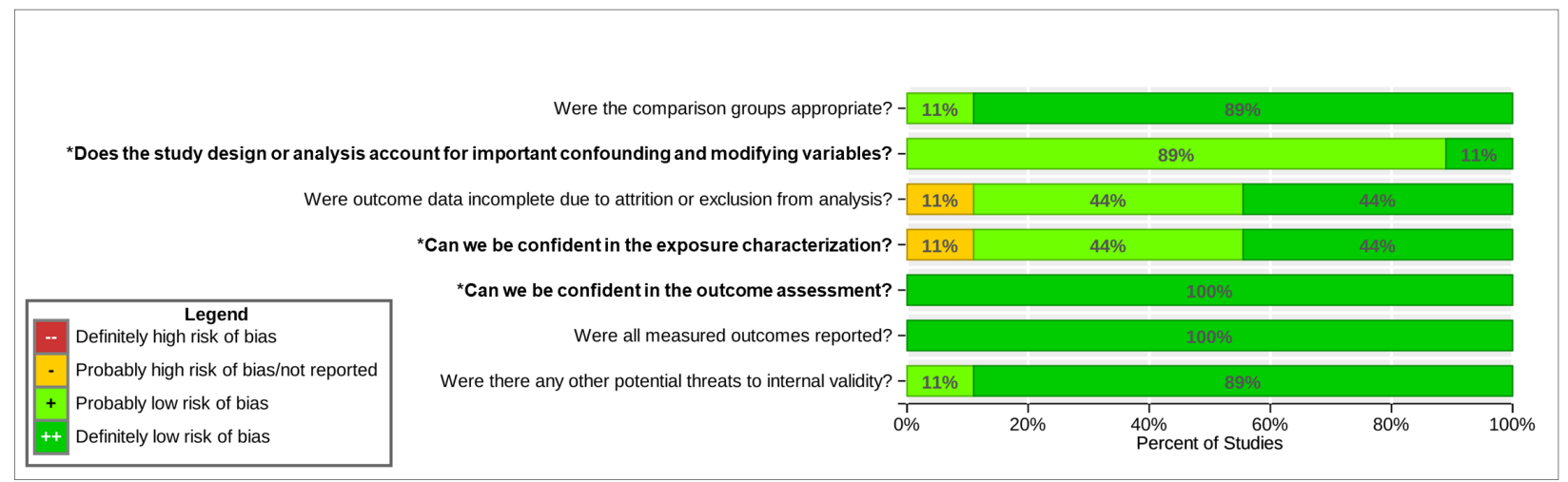

Figure 17. Risk-of-bias Bar Chart: $\mathrm{NO}_{\mathrm{x}}$ and Hypertensive Disorders of Pregnancy

Interactive figure and additional study details in HAWC (NTP, 2019a).

*Questions in bold are the key risk-of-bias questions for human epidemiological studies. These key questions relate to areas of bias that may have a greater impact on estimates of the overall effect size and are generally considered to have a greater effect on the credibility of study results in environmental health studies.

\section{Exposure Characterization}

Overall, the exposure measurements were well characterized for the assessment of $\mathrm{NO}_{2}$ and $\mathrm{NO}_{\mathrm{x}}$. Most studies utilized LUR models or air dispersion-based models that used dense monitoring networks to allow for high temporal and spatial resolution. There was reasonable alignment between the exposure and outcome data, and appropriate adjustments were made to account for temporal trends in pollutants between the monitoring period and the study period. Residential mobility information was included in four studies (Madsen et al. 2018; Malmqvist et al. 2013; Pedersen et al. 2017; Pereira et al. 2013) and, of those, the three that performed sub-analyses (Madsen et al. 2018; Pedersen et al. 2017; Pereira et al. 2013) found slightly stronger associations between $\mathrm{NO}_{2}$ or $\mathrm{NO}_{\mathrm{x}}$ exposures and hypertensive disorders of pregnancy in 
nonmovers compared with those who had moved to a different location during pregnancy. The other studies included in these analyses did not account for residential mobility, and there may be some exposure misclassification as a result. In addition, the LUR model used in the Wu et al. (2011) study was developed based on data from Los Angeles, but the model was used to estimate $\mathrm{NO}_{2}$ concentrations in both Los Angeles and Orange Counties. Consequently, there might be exposure misclassification in the Orange County study which may contribute to the lack of statistical significance between $\mathrm{NO}_{2}$ exposure and preeclampsia for this cohort. There were no other concerns about exposure characterization in the body of evidence for $\mathrm{NO}_{2}$ or $\mathrm{NO}_{\mathrm{x}}$ exposures.

\section{Outcome Assessment}

As discussed in the $\mathrm{PM}_{2.5}$ section, chronic hypertension was usually excluded from the analyses by the study authors, but this is difficult to do with certainty, and outcome misclassification is likely to occur in the "noncases," resulting in bias for the effect estimates toward the null. In addition, the apparent effect of the delivery hospital on associations between $\mathrm{NO}_{2}$ exposure and hypertensive disorders of pregnancy is not entirely clear but may reflect differences in coding of hypertensive disorders of pregnancy across hospitals. As indicated in the $\mathrm{PM}_{2.5}$ section, the additional adjustment for delivery hospital is likely not necessary when evaluating severe preeclampsia or combined hypertensive disorders of pregnancy because outcome misclassification is less of a concern in these analyses. Estimates using fully adjusted models (including delivery hospital) were included in the meta-analyses and contributed over $20 \%$ to the overall effect estimate. Because the standard adjusted models showed positive associations for several outcomes, the overall effect size would be slightly larger (and would have reached statistical significance) if those estimates were included in the meta-analyses.

\section{Confounding and Modifying Variables}

Potential confounders are provided in tables for this report. All of the studies considered the standard covariates that are thought to be associated with hypertensive disorders of pregnancy (e.g., maternal age, race/ethnicity, socioeconomic status [SES]). Most studies adjusted for smoking and BMI, and the few studies that did not make those adjustments could have biased the results in opposing directions; however, given the consistency of the data and the fact that no single study significantly influenced the meta-analyses, these studies did not affect the overall confidence in the conclusions. There were no concerns over the internal validity or other factors that would increase or decrease the confidence in the body of evidence.

\section{Summary}

The few risk-of-bias concerns within the same studies potentially biased the results toward and away from the null. Given the general consistency of effects across studies despite the different directions of bias, the results support the likelihood of a true association between exposure to $\mathrm{NO}_{\mathrm{x}}$ during pregnancy and hypertensive disorders of pregnancy. For all remaining risk-of-bias questions in all other individual studies that evaluated $\mathrm{NO}_{\mathrm{x}}$, there was low risk of bias and, thus, no major concerns over the internal validity of the reported results that would decrease the overall confidence in the body of evidence.

\section{Experimental Animal Studies for $\mathbf{N O}_{2}$ or $\mathbf{N O}_{\mathbf{x}}$}

There were no animal data evaluating associations between $\mathrm{NO}_{2}$ or $\mathrm{NO}_{\mathbf{x}}$ exposures and hypertensive disorders of pregnancy that met the PECO criteria for this assessment. 


\section{Evidence Synthesis for Studies of $\mathrm{NO}_{2}$ or $\mathrm{NO}_{x}$}

Traffic-related $\mathrm{NO}_{2}$ or $\mathrm{NO}_{x}$ exposures are consistently associated with increased risk of hypertensive disorders of pregnancy in the available human studies. Because $\mathrm{NO}_{2}$ is a better indicator of anthropogenic $\mathrm{NO}_{x}$ contributions, the hazard conclusions are based on the $\mathrm{NO}_{2}$ data. There is moderate confidence in the body of evidence that exposure to traffic-related $\mathrm{NO}_{2}$ during the entire gestation period is associated with an increased risk for hypertensive disorders of pregnancy. The effect estimate for the main meta-analysis is 1.03 (95\% CI: 0.97, 1.09) for risk of hypertensive disorders of pregnancy during the full gestation $\mathrm{NO}_{2}$ exposure. No animal studies were identified. The confidence ratings are summarized below.

- Human body of evidence: Moderate confidence

- Animal body of evidence: No studies

The human body of evidence presents a consistent pattern of findings that exposure to higher levels of traffic-related $\mathrm{NO}_{2}$ or $\mathrm{NO}_{\mathrm{x}}$ is associated with the development of hypertensive disorders of pregnancy and supports a moderate confidence rating.

\section{Other Pollutants and Hypertensive Disorders of Pregnancy}

Three additional TRAP components were identified in the literature that met the inclusion criteria: carbon monoxide (CO), elemental carbon (EC), and black carbon (BC). CO is produced in the incomplete combustion of carbon-containing fuels, and vehicle emissions represent the largest anthropogenic source of CO in the United States. EC that is attributable to traffic (ECAT) is generated from traffic-related diesel combustion. $\mathrm{BC}$ is a component of fine PM consisting of several linked forms of pure carbon and is formed through the incomplete combustion of a variety of sources, including fossil fuels, biofuels, and biomass. The available evidence for these exposures was limited: Three studies evaluated carbon monoxide, two studies evaluated $\mathrm{BC}$, and one study evaluated EC. The studies evaluated associations between these exposures and preeclampsia, gestational hypertension, combined hypertensive disorders of pregnancy, or blood pressure changes.

\section{Human and Experimental Animal Health Effects for CO, ECAT, and BC}

\section{Summary}

There were too few studies to conduct a full evaluation on these bodies of evidence for either $\mathrm{CO}$, ECAT, or BC. The following section describes the available evidence for all three TRAP components (Table 12; Table 13).

\section{Overview of Available Data and Summary of Carbon Monoxide, Elemental Carbon Attributable to Traffic, and Black Carbon Findings}

Two human studies (three cohorts) and one animal study in the body of evidence evaluated the association between exposure to $\mathrm{CO}$ and health outcomes of interest. The human studies (Rudra et al. 2011; Wu et al. 2011) were conducted in the United States and evaluated preeclampsia. The single animal study measured changes in blood pressure in mice (Venditti et al. 2014). The data from the human studies are inadequate to evaluate whether exposure to $\mathrm{CO}$ is related to hypertension in pregnancy due to the paucity of studies and inconclusive findings across studies. Wu et al. (2011) reported a positive association for $\mathrm{CO}$ exposure measured by monitors and preeclampsia in the Los Angeles County cohort (OR: 1.11, 95\% CI: 1.03, 1.91 per IQR 
increase); however, the OR was close to unity in the Orange County cohort. In a study in Washington State, no association was found between predicted periconceptional CO exposure and preeclampsia in a statistical model that adjusted for year of conception, although a positive association was found using a statistical model adjusting for other factors but not year of conception (OR: 0.98, 95\% CI: 0.91, 1.06 per 0.1 CO ppm increase) (Rudra et al. (2011)). It is unclear whether adjusting for conception year was appropriate because both the incidence of preeclampsia and $\mathrm{CO}$ concentrations had decreased over time. The experimental animal study found decreased blood pressure following CO exposure in mice (Venditti et al. 2014), which is consistent with known vasodilatory effects of $\mathrm{CO}$. However, it is important to note that the objective for that animal study was to determine the effectiveness of CO in decreasing blood pressure in a hypertensive pregnant mouse model rather than to determine if $\mathrm{CO}$ affected blood pressure in normotensive pregnant mice. The risk-of-bias ratings for the two human studies were generally rated probably low or definitely low risk of bias, and any potential threats to bias were unclear (likely directed toward and away from the null) (Figure D-2 and Figure D-4). The animal study was rated probably high risk of bias for five of the nine domains, although the exposure was well characterized (Figure D-1 and Figure D-3).

In addition to $\mathrm{CO}$, one study conducted in Ohio evaluated associations between ECAT exposure and blood pressure or hypertensive disorders of pregnancy (Sears et al. 2018). Systolic blood pressure in late pregnancy was significantly associated with ECAT exposures; however, no significant associations were observed between ECAT and hypertensive disorders of pregnancy in the same study (Sears et al. 2018). Two U.S. studies (Assibey-Mensah et al. 2019; Choe et al. 2018) evaluated BC exposure and gestation hypertension, preeclampsia, or combined hypertensive disorders of pregnancy (Assibey-Mensah et al. 2019; Choe et al. 2018). No significant associations were found between exposure to $\mathrm{BC}$ and hypertensive disorders of pregnancy for two studies that evaluated these associations for each trimester (Assibey-Mensah et al. 2019; Choe et al. 2018) or gestational month (Assibey-Mensah et al. 2019). There were no major risk-of-bias concerns for most of the domains for these studies, although there was a probably high risk of bias for the exposure characterization in one study (Assibey-Mensah et al. 2019) because the monitoring network may not have been sufficiently dense for this evaluation. Overall, the data were inconsistent across studies, or the small number of studies precluded the ability to draw meaningful conclusions. As such, additional evaluation of this body of evidence was not conducted. 
Table 12. Studies on Hypertensive Disorders of Pregnancy with TRAP-related CO, ECAT, and BC Exposure in Humans

\begin{tabular}{|c|c|c|c|c|c|c|c|c|c|c|}
\hline Study & $\begin{array}{c}\text { Study Design } \\
\text { (Location) } \\
\text { Exposure } \\
\text { Measure }\end{array}$ & Outcome & Exposure & Exposure Period & Sample Size & Cases & OR $(95 \%$ CI $)$ & Unit Increase & $\begin{array}{c}\text { Mean (SD) } \\
\text { Exposure Level }\end{array}$ & $\begin{array}{l}\text { Covariates } \\
\text { Considered for } \\
\text { Inclusion }\end{array}$ \\
\hline \multirow{9}{*}{$\begin{array}{l}\text { Assibey- } \\
\text { Mensah et } \\
\text { al. (2019) }\end{array}$} & \multirow{9}{*}{$\begin{array}{l}\text { Retrospective } \\
\text { cohort } \\
\text { (Monroe County, } \\
\text { New York, USA) } \\
\text { Land use } \\
\text { regression } \\
\text { models }\end{array}$} & \multirow{9}{*}{$\begin{array}{l}\text { Hypertensive } \\
\text { disorders of } \\
\text { pregnancy }\end{array}$} & \multirow{9}{*}{$\begin{array}{l}\text { Black } \\
\text { carbon }\end{array}$} & Month 1 & 4,726 & 387 & $1.03(0.90-1.17)$ & \multirow[t]{9}{*}{ Per $0.86 \mu \mathrm{g} / \mathrm{m}^{3^{*}}$} & \multirow[t]{9}{*}{$1.14(0.75) \mu \mathrm{g} / \mathrm{m}^{3 \mathrm{~b}}$} & \multirow{9}{*}{$\begin{array}{l}\text { Parity, multi-fetal } \\
\text { gestation, pre- } \\
\text { pregnancy diabetes, } \\
\text { gestational diabetes, } \\
\text { maternal age, } \\
\text { race/ethnicity, } \\
\text { education, paternity } \\
\text { acknowledgement, } \\
\text { BMI, year and } \\
\text { season of conception, } \\
\text { birth hospital, } \\
\text { prenatal care } \\
\text { received, trimester } \\
\text { prenatal care began, } \\
\text { Medicaid-funded } \\
\text { delivery, smoking, } \\
\text { alcohol consumption, } \\
\text { average relative } \\
\text { humidity, average } \\
\text { relative temperature }\end{array}$} \\
\hline & & & & Month 2 & 5,069 & 401 & $1.07(0.94-1.23)$ & & & \\
\hline & & & & Month 3 & 5,261 & 402 & $1.12(0.98-1.28)$ & & & \\
\hline & & & & Month 4 & 5,246 & 403 & $0.97(0.85-1.12)$ & & & \\
\hline & & & & Month 5 & 5,224 & 407 & $1.04(0.91-1.19)$ & & & \\
\hline & & & & Month 6 & 5,017 & 394 & $1.05(0.91-1.20)$ & & & \\
\hline & & & & Month 7 & 4,688 & 375 & $1.12(0.96-1.29)$ & & & \\
\hline & & & & Month 8 & 4,327 & 339 & $1.04(0.89-1.21)$ & & & \\
\hline & & & & Month 9 & 3,777 & 267 & $0.89(0.74-1.06)$ & & & \\
\hline \multirow{6}{*}{$\begin{array}{l}\text { Choe et al. } \\
(2018)\end{array}$} & \multirow{6}{*}{$\begin{array}{l}\text { Retrospective } \\
\text { cohort } \\
\text { (Rhode Island) } \\
\text { Land use } \\
\text { regression } \\
\text { models }\end{array}$} & \multirow[t]{3}{*}{ Preeclampsia } & \multirow{3}{*}{$\begin{array}{l}\text { Black } \\
\text { carbon }\end{array}$} & Trimester 1 & \multirow[t]{3}{*}{61,640} & \multirow[t]{3}{*}{2,221} & $0.98(0.92-1.06)$ & Per $0.13 \mu \mathrm{g} / \mathrm{m}^{3}$ & \multirow[t]{6}{*}{$0.5(0.1) \mu \mathrm{g} / \mathrm{m}^{3}$} & \multirow{6}{*}{$\begin{array}{l}\text { Maternal age, parity, } \\
\text { race, education, } \\
\text { marital status, health } \\
\text { insurance status, } \\
\text { tobacco use, } \\
\text { neighborhood } \\
\text { socioeconomic } \\
\text { status, year of last } \\
\text { menstrual period }\end{array}$} \\
\hline & & & & Trimester 2 & & & $1.03(0.95-1.10)$ & $\begin{array}{l}\text { Undefined IQR } \\
\text { increase }\end{array}$ & & \\
\hline & & & & Trimester 3 & & & $0.94(0.88-1.01)$ & $\begin{array}{l}\text { Undefined IQR } \\
\text { increase }\end{array}$ & & \\
\hline & & \multirow{3}{*}{$\begin{array}{l}\text { Gestational } \\
\text { hypertension }\end{array}$} & \multirow{3}{*}{$\begin{array}{l}\text { Black } \\
\text { carbon }\end{array}$} & Trimester 1 & \multirow[t]{3}{*}{61,640} & \multirow[t]{3}{*}{2,877} & $0.95(0.89-1.01)$ & Per $0.13 \mu \mathrm{g} / \mathrm{m}^{3}$ & & \\
\hline & & & & Trimester 2 & & & $0.97(0.91-1.04)$ & $\begin{array}{l}\text { Undefined IQR } \\
\text { increase }\end{array}$ & & \\
\hline & & & & Trimester 3 & & & $0.95(0.90-1.01)$ & $\begin{array}{l}\text { Undefined IQR } \\
\text { increase }\end{array}$ & & \\
\hline
\end{tabular}


Systematic Review of TRAP and Hypertensive Disorders of Pregnancy

\begin{tabular}{|c|c|c|c|c|c|c|c|c|c|c|}
\hline Study & $\begin{array}{c}\text { Study Design } \\
\text { (Location) } \\
\text { Exposure } \\
\text { Measure }\end{array}$ & Outcome & Exposure & Exposure Period & Sample Size & Cases & OR (95\% CI) & Unit Increase & $\begin{array}{c}\text { Mean (SD) } \\
\text { Exposure Level }^{\mathrm{a}}\end{array}$ & $\begin{array}{l}\text { Covariates } \\
\text { Considered for } \\
\text { Inclusion }\end{array}$ \\
\hline $\begin{array}{l}\text { Rudra et } \\
\text { al. (2011) }\end{array}$ & $\begin{array}{l}\text { Prospective } \\
\text { cohort } \\
\text { (Western } \\
\text { Washington, } \\
\text { USA) } \\
\text { Land use } \\
\text { regression } \\
\text { models }\end{array}$ & Preeclampsia & $\begin{array}{l}\text { Carbon } \\
\text { monoxide }\end{array}$ & Periconceptional $^{c}$ & 3,675 & 117 & $0.98(0.91-1.06)$ & Per $0.1 \mathrm{ppm}$ & $0.80(0.43) \mathrm{ppm}$ & $\begin{array}{l}\text { Maternal age, } \\
\text { nulliparity, BMI, } \\
\text { race/ethnicity, } \\
\text { education, marital } \\
\text { status, smoking, } \\
\text { household income, } \\
\text { employment in early } \\
\text { pregnancy, pre- } \\
\text { pregnancy } \\
\text { secondhand smoke, } \\
\text { physical activity, } \\
\text { history of asthma, } \\
\text { diabetes, chronic } \\
\text { hypertension, year, } \\
\text { and month of } \\
\text { conception }\end{array}$ \\
\hline $\begin{array}{l}\text { Sears et } \\
\text { al. }(2018)\end{array}$ & $\begin{array}{l}\text { Prospective } \\
\text { cohort } \\
\text { (Cincinnati, } \\
\text { Ohio, USA) } \\
\text { Land use } \\
\text { regression } \\
\text { models }\end{array}$ & $\begin{array}{l}\text { Hypertensive } \\
\text { disorders of } \\
\text { pregnancy }\end{array}$ & $\begin{array}{l}\text { Elemental } \\
\text { carbon } \\
\text { attributable } \\
\text { to traffic }\end{array}$ & $\begin{array}{l}\text { Full gestational } \\
\text { period }\end{array}$ & 370 & 35 & $0.7(0.5-1.2)$ & Per $0.16 \mu \mathrm{g} / \mathrm{m}^{3}$ & $0.37(0.16) \mu \mathrm{g} / \mathrm{m}^{3}$ & $\begin{array}{l}\text { Maternal age, race, } \\
\text { education, marital } \\
\text { status, tobacco } \\
\text { smoke exposure, } \\
\text { BMI, parity, income, } \\
\text { gestational age, } \\
\text { exposure to traffic } \\
\text { noise, season of } \\
\text { conception, } \\
\text { neighborhood } \\
\text { socioeconomic status }\end{array}$ \\
\hline $\begin{array}{l}\text { Wu et al. } \\
(2011)\end{array}$ & $\begin{array}{l}\text { Retrospective } \\
\text { cohort } \\
\text { (Los Angeles } \\
\text { County, USA) } \\
\text { CALINE } 4 \text { air } \\
\text { dispersion } \\
\text { models }\end{array}$ & Preeclampsia & $\begin{array}{l}\text { Carbon } \\
\text { monoxide }\end{array}$ & $\begin{array}{l}\text { Full gestational } \\
\text { period }\end{array}$ & 38,709 & 1,303 & $1.11(1.03-1.19)$ & Per 0.4 ppm & $0.9(0.4) \mathrm{ppm}$ & $\begin{array}{l}\text { Maternal age, } \\
\text { race/ethnicity, parity, } \\
\text { prenatal care } \\
\text { insurance type, } \\
\text { season of conception, } \\
\text { diabetes, poverty }\end{array}$ \\
\hline
\end{tabular}


Systematic Review of TRAP and Hypertensive Disorders of Pregnancy

\begin{tabular}{|c|c|c|c|c|c|c|c|c|c|c|}
\hline Study & $\begin{array}{c}\text { Study Design } \\
\text { (Location) } \\
\text { Exposure } \\
\text { Measure }\end{array}$ & Outcome & Exposure & Exposure Period & Sample Size & Cases & OR $(95 \%$ CI) & Unit Increase & $\begin{array}{c}\text { Mean (SD) } \\
\text { Exposure Level }^{\mathrm{a}}\end{array}$ & $\begin{array}{c}\text { Covariates } \\
\text { Considered for } \\
\text { Inclusion }\end{array}$ \\
\hline & $\begin{array}{l}\text { Retrospective } \\
\text { cohort } \\
\text { (Orange County, } \\
\text { USA) } \\
\text { CALINE } 4 \text { air } \\
\text { dispersion } \\
\text { models }\end{array}$ & Preeclampsia & $\begin{array}{l}\text { Carbon } \\
\text { monoxide }\end{array}$ & $\begin{array}{l}\text { Full gestational } \\
\text { period }\end{array}$ & 42,477 & 1,139 & $0.97(0.87-1.09)$ & Per 0.4 ppm & $0.6(0.3) \mathrm{ppm}$ & \\
\hline
\end{tabular}

*Effect estimates marked with an asterisk were reported per interquartile range increase.

aRudra et al. (2011) and Sears et al. (2018) reported median (IQR) levels of elemental carbon attributable to traffic

${ }^{b}$ Assibey-Mensah et al. (2019) reported mean (SD) values for gestational month 1 only.

cRudra et al. (2011) defined the periconceptional period as the 7 months surrounding conception. 
Table 13. Studies on Hypertensive Disorders of Pregnancy with TRAP-related CO, ECAT, and BC Exposure in Animals

\begin{tabular}{|c|c|c|c|c|c|c|c|c|}
\hline Study & $\begin{array}{l}\text { Species/ } \\
\text { Strain }\end{array}$ & Sample Size & Exposure & $\begin{array}{l}\text { Dose } \\
\text { Level }\end{array}$ & $\begin{array}{c}\text { Dose } \\
\text { Duration }\end{array}$ & Groups & $\begin{array}{l}\text { Endpoints } \\
\text { Measured }\end{array}$ & Findings \\
\hline \multirow[t]{6}{*}{$\begin{array}{l}\text { Venditti et } \\
\text { al. (2014) }\end{array}$} & $\begin{array}{l}\text { Pregnant } \\
\text { female CD- } \\
1 \text { mice }\end{array}$ & 6/group & $\begin{array}{l}\text { Ambient } \\
\text { carbon } \\
\text { monoxide }\end{array}$ & $250 \mathrm{ppm}$ & $\begin{array}{l}\text { Gestational } \\
\text { day } 10.5-15.5\end{array}$ & Untreated Control $\pm \mathrm{CO}$ & Proteinuria & $\begin{array}{l}\text { No significant difference in } \\
\text { proteinuria between unexposed } \\
\text { control and control+CO groups }\end{array}$ \\
\hline & & & & & & & $\begin{array}{l}\text { Systolic } \\
\text { blood } \\
\text { pressure }\end{array}$ & $\begin{array}{l}\text { No significant difference in systolic } \\
\text { blood pressure between control and } \\
\text { control+CO groups }\end{array}$ \\
\hline & & 12-18/group & $\begin{array}{l}\text { Ambient } \\
\text { carbon } \\
\text { monoxide }\end{array}$ & $250 \mathrm{ppm}$ & $\begin{array}{l}\text { Gestational } \\
\text { day } 10.5-15.5\end{array}$ & $\begin{array}{l}\text { AdsFlt-1-induced } \\
\text { preeclampsia (hypertension } \\
\text { and proteinuria) } \pm \mathrm{CO}\end{array}$ & Proteinuria & $\begin{array}{l}\text { Significant increase in proteinuria } \\
\text { in the AdsFlt-1-induced unexposed } \\
\text { group compared with the AdsFlt- } \\
1+\text { CO group }\end{array}$ \\
\hline & & & & & & & $\begin{array}{l}\text { Systolic } \\
\text { blood } \\
\text { pressure }\end{array}$ & $\begin{array}{l}\text { Significant increase in systolic } \\
\text { blood pressure in the AdsFlt-1- } \\
\text { induced unexposed group } \\
\text { compared with the AdsFlt-1+CO } \\
\text { group }\end{array}$ \\
\hline & & 7-9/group & $\begin{array}{l}\text { Ambient } \\
\text { carbon } \\
\text { monoxide }\end{array}$ & $250 \mathrm{ppm}$ & $\begin{array}{l}\text { Gestational } \\
\text { day } 10.5-15.5\end{array}$ & $\mathrm{AdEV} \pm \mathrm{CO}$ & Proteinuria & $\begin{array}{l}\text { No significant difference in } \\
\text { proteinuria between unexposed } \\
\text { AdEV and AdEV+CO groups }\end{array}$ \\
\hline & & & & & & & $\begin{array}{l}\text { Systolic } \\
\text { blood } \\
\text { pressure }\end{array}$ & $\begin{array}{l}\text { No significant difference in systolic } \\
\text { blood pressure between unexposed } \\
\text { AdEV and AdEV+CO groups }\end{array}$ \\
\hline
\end{tabular}




\section{Traffic Measures}

Traffic measures are surrogate indicators of exposure to TRAP. Traffic measures may include distance to main road, length of main streets with a buffer zone around homes or schools, and traffic volume. These measurements are relatively easy to obtain and often involve use of GISbased methods. One potential limitation of traffic measures is the lack of precision because often they do not account for meteorology, dispersion, and terrain (HEI 2010). However, information from studies evaluating associations between traffic measures and hypertensive disorders of pregnancy are still useful, particularly when evaluating potential effects of a combined TRAP exposure. Further, when considered with surrogates of traffic pollutants, traffic measures can strengthen the confidence in the body of evidence.

The following sections begin with a brief summary of the body of evidence followed by a narrative summary or meta-analysis of the human evidence and a confidence rating for the body of evidence. Because some studies evaluated multiple measures of TRAP, there are instances of overlap across studies.

\section{Traffic Measures and Hypertensive Disorders of Pregnancy}

Traffic density (i.e., number of vehicles per day on a given stretch of roadway) and proximity to a major road were the two traffic measures that were reported in the available literature. For the analyses that follow, traffic density and proximity to a major road were evaluated separately and then combined as "traffic measures" to determine associations with hypertensive disorders of pregnancy.

\section{Human Traffic Measures Data}

\section{Summary}

There is low confidence in the body of evidence that combined traffic measures is associated with an increased risk for hypertensive disorders of pregnancy. The nine studies identified (six cohort studies, one cross-sectional study, and two case-control studies (Choe et al. 2018; Madsen et al. 2018; Malmqvist et al. 2013; Miranda et al. 2013; Olsson et al. 2015; van den Hooven et al. 2009; Wu et al. 2011; Wu et al. 2016; Yorifuji et al. 2015)) reported consistent evidence of an association between traffic density and proximity to a major road and the risk for hypertensive disorders of pregnancy. There were small but positive ORs reported for associations between hypertensive disorders of pregnancy and living in close proximity to a major road or near hightraffic density regions during the entire pregnancy period (Figure 18). The initial confidence rating was moderate based on the six cohort studies included in the body of evidence that contained three out of four study design features (exposure prior to outcome, individual outcome data, comparison group used). The initial confidence was downgraded to low for imprecision because several studies reported positive but nonsignificant associations between hypertensive disorders of pregnancy and traffic measures. There were no other changes to the confidence rating after considering factors that may increase or decrease confidence.

\section{Overview of Available Human Data for Traffic Measures}

Table 14 summarizes the available data in the human body of evidence that evaluated the associations between exposure to traffic measures and the health outcomes of interest. Nine studies were identified that reported associations between traffic measures and hypertensive 
disorders of pregnancy (Choe et al. 2018; Madsen et al. 2018; Malmqvist et al. 2013; Miranda et al. 2013; Olsson et al. 2015; van den Hooven et al. 2009; Wu et al. 2011; Wu et al. 2016;

Yorifuji et al. 2015). The available evidence comprised four retrospective cohort studies (Choe et al. 2018; Olsson et al. 2015; Wu et al. 2011; Yorifuji et al. 2015), two prospective cohort studies (Madsen et al. 2018; van den Hooven et al. 2009), one cross-sectional study (Miranda et al. 2013), and two case-control studies (Malmqvist et al. 2013; Wu et al. 2016). Three studies were conducted in the United States (Choe et al. 2018; Miranda et al. 2013; Wu et al. 2011), one study was conducted in Japan (Yorifuji et al. 2015), and five studies were conducted in Europe.

All but one study (Miranda et al. 2013) evaluated preeclampsia. Miranda et al. (2013) only assessed gestational hypertension, and van den Hooven et al. (2009) and Choe et al. (2018) assessed both gestational hypertension and preeclampsia. Five studies assessed traffic density as the exposure metric (Malmqvist et al. 2013; Olsson et al. 2015; van den Hooven et al. 2009; Wu et al. 2011; Wu et al. 2016) and five studies considered the proximity to major roadways (Choe et al. 2018; Madsen et al. 2018; Miranda et al. 2013; van den Hooven et al. 2009; Yorifuji et al. 2015). All included studies evaluated exposure over the entire gestational period. Sample sizes ranged from just over 7,300 to more than 460,000 women and included 50 to approximately 26,000 cases. 
Table 14. Studies on Hypertensive Disorders of Pregnancy and Traffic Measures in Humans

\begin{tabular}{|c|c|c|c|c|c|c|c|c|c|}
\hline Study & $\begin{array}{l}\text { Study Design } \\
\text { (Location) }\end{array}$ & $\begin{array}{l}\text { Sample } \\
\text { Size }\end{array}$ & Cases & Traffic Measure & Outcome & $\begin{array}{c}\text { Exposure } \\
\text { Period }\end{array}$ & $\begin{array}{c}\text { OR } \\
(95 \% \mathrm{CI}) \\
\end{array}$ & Exposure Level & $\begin{array}{c}\text { Covariates Considered } \\
\text { for Inclusion }\end{array}$ \\
\hline \multirow[t]{2}{*}{ Choe et al. (2018) } & \multirow[t]{2}{*}{$\begin{array}{l}\text { Retrospective } \\
\text { cohort (Rhode } \\
\text { Island, USA) }\end{array}$} & 61,541 & 2,221 & $\begin{array}{l}\text { Proximity to road: } \\
\text { living } \leq 150 \mathrm{~m} \text { of an } \\
\mathrm{A} 1 \text { or } \mathrm{A} 2 \text { roadway } \\
\text { or } \leq 50 \mathrm{~m} \text { of an } \mathrm{A} 3 \\
\text { roadway }\end{array}$ & Preeclampsia & $\begin{array}{l}\text { Full } \\
\text { gestational } \\
\text { period }\end{array}$ & $0.99(0.87,1.12)$ & \multirow{2}{*}{$\begin{array}{l}19.8 \% \text { live } \\
\text { within } \leq 150 \mathrm{~m} \\
\text { of an } \mathrm{A} 1 \text { or } \mathrm{A} 2 \\
\text { roadway } \\
\text { or } \leq 50 \mathrm{~m} \text { of an } \\
\text { A3 roadway }\end{array}$} & \multirow{2}{*}{$\begin{array}{l}\text { Maternal age, parity, } \\
\text { race, education, marital } \\
\text { status, health insurance } \\
\text { status, tobacco use, year } \\
\text { of last menstrual period, } \\
\text { neighborhood } \\
\text { socioeconomic status }\end{array}$} \\
\hline & & 57,793 & 2,877 & $\begin{array}{l}\text { Proximity to road: } \\
\text { living } \leq 150 \mathrm{~m} \text { of an } \\
\text { A1 or A2 roadway } \\
\text { or } \leq 50 \mathrm{~m} \text { of an A3 } \\
\text { roadway }\end{array}$ & $\begin{array}{l}\text { Gestational } \\
\text { hypertension }\end{array}$ & $\begin{array}{l}\text { Full } \\
\text { gestational } \\
\text { period }\end{array}$ & $0.97(0.87,1.09)$ & & \\
\hline \multirow[t]{2}{*}{$\begin{array}{l}\text { Madsen et al. } \\
(2018)\end{array}$} & \multirow[t]{2}{*}{$\begin{array}{l}\text { Prospective } \\
\text { cohort } \\
\text { (Norway) }\end{array}$} & 17,533 & 590 & $\begin{array}{l}\text { Proximity to road: } \\
\text { road within } 15 \mathrm{~m}\end{array}$ & Preeclampsia & $\begin{array}{l}\text { Full } \\
\text { gestational } \\
\text { period }\end{array}$ & $1.16(0.96,1.39)$ & \multirow{2}{*}{$\begin{array}{l}46.6 \% \text { live } \\
\text { within } 15 \mathrm{~m} \text { of a } \\
\text { road }\end{array}$} & \multirow{2}{*}{$\begin{array}{l}\text { Maternal age, marital } \\
\text { status, education, BMI, } \\
\text { parity, smoking, } \\
\text { diabetes, chronic } \\
\text { hypertension, child sex } \\
\text { of child, area, year of } \\
\text { birth }\end{array}$} \\
\hline & & & 941 & $\begin{array}{l}\text { Proximity to road: } \\
\text { road within } 15 \mathrm{~m}\end{array}$ & $\begin{array}{l}\text { Hypertension } \\
\text { during } \\
\text { pregnancy }\end{array}$ & $\begin{array}{l}\text { Full } \\
\text { gestational } \\
\text { period }\end{array}$ & $1.12(0.96,1.29)$ & & \\
\hline \multirow[t]{3}{*}{$\begin{array}{l}\text { Malmqvist et al. } \\
(2013)\end{array}$} & \multirow[t]{3}{*}{$\begin{array}{l}\text { Case-control } \\
\text { (Sweden) }\end{array}$} & \multirow[t]{3}{*}{81,110} & 2,323 & $\begin{array}{l}\text { Traffic density: no } \\
\text { road within } 200 \mathrm{~m} \\
\text { (reference) versus } \\
\text { road with } \\
>10 \text { vehicles } / \mathrm{min} \\
\text { within } 200 \mathrm{~m}\end{array}$ & $\begin{array}{l}\text { Preeclampsia } \\
\text { (all cases) }\end{array}$ & $\begin{array}{l}\text { Full } \\
\text { gestational } \\
\text { period }\end{array}$ & $1.10(0.94,1.30)$ & \multirow[t]{3}{*}{$\begin{array}{l}\text { Summary } \\
\text { measure not } \\
\text { reported }\end{array}$} & \multirow[t]{3}{*}{$\begin{array}{l}\text { Maternal age, BMI, } \\
\text { smoking, ethnicity, } \\
\text { parity, type } 1 \text { diabetes, } \\
\text { and gestational diabetes }\end{array}$} \\
\hline & & & 1,799 & $\begin{array}{l}\text { Traffic density: no } \\
\text { road within } 200 \mathrm{~m} \\
\text { (reference) versus } \\
\text { road with } \\
>10 \text { vehicles } / \mathrm{min} \\
\text { within } 200 \mathrm{~m}\end{array}$ & $\begin{array}{l}\text { Mild } \\
\text { preeclampsia }\end{array}$ & $\begin{array}{l}\text { Full } \\
\text { gestational } \\
\text { period }\end{array}$ & $1.04(0.86,1.26)$ & & \\
\hline & & & 571 & $\begin{array}{l}\text { Traffic density: no } \\
\text { road within } 200 \mathrm{~m} \\
\text { (reference) versus } \\
\text { road with } \\
>10 \text { vehicles } / \mathrm{min} \\
\text { within } 200 \mathrm{~m}\end{array}$ & $\begin{array}{l}\text { Severe } \\
\text { preeclampsia }\end{array}$ & $\begin{array}{l}\text { Full } \\
\text { gestational } \\
\text { period }\end{array}$ & $1.24(0.86,1.77)$ & & \\
\hline
\end{tabular}




\begin{tabular}{|c|c|c|c|c|c|c|c|c|c|}
\hline Study & $\begin{array}{l}\text { Study Design } \\
\text { (Location) }\end{array}$ & $\begin{array}{l}\text { Sample } \\
\text { Size }\end{array}$ & Cases & Traffic Measure & Outcome & $\begin{array}{c}\text { Exposure } \\
\text { Period }\end{array}$ & $\begin{array}{c}\text { OR } \\
(95 \% \mathrm{CI}) \\
\end{array}$ & Exposure Level & $\begin{array}{c}\text { Covariates Considered } \\
\text { for Inclusion }\end{array}$ \\
\hline $\begin{array}{l}\text { Miranda et al. } \\
(2013)\end{array}$ & $\begin{array}{l}\text { Cross-sectional } \\
\text { (North Carolina, } \\
\text { USA) }\end{array}$ & 468,517 & 25,768 & $\begin{array}{l}\text { Proximity to road: } \\
\geq 500 \mathrm{~m} \text { to major road } \\
\text { (reference) vs. }<250 \mathrm{~m} \\
\text { to major roads }\end{array}$ & $\begin{array}{l}\text { Gestational } \\
\text { hypertension }\end{array}$ & $\begin{array}{l}\text { Full } \\
\text { gestational } \\
\text { period }\end{array}$ & $1.04(1.00,1.07)$ & $\begin{array}{l}65.8 \% \text { Live } \\
\text { within } \geq 500 \mathrm{~m} \\
\text { of major roads } \\
18.4 \% \\
\text { Live within } \\
<250 \mathrm{~m} \text { of } \\
\text { major roads } \\
\end{array}$ & $\begin{array}{l}\text { Maternal age, race, } \\
\text { nativity, education, } \\
\text { marital status, parity, } \\
\text { tobacco use, season of } \\
\text { birth, tract-level } \\
\text { urbanization, and tract- } \\
\text { level median income }\end{array}$ \\
\hline Olsson et al. (2015) & $\begin{array}{l}\text { Retrospective } \\
\text { cohort (Sweden) }\end{array}$ & 102,726 & 2,671 & $\begin{array}{l}\text { Traffic density: per } \\
3,672 \text { vehicles/day } \\
\text { increase within } \\
100 \mathrm{~m}^{2} \text { of home } \\
\text { address }\end{array}$ & $\begin{array}{l}\text { Pregnancy- } \\
\text { induced } \\
\text { hypertensive } \\
\text { disorders }\end{array}$ & $\begin{array}{l}\text { Full } \\
\text { gestational } \\
\text { period }\end{array}$ & $1.02(1.00,1.04)$ & $\begin{array}{l}\text { Mean }(\mathrm{SD}) \\
\text { maximal traffic } \\
\text { flow within } \\
100 \mathrm{~m}^{2} \text { of home } \\
\text { address: } 2,569 \\
(7,712) \\
\text { vehicles/day }\end{array}$ & $\begin{array}{l}\text { Maternal age, education, } \\
\text { region of origin, asthma, } \\
\text { parity, date of } \\
\text { conception, first } \\
\text { trimester ozone, and first } \\
\text { trimester temperature, } \\
\text { smoking, BMI, family } \\
\text { situation }\end{array}$ \\
\hline \multirow[t]{4}{*}{$\begin{array}{l}\text { van den Hooven et } \\
\text { al. }(2009)\end{array}$} & \multirow[t]{4}{*}{$\begin{array}{l}\text { Prospective } \\
\text { cohort } \\
\text { (Rotterdam, } \\
\text { Netherlands) }\end{array}$} & \multirow[t]{4}{*}{7,339} & 144 & $\begin{array}{l}\text { Traffic density: } \\
<158,503 \\
\text { vehicles/day*m within } \\
150 \mathrm{~m} \text { (reference) } \\
\text { versus }>1,235,384 \\
\text { vehicles/day*m within } \\
150 \mathrm{~m}\end{array}$ & Preeclampsia & $\begin{array}{l}\text { Full } \\
\text { gestational } \\
\text { period }\end{array}$ & $1.14(0.71,1.82)$ & $\begin{array}{l}\text { Median traffic } \\
\text { density: } \\
550,000 \\
\text { vehicles/day*m }\end{array}$ & \multirow[t]{4}{*}{$\begin{array}{l}\text { Maternal age, education, } \\
\text { ethnicity, BMI, parity, } \\
\text { smoking, alcohol use, } \\
\text { and fetal sex }\end{array}$} \\
\hline & & & 250 & $\begin{array}{l}\text { Traffic density: } \\
<158,503 \\
\text { vehicles/day*m within } \\
150 \mathrm{~m} \text { (reference) } \\
\text { versus }>1,235,384 \\
\text { vehicles/day*m within } \\
150 \mathrm{~m}\end{array}$ & $\begin{array}{l}\text { Pregnancy- } \\
\text { induced } \\
\text { hypertension }\end{array}$ & $\begin{array}{l}\text { Full } \\
\text { gestational } \\
\text { period }\end{array}$ & $1.07(0.75,1.53)$ & $\begin{array}{l}\text { Median traffic } \\
\text { density: } \\
550,000 \\
\text { vehicles/day*m }\end{array}$ & \\
\hline & & & 144 & $\begin{array}{l}\text { Proximity to road: } \\
>200 \mathrm{~m} \text { to major roads } \\
\text { (reference) versus } \\
<50 \text { m to major roads }\end{array}$ & Preeclampsia & $\begin{array}{l}\text { Full } \\
\text { gestational } \\
\text { period }\end{array}$ & $1.03(0.63,1.69)$ & $\begin{array}{l}\text { Median distance } \\
\text { to major road: } \\
143 \mathrm{~m}\end{array}$ & \\
\hline & & & 250 & $\begin{array}{l}\text { Proximity to road: } \\
>200 \text { m to major roads } \\
\text { (reference) versus } \\
<50 \text { m to major roads }\end{array}$ & $\begin{array}{l}\text { Pregnancy- } \\
\text { induced } \\
\text { hypertension }\end{array}$ & $\begin{array}{l}\text { Full } \\
\text { gestational } \\
\text { period }\end{array}$ & $1.08(0.74,1.60)$ & $\begin{array}{l}\text { Median distance } \\
\text { to major road: } \\
143 \mathrm{~m}\end{array}$ & \\
\hline
\end{tabular}


Systematic Review of TRAP and Hypertensive Disorders of Pregnancy

\begin{tabular}{|c|c|c|c|c|c|c|c|c|c|}
\hline Study & $\begin{array}{l}\text { Study Design } \\
\text { (Location) }\end{array}$ & $\begin{array}{c}\text { Sample } \\
\text { Size }\end{array}$ & Cases & Traffic Measure & Outcome & $\begin{array}{c}\text { Exposure } \\
\text { Period } \\
\end{array}$ & $\begin{array}{c}\text { OR } \\
(95 \% \mathrm{CI}) \\
\end{array}$ & Exposure Level & $\begin{array}{c}\text { Covariates Considered } \\
\text { for Inclusion }\end{array}$ \\
\hline \multirow[t]{2}{*}{ Wu et al. (2011) } & $\begin{array}{l}\text { Retrospective } \\
\text { cohort (Los } \\
\text { Angeles } \\
\text { County, } \\
\text { California } \\
\text { United States) } \\
\end{array}$ & 38,709 & 1,303 & $\begin{array}{l}\text { Traffic density: } \\
\text { per } 76.6 \\
\text { vehicles } / \text { day*m/m } / \mathrm{m}^{2} \\
\text { increase within } 300 \mathrm{~m}\end{array}$ & Preeclampsia & $\begin{array}{l}\text { Full } \\
\text { gestational } \\
\text { period }\end{array}$ & $1.03(0.99,1.06)$ & $\begin{array}{l}\text { Mean (SD) } \\
\text { traffic density: } \\
82.5(114.2) \\
\text { vehicles/day*m/ } \\
\mathrm{m}^{2}\end{array}$ & $\begin{array}{l}\text { Maternal age, } \\
\text { race/ethnicity, parity, } \\
\text { prenatal care insurance } \\
\text { type, season of } \\
\text { conception, diabetes, } \\
\text { and poverty }\end{array}$ \\
\hline & $\begin{array}{l}\text { Retrospective } \\
\text { cohort (Orange } \\
\text { County, } \\
\text { California, } \\
\text { United States) }\end{array}$ & 42,477 & 1,139 & $\begin{array}{l}\text { Traffic density: } \\
\text { per } 76.6 \\
\text { vehicles } / \text { day*m/ } / \mathrm{m}^{2} \\
\text { increase within } 300 \mathrm{~m}\end{array}$ & Preeclampsia & $\begin{array}{l}\text { Full } \\
\text { gestational } \\
\text { period }\end{array}$ & $1.03(1.00,1.07)$ & $\begin{array}{l}\text { Mean (SD) } \\
\text { traffic density: } \\
66.0(117.6) \\
\text { vehicles/day*m/ } \\
\mathrm{m}^{2}\end{array}$ & $\begin{array}{l}\text { Maternal age, } \\
\text { race/ethnicity, parity, } \\
\text { prenatal care insurance } \\
\text { type, season of } \\
\text { conception, diabetes, } \\
\text { and poverty }\end{array}$ \\
\hline \multirow[t]{3}{*}{ Wu et al. (2016) } & $\begin{array}{l}\text { Case-control } \\
\text { (Basel, } \\
\text { Switzerland) }\end{array}$ & 100 & 50 & $\begin{array}{l}\text { Traffic density: total } \\
\text { length of major roads } \\
\text { within } 500 \mathrm{~m}\end{array}$ & Preeclampsia & $\begin{array}{l}\text { Full } \\
\text { gestational } \\
\text { period }\end{array}$ & $\begin{array}{l}\text { Significant } \\
\text { difference in } \\
\text { median total } \\
\text { length between } \\
\text { cases }(1,571 \mathrm{~m}) \\
\text { and controls } \\
(2,311 \mathrm{~m})\end{array}$ & $\begin{array}{l}\text { Summary } \\
\text { measure not } \\
\text { reported }\end{array}$ & Maternal age \\
\hline & & & & $\begin{array}{l}\text { Proximity to road: } \\
\text { distance to nearest } \\
\text { first-class main road }\end{array}$ & Preeclampsia & $\begin{array}{l}\text { Full } \\
\text { gestational } \\
\text { period }\end{array}$ & $\begin{array}{l}\text { No statistical } \\
\text { difference } \\
\text { between cases } \\
(114 \mathrm{~m}) \text { and } \\
\text { controls }(160 \mathrm{~m})\end{array}$ & & \\
\hline & & & & $\begin{array}{l}\text { Proximity to road: } \\
\text { distance to nearest } \\
\text { freeway }\end{array}$ & Preeclampsia & $\begin{array}{l}\text { Full } \\
\text { gestational } \\
\text { period }\end{array}$ & $\begin{array}{l}\text { No statistical } \\
\text { difference } \\
\text { between cases } \\
(1,087 \mathrm{~m}) \text { and } \\
\text { controls }(926 \mathrm{~m})\end{array}$ & & \\
\hline $\begin{array}{l}\text { Yorifuji et al. } \\
\text { (2015) }\end{array}$ & $\begin{array}{l}\text { Retrospective } \\
\text { cohort (Japan) }\end{array}$ & 19,077 & 630 & $\begin{array}{l}\text { Proximity to road: } \\
>200 \mathrm{~m} \text { to major roads } \\
\text { (reference) vs. } \leq 200 \mathrm{~m} \\
\text { to major roads }\end{array}$ & Preeclampsia & $\begin{array}{l}\text { Full } \\
\text { gestational } \\
\text { period }\end{array}$ & $1.3(1.0,1.8)$ & $\begin{array}{l}\text { Summary } \\
\text { measure not } \\
\text { reported }\end{array}$ & $\begin{array}{l}\text { Maternal age, } \\
\text { occupation, smoking, } \\
\text { BMI, area } \\
\text { socioeconomic status, } \\
\text { season, and year of } \\
\text { conception }\end{array}$ \\
\hline
\end{tabular}




\section{Summary of the Human Evidence}

\section{Traffic Density}

In general, there were small but positive associations that did not reach statistical significance between traffic density measures and combined hypertensive disorders of pregnancy (Figure 18) or preeclampsia only (Figure 19). With the exception of van den Hooven et al. (2009), these studies also evaluated one or more traffic-related air pollutants. Although correlations between the air pollutants and traffic density were not discussed for most studies, Wu et al. (2011) found that traffic density measures were moderately correlated with CALINE4-modeled exposures and poorly correlated with ambient monitor-based measures. In all studies, ORs for traffic density and hypertensive disorders of pregnancy were smaller than those reported for the air pollutants (Malmqvist et al. 2013; Olsson et al. 2015; van den Hooven et al. 2009; Wu et al. 2011).

\begin{tabular}{|c|c|c|}
\hline Study Name & Outcome & $\begin{array}{l}\text { Odds Ratios } \\
\qquad(95 \% \mathrm{Cl})\end{array}$ \\
\hline Malmqvist 2013 & Preeclampsia & $1.10(0.94,1.30)$ \\
\hline Olsson 2015 & Pregnancy-induced Hypertensive Disorders & $1.02(1.00,1.04)$ \\
\hline Wu 2011 & Preeclampsia & $1.03(0.99,1.06)$ \\
\hline Wu 2011 & Preeclampsia & $1.03(1.00,1.07)$ \\
\hline van den Hooven 2009 & $\mathrm{HDP}$ & $1.10(0.82,1.46)$ \\
\hline & 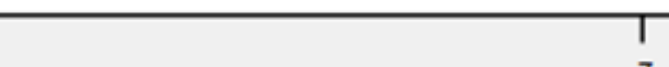 & $T$ \\
\hline
\end{tabular}

Figure 18. Traffic Density and Hypertensive Disorders of Pregnancy

When $\mathrm{I}^{2} \mathrm{p}$ value is significant $(\mathrm{p}<0.05)$, the random-effects model results are presented. When nonsignificant, the random-effects model results are identical to the fixed-effects model results. HDP $=$ hypertensive disorders of pregnancy. 


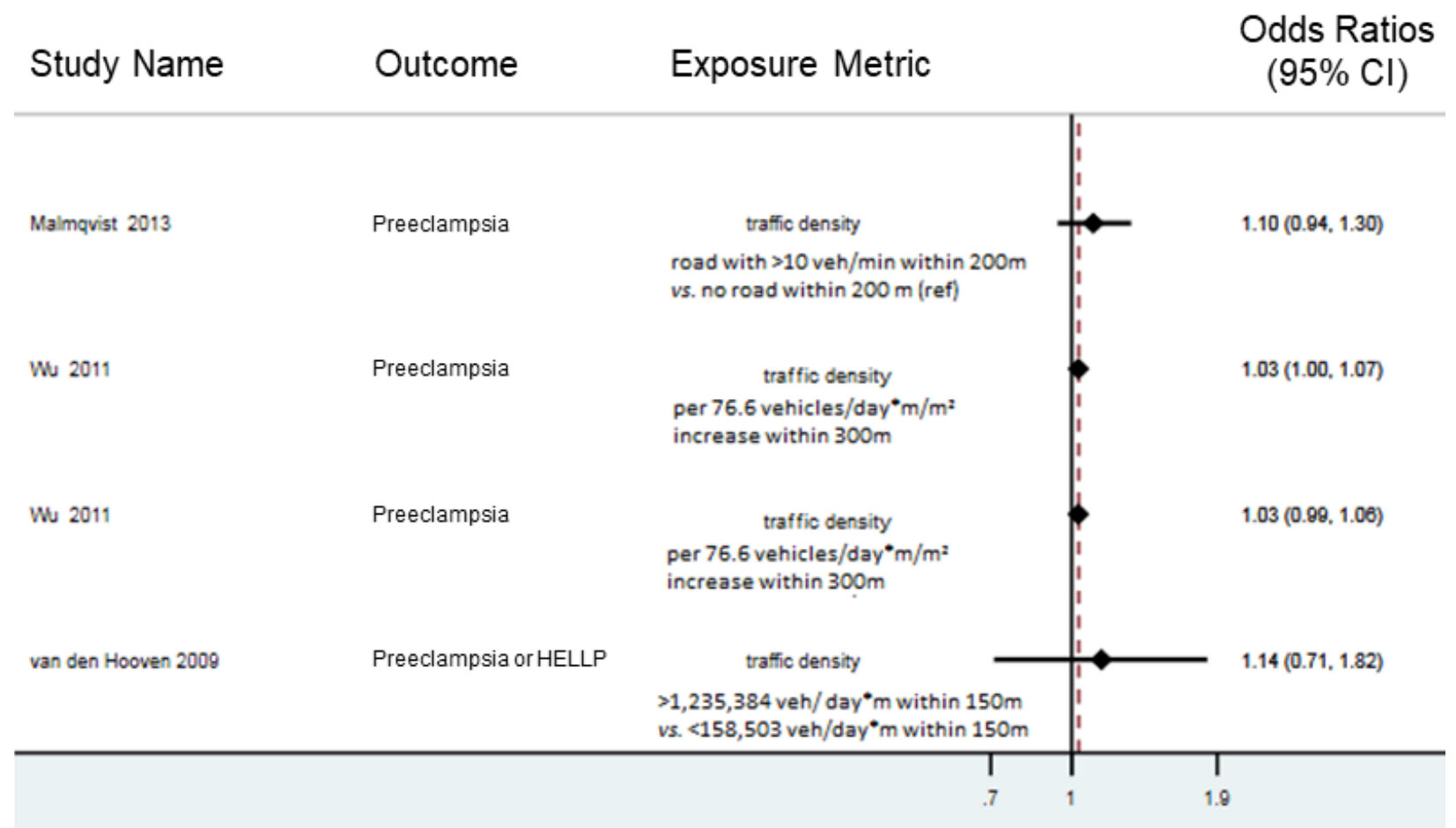

Figure 19. Traffic Density and Preeclampsia

HELLP $=$ hemolysis, elevated liver enzyme levels, and low platelet count syndrome.

\section{Proximity to Road Measures}

The five studies that evaluated proximity to main road measures and hypertensive disorders of pregnancy reported small but positive associations, with some reaching statistical significance (Choe et al. 2018; Madsen et al. 2018; Miranda et al. 2013; van den Hooven et al. 2009; Yorifuji et al. 2015) (Figure 20). Correlations between these proximity to road measures and modeled or measured air pollutants were not reported, but ORs were similar in the studies that evaluated both metrics (Choe et al. 2018; Madsen et al. 2018). In addition, Wu et al. (2016) reported statistically significant positive associations between exposure to TRAP and development of late-onset preeclampsia but only performed descriptive analyses for incidence of preeclampsia and road density parameters and did not calculate ORs or CIs. 


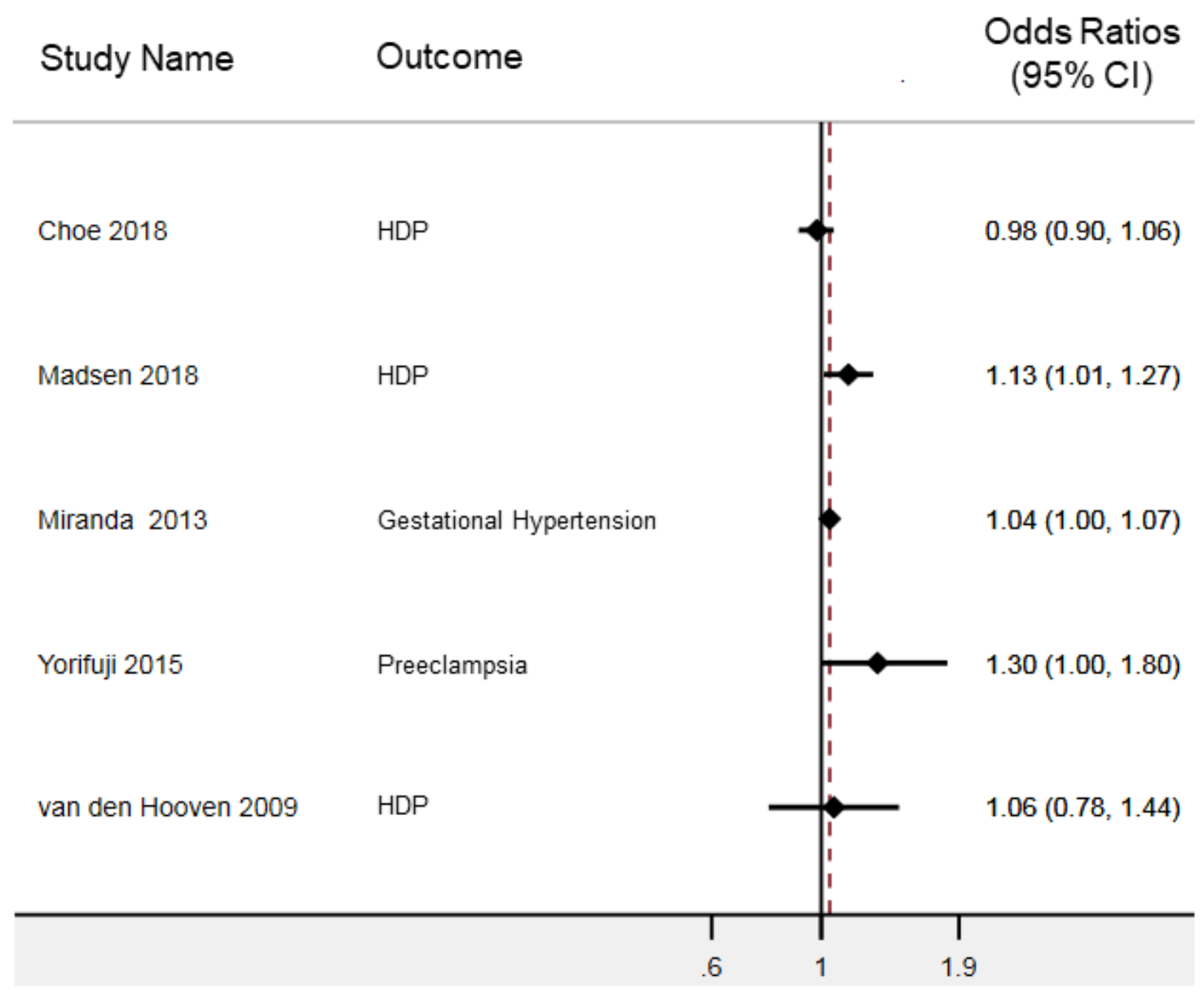

Figure 20. Proximity to Traffic and Combined Hypertensive Disorders during Pregnancy

HDP $=$ hypertensive disorders of pregnancy.

\section{Risk-of-Bias Considerations}

Risk-of-bias ratings for individual studies of traffic density or proximity to road measures were generally rated probably low or definitely low across most risk-of-bias domains, as shown in the risk-of-bias heatmap (Figure 21) and bar chart (Figure 22), and the overall confidence rating was not changed because of risk of bias.

\section{Exposure Characterization}

Inherent in studies evaluating traffic measures is a reduction in precision (resulting in bias toward the null) for the exposure measurements compared with measurements of surrogates for traffic-related air pollutants. Therefore, the true effect of TRAP exposure on hypertensive disorders of pregnancy may not be reflected in studies that evaluate traffic measures. Two studies were included in which there were risk-of-bias concerns about the exposure characterization (Miranda et al. 2013; Yorifuji et al. 2015). In both cases, there was a probably high risk of bias for the exposure characterization because there was poor alignment between the exposure assessments and outcome measurements (i.e., the timing of the exposure measurements did not line up well with the timing of the pregnancy periods). Most studies accounted for residential mobility in sensitivity analyses; thus, exposure misclassification due to residential mobility was minimal. 


\section{Outcome Assessment}

Risk-of-bias ratings for the outcome assessment were probably low or definitely low for all studies that reported traffic measurements.

\section{Confounding and Modifying Variables}

Most studies that evaluated traffic measures adjusted for smoking and BMI; however, those studies that did not adjust for smoking also did not adjust for BMI resulting in potential bias in both directions. In the Wu et al. (2016) study, there were also clear risk-of-bias concerns that would lower the confidence of the overall conclusions in this study, including probably high risk of bias for comparison groups and confounding variables. However, exclusion of this study did not affect the overall ratings for traffic measures and hypertensive disorders of pregnancy.

\section{Summary}

In some studies, there were a few risk-of-bias concerns about exposure characterization and confounding variables that would potentially bias the results toward and away from the null. For all remaining risk-of-bias questions for all of the individual studies that evaluated traffic measures, there was probably low or definitely low risk of bias and, therefore, no concerns over the internal validity of the reported results that would further decrease the confidence in the body of evidence.

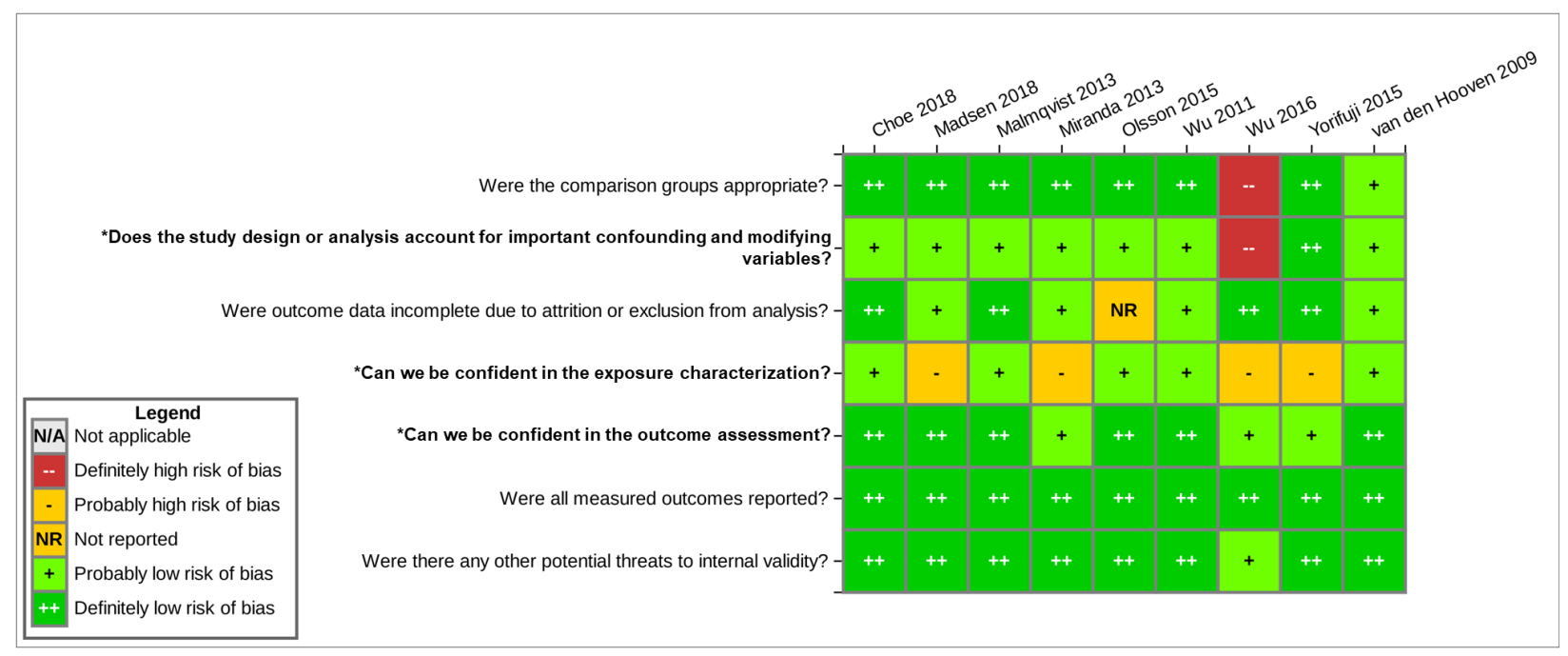

Figure 21. Risk-of-bias Heatmap: Traffic and Hypertensive Disorders of Pregnancy

Interactive figure and additional study details in HAWC (NTP, 2019a).

*Questions in bold are the key risk-of-bias questions for human epidemiological studies. These key questions relate to areas of bias that may have a greater impact on estimates of the overall effect size and are generally considered to have a greater effect on the credibility of study results in environmental health studies. 


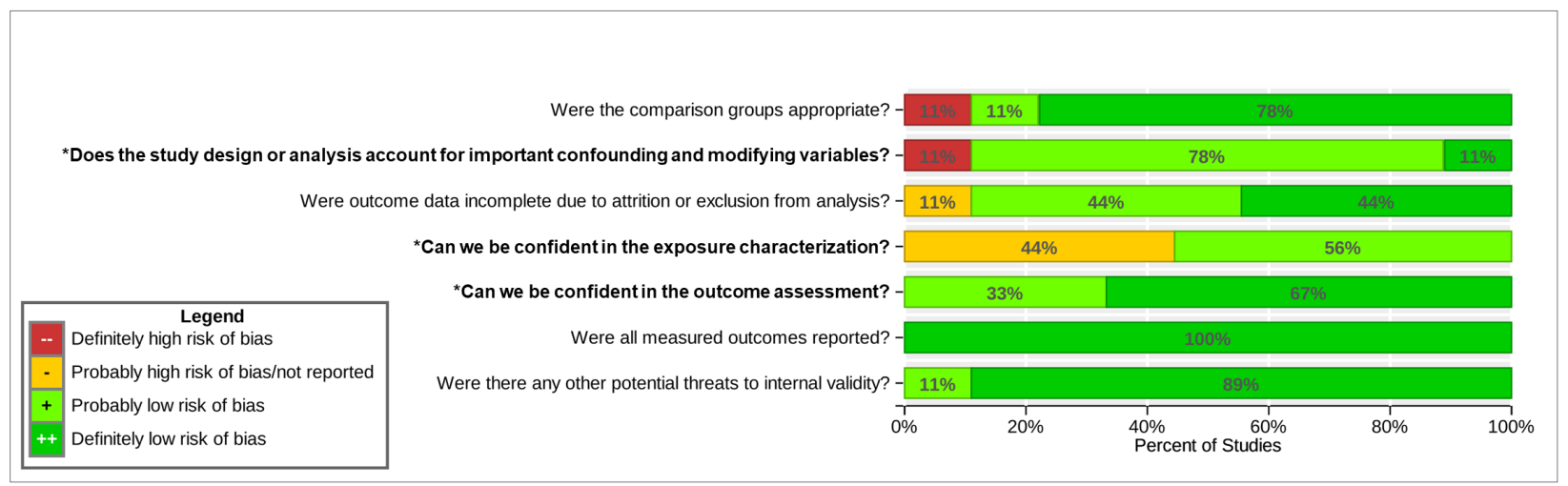

Figure 22. Risk-of-bias Bar Chart: Traffic and Hypertensive Disorders of Pregnancy

Interactive figure and additional study details in HAWC (NTP, 2019a).

*Questions in bold are the key risk-of-bias questions for human epidemiological studies. These key questions relate to areas of bias that may have a greater impact on estimates of the overall effect size and are generally considered to have a greater effect on the credibility of study results in environmental health studies.

\section{Animal Traffic Measures Data}

There were no animal data evaluating associations between traffic measures and hypertensive disorders of pregnancy that met the PECO criteria for this assessment.

\section{Evidence Synthesis for Traffic Measures}

Both traffic density and proximity to road measures showed positive but nonsignificant associations with increased risk for developing hypertensive disorders of pregnancy in the available human evidence. There is low confidence in the body of evidence that close proximity to a major road or increased traffic density during pregnancy is associated with an increased risk for a hypertensive disorder of pregnancy. The confidence ratings are summarized below.

- Human body of evidence: Low confidence

\section{- Animal body of evidence: No studies}

The human body of evidence suggests that one's proximity to main roads and proximity to hightraffic density regions during pregnancy could be associated with the development of a hypertensive disorder of pregnancy. 


\section{Discussion}

Following a systematic review of the evidence, the National Toxicology Program (NTP) reached conclusions on hypertensive disorders of pregnancy following exposures to traffic-related air pollution (TRAP). NTP concludes that exposure to TRAP is presumed to be a hazard to pregnant women on the basis of the available evidence across multiple measures of TRAP exposure (e.g., traffic-related fine particulate matter $\left[\mathrm{PM}_{2.5}\right]$ and nitrogen dioxide $\left[\mathrm{NO}_{2}\right]$, residing in high-traffic density regions or in close proximity to major roads) and that TRAP is associated with the development of hypertensive disorders of pregnancy. The overall hazard conclusion was based on moderate confidence and moderate level of evidence in the human evidence for the combined TRAP exposure.

The hazard conclusion for combined TRAP exposure was considered to better reflect true exposure to TRAP than individual measures of exposure. The effect of TRAP was consistent across bodies of evidence for individual components and was supported by meta-analyses for individual traffic-related metrics (i.e., $\mathrm{PM}_{2.5}$ and $\mathrm{NO}_{2}$ ). When considered together, evidence across the air pollutant and traffic measures collectively showed consistency in the direction of effect across multiple populations and geographic locations, strengthening the confidence in the association between the combined TRAP exposure and hypertensive disorders of pregnancy compared with exposure to individual TRAP components and this outcome. Many studies evaluated only one TRAP component (with or without a traffic measurement), and those that evaluated more than one component still found significant associations between the individual components and hypertensive disorders of pregnancy after statistically accounting for other exposures. The robustness of the body of evidence for the combined TRAP exposure due to the greater number of studies, the consistency in the direction of the effect across multiple populations and geographic locations, and the high likelihood of exposure to multiple TRAP components strengthened the confidence in the evidence for combined TRAP exposure compared with exposure to the individual TRAP components, resulting in a hazard conclusion of presumed to be a hazard to pregnant women.

In addition to the evidence for $\mathrm{PM}_{2.5}, \mathrm{NO}_{2}$, and traffic measures, a few studies were available that investigated potential associations between carbon monoxide $(\mathrm{CO})$, black carbon $(\mathrm{BC})$, or elemental carbon (EC) and hypertensive disorders of pregnancy. Although findings from the epidemiological studies for CO exposure were unclear, the experimental animal study used in this assessment (as well as other studies evaluating the effects of smoking on blood pressure during pregnancy) suggest carbon monoxide may promote vasodilation and reduce the risk of preeclampsia (Conde-Agudelo et al. 1999; Engel et al. 2013; England and Zhang 2007; Jeyabalan et al. 2008; Karumanchi and Levine 2010; Wei et al. 2015; Wikstrom et al. 2010). However, consistent with the observed associations between TRAP components and hypertensive disorders of pregnancy, potential protective effects of $\mathrm{CO}$ on blood pressure do not appear to be mitigating the associations between TRAP and hypertensive disorders of pregnancy. This is further illustrated by small but positive associations between traffic measures (which would include the totality of traffic-related air pollutants, including $\mathrm{CO}$ ) and hypertensive disorders of pregnancy, supporting an overall effect of TRAP on this outcome. The few studies in the available evidence for $\mathrm{BC}$ and $\mathrm{EC}$ exposures are inadequate for reaching meaningful conclusions. 


\section{Potential Mechanisms}

The mechanisms by which TRAP components increase blood pressure during pregnancy is not entirely understood, and a mechanistic understanding is challenged by the complexity of the series of adaptive processes that occur for a healthy pregnancy. However, insights from mechanistic studies that demonstrate how blood pressure is elevated in the nonpregnant state show significant overlap with mechanisms that appear to play a role in the pathogenesis of preeclampsia, thus providing a plausible mechanism for the observed association between TRAP exposure and increased risk for hypertensive disorders. Exposure to PM can induce endothelial and/or smooth muscle dysfunction through vascular inflammation and oxidative stress pathways (Haberzettl et al. 2018). $\mathrm{NO}_{2}$ exposures can also induce oxidative stress. In addition, changes in autonomic nervous system (ANS) balance favoring sympathetic nervous system-mediated arterial vasoconstriction, the generation and release of endogenous biological mediators from various sources (most notably from lung cells), and/or potential direct vascular actions of PM constituents that can reach the systemic circulation may all contribute to hypertension. TRAPmediated increases in blood pressure likely occur in a biphasic manner, with an initial response caused by rapid changes in ANS balance followed by increased sensitivity to vasoconstrictive responses (Link and Dockery 2010) [reviewed in Brook and Rajagopalan (2009)].

During a normal healthy pregnancy, highly coordinated events occur to ensure adequate blood flow to the placenta and fetus and to facilitate the exchange of gas and nutrients. This process includes early vascular adaptations that begin during embryo implantation in the uterus, resulting in a series of migration and invasion events by fetus-derived cytotrophoblasts into the maternal spiral arteries. These invasive trophoblasts gradually replace the endothelial lining of the spiral arteries, themselves undergoing a shift to become endothelial-like cells, to remodel these normally low capacitance, high resistance vessels to high capacitance, low resistance vessels by the second trimester (reviewed in George and Granger (2011)). In addition, maternal hormones increase blood volume, and cardiac output increases by up to $50 \%$ compared with the nonpregnant state, with the majority of this change occurring during the first 8 weeks of pregnancy (Clark et al. 1989). Such a change in the nonpregnant state would result in a compensatory increase in vascular resistance and blood pressure to maintain homeostasis. However, during pregnancy, the increase in blood volume and cardiac output is associated with a decrease in blood pressure because of the general decrease in vascular resistance resulting from the early arterial remodeling events. Although vascular resistance decreases throughout the body, there is a disproportionally large drop in vascular resistance in the uterine circulation, resulting in a greater proportion of the cardiac output going to the uteroplacental unit to meet the demands of the growing fetus (reviewed in Boeldt and Bird (2017)).

Although the data are limited, some studies have suggested associations between diminished vascularization indices in the placenta during the first trimester of pregnancy and air pollutants, particularly $\mathrm{NO}_{2}$ (Hettfleisch et al. 2017). These indices have been shown to be lower in patients with preeclampsia compared with normotensive pregnancies (Costa et al. 2010). Animal studies evaluating ozone exposure during pregnancy have also demonstrated impaired implantation processes and impaired trophoblast metabolic capacity (Miller et al. 2019), and as technologies continue to improve, these relationships will be explored in more detail and may provide more insight on the role of air pollutants on blood flow to the placenta and subsequent effects. 
In addition, a large body of literature has highlighted the importance of endothelial cells in the normal adaptive processes of pregnancy, and endothelial dysfunction is a key event that contributes to all major symptoms of preeclampsia. Endothelial cells play a critical role on the control of vascular function by sensing the blood composition as well as providing a physical barrier to the improper movement of water, ions, proteins, and cells from the blood vessel into the vessel walls. In women who develop hypertensive disorders of pregnancy, there is evidence to suggest that these key physiologic functions of endothelial cells are compromised (Boeldt and Bird 2017). Long-term exposure to constituents of PM can induce an inflammatory response and oxidative stress, which has been shown to play a causal role in the endothelial cell dysfunction and impaired vasomotor balance observed in humans and animal models in the nonpregnant state (Gamboa et al. 2007; Lassegue and Griendling 2004; Nedeljkovic et al. 2003; Sun et al. 2008). Activation of inflammation and oxidative stress pathways sensitize the vasculature to the provasoconstrictive effects of endogenous mediators that lead to vasoconstriction and, ultimately, elevated blood pressure. Similar to the increased sensitivity to vasoconstrictors in the nonpregnant state, endothelial dysfunction in preeclamptic pregnancies results in a failure to develop insensitivity to vasoconstrictors as well as insufficient calcium signaling and vasodilator production (Krupp et al. 2013), causing an increase in vascular resistance. Thus, the normal increase in blood volume paired with the insufficient drop in uterine and vascular resistance contributes significantly to the hypertensive component of preeclampsia. Further, endothelial dysfunction in glomerular cells in the kidney leads to proteinuria due to the loss of barrier function integrity causing pathologically permissive protein movement into the urine (Wang et al. 2015). Direct evidence demonstrating that exposure to TRAP components during pregnancy activates inflammation and oxidative stress pathways, thus causing endothelial dysfunction and impaired sensitivity to vasoconstrictive and vasodilatory factors to increase vascular resistance and elevate blood pressure is not yet available. However, studies evaluating components of these pathways and evidence from studies in the nonpregnant state provide a biologically plausible mechanism for the observed association between TRAP exposure and hypertensive disorders of pregnancy reported in this assessment. Additional studies will be needed to test components of the proposed mode of action to support the epidemiological findings.

\section{Limitations of the Evidence Base}

Several limitations in the body of evidence apply across the different exposures. The air pollutants identified for inclusion have been commonly used as exposure surrogates for TRAP in other evaluations. While the specificity of the exposure characterization in the inclusion criteria along with the supporting evidence from the traffic measures do increase the confidence that the exposures reported and subsequent associations with hypertensive disorders of pregnancy are due to traffic, it is recognized that many of the exposure surrogates used to identify TRAP are also generated by other sources. Thus, this limits the ability to attribute associations exclusively to traffic-derived sources. It is also likely that exposure to other TRAP components (e.g., ultrafine particles, sulfur oxides, volatile organic compounds) may contribute to the development or exacerbation of hypertensive disorders of pregnancy; however, to date, no studies have evaluated those associations. In addition, traffic noise is likely a co-exposure for all TRAP studies, but relatively few studies have tried to disentangle the possible effects of traffic noise verses TRAP. Because the correlation between the two exposures is not always colinear (Fecht et al. 2016), the extent to which TRAP is confounded by traffic noise is unclear. In addition, exposure levels are based on 2-dimensional maps and assumes pregnant women residing in tall 
buildings are exposed to the same levels of TRAP as those residing at ground level. Exposures are likely to be lower for women at higher levels, and this source of heterogeneity may bias the results toward the null, particularly when tall multi-unit residence buildings are colinear with traffic density and modeled exposure levels.

In general, relatively few studies evaluated TRAP and hypertensive disorders of pregnancy and almost all of the studies were cohort studies. The overall prevalence of hypertensive disorders of pregnancy in these cohorts is low, and the cases identified in these studies are likely more serious because the more severe cases are more likely to be diagnosed. Opportunities for more prospective studies and studies using larger data sets with improved data sources (e.g., electronic health records that include prenatal care) will increase the likelihood of capturing the full range of hypertensive disorders during pregnancy, including early- and late-onset preeclampsia, which are thought to have different etiologies. Although many studies stated that women with preexisting hypertension were excluded, given the challenges of accurately excluding those women (which would depend on when they began treatment and the quality of the source of the outcome assessment), considerable heterogeneity is likely within the study populations for this condition. However, women with preexisting hypertension may represent a particularly vulnerable group that warrants more evaluation because they are often understudied and at a high risk for developing pregnancy complications and other adverse outcomes, including those in their infants. In addition, no studies to date use personal sampling data or biomonitoring methods to determine exposure to TRAP in humans and use of those methods could improve the exposure data. Additional studies that better characterize actual TRAP exposures in pregnant women and evaluate outcomes of interest would increase the confidence in the body of evidence.

Finally, very few studies evaluated TRAP exposure and blood pressure parameters during pregnancy in experimental animal models. Studies conducted in nonpregnant animals can likely elucidate potential overlapping mechanisms but would not provide insight on how environmental exposures affect mechanisms related to blood pressure and hemodynamic regulation during pregnancy. Animal studies and mechanistic studies in humans or human cell-based systems could help elucidate mechanisms to strengthen overall conclusions.

\section{Limitations of the Systematic Review}

The hazard identification conclusions in this evaluation were based solely on the epidemiological data because there were no experimental animal studies that met the specific PECO inclusion criteria, nor were there studies that evaluated hypertensive disorders of pregnancy associated with exposure to other traffic-related air pollutants (e.g., diesel, sulfur oxides, BC). Although there are studies that evaluate effects of other traffic-related air pollutants, there were no other studies that evaluated these pollutants in relation to hypertensive disorders of pregnancy that also characterized the exposure to the extent that would allow for exposure to be reasonably attributed to traffic. Additional prospective epidemiological studies with well-characterized exposure and outcome assessments would strengthen the human evidence. In addition, this evaluation focused on primary emissions from traffic sources. Although there are studies that have evaluated effects of secondary products on hypertensive disorders of pregnancy, such as ozone, inclusion of those studies was beyond the scope of this review and were not evaluated. The dearth of animal data and exposure data are significant data gaps that need to be addressed to strengthen overall conclusions about the potential causal relationship between TRAP constituents and hypertensive disorders of pregnancy. 


\section{Conclusion}

NTP concludes that exposure to traffic-related air pollution (TRAP) is presumed to be a hazard to pregnant women for developing hypertensive disorders of pregnancy based on the available evidence across multiple measures of TRAP exposure (i.e., traffic-related $\mathrm{PM}_{2.5}$ and $\mathrm{NO}_{2}$ ) with support from studies on traffic measures (residing in high-traffic density regions or in close proximity to major roads during pregnancy).

The effect of TRAP was consistent across bodies of evidence for individual TRAP components and was supported by meta-analyses for individual traffic-related air pollutants (i.e., $\mathrm{PM}_{2.5}$ and $\mathrm{NO}_{2}$ ). There is a similar pattern of findings, but smaller effect sizes, for bodies of evidence that residing in high-traffic density regions or in close proximity to major roads are associated with developing hypertensive disorders during pregnancy. The collective evidence across the air pollutant measures and the traffic measures shows consistency in the direction of effect across multiple populations and geographic locations, strengthening the confidence in the association between the combined TRAP exposure (versus exposure to the individual TRAP components) and hypertensive disorders of pregnancy. The combined body of evidence is more robust due to the greater number of studies, the multiple mechanisms by which the individual components can affect blood pressure, and the greater likelihood of exposure to multiple components of TRAP.

Overall, the available evidence supports that exposure to TRAP increases the odds for developing hypertensive disorders of pregnancy. Because of the recognized relationship between maternal blood pressure status and the effect of hypertension during pregnancy on fetal and infant health outcomes, hypertensive disorders of pregnancy associated with TRAP exposure may have significant adverse health effects in the developing offspring. 


\section{References}

Abraham E, Rousseaux S, Agier L, Giorgis-Allemand L, Tost J, Galineau J, Hulin A, Siroux V, Vaiman D, Charles MA et al. 2018. Pregnancy exposure to atmospheric pollution and meteorological conditions and placental DNA methylation. Environ Int. 118:334-347. http://dx.doi.org/10.1016/j.envint.2018.05.007

Agency for Healthcare Research Quality (AHRQ). 2014. AHRQ training modules for the systematic reviews methods guide. http://www.effectivehealthcare.ahrq.gov/index.cfm/toolsand-resources/slide-library/.

Assibey-Mensah V, Glantz JC, Hopke PK, Jusko TA, Thevenet-Morrison K, Chalupa D, Rich DQ. 2019. Ambient wintertime particulate air pollution and hypertensive disorders of pregnancy in Monroe County, New York. Environ Res. 168:25-31.

http://dx.doi.org/10.1016/j.envres.2018.09.003

Bauer ST, Cleary KL. 2009. Cardiopulmonary complications of pre-eclampsia. Seminars in Perinatoloy. 33(3):158-165. http://dx.doi.org/10.1053/j.semperi.2009.02.008

Bellamy L, Casas JP, Hingorani AD, Williams DJ. 2007. Pre-eclampsia and risk of cardiovascular disease and cancer in later life: Systematic review and meta-analysis. Br Med J (Clin Res Ed). 335(7627):974. http://dx.doi.org/10.1136/bmj.39335.385301.BE

Boeldt DS, Bird IM. 2017. Vascular adaptation in pregnancy and endothelial dysfunction in preeclampsia. J Endocrinol. 232(1):R27-R44. http://dx.doi.org/10.1530/JOE-16-0340

Boothe VL, Boehmer TK, Wendel AM, Yip FY. 2014. Residential traffic exposure and childhood leukemia: A systematic review and meta-analysis. Am J Prev Med. 46(4):413-422. http://dx.doi.org/10.1016/j.amepre.2013.11.004

Brook RD, Rajagopalan S. 2009. Particulate matter, air pollution, and blood pressure. J Am Soc Hypertens. 3(5):332-350. http://dx.doi.org/10.1016/j.jash.2009.08.005

Choe SA, Kauderer S, Eliot MN, Glazer KB, Kingsley SL, Carlson L, Awad YA, Schwartz JD, Savitz DA, Wellenius GA. 2018. Air pollution, land use, and complications of pregnancy. Sci Total Environ. 645:1057-1064. http://dx.doi.org/10.1016/j.scitotenv.2018.07.237

Clark SL, Cotton DB, Lee W, Bishop C, Hill T, Southwick J, Pivarnik J, Spillman T, DeVore GR, Phelan J. 1989. Central hemodynamic assessment of normal term pregnancy. Am J Obstet Gynecol. 161(6):1439-1442. http://dx.doi.org/10.1016/0002-9378(89)90900-9

Cochran WG. 1954. The combination of estimates from different experiments. Biometrics. 10(1):101-129. http://dx.doi.org/10.2307/3001666

Conde-Agudelo A, Althabe F, Belizan JM, Kafury-Goeta AC. 1999. Cigarette smoking during pregnancy and risk of preeclampsia: A systematic review. Am J Obstet Gynecol. 181(4):10261035. http://dx.doi.org/10.1016/S0002-9378(99)70341-8

Coogan PF, White LF, Jerrett M, Brook RD, Su JG, Seto E, Burnett R, Palmer JR, Rosenberg L. 2012. Air pollution and incidence of hypertension and diabetes mellitus in black women living in 
Los Angeles. Circulation. 125(6):767-772.

http://dx.doi.org/10.1161/CIRCULATIONAHA.111.052753

Costa J, Rice H, Cardwell C, Hunter A, Ong S. 2010. An assessment of vascularity and flow intensity of the placenta in normal pregnancy and pre-eclampsia using three-dimensional ultrasound. J Matern Fetal Neonatal Med. 23(8):894-899.

http://dx.doi.org/10.3109/14767051003649862

Dadvand P, Figueras F, Basagana X, Beelen R, Martinez D, Cirach M, Schembari A, Hoek G, Brunekreef B, Nieuwenhuijsen MJ. 2013. Ambient air pollution and preeclampsia: A spatiotemporal analysis. Environ Health Perspect. 121(11-12):1365-1371.

http://dx.doi.org/10.1289/ehp.1206430

DerSimonian R, Laird N. 1986. Meta-analysis in clinical trials. Control Clin Trials. 7(3):177188. http://dx.doi.org/10.1016/0197-2456(86)90046-2

Doyle LW. 2008. Cardiopulmonary outcomes of extreme prematurity. Semin Perinatol. 32(1):28-34. http://dx.doi.org/10.1053/j.semperi.2007.12.005

Duley L. 2009. The global impact of pre-eclampsia and eclampsia. Semin Perinatol. 33(3):130137. http://dx.doi.org/10.1053/j.semperi.2009.02.010

Egger M, Smith GD, Schneider M, Minder C. 1997. Bias in meta-analysis detected by a simple, graphical test. Br Med J (Clin Res Ed). 315(7109):629-634.

http://dx.doi.org/10.1136/bmj.315.7109.629

Engel SM, Scher E, Wallenstein S, Savitz DA, Alsaker ER, Trogstad L, Magnus P. 2013. Maternal active and passive smoking and hypertensive disorders of pregnancy: Risk with trimester-specific exposures. Epidemiology. 24(3):379-386.

http://dx.doi.org/10.1097/EDE.0b013e3182873a73

England L, Zhang J. 2007. Smoking and risk of preeclampsia: A systematic review. Front Biosci. 12:2471-2481. http://dx.doi.org/10.2741/2248

Fecht D, Hansell AL, Morley D, Dajnak D, Vienneau D, Beevers S, Toledano MB, Kelly FJ, Anderson HR, Gulliver J. 2016. Spatial and temporal associations of road traffic noise and air pollution in London: Implications for epidemiological studies. Environ Int. 88:235-242.

http://dx.doi.org/10.1016/j.envint.2015.12.001

Gamboa A, Shibao C, Diedrich A, Choi L, Pohar B, Jordan J, Paranjape S, Farley G, Biaggioni I. 2007. Contribution of endothelial nitric oxide to blood pressure in humans. Hypertension. 49(1):170-177. http://dx.doi.org/10.1161/01.HYP.0000252425.06216.26

George EM, Granger JP. 2011. Mechanisms and potential therapies for preeclampsia. Curr Hypertens Rep. 13(4):269-275. http://dx.doi.org/10.1007/s11906-011-0204-0

Guo Y, Barnett AG, Zhang Y, Tong S, Yu W, Pan X. 2010. The short-term effect of air pollution on cardiovascular mortality in Tianjin, China: Comparison of time series and case-crossover analyses. Sci Total Environ. 409(2):300-306. http://dx.doi.org/10.1016/j.scitotenv.2010.10.013 
Guyatt GH, Oxman AD, Akl EA, Kunz R, Vist G, Brozek J, Norris S, Falck-Ytter Y, Glasziou P, Debeer $\mathrm{H}$ et al. 2011. GRADE guidelines: 1. Introduction-GRADE evidence profiles and summary of findings tables. J Clin Epidemiol. 64(4):383-394.

http://dx.doi.org/10.1016/j.jclinepi.2010.04.026

Haberzettl P, Conklin DJ, Abplanalp W, T., Bhatnagar A, O'Toole TE. 2018. Inhalation of fine particulate matter impairs endothelial progenitor cell function via pulmonary oxidative stress. Arteriosclerosis, Thrombosis, and Vascular Biology. 38(1):131-142.

https://doi.org/10.1161/ATVBAHA.117.309971

Health Effects Institute (HEI). 2010. Traffic-related air pollution: A critical review of the literature on emissions, exposure, and health effects. Boston, MA: Health Effects Institute. https://www.healtheffects.org/publication/traffic-related-air-pollution-critical-review-literatureemissions-exposure-and-health.

Hettfleisch K, Bernardes LS, Carvalho MA, Pastro LD, Vieira SE, Saldiva SR, Saldiva P, Francisco RP. 2017. Short-term exposure to urban air pollution and influences on placental vascularization indexes. Environ Health Perspect. 125(4):753-759.

http://dx.doi.org/10.1289/EHP300

Higgins JPT, Green S. 2011. Cochrane Handbook for Systematic Reviews of Interventions. The Cochrane Collaboration.

Hu H, Ha S, Roth J, Kearney G, Talbott EO, Xu X. 2014. Ambient air pollution and hypertensive disorders of pregnancy: A systematic review and meta-analysis. Atmos Environ. 97:336-345. http://dx.doi.org/10.1016/j.atmosenv.2014.08.027

Jeyabalan A, Powers RW, Durica AR, Harger GF, Roberts JM, Ness RB. 2008. Cigarette smoke exposure and angiogenic factors in pregnancy and preeclampsia. Am J Hypertens. 21(8):943947. http://dx.doi.org/10.1038/ajh.2008.219

Karumanchi SA, Levine RJ. 2010. How does smoking reduce the risk of preeclampsia? Hypertension. 55(5):1100-1101. http://dx.doi.org/10.1161/HYPERTENSIONAHA.109.148973

Krupp J, Boeldt DS, Yi FX, Grummer MA, Bankowski Anaya HA, Shah DM, Bird IM. 2013. The loss of sustained $\mathrm{Ca}(2+)$ signaling underlies suppressed endothelial nitric oxide production in preeclamptic pregnancies: Implications for new therapy. Am J Physiol. 305(7):H969-979. http://dx.doi.org/10.1152/ajpheart.00250.2013

Krzyzanowski M, Vandenberg J, Stieb D. 2005. Perspectives on air quality policy issues in Europe and North America. Journal of Toxicology and Environmental Health. 68(13-14):10571061. http://dx.doi.org/10.1080/15287390590935897

Lassegue B, Griendling KK. 2004. Reactive oxygen species in hypertension: An update. Am J Hypertens. 17(9):852-860. http://dx.doi.org/10.1016/j.amjhyper.2004.02.004

Link MS, Dockery DW. 2010. Air pollution and the triggering of cardiac arrhythmias. Curr Opin Cardiol. 25(1):16-22. http://dx.doi.org/10.1097/HCO.0b013e32833358cd

Madsen C, Haberg SE, Aamodt G, Stigum H, Magnus P, London SJ, Nystad W, Nafstad P. 2018. Preeclampsia and hypertension during pregnancy in areas with relatively low levels of 
traffic air pollution. Matern Child Health J. 22(4):512-519. http://dx.doi.org/10.1007/s10995$\underline{017-2417-6}$

Malmqvist E, Jakobsson K, Tinnerberg H, Rignell-Hydbom A, Rylander L. 2013. Gestational diabetes and preeclampsia in association with air pollution at levels below current air quality guidelines. Environ Health Perspect. 121(4):488-493. http://dx.doi.org/10.1289/ehp.1205736

Mantel N, Haenszel W. 1959. Statistical aspects of the analysis of data from retrospective studies of disease. J Natl Cancer Inst. 22(4):719-748.

Miller CN, Stewart EJ, Snow SJ, Williams WC, Richards JH, Thompson LC, Schladweiler MC, Farraj AK, Kodavanti UP, Dye JA. 2019. Ozone exposure during implantation increases serum bioactivity in HTR-8/SVneo trophoblasts. Toxicol Sci. 168(2):535-550.

http://dx.doi.org/10.1093/toxsci/kfz003

Miranda ML, Edwards SE, Chang HH, Auten RL. 2013. Proximity to roadways and pregnancy outcomes. J Expo Sci Environ Epidemiol. 23(1):32-38. http://dx.doi.org/10.1038/jes.2012.78

Mozaffarian D, Benjamin EJ, Go AS, Arnett DK, Blaha MJ, Cushman M, Das SR, de Ferranti S, Despres JP, Fullerton HJ et al. 2016. Heart disease and stroke statistics-2016 update: A report from the American Heart Association. Circulation. 133(4):e38-360.

http://dx.doi.org/10.1161/CIR.0000000000000350

National Toxicology Program (NTP). 2015. Handbook for conducting a literature-based health assessment using OHAT approach for systematic review and evidence integration - January 9 2015. RTP, NC. http://ntp.niehs.nih.gov/go/38673. [Accessed: 25 Jan 2015]

National Toxicology Program (NTP). 2019a. Health Assessment Workspace Collaborative (HAWC) page for traffic-related air pollution and hypertensive disorders during pregnancy. https://hawcproject.org/assessment/60/.

National Toxicology Program (NTP). 2019b. MGRAPH-7: Traffic-related air pollution and hypertensive disorders of pregnancy supplementary files. Research Triangle Park, NC: U.S. Department of Health and Human Services, National Institute of Environmental Health Sciences, National Toxicology Program. https://doi.org/10.22427/NTP-DATA-MGRAPH-7.

Nedeljkovic ZS, Gokce N, Loscalzo J. 2003. Mechanisms of oxidative stress and vascular dysfunction. Postgrad Med J. 79(930):195-199; quiz 198-200.

http://dx.doi.org/10.1136/pmj.79.930.195

Olsson D, Mogren I, Eneroth K, Forsberg B. 2015. Traffic pollution at the home address and pregnancy outcomes in Stockholm, Sweden. Br Med J Open. 5(8):e007034.

http://dx.doi.org/10.1136/bmjopen-2014-007034

Pedersen M, Halldorsson TI, Olsen SF, Hjortebjerg D, Ketzel M, Grandstrom C, RaaschouNielsen O, Sorensen M. 2017. Impact of road traffic pollution on pre-eclampsia and pregnancyinduced hypertensive disorders. Epidemiology. 28(1):99-106.

http://dx.doi.org/10.1097/EDE.0000000000000555

Pedersen M, Stayner L, Slama R, Sorensen M, Figueras F, Nieuwenhuijsen MJ, RaaschouNielsen O, Dadvand P. 2014. Ambient air pollution and pregnancy-induced hypertensive 
disorders: A systematic review and meta-analysis. Hypertension. 64(3):494-+. http://dx.doi.org/10.1161/HYPERTENSIONAHA.114.03545

Pereira G, Haggar F, Shand AW, Bower C, Cook A, Nassar N. 2013. Association between preeclampsia and locally derived traffic-related air pollution: A retrospective cohort study. Journal of Epidemiology and Community Health. 67(2):147-152. http://dx.doi.org/10.1136/jech-2011$\underline{200805}$

Rooney AA, Boyles AL, Wolfe MS, Bucher JR, Thayer KA. 2014. Systematic review and evidence integration for literature-based environmental health science assessments. Environ Health Perspect. 122(7):711-718. http://dx.doi.org/10.1289/ehp.1307972

Rooney AA, Cooper GS, Jahnke GD, Lam J, Morgan RL, Boyles AL, Ratcliffe JM, Kraft AD, Schünemann HJ, Schwingl P et al. 2016. How credible are the study results? Evaluating and applying internal validity tools to literature-based assessments of environmental health hazards. Environ Int. 92-93:617-629. https://doi.org/10.1016/j.envint.2016.01.005

Rudra CB, Williams MA, Sheppard L, Koenig JQ, Schiff MA. 2011. Ambient carbon monoxide and fine particulate matter in relation to preeclampsia and preterm delivery in western Washington State. Environ Health Perspect. 119(6):886-892. http://dx.doi.org/10.1289/ehp.1002947

Savitz DA, Elston B, Bobb JF, Clougherty JE, Dominici F, Ito K, Johnson S, McAlexander T, Ross Z, Shmool JL et al. 2015. Ambient fine particulate matter, nitrogen dioxide, and hypertensive disorders of pregnancy in New York City. Epidemiology. 26(5):748-757. http://dx.doi.org/10.1097/EDE.0000000000000349

Sears CG, Braun JM, Ryan PH, Xu Y, Werner EF, Lanphear BP, Wellenius GA. 2018. The association of traffic-related air and noise pollution with maternal blood pressure and hypertensive disorders of pregnancy in the HOME study cohort. Environ Int. 121(Pt 1):574-581. http://dx.doi.org/10.1016/j.envint.2018.09.049

Sorensen M, Hoffmann B, Hvidberg M, Ketzel M, Jensen SS, Andersen ZJ, Tjonneland A, Overvad K, Raaschou-Nielsen O. 2012. Long-term exposure to traffic-related air pollution associated with blood pressure and self-reported hypertension in a Danish cohort. Environ Health Perspect. 120(3):418-424. http://dx.doi.org/10.1289/ehp.1103631

StataCorp. 2017. Stata statistical software: Release 15. College Station, TX: StataCorp LLC.

Sun Q, Yue P, Ying Z, Cardounel AJ, Brook RD, Devlin R, Hwang JS, Zweier JL, Chen LC, Rajagopalan S. 2008. Air pollution exposure potentiates hypertension through reactive oxygen species-mediated activation of Rho/ROCK. Arteriosclerosis, Thrombosis, and Vascular Biology. 28(10):1760-1766. http://dx.doi.org/10.1161/ATVBAHA.108.166967

The American College of Obstetricians Gynecologists (ACOG). 2013. Hypertension in pregnancy. Washington, DC: The American College of Obstetricians and Gynecologists. https://www.acog.org/Clinical-Guidance-and-Publications/Task-Force-and-Work-GroupReports/Hypertension-in-Pregnancy. 
U.S. Environmental Protection Agency (USEPA). 2008. Integrated Science Assessment (ISA) for oxides of nitrogen and sulfur: Ecological criteria. RTP, NC: U.S. Environmental Protection Agency, Office of Research and Development, National Center for Environmental Assessment. EPA/600/R-08/082F. https://cfpub.epa.gov/ncea/isa/recordisplay.cfm?deid=201485.

U.S. Environmental Protection Agency (USEPA). 2009. Integrated Science Assessment (ISA) for particulate matter. RTP, NC: U.S. Environmental Protection Agency, Office of Research and Development, National Center for Environmental Assessment. EPA/600/R-08/139F. https://cfpub.epa.gov/ncea/risk/recordisplay.cfm?deid=216546.

U.S. Environmental Protection Agency (USEPA). 2010. Integrated Science Assessment (ISA) for carbon monoxide. RTP, NC: U.S. Environmental Protection Agency, Office of Research and Development, National Center for Environmental Assessment. EPA/600/R-09/019F. https://cfpub.epa.gov/ncea/isa/recordisplay.cfm?deid=218686.

U.S. Environmental Protection Agency (USEPA). 2016. Integrated Science Assessment (ISA) for oxides of nitrogen-health criteria (final report). RTP, NC: U.S. Environmental Protection Agency, Office of Research and Development, National Center for Environmental Assessment. EPA/600/R-15/068. https://cfpub.epa.gov/ncea/isa/recordisplay.cfm?deid=310879.

van den Hooven EH, de Kluizenaar Y, Pierik FH, Hofman A, van Ratingen SW, Zandveld PY, Mackenbach JP, Steegers EA, Miedema HM, Jaddoe VW. 2011. Air pollution, blood pressure, and the risk of hypertensive complications during pregnancy: The generation R study. Hypertension. 57(3):406-412. http://dx.doi.org/10.1161/HYPERTENSIONAHA.110.164087

van den Hooven EH, Jaddoe VW, de Kluizenaar Y, Hofman A, Mackenbach JP, Steegers EA, Miedema HM, Pierik FH. 2009. Residential traffic exposure and pregnancy-related outcomes: A prospective birth cohort study. Environ Health. 8:59. http://dx.doi.org/10.1186/1476-069X-8-59

Venditti CC, Casselman R, Young I, Karumanchi SA, Smith GN. 2014. Carbon monoxide prevents hypertension and proteinuria in an adenovirus sFlt-1 preeclampsia-like mouse model. PLoS One. 9(9). http://dx.doi.org/10.1371/journal.pone.0106502

Wang Y, Gu Y, Loyd S, Jia X, Groome LJ. 2015. Increased urinary levels of podocyte glycoproteins, matrix metallopeptidases, inflammatory cytokines, and kidney injury biomarkers in women with preeclampsia. Am J Physiol. 309(12):F1009-1017.

http://dx.doi.org/10.1152/ajprenal.00257.2015

Wei J, Liu CX, Gong TT, Wu QJ, Wu L. 2015. Cigarette smoking during pregnancy and preeclampsia risk: A systematic review and meta-analysis of prospective studies. Oncotarget. 6(41):43667-43678. http://dx.doi.org/10.18632/oncotarget.6190

Wikstrom AK, Stephansson O, Cnattingius S. 2010. Tobacco use during pregnancy and preeclampsa risk: Effects of cigarette smoking and snuff. Hypertension. 55(5):1254-1259. http://dx.doi.org/10.1161/HYPERTENSIONAHA.109.147082

World Health Organization (WHO). 2016. Ambient (outdoor) air quality and health: Fact sheet. World Health Organization. http://www.who.int/mediacentre/factsheets/fs313/en/. 
Wu J, Wilhelm M, Chung J, Ritz B. 2011. Comparing exposure assessment methods for trafficrelated air pollution in an adverse pregnancy outcome study. Environ Res. 111(5):685-692.

http://dx.doi.org/10.1016/j.envres.2011.03.008

Wu M, Ries JJ, Proietti E, Vogt D, Hahn S, Hoesli I. 2016. Development of late-onset preeclampsia in association with road densities as a proxy for traffic-related air pollution. Fetal Diagn Ther. 39(1):21-27. http://dx.doi.org/10.1159/000381802

Yorifuji T, Naruse H, Kashima S, Murakoshi T, Doi H. 2015. Residential proximity to major roads and obstetrical complications. Sci Total Environ. 508:188-192.

http://dx.doi.org/10.1016/j.scitotenv.2014.11.077 


\section{Appendix A. Data Figures}

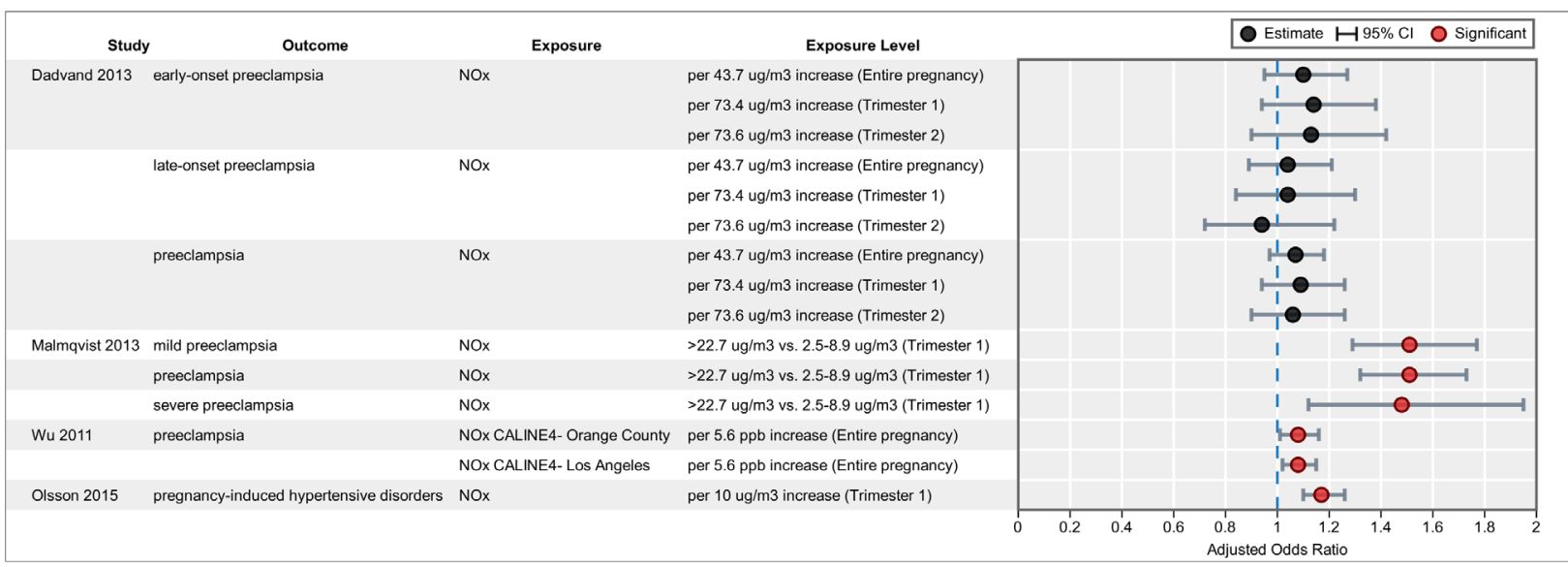

Figure A-1. NO $\mathrm{N}_{\mathrm{x}}$ Exposure and Hypertensive Disorders of Pregnancy in Humans

Results are indicated as significant if the associated confidence interval did not encompass 1.0, regardless of whether the study reported $\mathrm{p}$ values. Interactive figure and additional study details in $\underline{\mathrm{HAWC}}$ (NTP, 2019a). 


\section{Appendix B. Literature Search Strategy}

The search terms for PubMed, Scopus, and Web of Science are provided below. The specific search strategies for other databases are available in the protocol (Appendix G).

Table B-1. Literature Search Strategy

\begin{tabular}{|c|c|c|}
\hline Database & Set & Search Terms \\
\hline \multirow[t]{2}{*}{ PubMed } & 1 & $\begin{array}{l}\text { "air pollution"[mh:noexp] OR "air pollutants"[mh:noexp] OR (("air pollution"[tiab] OR } \\
\text { "air pollutant"[tiab] OR "air pollutants"[tiab]) NOT (indoor*[tiab] OR household[tiab])) } \\
\text { OR "particulate matter"[mh:noexp] OR smog[mh] OR soot[mh] OR "particulate } \\
\text { matter"[tiab] OR PM2.5[tiab] OR "PM(2.5)"[tiab] OR PM10[tiab] OR "PM(10)"[tiab] } \\
\text { OR smog[tiab] OR soot[tiab] OR "carbon black"[tiab] OR "black carbon"[tiab] OR } \\
\text { "elemental carbon"[tiab] OR ((air[tiab] OR airborne[tiab] OR coarse[tiab] OR } \\
\text { ultrafine[tiab] OR fine[tiab]) AND (particle*[tiab] OR particulate*[tiab])) OR "vehicle } \\
\text { emissions"[mh] OR motor vehicles[mh] OR ((vehicle[tiab] OR vehicles[tiab] OR } \\
\text { vehicular[tiab] OR auto[tiab] OR automobile[tiab] OR bus[tiab] OR buses[tiab] OR } \\
\text { car[tiab] OR truck*[tiab] OR engine[tiab] OR transport[tiab]) AND (emissions[tiab] OR } \\
\text { exhaust[tiab] OR fume*[tiab])) OR (traffic[tiab] NOT (safety[tiab] OR accident*[tiab] } \\
\text { OR injur*[tiab] OR collision*[tiab] OR crash*[tiab])) OR ((proximity OR near) AND } \\
\text { (road*[tiab] OR highway*[tiab] OR freeway*[tiab] OR motorway*[tiab])) OR } \\
\text { ((air[tiab] OR outdoor[tiab] OR ambient[tiab] OR pollut*[tiab] OR emissions[tiab] OR } \\
\text { exhaust*[tiab]) AND ("sulfur dioxide"[mh] OR "sulfur dioxide"[tiab] OR S02[tiab] OR } \\
\text { ozone[mh] OR ozone[tiab] OR O3[tiab] OR "hydrogen sulfide"[mh] OR "hydrogen } \\
\text { sulfide"[tiab] OR H2S[tiab] OR "carbon monoxide"[mh] OR "carbon monoxide"[tiab] } \\
\text { OR "nitric oxide"[tiab] OR "nitrogen oxide"[tiab] OR "nitrogen oxides"[tiab] OR } \\
\text { "nitrogen dioxide"[mh] OR "nitrogen dioxide"[tiab] OR NOx [tiab] OR "NO(x)"[tiab] } \\
\text { OR NO2[tiab])) OR "volatile organic compounds"[mh] OR "fossil fuels"[mh] OR } \\
\text { "volatile organic compounds"[tiab] OR gasoline*[tiab] OR diesel[tiab] OR petrol*[tiab] } \\
\text { OR Polycyclic hydrocarbons, aromatic[mh:noexp] OR "benzo(a)pyrene"[mh] OR } \\
\text { benzene[mh] OR "polycyclic aromatic hydrocarbons"[tiab] OR "benzopyrene"[tiab] OR } \\
\text { "benzo a pyrene"[tiab] OR "3,4-benzopyrene"[tiab] OR benzene[tiab] }\end{array}$ \\
\hline & 2 & $\begin{array}{l}\text { AND } \\
\text { "Hypertension, Pregnancy-Induced"[Mesh] OR "Gestational Hypertension"[tiab] OR } \\
\text { "pregnancyinduced hypertension"[tiab] OR (pregnan*[tiab] AND hypertens*[tiab]) OR } \\
\text { pre-eclampsia[tiab] OR preeclampsia[tiab] OR (pregnan*[tiab] AND toxemia*[tiab]) }\end{array}$ \\
\hline Scopus & 1 & $\begin{array}{l}\text { ((("air pollution" OR "air pollutant" OR "air pollutants") AND NOT (indoor* OR } \\
\text { household)) OR "particulate matter" OR PM2.5 OR PM10 OR smog OR soot OR } \\
\text { "carbon black" OR "black carbon" OR "elemental carbon" OR ((air OR airborne OR } \\
\text { coarse OR ultrafine OR fine) AND (particle* OR particulate*)) OR ((vehicle OR } \\
\text { vehicles OR vehicular OR auto OR automobile OR bus OR buses OR car OR truck* OR } \\
\text { engine OR transport) AND (emissions OR exhaust OR fume*)) OR (traffic AND NOT } \\
\text { (safety OR accident* OR injur* OR collision* OR crash*)) OR ((proximity OR near) } \\
\text { AND (road* OR highway* OR freeway* OR motorway*)) OR ((air OR outdoor OR } \\
\text { ambient OR pollut* OR emissions OR exhaust*) AND ("sulfur dioxide" OR S02 OR } \\
\text { ozone OR O3 OR "hydrogen sulfide" OR H2S OR "carbon monoxide" OR "nitric } \\
\text { oxide" OR "nitrogen oxide" OR "nitrogen oxides" OR "nitrogen dioxide" OR NOx OR } \\
\text { "NO(x)" OR NO2)) OR "volatile organic" OR "fossil fuel" OR "fossil fuels" OR } \\
\text { gasoline* OR diesel OR petrol* OR "polycyclic aromatic hydrocarbons" OR } \\
\text { "benzopyrene" OR "benzo a pyrene" OR "3,4-benzopyrene" OR benzene) }\end{array}$ \\
\hline
\end{tabular}


Systematic Review of TRAP and Hypertensive Disorders of Pregnancy

\begin{tabular}{|c|c|c|}
\hline Database & Set & Search Terms \\
\hline \multirow{3}{*}{$\begin{array}{l}\text { Web of } \\
\text { Science }\end{array}$} & 2 & $\begin{array}{l}\text { AND } \\
\text { ("Gestational Hypertension" OR "pregnancy-induced hypertension" OR (pregnan* w/8 } \\
\text { hypertens*) OR pre-eclampsia OR preeclampsia OR (pregnan* w/8 toxemia*)) }\end{array}$ \\
\hline & 1 & $\begin{array}{l}\text { ((("air pollution" OR "air pollutant" OR "air pollutants") NOT (indoor* OR household)) } \\
\text { OR "particulate matter" OR PM2.5 OR "PM(2.5)" OR PM10 OR "PM(10)" OR smog } \\
\text { OR soot OR "carbon black" OR "black carbon" OR "elemental carbon" OR ((air OR } \\
\text { airborne OR coarse OR ultrafine OR fine) AND (particle* OR particulate*)) OR } \\
\text { ((vehicle OR vehicles OR vehicular OR auto OR automobile OR bus OR buses OR car } \\
\text { OR truck* OR engine OR transport) AND (emissions OR exhaust OR fume*)) OR } \\
\text { (traffic NOT (safety OR accident* OR injur* OR collision* OR crash*)) OR } \\
\text { ((proximity OR nearby) AND (road* OR highway* OR freeway* OR motorway*)) OR } \\
\text { ((air OR outdoor OR ambient OR pollut* OR emissions OR exhaust*) AND ("sulfur } \\
\text { dioxide" OR S02 OR ozone OR O3 OR "hydrogen sulfide" OR H2S OR "carbon } \\
\text { monoxide" OR "nitric oxide" OR "nitrogen oxide" OR "nitrogen oxides" OR "nitrogen } \\
\text { dioxide" OR NOx OR NO2)) OR "volatile organic" OR "fossil fuel" OR "fossil fuels" } \\
\text { OR gasoline* OR diesel OR petrol* OR "polycyclic aromatic hydrocarbons" OR } \\
\text { "benzopyrene" OR "benzo a pyrene" OR "3,4-benzopyrene" OR benzene) }\end{array}$ \\
\hline & 2 & $\begin{array}{l}\text { AND } \\
\text { ("Gestational Hypertension" OR "pregnancy-induced hypertension" OR (pregnan* } \\
\text { near/8 hypertens*) OR pre-eclampsia OR preeclampsia OR (pregnan* near/8 toxemia*)) }\end{array}$ \\
\hline
\end{tabular}




\section{Appendix C. List of Included Studies}

\section{C.1. Studies in Humans}

Choe SA, Kauderer S, Eliot MN, Glazer KB, Kingsley SL, Carlson L, Awad YA, Schwartz JD, Savitz DA, Wellenius GA. 2018. Air pollution, land use, and complications of pregnancy. Sci Total Environ. 645:1057-1064. http://dx.doi.org/10.1016/j.scitotenv.2018.07.237

Dadvand P, Figueras F, Basagana X, Beelen R, Martinez D, Cirach M, Schembari A, Hoek G, Brunekreef B, Nieuwenhuijsen MJ. 2013. Ambient air pollution and preeclampsia: A spatiotemporal analysis. Environ Health Perspect. 121(11-12):1365-1371.

http://dx.doi.org/10.1289/ehp.1206430

Huang X, Qiu J, Zhang Y, Qiu W, He X, Wang Y, Sun Q, Zhao N, Cui H, Liu S et al. 2015. Ambient air pollutant PM10 and risk of pregnancy-induced hypertension in urban China. Environ Res Lett. 10(8). 1 http://dx.doi.org/0.1088/1748-9326/10/8/084025

Madsen C, Haberg SE, Aamodt G, Stigum H, Magnus P, London SJ, Nystad W, Nafstad P. 2018. Preeclampsia and hypertension during pregnancy in areas with relatively low levels of traffic air pollution. Matern Child Health J. 22(4):512-519. http://dx.doi.org/10.1007/s10995$\underline{017-2417-6}$

Malmqvist E, Jakobsson K, Tinnerberg H, Rignell-Hydbom A, Rylander L. 2013. Gestational diabetes and preeclampsia in association with air pollution at levels below current air quality guidelines. Environ Health Perspect. 121(4):488-493. http://dx.doi.org/10.1289/ehp.1205736

Miranda ML, Edwards SE, Chang HH, Auten RL. 2013. Proximity to roadways and pregnancy outcomes. J Expo Sci Environ Epidemiol. 23(1):32-38.

http://dx.doi.org/10.1038/jes.2012.78Olsson D, Mogren I, Eneroth K, Forsberg B. 2015. Traffic pollution at the home address and pregnancy outcomes in Stockholm, Sweden. Br Med J Open. 5(8):e007034. http://dx.doi.org/10.1136/bmjopen-2014-007034

Pedersen M, Halldorsson TI, Olsen SF, Hjortebjerg D, Ketzel M, Grandstrom C, RaaschouNielsen O, Sorensen M. 2017. Impact of road traffic pollution on pre-eclampsia and pregnancyinduced hypertensive disorders. Epidemiology. 28(1):99-106.

http://dx.doi.org/10.1097/EDE.0000000000000555

Pereira G, Haggar F, Shand AW, Bower C, Cook A, Nassar N. 2013. Association between preeclampsia and locally derived traffic-related air pollution: A retrospective cohort study. $\mathrm{J}$ Epidemiol Community Health. 67(2):147-152. http://dx.doi.org/10.1136/jech-2011-200805

Rudra CB, Williams MA, Sheppard L, Koenig JQ, Schiff MA. 2011. Ambient carbon monoxide and fine particulate matter in relation to preeclampsia and preterm delivery in western Washington State. Environ Health Perspect. 119(6):886-892.

http://dx.doi.org/10.1289/ehp.1002947

Savitz DA, Elston B, Bobb JF, Clougherty JE, Dominici F, Ito K, Johnson S, McAlexander T, Ross Z, Shmool JL et al. 2015. Ambient fine particulate matter, nitrogen dioxide, and 
hypertensive disorders of pregnancy in New York City. Epidemiology. 26(5):748-757. http://dx.doi.org/10.1097/EDE.0000000000000349

Sears CG, Braun JM, Ryan PH, Xu Y, Werner EF, Lanphear BP, Wellenius GA. 2018. The association of traffic-related air and noise pollution with maternal blood pressure and hypertensive disorders of pregnancy in the HOME study cohort. Environmental International. 121(Pt 1):574-581. http://dx.doi.org/10.1016/j.envint.2018.09.049

van den Hooven EH, Jaddoe VW, de Kluizenaar Y, Hofman A, Mackenbach JP, Steegers EA, Miedema HM, Pierik FH. 2009. Residential traffic exposure and pregnancy-related outcomes: A prospective birth cohort study. Environ Health. 8:59. http://dx.doi.org/10.1186/1476-069X-8-59

van den Hooven EH, de Kluizenaar Y, Pierik FH, Hofman A, van Ratingen SW, Zandveld PY, Mackenbach JP, Steegers EA, Miedema HM, Jaddoe VW. 2011. Air pollution, blood pressure, and the risk of hypertensive complications during pregnancy: The generation R study. Hypertension. 57(3):406-412. http://dx.doi.org/10.1161/HYPERTENSIONAHA.110.164087

Wu J, Wilhelm M, Chung J, Ritz B. 2011. Comparing exposure assessment methods for trafficrelated air pollution in an adverse pregnancy outcome study. Environ Res. 111(5):685-692. http://dx.doi.org/10.1016/j.envres.2011.03.008

Wu M, Ries JJ, Proietti E, Vogt D, Hahn S, Hoesli I. 2016. Development of late-onset preeclampsia in association with road densities as a proxy for traffic-related air pollution. Fetal Diagn Ther. 39(1):21-27. http://dx.doi.org/10.1159/000381802

Yorifuji T, Naruse H, Kashima S, Murakoshi T, Doi H. 2015. Residential proximity to major roads and obstetrical complications. Sci Total Environ. 508:188-192. http://dx.doi.org/10.1016/j.scitotenv.2014.11.077

\section{C.2. Studies in Nonhuman Animals}

Venditti CC, Casselman R, Young I, Karumanchi SA, Smith GN. 2014. Carbon monoxide prevents hypertension and proteinuria in an adenovirus sFlt-1 preeclampsia-like mouse model. PLoS One. 9(9). http://dx.doi.org/10.1371/journal.pone.0106502 


\section{Appendix D. Risk-of-bias Figures}

\section{Figures}

Figure D-1. Risk-of-bias Heatmap: Other Pollutants and Hypertensive Disorders of Pregnancy for Animal Studies ...................................................................... D-2

Figure D-2. Risk-of-bias Heatmap: Other Pollutants and Hypertensive Disorders of Pregnancy for Epidemiological Studies ......................................................... D-2

Figure D-3. Risk-of-bias Bar Chart: Other Pollutants and Hypertensive Disorders of Pregnancy for Animal Studies D-3

Figure D-4. Risk-of-bias Bar Chart: Other Pollutants and Hypertensive Disorders of Pregnancy for Epidemiological Studies 


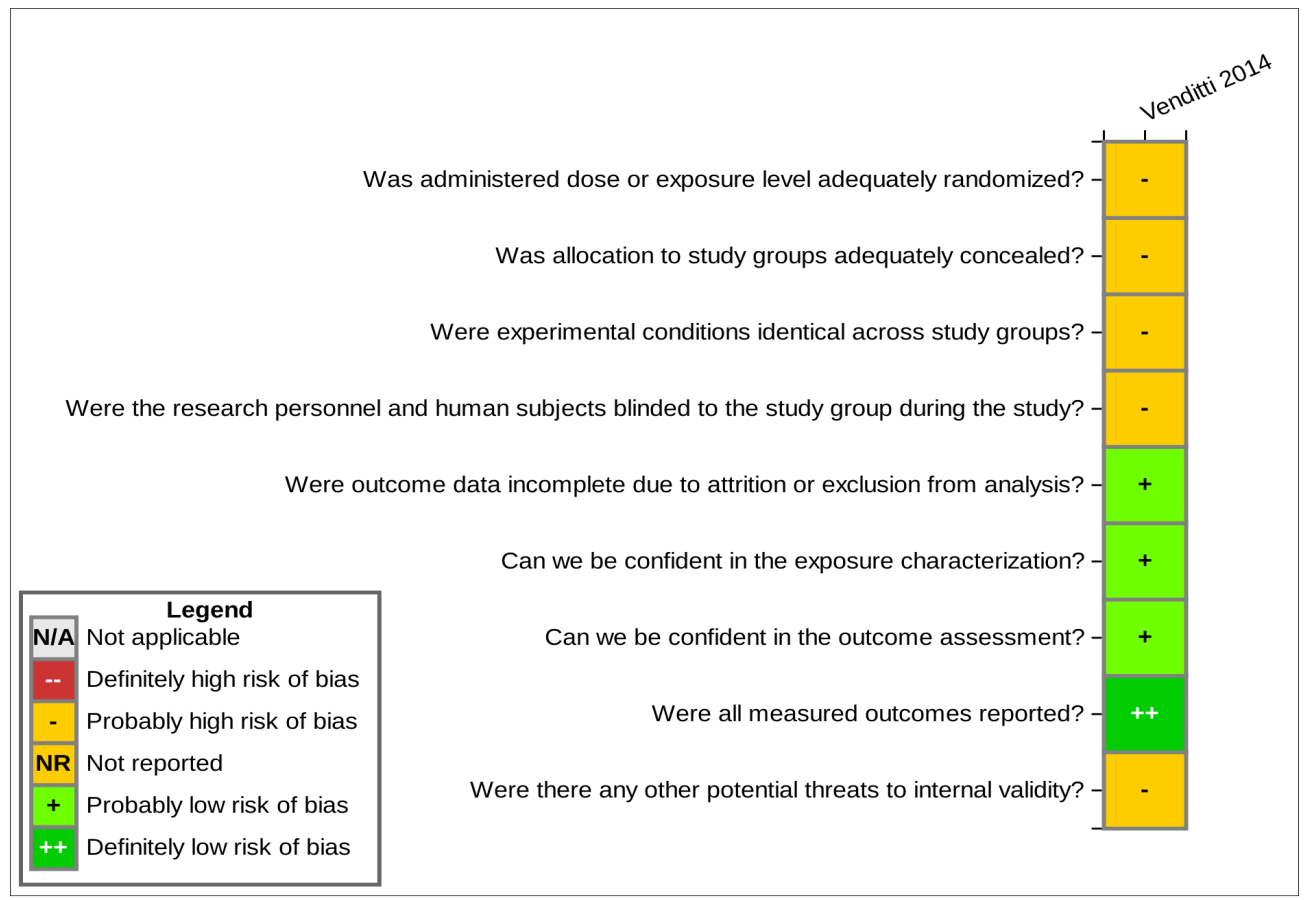

Figure D-1. Risk-of-bias Heatmap: Other Pollutants and Hypertensive Disorders of Pregnancy for Animal Studies

Interactive figure and additional study details in $\underline{\mathrm{HAWC}}$ (NTP, 2019a).

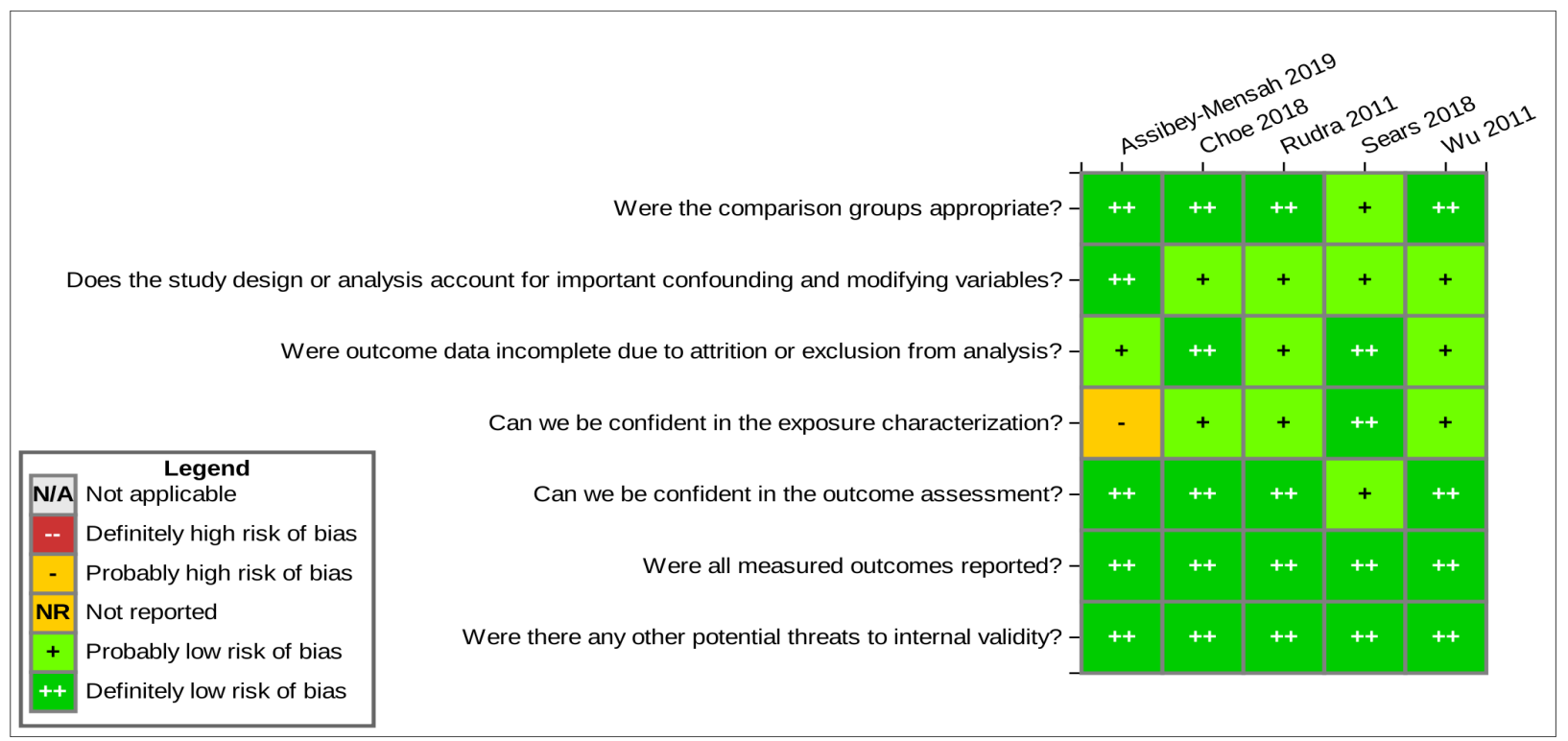

Figure D-2. Risk-of-bias Heatmap: Other Pollutants and Hypertensive Disorders of Pregnancy for Epidemiological Studies

Interactive figure and additional study details in $\underline{\mathrm{HAWC}}$ (NTP, 2019a). 
Systematic Review of TRAP and Hypertensive Disorders of Pregnancy

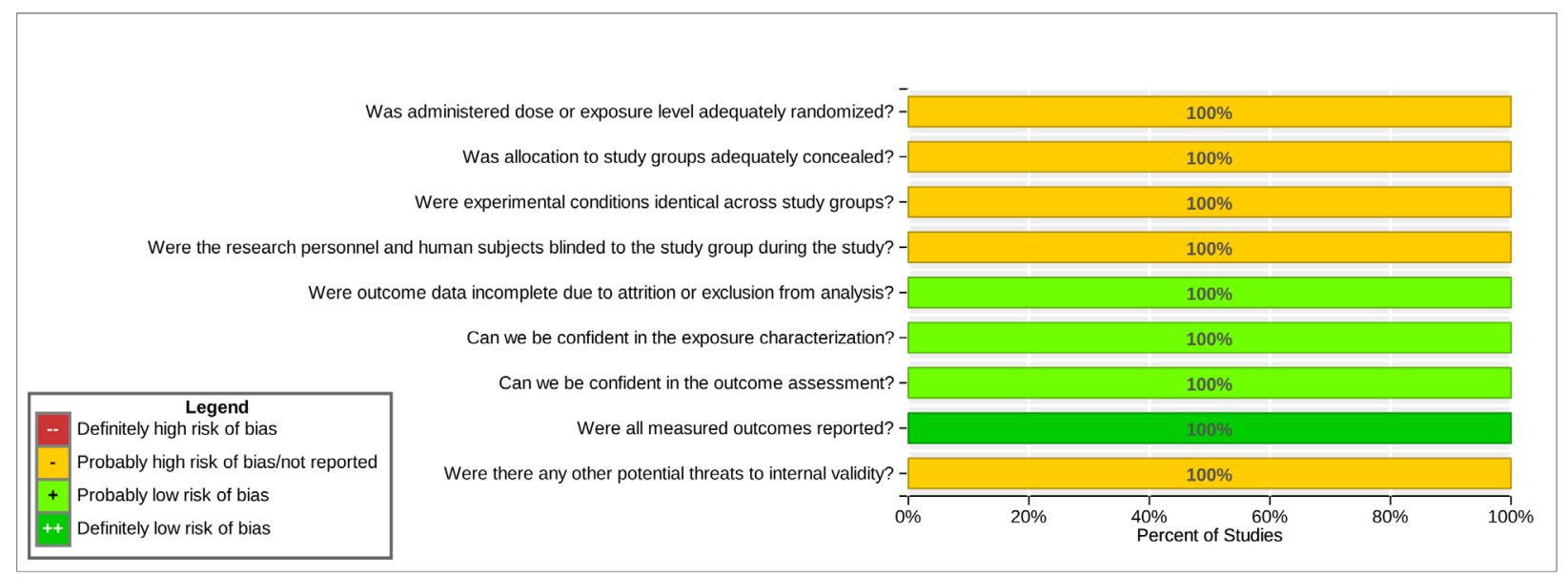

Figure D-3. Risk-of-bias Bar Chart: Other Pollutants and Hypertensive Disorders of Pregnancy for Animal Studies

Interactive figure and additional study details in HAWC (NTP, 2019a).

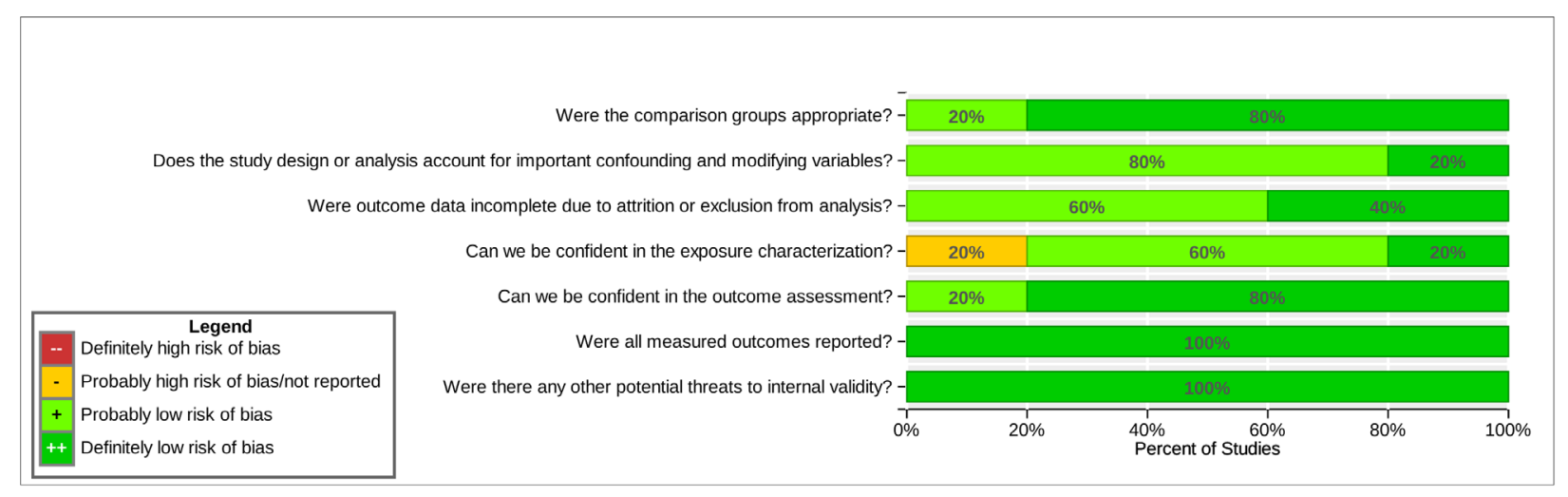

Figure D-4. Risk-of-bias Bar Chart: Other Pollutants and Hypertensive Disorders of Pregnancy for Epidemiological Studies

Interactive figure and additional study details in $\underline{\text { HAWC }}$ (NTP, 2019a). 


\section{Appendix E. Meta-analysis Sub-analyses Results}

\section{Tables}

Table E-1. Influence Analysis of References Included in the Full Gestational Period $\mathrm{PM}_{2.5}$ Exposure and Preeclampsia Meta-analysis

Table E-2. Publication Bias in References Included in the Full Gestational Period PM 2.5

Exposure and Preeclampsia Meta-analysis

Table E-3. Influence Analysis of References Included in the Full Gestational Period $\mathrm{NO}_{2}$

Exposure and Hypertensive Disorders of Pregnancy Meta-analysis ....

Table E-4. Influence Analysis of References Included in the Full Gestational Period $\mathrm{NO}_{2}$

Exposure and Preeclampsia Meta-analysis

Table E-5. Publication Bias in References Included in the Full Gestational Period $\mathrm{NO}_{2}$

Exposure and Hypertensive Disorders of Pregnancy Meta-analysis

Table E-6. Publication Bias in References Included in the Full Gestational Period $\mathrm{NO}_{2}$

Exposure and Preeclampsia Meta-analysis

\section{Figures}

Figure E-1. Influence Analysis Plot: References Included in the Full Gestational Period

$\mathrm{PM}_{2.5}$ Exposure and Preeclampsia Meta-analysis

Figure E-2. Publication Bias in References Included in the Full Gestational Period PM2.5

Exposure and Preeclampsia Meta-analysis

Figure E-3. Influence Analysis Plot: References Included in the Full Gestational Period

$\mathrm{NO}_{2}$ Exposure and Hypertensive Disorders of Pregnancy Meta-analysis.

Figure E-4. Influence Analysis Plot: References Included in the Full Gestational Period $\mathrm{NO}_{2}$ Exposure and Preeclampsia Meta-analysis

Figure E-5. Publication Bias in References Included in the Full Gestational Period $\mathrm{NO}_{2}$ Exposure and Hypertensive Disorders of Pregnancy Meta-analysis.

Figure E-6. Publication Bias in References Included in the Full Gestational Period $\mathrm{NO}_{2}$ Exposure and Preeclampsia Meta-analysis 


\section{E.1. Full Gestation $\mathrm{PM}_{2.5}$ Results}

Table E-1. Influence Analysis of References Included in the Full Gestational Period PM 2.5 Exposure and Preeclampsia Meta-analysis

\begin{tabular}{lc}
\hline \multicolumn{1}{c}{ Study Omitted } & Odds Ratio (95\% Confidence Interval) \\
\hline Dadvand et al. (2013) & $1.47(0.97,2.32)$ \\
Rudra et al. (2011) & $1.52(0.95,2.40)$ \\
Savitz et al. (2015) & $1.73(1.14,1.98)$ \\
Wu et al. (2011) & $1.41(0.93,2.09)$ \\
Wu et al. (2011) & $1.46(0.95,2.32)$ \\
\hline Combined & $1.51(1.04,2.20)$ \\
\hline
\end{tabular}

Table E-2. Publication Bias in References Included in the Full Gestational Period $\mathbf{P M}_{2.5}$ Exposure and Preeclampsia Meta-analysis

Egger's Test for Small-study Effects:

Regress Standard Normal Deviate of Intervention Effect Estimate against Its Standard Error

\begin{tabular}{lccccc}
\hline Number of Studies $=5$ & & \multicolumn{5}{c}{ Root MSE $=11.22$} \\
\hline \multicolumn{1}{c}{ Standard Effect } & Coefficient & Standard Error & $\mathbf{t}$ & $\mathbf{P}>|\mathbf{t}|$ & $\mathbf{9 5 \%}$ Confidence Interval \\
\hline Slope & -0.1397884 & 0.3333834 & -0.42 & 0.703 & $(-1.200763,0.9211864)$ \\
Bias & 12.52648 & 10.47258 & 1.20 & 0.318 & $(-20.80195,45.85491)$ \\
\hline Test of $\mathrm{H}_{0}$ : No small-study effects & \multicolumn{5}{c}{$\mathrm{p}=0.318$} \\
\hline MSE $=$ mean square error.
\end{tabular}




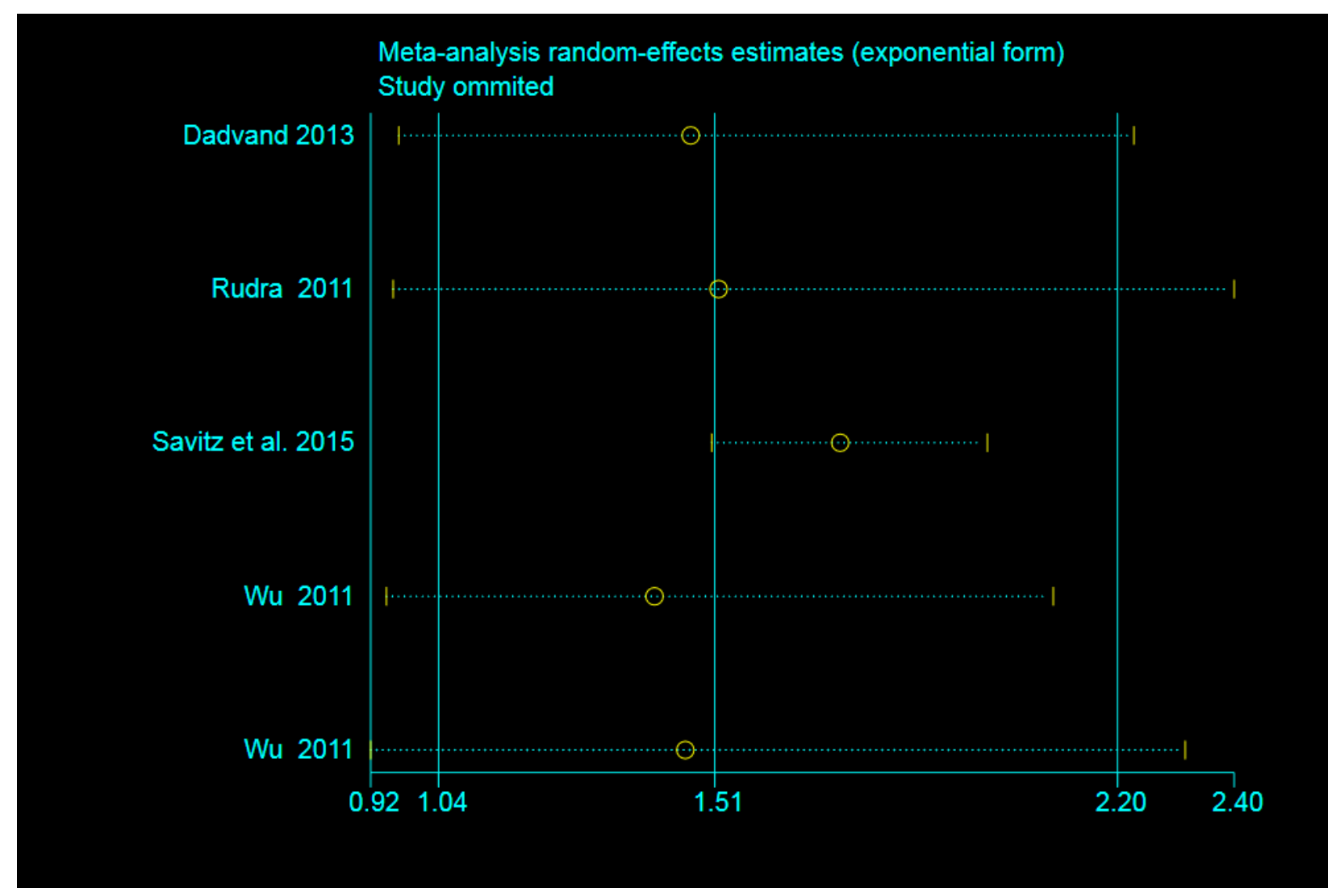

Figure E-1. Influence Analysis Plot: References Included in the Full Gestational Period PM2.5 Exposure and Preeclampsia Meta-analysis 


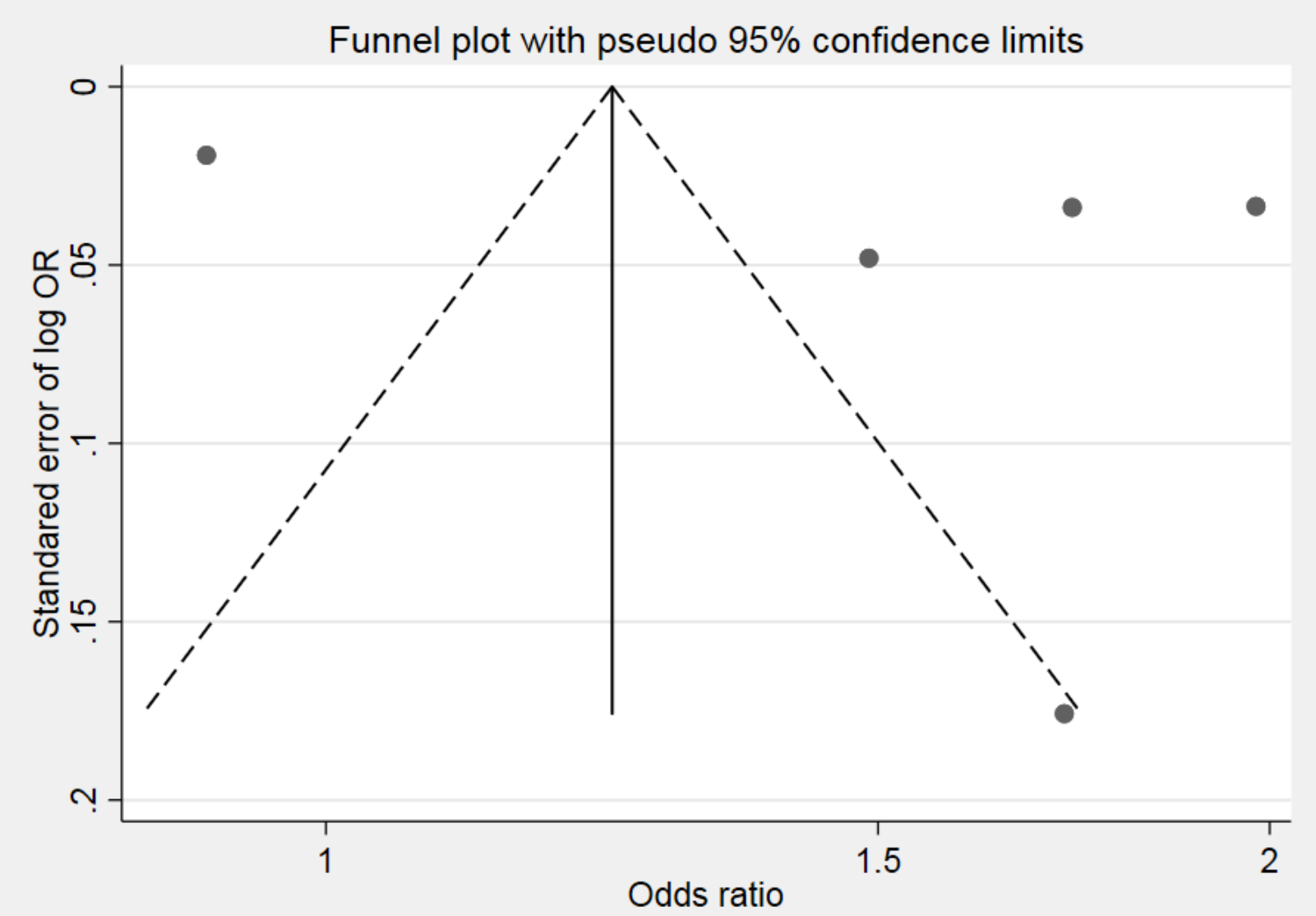

Figure E-2. Publication Bias in References Included in the Full Gestational Period PM $\mathbf{M}_{2.5}$ Exposure and Preeclampsia Meta-analysis

\section{E.2. Full Gestation $\mathrm{NO}_{2}$ Results}

Table E-3. Influence Analysis of References Included in the Full Gestational Period $\mathrm{NO}_{2}$ Exposure and Hypertensive Disorders of Pregnancy Meta-analysis

\begin{tabular}{lc}
\hline \multicolumn{1}{c}{ Study Omitted } & Odds Ratio (95\% Confidence Interval) \\
\hline Dadvand et al. (2013) & $1.03(0.97,1.10)$ \\
Madsen et al. (2018) & $1.05(0.98,1.12)$ \\
Pedersen et al. (2017) & $1.02(0.96,1.09)$ \\
Pereira et al. (2013) & $1.02(0.96,1.09)$ \\
Savitz et al. (2015) & $1.05(0.99,1.11)$ \\
van den Hooven et al. (2011) & $1.03(0.97,1.09)$ \\
Wu et al. (2011) & $1.03(0.97,1.11)$ \\
Wu et al. (2011) & $1.02(0.96,1.08)$ \\
\hline Combined & $1.03(0.97,1.09)$ \\
\hline
\end{tabular}


Table E-4. Influence Analysis of References Included in the Full Gestational Period $\mathrm{NO}_{2}$ Exposure and Preeclampsia Meta-analysis

\begin{tabular}{lc}
\hline \multicolumn{1}{c}{ Study Omitted } & Odds Ratio (95\% CI) \\
\hline Dadvand et al. (2013) & $1.03(0.97,1.11)$ \\
Madsen et al. (2018) & $1.04(0.98,1.12)$ \\
Pedersen et al. (2017) & $1.02(0.96,1.10)$ \\
Pereira et al. (2013) & $1.02(0.96,1.09)$ \\
Savitz et al. (2015) & $1.06(1.01,1.11)$ \\
van den Hooven et al. (2011) & $1.03(0.97,1.10)$ \\
Wu et al. (2011) & $1.04(0.96,1.12)$ \\
Wu et al. (2011) & $1.02(0.96,1.09)$ \\
\hline Combined & $1.04(0.97,1.10)$ \\
\hline
\end{tabular}

Table E-5. Publication Bias in References Included in the Full Gestational Period $\mathrm{NO}_{2}$ Exposure and Hypertensive Disorders of Pregnancy Meta-analysis

Egger's Test for Small-study Effects:

Regress Standard Normal Deviate of Intervention Effect Estimate against Its Standard Error

\begin{tabular}{lccccc}
\hline \multicolumn{1}{c}{ Number of Studies $=8$} & \multicolumn{5}{c}{ Root MSE $=1.563$} \\
\hline Standard Effect & Coefficient & Standard Error & $\mathbf{t}$ & $\mathbf{P}>|\mathbf{t}|$ & $\mathbf{9 5 \%}$ CI \\
Slope & -0.0499923 & 0.0204239 & -2.45 & 0.050 & $(-0.0999678,-0.0000169)$ \\
Bias & 1.758844 & 0.7933426 & 2.22 & 0.068 & $(-0.1823958,3.700083)$ \\
\hline \multicolumn{7}{l}{ Test of $\mathrm{H}_{0}$ : No small-study effects } & \multicolumn{5}{c}{$\mathrm{p}=0.068$} \\
\hline
\end{tabular}

MSE $=$ mean square error.

Table E-6. Publication Bias in References Included in the Full Gestational Period $\mathrm{NO}_{2}$ Exposure and Preeclampsia Meta-analysis

Egger's Test for Small-study Effects:

Regress Standard Normal Deviate of Intervention Effect Estimate against Its Standard Error

\begin{tabular}{llllll}
\hline Number of Studies $=8$ & & \multicolumn{5}{c}{ Root MSE $=1.591$} \\
\hline \multicolumn{1}{c}{ Standard Effect } & Coefficient & \multicolumn{1}{c}{ Standard Error } & \multicolumn{1}{c}{$\mathbf{P}>|\mathbf{t}|$} & $\mathbf{9 5 \%}$ CI \\
\hline Slope & -0.0516838 & 0.0246087 & -2.10 & 0.080 & $(-0.1118992,0.0085316)$ \\
Bias & 1.674924 & 0.8264967 & 2.03 & 0.089 & $(-0.3474407,3.697288)$ \\
\hline \multicolumn{5}{l}{ Test of $\mathrm{H}_{0}$ : No small-study effects } & \multicolumn{5}{c}{$\mathrm{p}=0.089$} \\
\hline
\end{tabular}

$\mathrm{MSE}=$ mean square error. 
Systematic Review of TRAP and Hypertensive Disorders of Pregnancy

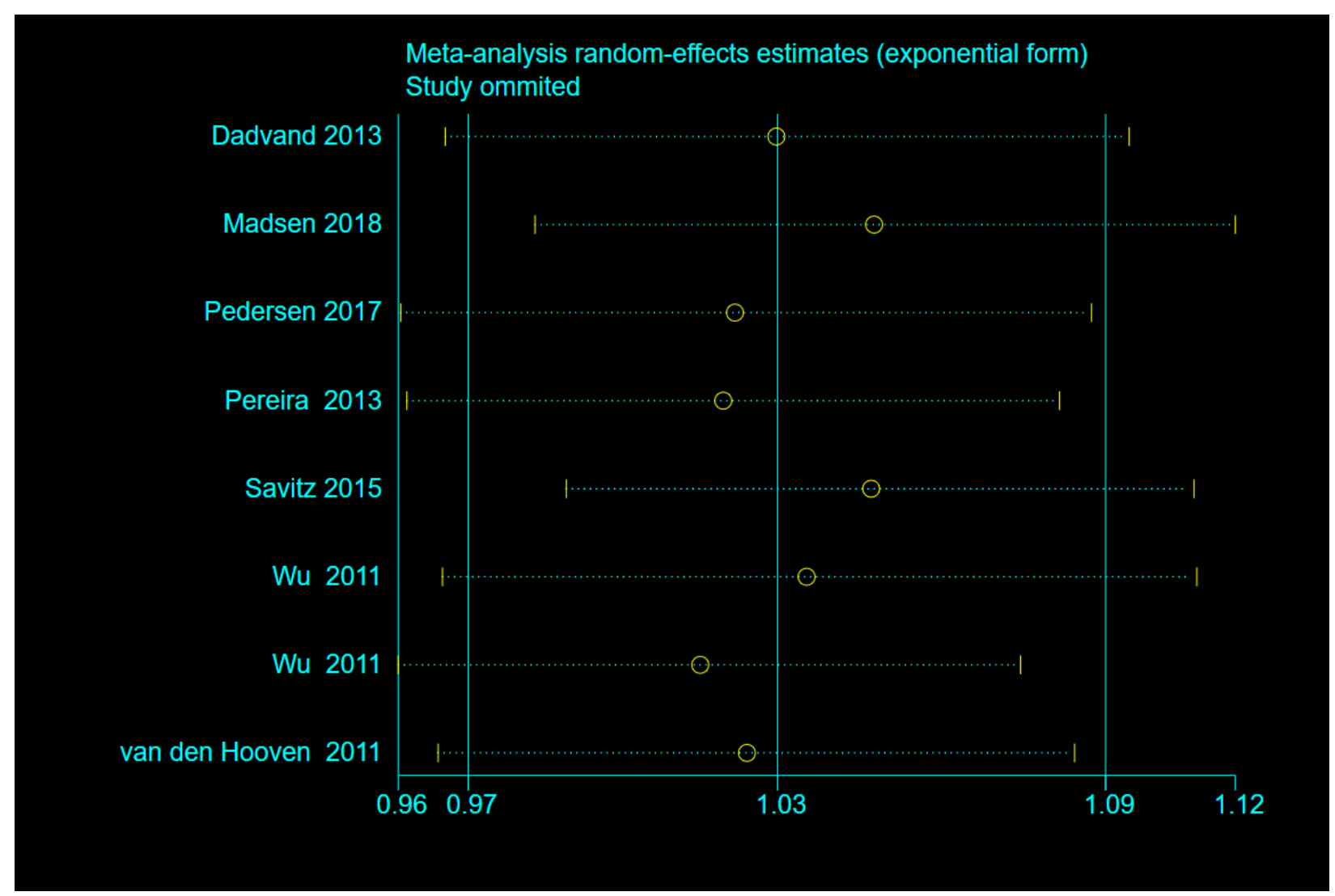

Figure E-3. Influence Analysis Plot: References Included in the Full Gestational Period $\mathrm{NO}_{2}$ Exposure and Hypertensive Disorders of Pregnancy Meta-analysis 
Systematic Review of TRAP and Hypertensive Disorders of Pregnancy

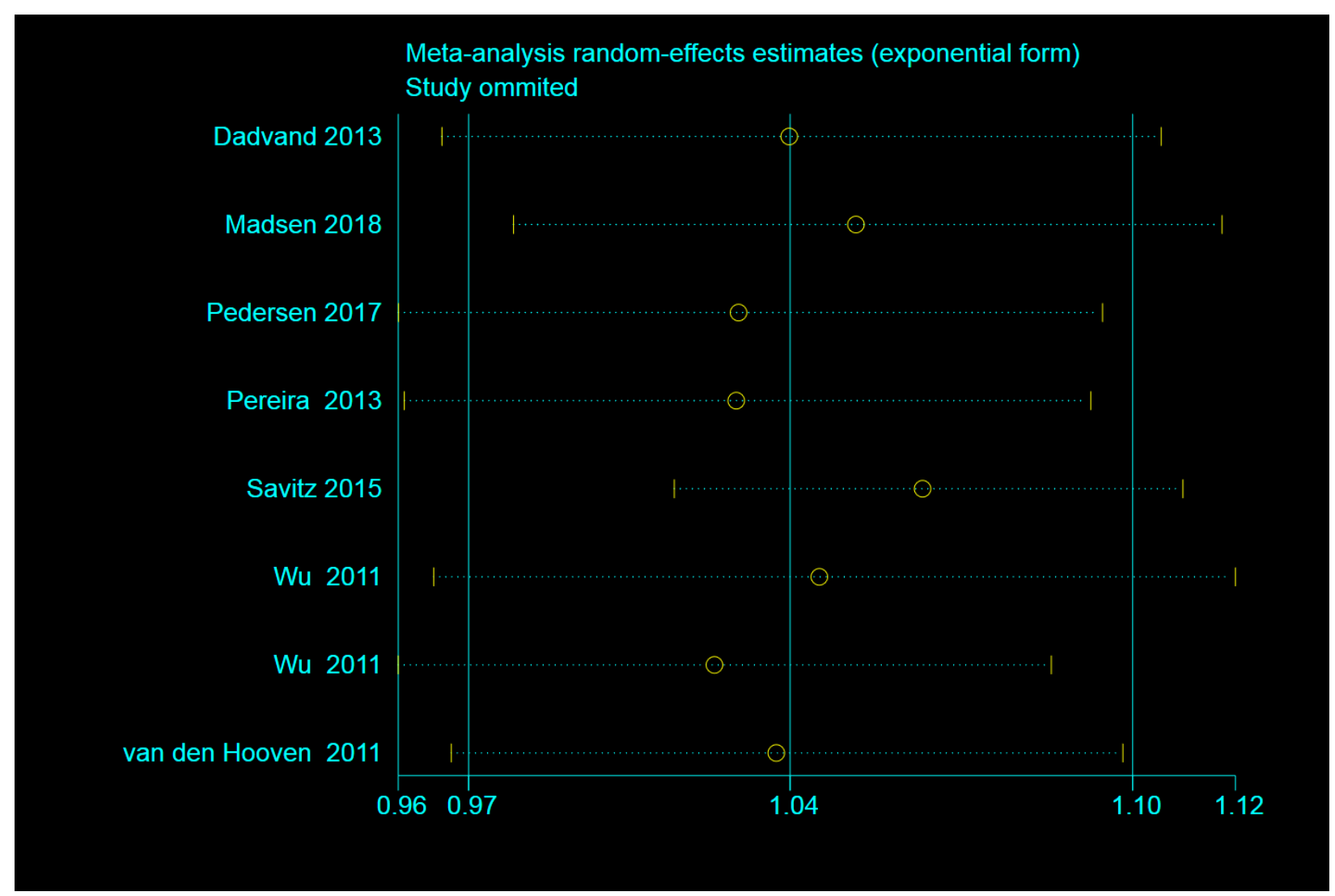

Figure E-4. Influence Analysis Plot: References Included in the Full Gestational Period $\mathrm{NO}_{2}$ Exposure and Preeclampsia Meta-analysis 


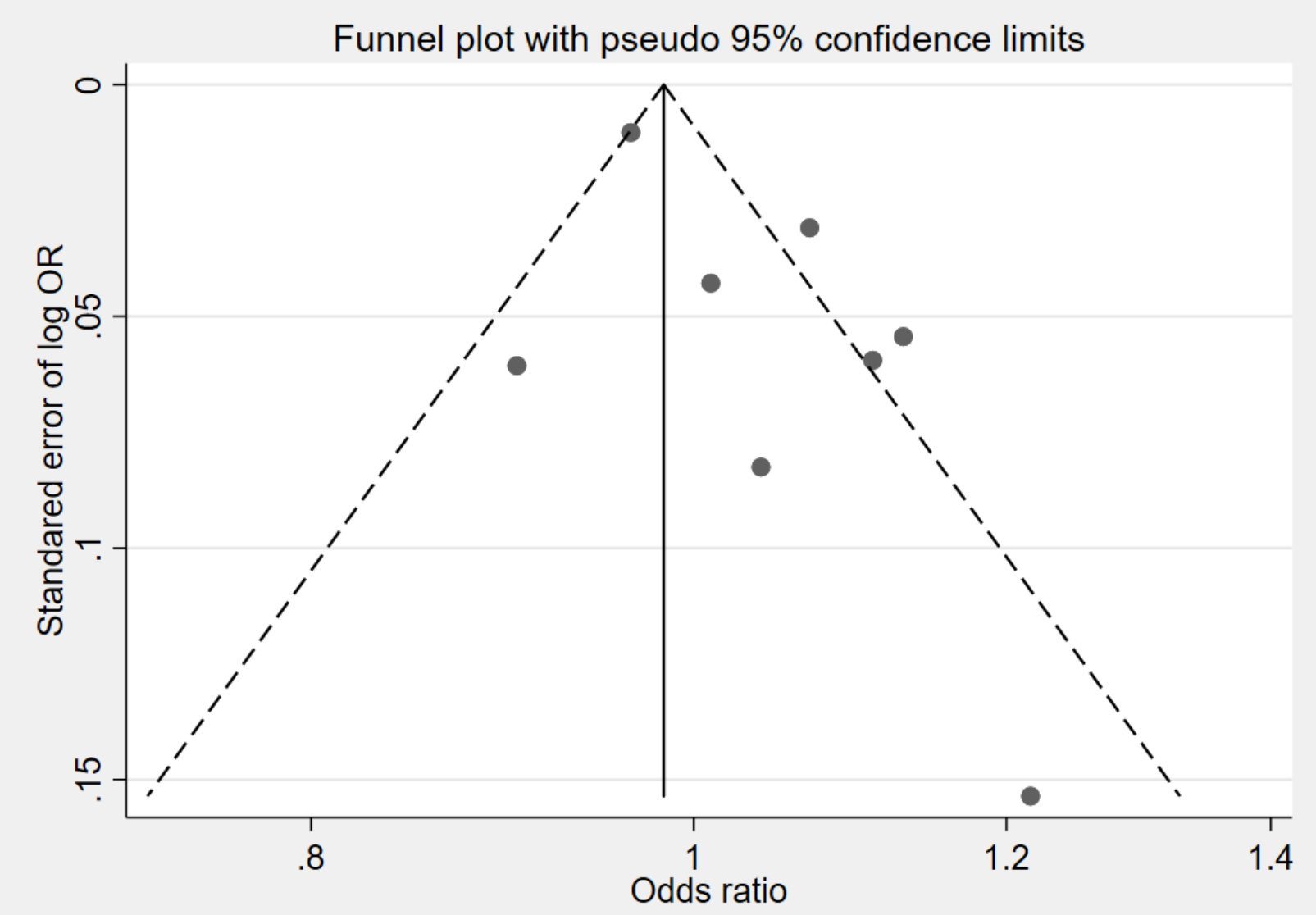

Figure E-5. Publication Bias in References Included in the Full Gestational Period $\mathrm{NO}_{2}$ Exposure and Hypertensive Disorders of Pregnancy Meta-analysis 


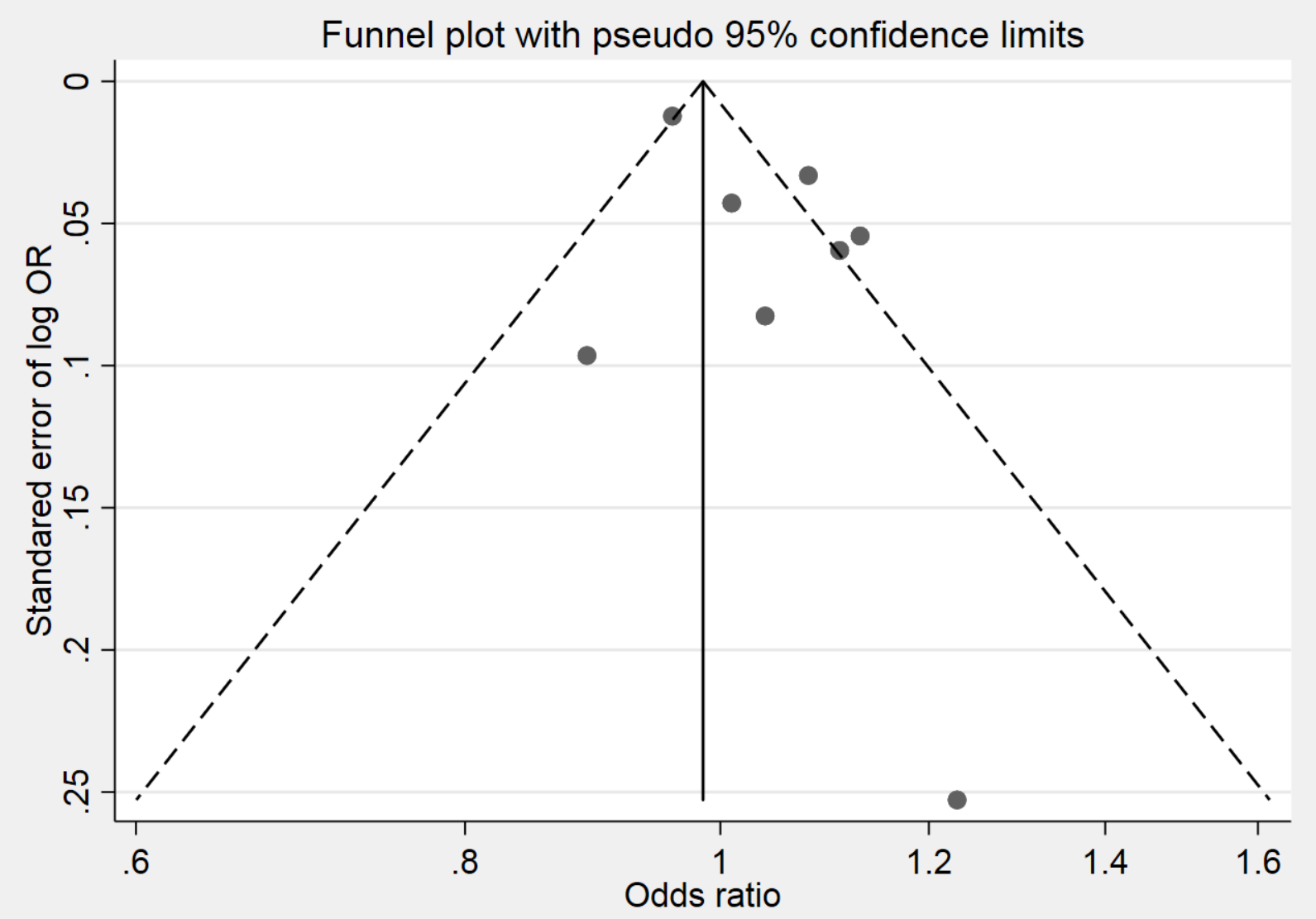

Figure E-6. Publication Bias in References Included in the Full Gestational Period $\mathrm{NO}_{2}$ Exposure and Preeclampsia Meta-analysis 


\section{Appendix F. Protocol History}

The original and revised protocols are available in Appendix G.

Table F-1. Protocol History and Revisions

\begin{tabular}{|c|c|}
\hline Date & Activity or Revision \\
\hline September 5, 2015 & Draft protocol reviewed: sent to peer reviewers for comment/review \\
\hline June 24, 2016 & Evaluation protocol to be posted on OHAT website \\
\hline \multirow[t]{9}{*}{ August 7, 2019} & $\begin{array}{l}\text { Revised protocol posted on OHAT website to reflect principal updates made during } \\
\text { evaluation with justifications and date implemented noted: }\end{array}$ \\
\hline & 1. Added Brandiese Beverly, Ph.D., as the Project Co-Lead (February 2017); \\
\hline & $\begin{array}{l}\text { 2. Protocol was originally developed to outline two OHAT systematic reviews, } \\
\text { however, only TRAP and Hypertensive Disorders of Pregnancy was pursued (January } \\
\text { 2018); }\end{array}$ \\
\hline & $\begin{array}{l}\text { 3. Systematic review on neurological disorders and TRAP was not pursued because } \\
\text { this topic is currently under review by other organizations; here and throughout, text } \\
\text { related to neurological disorders has a strike-through notation or is noted with a } \\
\text { footnote that NTP will not pursue this topic (January 2018); }\end{array}$ \\
\hline & $\begin{array}{l}\text { 4. Here and throughout, the term pregnancy-induced hypertension or pregnancy- } \\
\text { associated hypertension has been replaced with hypertensive disorders of pregnancy to } \\
\text { reflect the more accurate term to describe the collection of disorders (February 2017); }\end{array}$ \\
\hline & $\begin{array}{l}\text { 5. The American College of Obstetrics and Gynecology recognizes } 4 \text { categories of } \\
\text { hypertensive disorders of pregnancy, which include chronic hypertension and chronic } \\
\text { hypertension with superimposed preeclampsia, and studies were not excluded solely } \\
\text { based on the inclusion of pregnant women with chronic hypertension (August 2018); }\end{array}$ \\
\hline & $\begin{array}{l}\text { 6. Updated Figure } 3 \text { to reflect a clarification and update to the OHAT approach for } \\
\text { systematic review and evidence integration, which clarified how hazard conclusions } \\
\text { are reached when there is moderate level-of-evidence for human data with low or } \\
\text { inadequate level-of-evidence for the animal evidence stream (March 2019); }\end{array}$ \\
\hline & $\begin{array}{l}\text { 7. Brandiese Beverly, Ph.D., added as Project Co-Lead in affiliation section, along } \\
\text { with updates to contributor affiliations (July 2019); and }\end{array}$ \\
\hline & $\begin{array}{l}\text { 8. Paradoxically, smoking is a negative risk factor for preeclampsia and is not a } \\
\text { confounder. Body mass index (BMI) is a risk factor for preeclampsia and was added as } \\
\text { a confounder (August 2018). }\end{array}$ \\
\hline
\end{tabular}




\section{Appendix G. Supplemental Files}

The following supplemental files are available at https://doi.org/10.22427/NTP-DATA-MGRAPH7.

\section{G.1. Protocol Information}

Protocol

Protocol.pdf

Revised Protocol

TRAP_Revised_Protocol.pdf 


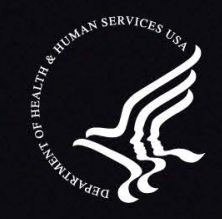

National Toxicology Program

NTP Central Data Management, MD K2-05

National Institute of Environmental Health Sciences

P.O. Box 12233

Research Triangle Park, NC 27709

http://ntp.niehs.nih.gov 